University of San Diego

Digital USD

2019-05-19

\title{
Examining Inter-Relationships Between Supervisor Full-Range Leadership, Organizational Climate Strength, and Employee Job Satisfaction Using Multi-Level Modeling
}

Bharat Mohan

University of San Diego

Follow this and additional works at: https://digital.sandiego.edu/dissertations

Part of the Business Administration, Management, and Operations Commons, Higher Education Commons, Management Sciences and Quantitative Methods Commons, Organizational Behavior and Theory Commons, Strategic Management Policy Commons, and the Training and Development Commons

\section{Digital USD Citation}

Mohan, Bharat, "Examining Inter-Relationships Between Supervisor Full-Range Leadership, Organizational Climate Strength, and Employee Job Satisfaction Using Multi-Level Modeling" (2019). Dissertations. 132. https://digital.sandiego.edu/dissertations/132

This Dissertation: Open Access is brought to you for free and open access by the Theses and Dissertations at Digital USD. It has been accepted for inclusion in Dissertations by an authorized administrator of Digital USD. For more information, please contact digital@sandiego.edu. 
EXAMINING INTER-RELATIONSHIPS BETWEEN SUPERVISOR FULL-RANGE LEADERSHIP, ORGANIZATIONAL CLIMATE STRENGTH, AND EMPLOYEE JOB SATISFACTION USING MULTI-LEVEL MODELING

by

Bharat Mohan

A dissertation submitted in partial fulfillment

of the requirements for the degree of

Doctor of Philosophy

May 2019

Dissertation Committee

Fred J. Galloway, EdD, Chair

Afsaneh Nahavandi, PhD, Member

Karen Briggs, $\mathrm{PhD}$, Member

University of San Diego 
Copyright page 


\section{University of San Diego School of Leadership and Education Sciences}

CANDIDATE'S NAME: Bharat Mohan

TITLE OF DISSERTATION: EXAMINING INTER-RELATIONSHIPS BETWEEN SUPERVISOR FULL-RANGE LEADERSHIP, ORGANIZATIONAL CLIMATE STRENGTH, AND EMPLOYEE JOB SATISFACTION USING MULTI-LEVEL MODELING

APPROVAL:

, Chair

Fred J. Galloway, EdD

, Member

Afsaneh Nahavandi, $\mathrm{PhD}$

, Member

Karen Briggs, PhD

DATE: March 12, 2019 


\begin{abstract}
Employee job satisfaction, organizational climate, and supervisor leadership style have long been researched due to their influences on critical metrics for measuring organizational success. While the relationships between these three variables have been investigated, current research suffers from two major issues. First, no existing study has explored the inter-relationships between the aforementioned components within the same model. Second, existing studies are fraught with levels-of-analysis issues that yield findings that are either incomplete or inaccurate. This study addresses these issues by introducing organizational climate strength as a mediating variable (between supervisor leadership and employee satisfaction) and by employing multi-level modeling techniques.

A total of 100 full-time staff, administrators, and supervisors across seven departments in a private university completed a 53-question survey measuring the three dimensions of the study. A range of data analysis techniques were conducted, including descriptive statistics, gap analysis, reverse regressions, traditional regressions, and multilevel modeling. Findings from these analyses revealed that the lowest levels of satisfaction and lowest leadership ratings of supervisors came from employees with 1-2 years of service. Additionally, misalignment between employee and supervisor perceptions of supervisor leadership style contributed to lower levels of employee satisfaction. Using traditional regressions, higher levels of Intellectual Stimulation and Individualized Consideration behaviors by supervisors were found to have the greatest positive returns to employee satisfaction. Organizational climate strength was not found to mediate the relationship between supervisors' leadership styles and employee
\end{abstract}


satisfaction. Furthermore, no statistically significant results were found using multi-level modeling.

Practical implications of this study at the research site include specifically addressing the employee experience of those with 1-2 years of service; encouraging selfawareness of supervisors about their leadership abilities (particularly Intellectual Stimulation); and developing the capacities of supervisors to practice Intellectual Stimulation and Individualized Consideration behaviors. Future research can also benefit from this study by utilizing the mediating variable framework, as well as attempting to employ multi-level modeling techniques to the data. Despite a number of limitations, this study not only provides value for specific stakeholders related to the research site, but also makes multiple contributions to the broader literature and research in the field of leadership. 


\section{TABLE OF CONTENTS}

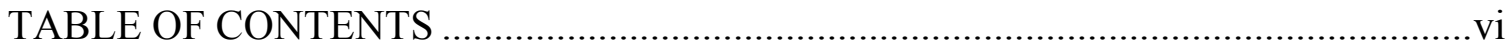

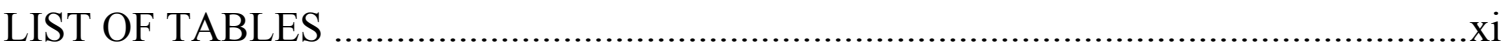

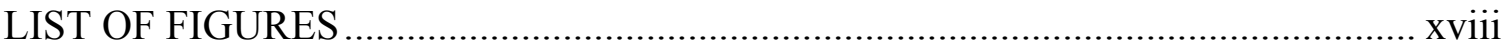

CHAPTER ONE INTRODUCTION TO THE STUDY …......................................... 1

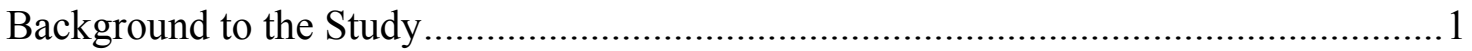

Employee Job Satisfaction ........................................................................ 1

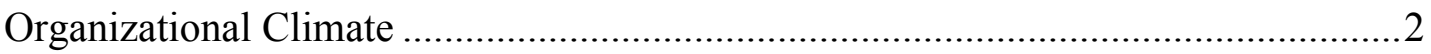

Supervisor Leadership Style (Transformational Leadership) ................................

Statement of the Problem........................................................................................ 4

Existing Models: Limited Exploration of Relationships between Variables ...............5

Levels-of-Analysis Issues ................................................................................ 6

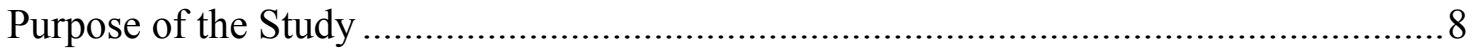

Research Questions ........................................................................................ 10

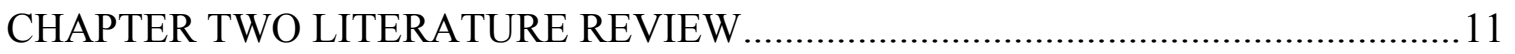

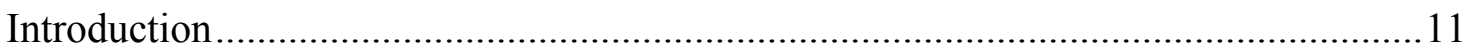

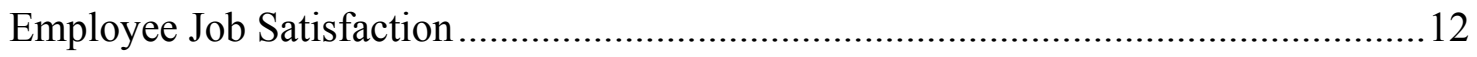

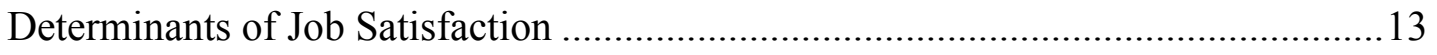

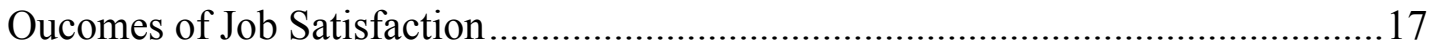

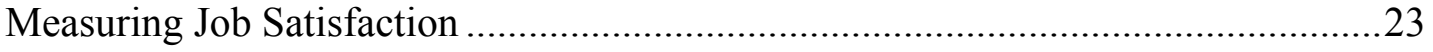

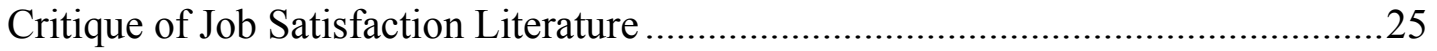

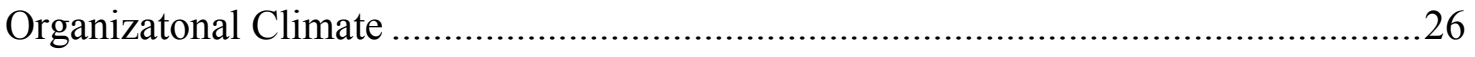

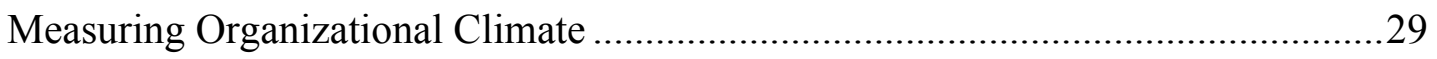




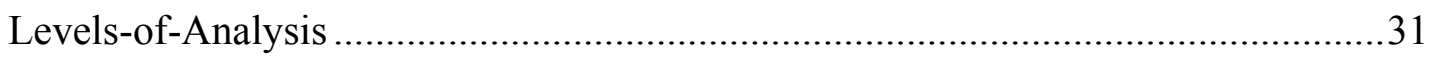

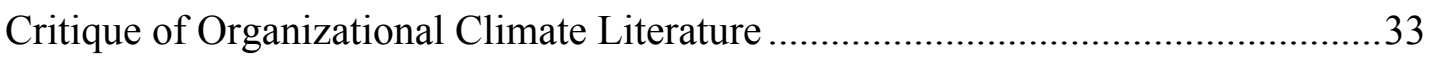

Relationship Between Organizational Climate and Job Satisfaction..............................34

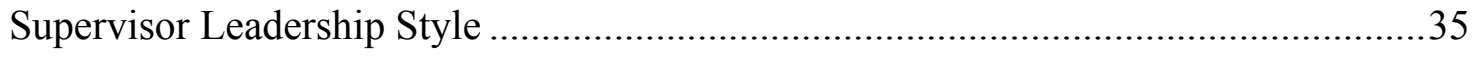

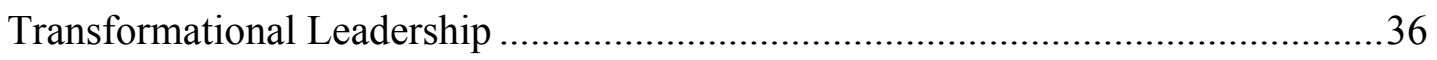

Measuring Transformational Leadership …………….............................................4 40

Relationship Between Transformational Leadership and Job Satisfaction.................43

Relationship Between Transformational Leadership and Organizational Climate....45

Critique of Transformational Leadership Literature ..................................................4

Multi-Level Modeling Techniques ……………………...........................................49

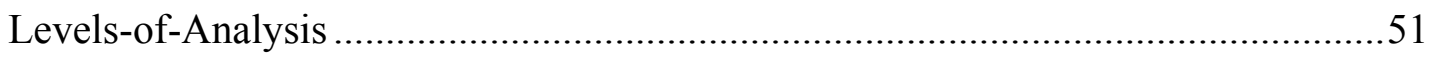

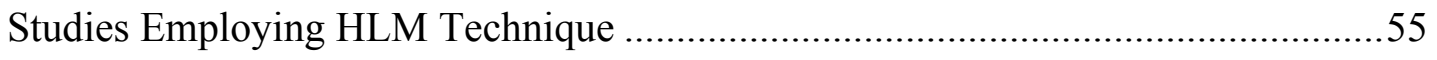

Critique of HLM Data Analysis Methodology .......................................................57

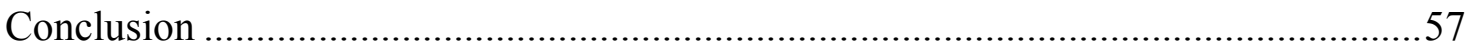

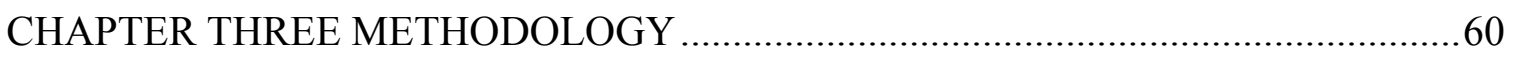

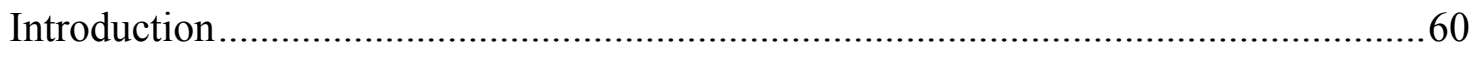

Research Site

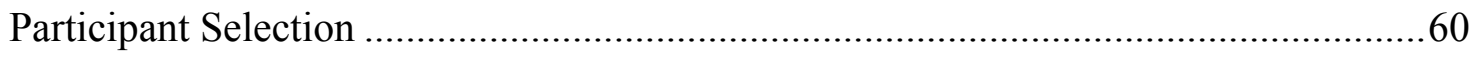

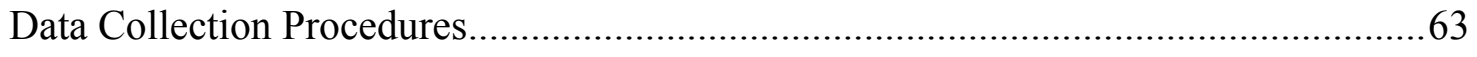

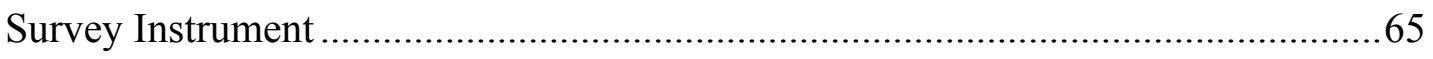

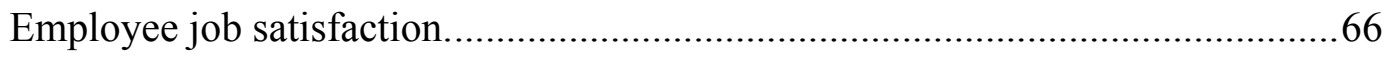

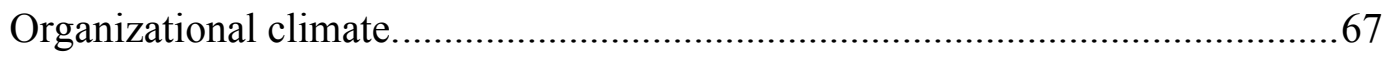

Supervisor's transformational leadership..........................................................69

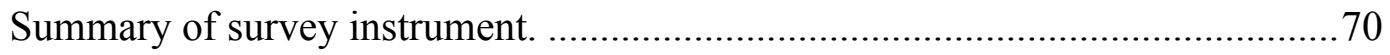

Data Analysis Procedures ………………........................................................... 


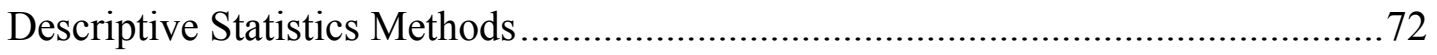

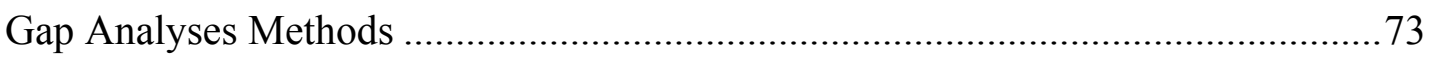

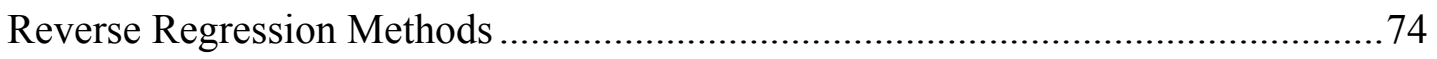

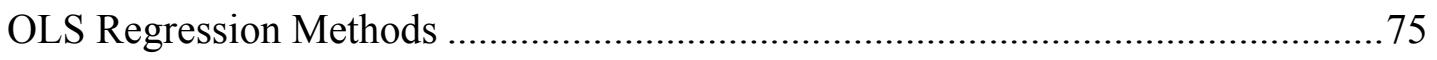

Multi-Level Modeling (HLM) Regression Methods ...........................................76

CHAPTER FOUR DATA ANALYSIS .................................................................. 79

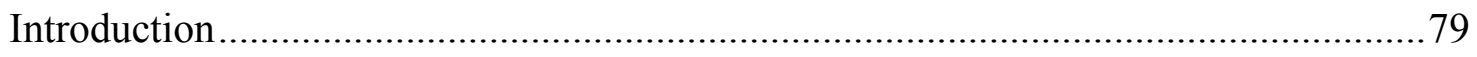

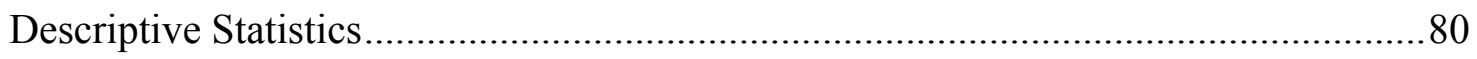

Employee Job Satisfaction Descriptive Statistics ............................................... 83

Organizational Climate Strength Descriptive Statistics .......................................8 85

Supervisor Leadership Style Descriptive Statistics ......................................... 87

Gap Analyses Regression Results ............................................................. 98

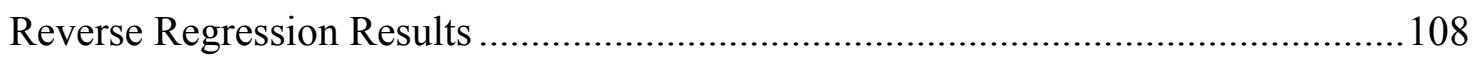

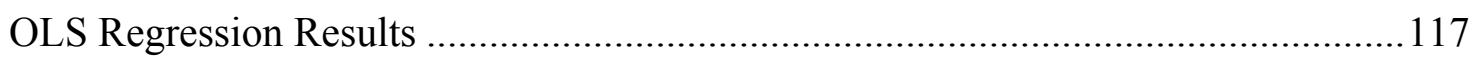

Transformational Leadership OLS Regression Results ................................... 118

Transactional Leadership OLS Regression Results .......................................... 132

Laissez-Faire Leadership OLS Regression Results ......................................... 140

Multi-Level Modeling (HLM) Regression Results............................................. 147

Transformational Leadership HLM Regression Results.................................... 149

Transactional Leadership HLM Regression Results ......................................... 151

Laissez-Faire Leadership HLM Regression Results .......................................... 153

CHAPTER FIVE DISCUSSION OF FINDINGS AND CONCLUSION ...................... 155

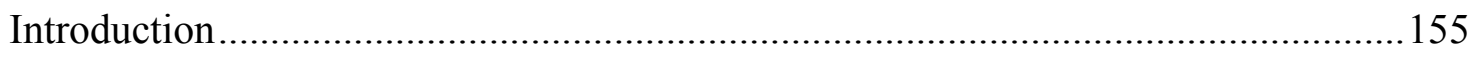

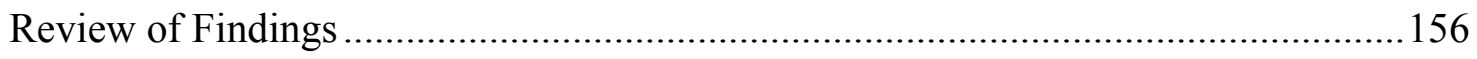

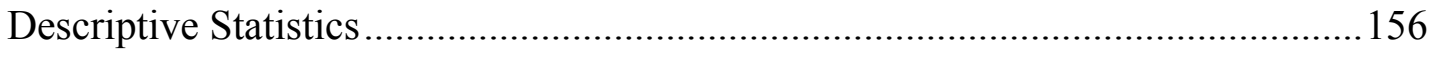


Gap Analyses 160

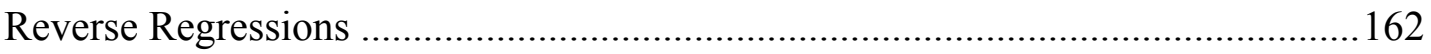

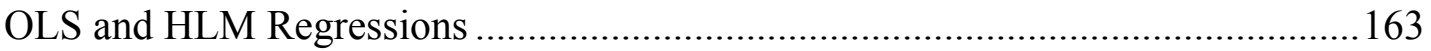

Implications for Policy/Practice ........................................................................ 168

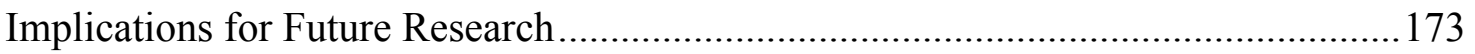

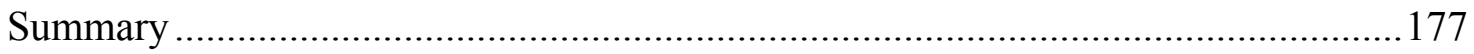

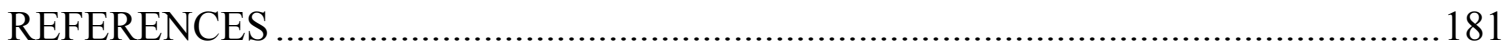

APPENDIX A Sample Of Survey Used in Study ………...............................................199

APPENDIX B Survey E-mail Invitation and Reminder ................................................214

APPENDIX C Multi-Level Modeling Technical Explanation..........................................216

APPENDIX D Level of Satisfaction on Dimensions over Years of Service ...................219

APPENDIX E Transformational Leadership Dimension Ratings of AVP over Years of

Service

APPENDIX F Transactional Leadership Dimension Ratings of AVP over Years of Service .225

APPENDIX G Laissez-Faire Leadership Ratings of AVP over Years of Service. .227

APPENDIX H Absolute Value of Difference Between Employee Ratings and AVP Rating of Transformational Leadership Dimensions over Years of Service.. .229

APPENDIX I Absolute Value of Difference Between Employee Ratings and AVP Rating of Transactional Leadership Dimensions over Years of Service .234

APPENDIX J Absolute Value of Difference Between Employee Ratings and AVP Rating of Laissez-Faire Leadership Dimensions over Years of Service.

APPENDIX K Transformational Leadership and Dimensions of Satisfaction HLM Fixed

Effects Components Estimation ......

APPENDIX L Tranactional Leadership and Dimensions of Satisfaction HLM Fixed Effects Components Estimation .248

APPENDIX M Laissez-Faire Leadership and Dimensions of Satisfaction HLM Fixed Effects Components Estimation 
APPENDIX N Transformational Leadership and Dimensions of Satisfaction HLM

Variance Components Estimation ...............................................................................259

APPENDIX O Transactional Leadership and Dimensions of Satisfaction HLM Variance

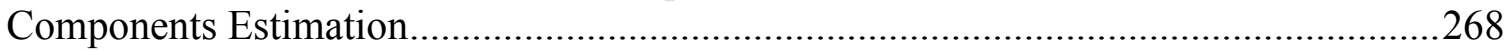

APPENDIX P Laissez-Faire Leadership and Dimensions of Satisfaction HLM Variance

Components Estimation. .274 


\section{LIST OF TABLES}

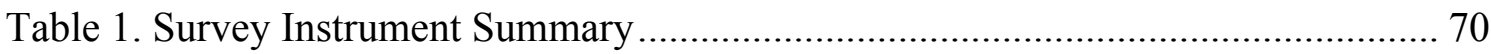

Table 2. Number of Respondents to the Survey by Department/Group....................... 80

Table 3. Ranges for Each Dimension Measured in the Survey ................................... 82

Table 4. Employee Job Satisfaction Means and Standard Deviations by Department.... 83

Table 5. Organizational Climate Strength Descriptive Statistics by Department ........... 86

Table 6. Transformational Leadership Means \& Standard Deviations by Department .. 88

Table 7. Transactional Leadership Means \& Standard Deviations by Department ........ 89

Table 8. Laissez-Faire Leadership Means \& Standard Deviations by Department........ 89

Table 9. Leadership Difference Scores/Supervision Satisfaction Regression Results ... 99

Table 10. Direction of Leadership Difference Scores and Supervision Satisfaction

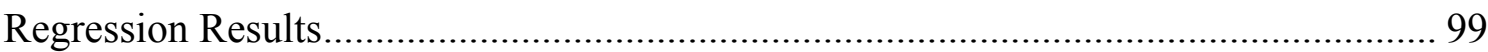

Table 11. Leadership Difference Scores and Contingent Rewards Satisfaction Regression

Results 101

Table 12. Direction of Leadership Difference Scores and Contingent Rewards Satisfaction Regression Results 102

Table 13. Leadership Difference Scores and Nature of Work Satisfaction Regression

Results 103

Table 14. Direction of Leadership Difference Scores and Nature of Work Satisfaction

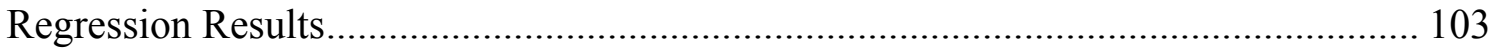

Table 15. Leadership Difference Scores and Communication Satisfaction Regression

Results 105 
Table 16. Direction of Leadership Difference Scores and Communication Satisfaction

Regression Results 106

Table 17. Satisfaction Ratings and Transformational Leadership Overall Regression

Results 109

Table 18. Satisfaction Ratings and Idealized Influence Regression Results 110

Table 19. Satisfaction Ratings and Inspirational Motivation Regression Results 110

Table 20. Satisfaction Ratings and Intellectual Stimulation Regression Results 112

Table 21. Satisfaction Ratings \& Individualized Consideration Regression Results.... 112

Table 22. Satisfaction Ratings and Transactional Leadership Behaviors Overall

Regression Results 113

Table 23. Satisfaction Ratings and Contingent Rewards Regression Results..... 114

Table 24. Satisfaction Ratings and Management by Exception Regression Results .... 115

Table 25. Satisfaction Ratings and Laissez-Faire Leadership Regression Results ....... 116

Table 26. Transformational Leadership Behaviors and Overall Satisfaction OLS

Regression Results

Table 27. Transformational Leadership and Supervision Satisfaction OLS Regression

Results 122

Table 28. Transformational Leadership and Contingent Rewards Satisfaction OLS

Regression Results.

Table 29. Transformational Leadership and Nature of Work Satisfaction OLS Regression Results 127

Table 30. Transformational Leadership and Communication Satisfaction OLS Regression Results 129 
Table 31. Transactional Leadership Behaviors and Overall Satisfaction OLS Regression

Results 130

Table 32. Transactional Leadership Behaviors and Supervision Satisfaction OLS

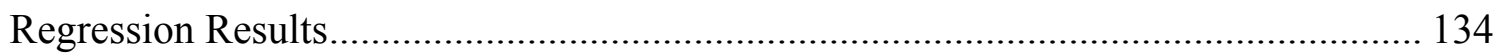

Table 33. Transactional Leadership and Contingent Rewards Satisfaction OLS

Regression Results................................................................................................... 135

Table 34. Transactional Leadership and Nature of Work Satisfaction OLS Regression

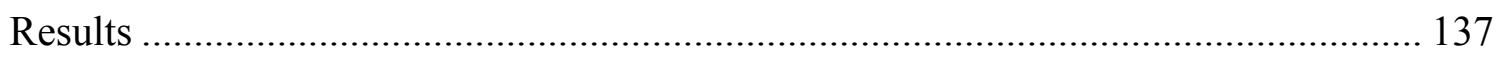

Table 35. Transactional Leadership and Communication Satisfaction OLS Regression

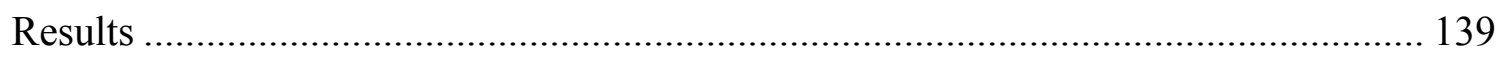

Table 36. Laissez-Faire Leadership Behaviors and Overall Satisfaction OLS Regression

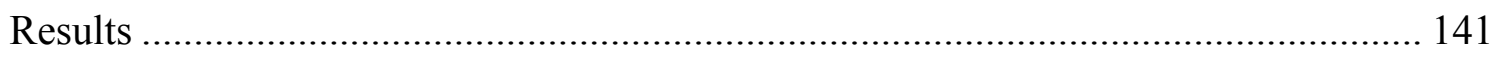

Table 37. Laissez-Faire Leadership \& Supervision Satisfaction Regression Results ... 142

Table 38. Laissez-Faire Leadership and Contingent Rewards Satisfaction Regression

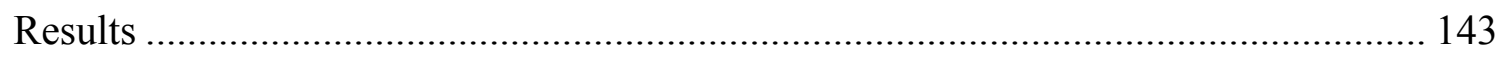

Table 39. Laissez-Faire Leadership Behaviors and Nature of Work Satisfaction

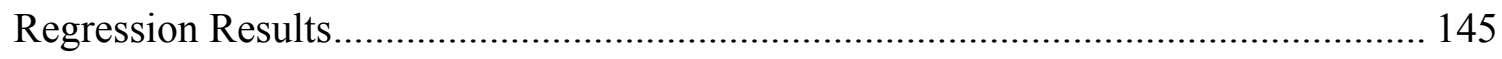

Table 40. Laissez-Faire Leadership Behaviors and Communication Satisfaction

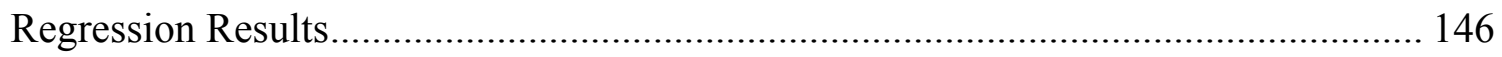

Table 41. Transformational Leadership and Overall Satisfaction HLM Fixed Effects

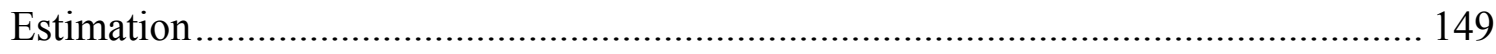

Table 42. Transactional Leadership and Overall Satisfaction HLM Fixed Effects

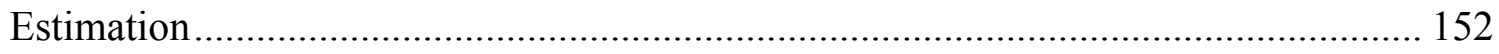


Table 43. Laissez-Faire Leadership and Overall Satisfaction HLM Fixed Effects

Estimation

Table K1. Transformational Leadership and Overall Satisfaction HLM Fixed Effects

Estimation

Table K2. Transformational Leadership and Supervision Satisfaction HLM Fixed Effects

Estimation 241

Table K3. Transformational Leadership and Contingent Reward Satisfaction HLM Fixed Effects Estimation 243

Table K4. Transformational Leadership and Nature of Work Satisfaction HLM Fixed

Effects Estimation 244

Table K5. Transformational Leadership and Communication Satisfaction HLM Fixed

Effects Estimation 246

Table L1. Transactional Leadership and Overall Satisfaction HLM Fixed Effects

Estimation

Table L2. Transactional Leadership and Supervision Satisfaction HLM Fixed Effects

Estimation 250

Table L3. Transactional Leadership and Contingent Reward Satisfaction HLM Fixed

Effects Estimation 251

Table L4. Transactional Leadership and Nature of Work Satisfaction HLM Fixed Effects Estimation 252

Table L5. Transactional Leadership and Communication Satisfaction HLM Fixed Effects

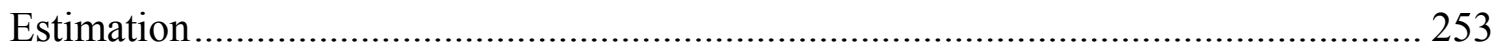


Table M1. Laissez-Faire Leadership and Overall Satisfaction HLM Fixed Effects

Estimation

Table M2. Laissez-Faire Leadership and Supervision Satisfaction HLM Fixed Effects

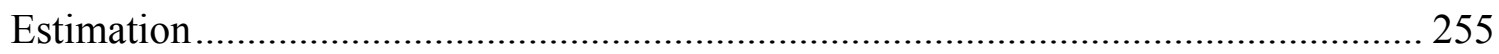

Table M3. Laissez-Faire Leadership and Contingent Reward Satisfaction HLM Fixed

Effects Estimation ................................................................................................ 256

Table M4. Laissez-Faire Leadership and Nature of Work Satisfaction HLM Fixed Effects

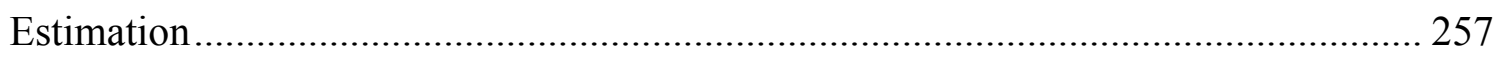

Table M5. Laissez-Faire Leadership and Communication Satisfaction HLM Fixed Effects

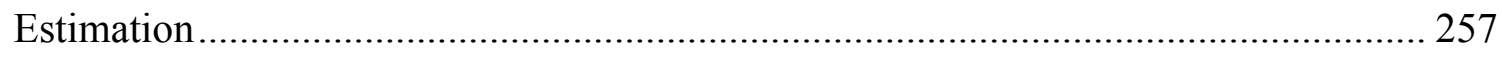

Table N1. Transformational Leadership and Overall Satisfaction HLM Variance

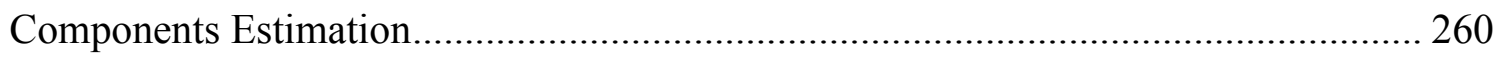

Table N2. Transformational Leadership and Supervision Satisfaction HLM Variance

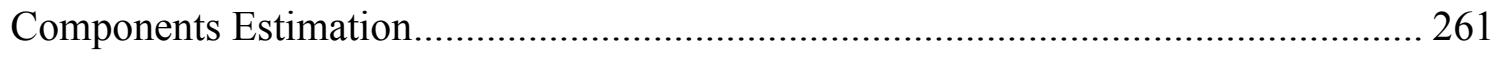

Table N3. Transformational Leadership and Contingent Reward Satisfaction HLM

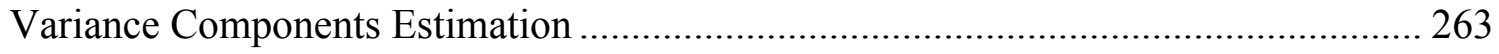

Table N4. Transformational Leadership and Nature of Work Satisfaction HLM Variance

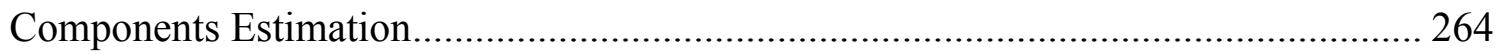

Table N5. Transformational Leadership and Communication Satisfaction HLM Variance

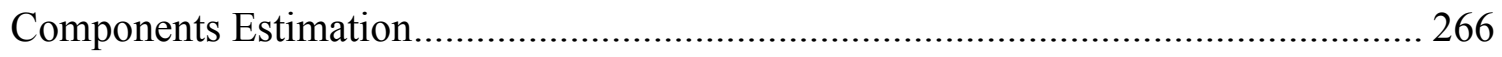

Table O1. Transactional Leadership and Overall Satisfaction HLM Variance Components

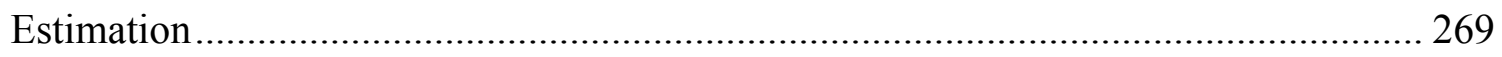


Table O2. Transactional Leadership and Supervision Satisfaction HLM Variance

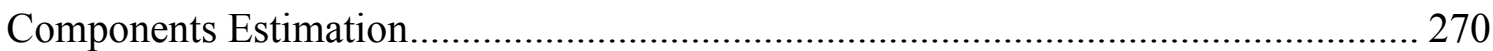

Table O3. Transactional Leadership and Contingent Reward Satisfaction HLM Variance

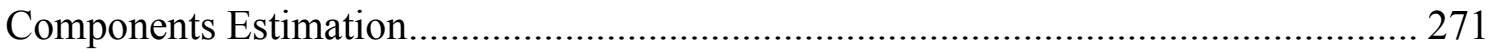

Table O4. Transactional Leadership and Nature of Work Satisfaction HLM Variance

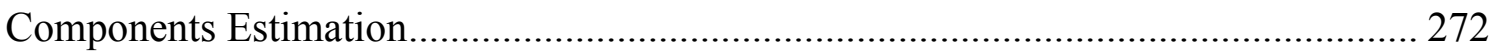

Table O5. Transactional Leadership and Communication Satisfaction HLM Variance

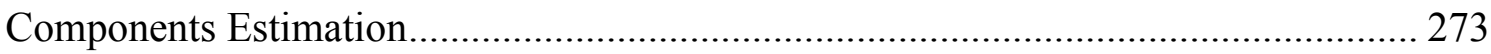

Table P1. Laissez-Faire Leadership and Overall Satisfaction HLM Variance Components

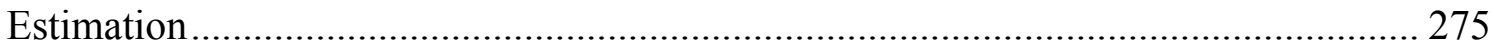

Table P2. Laissez-Faire Leadership and Supervision Satisfaction HLM Variance

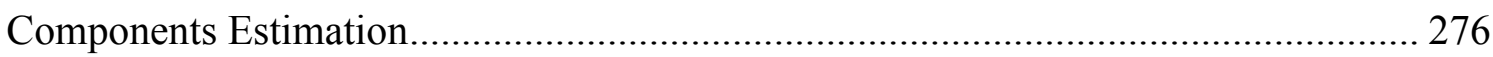

Table P3. Laissez-Faire Leadership and Contingent Reward Satisfaction HLM Variance

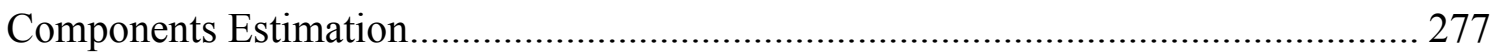

Table P4. Laissez-Faire Leadership and Nature of Work Satisfaction HLM Variance

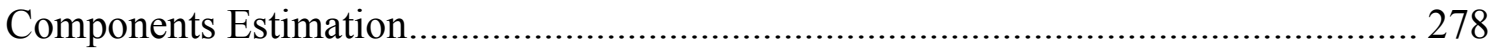

Table P5. Laissez-Faire Leadership and Communication Satisfaction HLM Variance

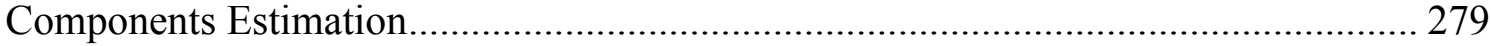




\section{LIST OF FIGURES}

Figure 1. Theoretical framework 6

Figure 2. Level of overall employee job satisfaction by years of service deciles 84

Figure 3. Employee ratings of AVP Transformational Leadership over years of service deciles

Figure 4. Employee ratings of AVP Transactional Leadership over years of service deciles

Figure 5. Absolute value of difference in ratings given by employees and AVPs of AVPS' Transformational Leadership behaviors over years of service deciles 94

Figure 6. Absolute value of difference in ratings given by employees and AVPs of AVPS' Transactional Leadership behaviors over years of service deciles .96

Figure 7. Stakeholder benefits from this study

Figure D1. Level of satisfaction with Supervision over years of service 220

Figure D2. Level of satisfaction with Contingent Rewards over years of service 220

Figure D3. Level of satisfaction with Nature of Work over years of service. 221

Figure D4. Level of satisfaction with Communication over years of service 221

Figure E1. Idealized Influence ratings of AVP over years of service 223

Figure E2. Inspirational Motivation ratings of AVP over years of service 223

Figure E3. Intellectual Stimulation ratings of AVP over years of service 224

Figure E4. Individualized Consideration ratings of AVP over years of service 224

Figure F1. Contingent Reward ratings of AVP over years of service 226

Figure F2. Management by Exception ratings of AVP over years of service 226

Figure G1. Laissez-Faire Leadership ratings of AVP over years of service 228 
Figure H1. Absolute value of difference between employee ratings and AVP rating of AVP Idealized Influence over years of service 230

Figure H2. Absolute value of difference between employee ratings and AVP rating of AVP Inspirational Motivation over years of service. 231

Figure H3. Absolute value of difference between employee ratings and AVP rating of AVP Intellectual Stimulation over years of service 232

Figure H4. Absolute value of difference between employee ratings and AVP rating of AVP Individualized Consideration over years of service 233

Figure I1. Absolute value of difference between employee ratings and AVP rating of AVP Contingent Rewards over years of service 235

Figure I2. Absolute value of difference between employee ratings and AVP rating of AVP Management by Exception over years of service 236

Figure J1. Absolute value of difference between employee ratings and AVP rating of AVP Laissez-Faire Leadership over years of service 


\section{CHAPTER ONE \\ INTRODUCTION TO THE STUDY}

\section{Background to the Study}

Employee job satisfaction, organizational climate, and leadership style have all been studied thoroughly and discussed in considerable detail within the academic literature. Each of these three variables has been researched in different ways and the exploration of the relationship between these three distinct factors has represented a sizeable portion of the existing literature. These three variables, as well as the relationships that have been established in the literature between the three, will be discussed in-depth in this section. At the conclusion of this chapter, justification for the usage of more realistic models and robust analytical procedures to investigate the relationships between these three constructs are provided. Through the employment of more precise statistical models and advanced quantitative techniques, this study will contribute to a better understanding of employee job satisfaction, organizational climate, and leadership.

\section{Employee Job Satisfaction}

Job satisfaction has been defined as the pleasurable emotional state resulting from the appraisal of one's job as facilitating the achievement of one's job values (Locke, 1969; Locke, 1975). The job satisfaction variable has been central to the field of industrial and organizational psychology (Henne \& Locke, 1985). Locke (1975; 1985) identified dimensions contributing to job satisfaction, including the work itself, pay, promotions, working conditions, coworkers, supervisors, and organizations. Herzberg, Mausner, \& Snyderman (2011) noted that there are two general categories of job factors: 
intrinsic and extrinsic factors. Herzberg (1987) noted that intrinsic factors pertain to the work itself, while extrinsic factors encompass aspects of the work context, such as organizational policy and overall work conditions (Iiacqua, Schumacher, \& Li, 1995). Importantly, intrinsic factors are individual-level variables, while the extrinsic factors are organizational-level variables.

Employee job satisfaction is an outcome of interest that has been heavily researched due to its documented positive association with employee performance and negative relationship to employee turnover, both of which are critical organizational metrics for measuring organizational success (Igbaria \& Guimaraes, 1993; Spector, 1997; Yang, 2010). In addition to documenting consequences of job satisfaction, researchers have extensively explored the antecedents to employee job satisfaction. Two major contributors to job satisfaction recognized in the literature are organizational climate and supervisors' transformational leadership style.

\section{Organizational Climate}

Organizational climate has been defined as the shared meaning organizational members attach to the events, policies, practices, and procedures they experience and the behaviors they see being rewarded, supported, and expected (Ashkanasy, Wilderom, \& Peterson, 2000; Ehrhart, Schneider, \& Macey, 2013; Michela \& Burke, 2000). Litwin and Stringer (1968) articulated nine climate dimensions that contribute to an organization's climate: structure, responsibility, reward, risk, warmth, support, standards, conflict, and identity. In addition to specific climate dimensions, the concept of climate strength has been studied extensively (Dawson, Gonzalez-Roma, Davis, \& West, 2008).

Organizational climate strength is defined as the level of agreement between members 
within an organization about the meaning of organizational practices/procedures and the behaviors that are rewarded/expected (Dawson et al., 2008).

Organizational climate, in short, is an organizational-level variable that has often been studied due to its documented impact on individual-level outcomes (GonzalezRoma, Peiro, \& Tordera, 2002; Litwin \& Stringer, 1968; Zohar \& Luria, 2004; Zohar \& Tenne-Gazit, 2008). Additionally, organizational climate has been found to have an impact on organizational-level outcomes (Ehrhart et al., 2013). While the topic of organizational climate has long been studied due to its impact on an array of outcomes, the primary focus in the academic literature has been the relationship between organizational climate and job satisfaction in particular (Downey, Don, \& Slocum, 1975; Downey, Hellriegel, Phelps, \& Slocum, 1974; Johannesson, 1973; LaFollette \& Sims, 1975; Welsch \& LaVan, 1981). It is important to note that while organizational climate has been identified as an antecedent to job satisfaction, the literature has also recognized the influence of supervisor transformational leadership on employee job satisfaction. The construct of supervisor transformational leadership will be discussed in depth in the following subsection.

\section{Supervisor Leadership Style (Transformational Leadership)}

The leadership style of supervisors of groups has been explored in order to help develop leadership capacities in individuals (Bryman, Collinson, Grint, Jackson, \& UhlBien, 2011). While there are numerous leadership theories in the literature, one of the most heavily studied theories has been transformational leadership (Bryman et al., 2011). Transformational leadership is the process by which a leader fosters group or organizational performance beyond expectation by virtue of the strong emotional 
attachment with his or her followers combined with the collective commitment to a higher moral cause (Bryman et al., 2011; Diaz-Saenz, 2011). Transformational leaders utilize this strong emotional attachment to empower their followers to an awareness of organizational goals, thereby allowing them to perform above and beyond their expected roles (Bass \& Riggio, 2006; Burns, 2003; Crawford, Gould, \& Scott, 2003; Hartog, Muijen, \& Koopman, 1997; Muenjohn \& Armstrong, 2008; Northouse, 2015).

Transformational leadership has been found to have a favorable impact on a range of work outcomes; these include individual-level outcomes such as job satisfaction and innovation, as well as organizational-level outcomes such as team performance (Yukl, 1999; Zineldin \& Hytter, 2012). It is important to note that the literature has identified transformational leadership not only as an antecedent to employee job satisfaction (Berson \& Linton, 2005; Gill, Flaschner, Shah, \& Bhutani, 2010; Riaz \& Haider, 2010; Wiratmadja, Govindaraju, \& Rahyuda, 2008), but also as a precursor to the organizational climate construct as well (Dragoni, 2005; Ostroff, Kinicki, \& Tamkins, 2003; Zohar \& Tenne-Gazit, 2008). In other words, the style of leadership is not only associated with how satisfied an employee is, but it is also related to the organizational climate. It is also important to note that the organizational climate established by a leader may, in turn, contribute to employee job satisfaction.

\section{Statement of the Problem}

The purpose of this study is to investigate the inter-relationships between employee job satisfaction, organizational climate, and supervisor transformational leadership. As previously indicated, extensive research has been conducted on the topics of employee job satisfaction, organizational climate, and supervisors' transformational 
leadership. However, current research on these topics suffers from major issues. These issues create gaps in knowledge about the relationship between these three variables, which must be addressed for reasons described in greater detail in this section. These knowledge gaps stem from two primary issues: 1) existing models explore relationships between the three variables in limited ways; and, 2) the current research suffers from levels-of-analysis issues. These two problems will be explained in more depth in the following two subsections.

\section{Existing Models: Limited Exploration of Relationships between the Variables}

Current studies have explored the relationships between employee job satisfaction, organizational climate, and supervisor transformational leadership through three distinct models. One model has investigated the effect of transformational leadership on employee job satisfaction (Berson \& Linton, 2005; Gill et al., 2010; Riaz \& Haider, 2010; Wiratmadja et al., 2008). Other studies have explored the role of transformational leadership as a precursor to organizational climate (Dragoni, 2005; Ostroff et al., 2003; Zohar \& Tenne-Gazit, 2008). The final model used in a number of studies examined the effect of dimensions of organizational climate on dimensions of job satisfaction (Downey et al., 1974; Downey et al., 1975; Johannesson, 1973; LaFollette \& Sims, 1975; Welsch \& LaVan, 1981). While investigating these three distinct dyadic relationships is helpful, these models are limited in addressing the interrelationships between all three variables at the same time.

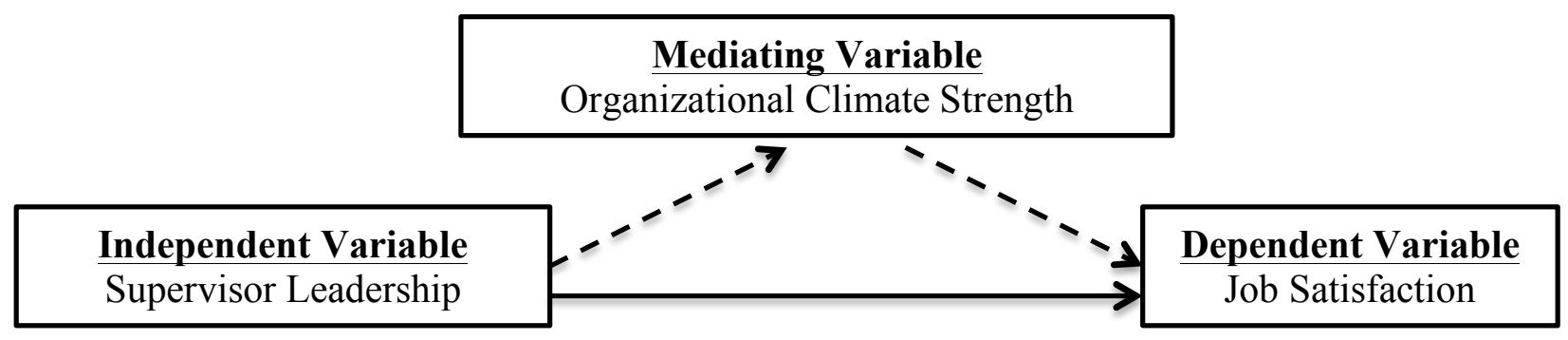


Figure 1. Theoretical framework.

By utilizing organizational climate strength as a mediating variable, researchers can test the direct relationship between transformational leadership and job satisfaction, as well as the indirect relationship between those two constructs (through organizational climate strength). This particular model has not yet been used in research about these three variables; as a result, there is a gap in knowledge about how all three concepts relate to each other empirically. Such a model would represent a marked improvement in the current literature in terms of the inter-relationships between these three variables.

\section{Levels-of-Analysis Issues}

In addition to complications that arise as a result of relatively simple models being used in the current literature, knowledge gaps about the inter-relationships between employee job satisfaction, organizational climate, and supervisor transformational leadership also arise due to the fact that existing studies do not adequately address levelsof-analysis issues present when investigating these three variables. As demonstrated in the Background of the Study section, aspects of the employee job satisfaction and organizational climate variables exist within different levels-of-analysis (specifically, both the organizational and individual levels).

For example, while employee job satisfaction is an individual-level variable that affects individual-level outcomes such as employee turnover and employee performance (Igbaria \& Guimaraes, 1993; Spector, 1997; Yang, 2010), organizational climate is an organizational-level variable that impacts both individual-level level outcomes such as motivation, performance, and commitment of team members (Gonzalez-Roma et al., 2002; Litwin \& Stringer, 1968), and organizational-level outcomes such as organizational 
capacity for innovation and organizational performance outcomes (Ehrhart et al., 2013). Furthermore, transformational leadership has been linked to both organizational climate (Dragoni, 2005; Ostroff et al., 2003; Zohar \& Tenne-Gazit, 2008) and employee job satisfaction (Berson \& Linton, 2005; Gill et al., 2010; Riaz \& Haider, 2010; Wiratmadja et al., 2008); therefore, supervisor transformational leadership impacts both organizational-level and individual-level variables.

Current research addresses these varying levels-of-analysis in one of two ways. First, research studies may address only one level-of-analysis in a particular study. Alternatively stated, researchers design studies to investigate either only individual-level variables or only organizational-level variables (Berson \& Linton, 2005; Johannesson, 1973; Zohar \& Luria, 2004; Zohar \& Tenne-Gazit, 2008). A second method used in current research is to simply conflate multiple levels-of-analysis into one, generally by utilizing Ordinary Least Squares (OLS) regression models. Researchers choose to fit individual-level attributes into the organizational-level, or they choose to simply treat organizational-level characteristics as individual-level outcomes (Dragoni, 2005; Ehrhart et al., 2013; Riaz \& Haider, 2010; Welsch \& LaVan, 1981).

Both of these methods to address the levels-of-analysis issue are inappropriate and lead to major problems. If the first method is employed, findings ascertained from those studies will be incomplete, as the model excludes key characteristics and variables that should be considered in order to gain realistic insights about the impact of selected independent variables. In short, models reflecting the first method almost certainly suffer from omitted variable bias (Berson \& Linton, 2005; Dragoni, 2005; Zohar \& TenneGazit, 2008), leading to imprecise coefficient estimates of the independent variables. 
If the second strategy is employed, explanations provided by those studies will be based on incorrect models and inappropriate statistical assumptions. If statistical assumptions are violated through the strategy of conflating multiple levels-of-analysis, the robustness of data analysis techniques (typically OLS regression) is drastically reduced. These issues yield a major knowledge problem, as current coefficient estimates in the literature about the relationship between employee job satisfaction, organizational climate, and supervisor transformational leadership may be biased. Therefore, the exploration of the relationships between these constructs must follow a new method of data analysis. Multi-level modeling is the most appropriate way to address levels-ofanalysis issues.

\section{Purpose of the Study}

The purpose of this study is to address the aforementioned problems. The problems in the existing literature about this topic will be addressed by employing a better, more precise, and more realistic theoretical model about the relationship between supervisor transformational leadership, organizational climate, and employee job satisfaction. Additionally, this study will utilize a more robust analytical procedure to confront the levels-of-analysis issues that are present when exploring the relationship between these three variables.

In terms of modeling the relationship between the variables, this study will use organizational climate as a mediating variable between supervisor transformational leadership level and employee job satisfaction. As stated previously, existing studies have already explored the relationship between: 1) transformational leadership and employee job satisfaction; 2) transformational leadership and organizational climate; and, 3) 
organizational climate and employee job satisfaction. A logical next step in research about these variables is to simultaneously explore the direct impact of supervisors' transformational leadership style on employee job satisfaction, as well as its indirect impact, through organizational climate; this is possible through the usage of organizational climate as a mediating variable in the model. Additionally, this model is a more realistic pathway to investigate the interrelationships between the three variables than the models that assume separate dyadic relationships, i.e., the models that have been used in the current literature.

To address the levels-of-analysis issues, this study will employ multi-level modeling techniques. Data analysis methods in current research on the variables of interest in this study forced researchers to generally limit their study in one of two ways: 1) researchers had to choose between focusing only on individual-levels or organizational-levels-of-analysis when investigating the relationship between supervisor transformational leadership level, organizational climate, and employee job satisfaction (Berson \& Linton, 2005; Johannesson, 1973; Zohar \& Luria, 2004; Zohar \& Tenne-Gazit, 2008); or, 2) researchers merged multiple levels-of-analysis into one when exploring these three variables (Dragoni, 2005; Ehrhart et al., 2013; Riaz \& Haider, 2010; Welsch \& LaVan, 1981). These two methods yield either incomplete answers or answers that were generated using inappropriate models and unrealistic assumptions. The use of multilevel modeling in this study will bypass these levels-of-analysis issues.

As a result of using a mediating variable model and utilizing multi-level modeling data analysis techniques, this study will provide more reliable, valid, and accurate estimates of the relationship between the three key components being investigated in this 
study: supervisor transformational leadership level, organizational climate, and employee job satisfaction.

\section{Research Questions}

The following research questions will guide this study:

1) To what degree does a relationship exist between supervisor full-range leadership (in particular, transformational leadership) and employee job satisfaction?

2) To what degree does organizational climate strength mediate the relationship between supervisor full-range leadership and employee job satisfaction?

3) How do findings regarding the interrelationships between supervisor full-range leadership, organizational climate strength, and employee job satisfaction differ when utilizing multi-level modeling techniques instead of OLS regression techniques?

\section{CHAPTER TWO \\ LITERATURE REVIEW \\ Introduction}

Job satisfaction has been linked to important organizational metrics such as employee performance and employee turnover. While the topic of organizational climate 
has long been studied due to its impact on an array of outcomes, the primary focus of the literature has been the relationship between organizational climate and job satisfaction in particular. The leadership style of supervisors of groups has been explored and argued as an antecedent for both organizational climate and employee job satisfaction.

Organizations across a number of contexts and industries view employee job satisfaction, organizational climate, and supervisor leadership style of utmost importance, as these three variables represent both key constructs that can be leveraged to improve an organization, as well as critical outcomes of success. Organizations can use the data generated from this study to have a clearer idea of which specific leadership behaviors they should develop in their supervisors in order to build more positive and stronger organizational climates and/or increase employee job satisfaction.

This chapter presents an extensive literature review of job satisfaction, organizational climate, and supervisor full-range leadership style (focusing on transformational leadership). Additionally, the chapter highlights the established interrelationships between supervisor transformational leadership style and employee job satisfaction, organizational climate and job satisfaction, and supervisor transformational leadership capacity and organizational climate. A review of existing studies employing multilevel-modeling strategy, as well as the rationale behind its advantages, are also be provided in this chapter.

Taken together, the four distinct sections of this literature review (employee job satisfaction, organizational climate, supervisor leadership style, and multi-level modeling) demonstrate two key areas of opportunity for the research around these topics to improve upon. First, this chapter will highlight the logic to utilize organizational 
climate as a mediating variable between supervisor transformational leadership style and employee job satisfaction. Second, this chapter will demonstrate the need for a new study design employing multi-level modeling data analysis to explore the relationships between job satisfaction, organizational climate, and transformational leadership in a higher education/university context.

\section{Employee Job Satisfaction}

The most commonly accepted definition of job satisfaction is that it is the pleasurable emotional state resulting from the appraisal of one's job as achieving or facilitating the achievement of one's job values (Judge, Weiss, Kammeyer-Mueller, \& Hulin, 2017; Locke, 1969; Locke, 1975; Rich, LePine, \& Crawford, 2010; Rhoades, Eisenberger, \& Armeli, 2001; Weiss, 2002). Additionally, job satisfaction is the function of the perceived relationship between what one wants from one's job and what one perceives it as offering or entailing (Judge et al., 2017; Locke, 1969; Locke, 1975). Henne \& Locke (1985) label job satisfaction as an emotional response to value judgment by individual employees. Early research by Hoppock (1935) noted relationships between job satisfaction and emotional adjustment, religion, social status, interest, age, fatigue, and size of community. While a wide breadth of consequences of job satisfaction have been explored in the existing literature (such as potential physical and psychological well-being of employees, organizational commitment, affective and continuance commitment, and absenteeism), the literature has identified that the two major outcomes of interest for practitioners when considering employee job satisfaction/dissatisfaction are employee performance and employee turnover (Chun, Shih, Choi, \& Kim, 2013; Igbaria 
\& Guimaraes, 1993; Messersmith, Patel, Lepak, \& Gould-Williams, 2011; Spector, 1997; Solinger, Hofmans, \& van Olffen, 2015; Sung \& Choi, 2014; Yang, 2010).

This section of the literature review delves into the many studies that have looked into the antecedents and consequences of job satisfaction. The subsection about outcomes of job satisfaction focuses primarily on performance and turnover, as these are the two major consequences of interest for practitioners. A discussion about measuring the job satisfaction construct follows, including considerations that must be taken into account when employing an instrument to measure the dimension. Lastly, this section of the literature review concludes with a critique of the job satisfaction literature.

\section{Determinants of Job Satisfaction}

The job satisfaction variable is central to many aspects of industrial and organizational psychology (Henne \& Locke, 1985; Rhoades et al., 2001; Weiss, 2002). One school of thought is that job satisfaction is the primary goal organizations; others view job satisfaction as a means to an end rather than the end itself (Henne \& Locke, 1985; Humphrey, Nahrang, \& Morgeson, 2007; Locke, 1985; Morgeson \& Humphrey, 2006). If job values are perceived as being fulfilled, employees will experience the pleasurable emotion of satisfaction, while if the job values are unfulfilled, employees will experience dissatisfaction (Dalal, Lam, Weiss, Welch, \& Hulin, 2009; Grant, 2008; Greguras \& Diefendorff, 2009; Henne \& Locke, 1985; Locke, 1975; Rich et al., 2010). The intensity of these possible emotional reactions is dependent upon the importance of the values whose fulfillment is being facilitated or inhibited by the work experience (Dalal et al., 2009; Grant, 2008; Henne \& Locke, 1985; Locke, 1975; Rhoades et al., 2001; Rich et al., 2010; Solinger, van Olffen, \& Roe, 2008). 
Locke $(1975 ; 1985)$ set the foundation for job satisfaction research by exploring what values employees typically seek from their jobs (Henne \& Locke, 1985). Locke $(1975 ; 1985)$ determined dimensions contributing to job satisfaction, including the work itself, pay, promotions, working conditions, coworkers, supervisors, and organizations. In terms of the work itself, Locke $(1975 ; 1985)$ noted that employees desire personally interesting and significant work, success/sense of accomplishment or progress, growth, responsibility, autonomy, role clarity, role congruence, feedback concerning performance, and minimal physical strain/drudgery.

For pay, employees want fairness, enough money to meet their expenses, competitive fringe benefits (such as work-life balance), and security. Employees indicate that for promotions, they want fairness, clarity. and availability of promotions. Locke $(1975 ; 1985)$ highlighted that for working conditions, employees prefer: convenient locations and hours, safe and attractive physical surroundings, and equipment and resources that facilitate work accomplishment. Employees prefer coworkers who share similar values and who facilitate work accomplishment, while they like supervisors who are considerate, honest, fair, competent, who recognize and reward good performance, and who allow participation from employees in decision-making. Lastly, Locke (1975; 1985) found that employees favor organizations that show a basic respect for employees and employee welfare (values) and that are competent in having a clear sense of direction, are managed effectively, and create good products.

Factors identified by research as affecting job satisfaction (and job dissatisfaction) levels include intrinsic rewards such as professional interest, job responsibility, psychological recognition, career advancement, skill utilization and development, 
enjoyment of work, and autonomy in decision-making (Greguras \& Diefendorff, 2009; Hanson, Martin, \& Tuch, 1987; Humprey et al., 2007; Iiacqua, Schumacher, \& Li, 1995; Kalleberg, 1977; Mortimer, 1979; Seybolt, 1976). Extrinsic rewards also impact job satisfaction/dissatisfaction; these factors include monetary income, fringe benefits, job security, administrative policy, company reputation, job supervision, working conditions, and relationship with peers and management (Iiacqua et al., 1995; Morgeson \& Humphrey, 2006; Seybolt, 1976; Solinger et al., 2008; Solinger et al., 2015). Research in the field has also shown evidence that both intrinsic and extrinsic factors are affected by socio-demographic factors of the employee, such as age, gender, and socioeconomic status (Glenn \& Weaver, 1982; Iiacqua et al., 1995; Judge et al., 2017; Kalleberg, 1977; Kalleberg \& Loscocco, 1983; Martin \& Hanson, 1985; Martin \& Shehan, 1989; Weiss, 2002). However, Lambert, Hogan, \& Barton (2001) found that work environment was more important in shaping worker job satisfaction than demographic characteristics. Churchill, Ford, \& Walker (1976) noted that 40\% of variation in job satisfaction was explained by organizational climate variables.

Herzberg, Mausner, \& Snyderman (2011) asserted that there are two distinct types of job factors: motivators and hygiene. Motivators pertain to the work itself, and, when present, lead to high satisfaction; alternatively hygiene factors pertain to the work context and, when absent, lead to job dissatisfaction and low performance (Henne \& Locke, 1985; Herzberg et al., 2011). These factors can also be thought of as intrinsic and extrinsic factors. Intrinsic factors, according to Herzberg (1987) are the work itself, responsibility, and growth or achievement; these are distinguished from extrinsic factors that include organizational policy, status, pay, benefits, and overall work conditions 
(Iiacqua et al., 1995). Herzberg (1987) and Herzberg et al. (2011) proposed that job satisfaction is determined only by the intrinsic factors. According to the two-factor (motivation-hygiene theory), the opposite of job satisfaction is "no job satisfaction", not job dissatisfaction; this is coupled with the opposite of job dissatisfaction being "no job dissatisfaction" instead of job satisfaction (Iiacqua et al., 1995; Judge et al., 2017). Therefore, Herzberg (1987) argued that job satisfaction and job dissatisfaction should be measured by different scales to account for the fact that an employee could be very happy with his or her professional work, yet extremely unhappy with the overall work environment. Efforts have been made to design measures of job satisfaction and job dissatisfaction, as well as to test the validity of the two-factor hypothesis developed by Herzberg (Cohen, 1974; Couger, 1988; Maidani, 1991; Iiacqua et al., 1995; Warr, Cook, $\&$ Wall, 1979). These studies also explored the relationship between demographic variables (such as education level, age, and number of dependents) and job satisfaction. Despite these seemingly clear distinctions between the two-factors made by Herzberg (1987), Rosenfeld \& Zdep (1971) argued that not all aspects of a job environment could be classified exclusively as either intrinsic or extrinsic. In asking a group of industrial psychologists to classify items as either intrinsic or extrinsic, the researchers found several items that were classified as "neutral" variables. Additionally, Locke (1975) and Miner (1980) discredited the two-factor theory based on logical, methodological, and empirical grounds. In agreement with the findings of Rosenfeld \& Zdep (1971), Dunnette, Campbell, \& Hakel (1967) stated that the Herzberg two-factor theory was a grossly oversimplified portrayal of the mechanism by which job satisfaction comes about. Dunnette et al. (1967) noted that job satisfaction could reside in the job 
content, job context, or jointly within both. The authors found that certain job dimensions (achievement, responsibility, and recognition) were important for both job satisfaction and job dissatisfaction. In addition to the intrinsic/extrinsic rewards factors, supervisor leadership style has also been found to affect job satisfaction (Berson \& Linton, 2005; Medley \& Larochelle, 1995; Riaz \& Haider, 2010).

\section{Outcomes of Job Satisfaction}

While a wide breadth of consequences of job satisfaction have been explored in the existing literature, the literature has identified that the two major outcomes of interest for practitioners when considering employee job satisfaction/dissatisfaction are employee performance and employee turnover (Bentein, Vandenberghe, Vandenberg, \& Stinglhamber, 2005; Igbaria \& Guimaraes, 1993; Lee, Gerhart, Weller, \& Trevor, 2008; Rotundo \& Sackett, 2002; Spector, 1997; Solinger et al., 2008; Yang, 2010). As a result, this subsection will delve into performance and turnover as the main consequences of job satisfaction.

Judge, Thoresen, Bono, \& Patton (2001) conducted a qualitative and quantitative review of the link between job satisfaction and performance based on seven models. Research has not yet provided conclusive confirmation or discontinuation of any of their models. The group of researchers found a correlation of 0.3 between job satisfaction and performance. However, this correlation does not attempt to explain the direction of the relationship between satisfaction and performance.

Greene and Craft (1979) borrowed from the human relations school by asserting the theory that a satisfied employee will also be a productive worker. Attempts have been made to establish a link that satisfaction leads to performance, under the assumption that 
"all good things go together" (Henne \& Locke, 1985). Brayfield \& Crockett (1955) initiated a classic review of the literature, in which they highlighted the "gratitude theory". The "gratitude theory" asserts that workers become productive due to gratitude to their supervisor for making their job satisfying (Brayfield \& Crockett, 1955; Henne \& Locke, 1985). Brayfield and Crockett (1955) mention other explanations, such as: 1) a satisfied worker is willing to accept management goals, including high production, or 2) increased satisfaction frees certain creative energies in the worker, manifesting itself in increased productivity and performance. Despite these logical explanations, research has failed to support these hypotheses (Henne \& Locke, 1985). However, Brayfield \& Crockett (1955) moved forward by advancing the idea that satisfaction may be the consequence of performance, rather than its antecedent.

While it is interesting to consider the idea that performance influences satisfaction (instead of satisfaction impacting performance), it is important to note that organizations differ in the connections they provide between performance and rewards. Therefore, high performance does not consistently relate to satisfaction, even with this reversal of the relationship direction (Brown \& Lam, 2008; Henne \& Locke, 1985; Meyer, Becker, \& Vandenberghe, 2004; Kish-Gephart, Harrison, \& Treviño, 2010; Whitman, Van Rooy, \& Viswesvaran, 2010). Locke (1970) argued that the effect of job performance on job satisfaction depends on the degree to which performance leads to the attainment of the individual's job values. Locke (1970) also noted that while performance could lead to the attainment of the individual's job values, it must do so without negating the employee's other important values in order to have a high, positive impact on job satisfaction. More research has confirmed that measures of satisfaction and performance were seemingly 
unrelated (Herzberg, Mausner, Peterson, \& Capwell, 1968; Henne \& Locke, 1985; Kahn, 1960; Vroom, 1982). However, Herzberg et al. (2011) has attempted to justify a relationship from the "satisfaction causes performances" theory by claiming that disconfirming findings were the result of problems with methodology and measurement. This led to Herzberg's work on the aforementioned "two-factors" theory in the previous sub-section of this paper.

Some researchers (Fisher, 1980; Organ, 1977) have continued to defend the "satisfaction causes performance" view of the relationship. They argued that work redesign efforts represent one manifestation of this line of thought (Henne \& Locke, 1985). Hackman and Oldham (1980) assert that work redesign efforts give employees work that is inherently more meaningful (and thereby more satisfying), which, in turn, leads to an increase in performance. Henne \& Locke (1985) note that there is no convincing proof of this assumption, and that the results of the research have indicated that while work redesign has sometimes been found to increase satisfaction, there is no effect of enrichment on performance unless it is combined with other motivational techniques such as goal setting (Umstot, Bell, \& Mitchell, 1976). Lawler (1969) found that job enrichment increases work quality, but Henne and Locke (1985) state that this may be attributed to the effects of work quality feedback combined with implicit or explicit goal setting.

Empirical tests have compared the "satisfaction causes performance" hypothesis with the "performance causes satisfaction" directionality (Porter and Lawler, 1968). Research has established that there is a greater plausibility in the direction of performance causing satisfaction, as seen through correlation analysis (Cherrington, 
Reitz, \& Scott, 1971; Greene, 1973; Henne \& Locke, 1985; Nathanson and Becker, 1973; Siegel and Bowen, 1971). While it is seemingly unclear what the relationship between satisfaction and performance is, it has been a heavily researched topic of interest. The sheer breadth of investigation regarding the relationship highlights the value organizations and individuals place on employee job satisfaction. However, it is important to note that performance is not the only variable deeply researched in terms of its relationship to employee job satisfaction. Another area of research in the field has been around the relationship between employee job satisfaction and turnover.

In his compilation of existing studies, Mobley (1977) noted that a consistent negative relationship has been reported about the link between job satisfaction and employee turnover (Brayfield \& Crockett, 1955; Locke, 1975; Porter \& Steers, 1973; Vroom, 1982). In their longitudinal study of 60 psychiatric technician trainees, Porter, Steers, Mowday, \& Boulian (1974) found a significant relationship between job satisfaction and turnover that was strongest at points in time closest to when individual employees left the organization. More recently, Lambert et al. (2001) found that job satisfaction was a highly salient antecedent of turnover event. The researchers also found that job satisfaction was a key mediating variable between the work environment and turnover intent. Locke (1975) noted that while the reported correlations between employee satisfaction and turnover have been consistent and significant, they have not been especially high - usually less than 0.40 (Mobley, 1977).

While most studies of turnover examine the direct relationship between job satisfaction and turnover, the existing literature has suggested that there are several possible intermediate steps in the withdrawal decision process (in this case, the decision 
to quit a job). Mobley (1977) outlined the following ten-step withdrawal decision process for employees: 1) evaluation of existing job; 2) experienced job satisfaction/job dissatisfaction; 3) thinking of quitting; 4) evaluation of expected utility of search and cost of quitting; 5) intention to search for alternatives; 6) search for alternatives; 7) evaluation of alternatives; 8) comparison of alternatives vs. present job; 9) intention to quit/stay; 10) quit/stay decision. A number of studies in the literature have supported each of these steps and have investigated the linkages between different steps in the process.

A few models have proposed the process between evaluation of existing job (step 1) and experiencing job satisfaction/job dissatisfaction (step 2). These include the valuepercept discrepancy model, the contribution-inducement ratio, the met-expectations model, and an instrumentality-valence model (Conway \& Briner, 2012; Hong, Liao, Hu, \& Jiang, 2013; Locke, 1969; March \& Simon, 1958; Porter \& Steers, 1973; Vroom, 1982). Recognizable consequences of experiencing job dissatisfaction (step 2) are other forms of withdrawal that are less extreme than quitting, such as absenteeism and passive job behavior (Brayfield \& Crockett, 1955; Kraut, 1975; Liu, Mitchell, Lee, Holtom, \& Hinkin, 2012; Piening, Baluh, \& Salge, 2013; Schneider, Hanges, Smith, \& Salvaggio, 2003; Zablah, Carlson, Donavan, Maxham III, and Brown, 2016). Mobley (1977) highlighted that details of step 4, which involves the evaluation of expected utility of search and cost of quitting, include considerations such as loss of seniority, loss of vested benefits, and costs associated with travel and lost work time. This step incorporates the “perceived ease of movement” concept popularized by March \& Simon (1958).

In addition to researchers contributing to different steps of Mobley's model, additional research has been done regarding the process and relationships between 
different steps in this model. Mobley (1977) found a high negative correlation between job satisfaction (step 2) and frequency of thinking of quitting (step 3). Additionally, Atchison \& Lefferts (1972) found that the frequency with which people thought about quitting their job (step 3) was significantly related to actual termination (step 10). Kraut (1975) investigated the associations among experienced job satisfaction/dissatisfaction (step 2), intention to stay/quit (step 9), and actual termination (step 10). He found that significant correlations existed between expressed intention to stay and subsequent participation; further, he noted that these correlations were much stronger than relationships between expressed satisfaction and continued participation (Mobley, 1977). Lastly, Armknecht \& Early (1972) conducted a review relevant to the relationships between the evaluation of expected utility of search and cost of quitting (step 4), search for alternatives (step 6), and actually quitting/staying (step 10). The researchers concluded that voluntary terminations are closely related to general economic conditions.

This chapter thus far has listed definitions, antecedents of, and outcomes resulting from the construct of job satisfaction. In order to fully operationalize the aspects of the discussion, existing measures of the dimension need to be explored. The following subsection provides an overview of the major scales utilized in the literature to measure job satisfaction.

\section{Measuring Job Satisfaction}

Traditionally, researchers have used a single scale to measure both job satisfaction and job dissatisfaction, with the high end of the scale measuring complete satisfaction and the low end assessing complete dissatisfaction. This type of measure reflects the prevailing view that the same groups of factors determine job satisfaction and job 
dissatisfaction (Iiacqua et al., 1995). As mentioned earlier, Herzberg (1987) argued that job satisfaction and job dissatisfaction should be measured by different scales to account for the fact that an employee could be very happy with his or her professional work, yet extremely unhappy with the overall work environment. Efforts have been made to design measures of job satisfaction and job dissatisfaction, as well as to test the validity of the two-factor hypothesis developed by Herzberg (Cohen, 1974; Couger, 1988; Maidani, 1991; Iiacqua et al., 1995; Warr et al., 1979).

Developed by Smith, Kendall, \& Hulin (1969), the Job Descriptive Index (JDI) has remained the primary instrument used to measure job satisfaction due to its strong emphasis on psychometric rigor, as well as its frequent updates over the years. Two major updates of the JDI occurred in 1985 and 1997 (Smith et al., 1987; Kihm, Smith, \& Irwin, 1997). While the initial JDI family of scales demonstrated excellent reliability and validity, the fast-paced, constantly evolving work environment within which people's work-related attitudes are formed requires updates of instruments designed to measure job satisfaction. The JDI measures five distinct aspects of job satisfaction: the work itself, pay, opportunity for promotion, supervision, and coworkers (Smith, 1969; Spector, 1994). The construct validity of the JDI has been supported by acceptable estimates of internal consistency and test-retest reliability, as well as well-demonstrated convergent and discriminant validity (Kinicki, McKee-Ryan, Schriesheim, \& Carson, 2002).

The JDI in its full form contains 72 total questions. The researchers released an abridged JDI (ADJI) containing 30 questions. It is important to note that, rather than asking questions to measure constructs, the JDI/ADJI list one-word phrases that the 
respondent must rate. This method of measuring a construct is less robust than full questions measuring various aspects of a construct.

An alternative to the JDI/AJDI is the Job Satisfaction Survey (JSS). Developed by Spector (1985), the JSS uses 36 questions to measure nine facets of employee attitudes about their job and aspects of the job. Each facet is assessed with four items. The JSS is comprised of nine dimensions, including satisfaction with: pay, promotion, supervision, fringe benefits, contingent rewards (performance-based rewards), operating procedures (required rules and procedures), coworkers, nature of work, and communication. Although the JSS was originally developed for use in human service organizations, it is applicable to all organizations in both the private and public sector.

The JSS employs a 6-point Likert Scale, ranging from "Disagree very much" to "Agree very much". Both reliability and validity of the instrument have been established over the course of the past two decades. Thousands of responses from various organization types and industries have been analyzed to ensure strong psychometric properties hold for the instrument. Considering its ubiquitous use in the existing literature, its utilization of full questions (as opposed to one-word phrases) to the measure its constructs, and its much shorter length in the number of questions (which would reduce survey administration time of respondents), the JSS is generally preferable to the JDI as a measure of job satisfaction.

Thus far, this chapter has expounded on the background of the literature regarding the job satisfaction construct, along with standard measures of the construct that have been developed and used over time in research on this topic. The following subsection will provide a general critique of the current state of the job satisfaction literature. 


\section{Critique of Job Satisfaction Literature}

As explained in this section, job satisfaction is linked to many outcomes of interest, most notably employee performance and employee turnover. As a result, this construct has been heavily researched. It is important to note that researchers attempting to measure job satisfaction should consider employing an instrument that gauges both intrinsic and extrinsic factors in order to adequately measure all aspects of job satisfaction. Even when taking this into consideration, the two-factor theory has been discredited as being oversimplified. Regardless, consensus exists that future studies measuring job satisfaction must include questions asking about both motivation and hygiene factors in order to adequately assess the job satisfaction dimension. Utilizing the JSS as the measure in a study to gather data regarding employee job satisfaction can do this.

Levels-of-analysis are also an important consideration when conducting research on job satisfaction. Intrinsic factors exist at the individual level-of-analysis while extrinsic factors can exist at the group or organizational levels. As a result, while a psychometrically strong instrument to measure job satisfaction is present by using the JSS, studies investigating job satisfaction require data analysis techniques that can account for different levels-of-analysis. Issues arise in accuracy of the data when only one level-of-analysis is considered, or when multiple levels-of-analysis are conflated. Therefore, multilevel modeling techniques would be appropriate when conducting a study in which job satisfaction is a dimension of interest.

A strong study containing job satisfaction as a construct generally will have at least one antecedent to job satisfaction present in the study design. While there are many 
antecedents to job satisfaction, a particular variable of interest is organizational climate. The construct of organizational climate will be discussed in further detail in the next section of this chapter.

\section{Organizational Climate}

The concept of organizational climate does not have a singular, concrete definition in the literature. For example, organizational climate has been defined as the shared meaning organizational members attach to the events, policies, practices, and procedures they experience and the behaviors they see being rewarded, supported, and expected (Ehrhart, Schneider, \& Macey, 2013). Alternatively, Ashkanasy, Wilderom, \& Peterson (2000) noted that the term climate is used to describe configurations of attitudes and perceptions by organization members that, in combination, reflect a substantial part of the context of which they are a part and within which they work. Michela \& Burke (2000) stated that organizational climate traditionally involves people's perceptions and experiences of the workplace in terms of warmth, trust, dynamism, ambiguity, and other affect-laden dimensions.

The "attraction-selection-retention" process portrays the dynamics of climate formation in terms of the interaction between membership changes and socialization processes (Schneider \& Reichers, 1983; Schneider, 1987; Reichers, 1987).

Organizational climate has also been explored through the social construction approach and that approach has provided rationale for viewing climates as an outgrowth of more basic value systems of organizations (Ashforth, 1985; Denison, 1996; Poole, 1985; Poole \& McPhee, 1983). In approaching organizational climate as a research topic, Denison 
(1996) stated that climate is founded in psychology, and therefore is best measured through quantitative survey data of surface-level manifestations in an organization.

The topic of climate was first broached by analyzing experimentally created social climates (Lewin, Lippit, \& White, 1939; Lewin, 1951). Qualitative analyses of organizational settings supplemented these initial studies (Barker, 1965; Likert, 1961). Tagiuri, Litwin, \& Barnes (1968) published essays encompassing a range of approaches to organizational climate, from being an "objective" group of organizational conditions to "subjective" interpretations of organizational and individual characteristics. Campbell, Dunnette, Lawler, and Weick (1970) and Likert $(1961,1967)$ added to this literature by expanding on dimensions representing the most salient aspects of organizational climate: autonomy, structure, reward orientation, and interpersonal relationships. These studies support the work of Litwin and Stringer (1968), who note nine climate dimensions to define organizational environments: structure, responsibility, reward, risk, warmth, support, standards, conflict, and identity.

Organizational climate researchers have investigated the antecedents of the construct, primarily focusing on organizational climate strength (Guion, 1973; Payne, Fineman, \& Wall, 1976; Zohar \& Luria, 2004). Climates tend to be stronger when: work units are smaller and more cohesive, there is high within-unit social interaction and dense social networks, unit members engage in higher levels of sense-making, units are more interdependent, and average tenure in the unit is high (Ehrhart et al., 2013; GonzalezRoma, Peiro, \& Tordera, 2002; Zohar \& Luria, 2004; Zohar \& Tenne-Gazit, 2008). Of all the issues that influence climate development and strength, the most commonly studied has been leadership (Ehrhart et al., 2013). Researchers have shown that units have 
stronger climates when leaders are described as higher on providing information, have more straightforward and less variable behavior patterns, and are more transformational (Ehrhart et al., 2013; Gonzalez-Roma et al., 2002; Zohar \& Luria, 2004; Zohar \& TenneGazit, 2008).

In addition to the antecedents of organizational climate, a number of authors have explored the outcomes of the construct. These outcomes exist at both the organizational and individual levels-of-analysis. Researchers have established a positive, linear relationship between organizational climate and individual levels of motivation, performance, and commitment of team members (Gonzalez-Roma et al., 2002; Litwin \& Stringer, 1968). Ehrhart et al. (2013) discussed the effects of climate in terms of its implications for change in organizations and organizational performance.

However, the link between climate to organizational outcomes is not clear. Dawson, Gonzalez-Roma, Davis, \& West (2008) found a nonlinear relationship between climate strength and overall hospital performance, such that both high and low climate strength resulted in lower performance relative to moderate climate strength. For the purposes of this dissertation, it is important to note that many researchers have established the link between organizational climate and job satisfaction (Ehrhart et al., 2013; Downey, Don, \& Slocum, 1975; Downey, Hellriegel, Phelps, \& Slocum, 1974; Gonzalez-Roma et al., 2002; Johannesson, 1973; LaFollette \& Sims, 1975; Schneider, 1975; Welsch \& LaVan, 1981). This link between organizational climate and job satisfaction, as identified in the literature, will be presented in an upcoming subsection of this chapter. 
This section of the chapter has thus far described definitions, antecedents of, and outcomes resulting from the construct of organizational climate. In order to fully operationalize the aspects of the discussion, existing measures of the dimension need to be explored. The following subsection provides an overview of the considerations in the current literature of how to measure organizational climate.

\section{Measuring Organizational Climate}

Denison (1996) noted that extensive literature has attempted to distinguish climate from “adjacent" topics such as organizational structure (Drexler, 1997; James, 1982; Lawler, Hall, \& Oldman, 197; Payne \& Pugh, 1976) and individual satisfaction (Guion, 1973; ohanneson, 1976; LaFollette \& Sims, 1975; Payne et al., 1976; Schneider \& Snyder, 1975). General consensus has been built around three distinct ways to study climate: 1) perceptual measurements of individual attributes; 2) perceptual measurements of organizational attributes; and 3) multiple measurements of organizational attributes combining perceptual and more "objective” measures (Hellriegel \& Slocum, 1974; James \& Jones, 1974; Payne \& Pugh, 1976). The first perspective has been labeled as "psychological climate", while the second and third perspectives are considered “organizational climate” (Denison, 1996; James \& Jones, 1974).

An area of ongoing debate in the literature regarding organizational climate has been whether the variable is a "shared perception" or a "shared set of conditions" (Denison, 1996). It has been argued that research on organizational climate would require the measurement of both objective organizational conditions as well as individual perceptions of those conditions. Hellriegel \& Slocum (1974) note a lack or inadequacy of effort to systematically use and blend both objective and perceptual measures of 
organizational climate. Taken together, James, Joyce, \& Slocum (1988) and Glick (1995, 1998) provide background into the logic associated with both the psychological and organizational perspectives on organizational climate research. In terms of psychometric properties, reliability of climate instruments is typically evaluated through inter-item, inter-scale, and split-half methods. Meanwhile, efforts around establishing validity have focused around construct validity (rather than concurrent validity) of climate instruments (Hellriegel \& Slocum, 1974).

Patterson, West, Shackleton, Dawson, Lawthorn, Maitlis, Robinson, \& Wallace (2005) developed the Organizational Climate Measure (OCM). Using Quinn and Rohrbaugh's (1981) Competing Values model, Patterson et al. (2005) designed an 82question survey measuring 17 distinct dimensions of organizational climate. The researchers divided these 17 dimensions into four quadrants: human relations, internal process, open systems, and rational goals. The organizational climate dimensions measured with the human relations quadrant are: autonomy, integration, involvement, supervisory support, training, and welfare. Within the internal process quadrant, the organizational climate dimensions measured are: formalization and tradition. The open systems quadrant contains: innovation \& flexibility, outward focus, and reflexivity. Lastly, the rational goal quadrant is comprised of: clarity of organizational goals, efficiency, effort, performance feedback, pressure to produce, and quality. Concurrent, predictive, and discriminant validity have all been established with this survey instrument. An important consideration to note is that administering an 82-question survey measuring 17 dimensions will increase survey administration time, which, in turn, will decrease response rates. 
As described in this subsection, the organizational climate construct contains both individual-level and organizational-level attributes. As a result, levels-of-analysis is a consideration that must be explored in more detail when discussing organizational climate. The following subsection of this chapter will expand upon the concept of levelsof-analysis, particularly in the context of organizational climate.

\section{Levels-of-Analysis}

A major component in the controversy between organizational climate and job satisfaction is the issue of unit-of-analysis (Hox, Moerbeek, \& Van de Schoot, 2017; Li, Chiaburu, \& Kirkman, 2017; Muchinsky, 1977). This issue stems from the distinction James \& Jones (1974) made between "psychological climate" and "organizational climate". Organizational climate refers to attributes of organizations measured through perceptions, while psychological climate refers to attributes of an individual. These individual attributes encompass a personal evaluation of events based upon interaction between actual events and the perceptions of those events (James \& Jones, 1974; Li et al., 2017; Muchinsky, 1977). The organizational climate and psychological climate concepts differ as a function of both the level of explanation utilized and of the focus of measurement. The level-of-analysis in "organizational climate" is the organization, while the level-of-analysis in "psychological climate" is the individual (Li et al., 2017; Muchinsky, 1977).

It is important to note that even the concept of "organizational climate" being measured at the organizational level poses challenges regarding levels-of-analysis. Pritchard \& Karasick (1973) found that organizational climate was affected by both the overall organization and subunits. Further, a strong relationship was found between 
organizational climate and subunit performance, as well as between organizational climate and individual satisfaction. The interaction between overall organization and subunits within the organization requires careful consideration of levels-of-analysis for future research about organizational climate.

Researchers have critiqued the levels-of-analysis issue in studies relating organizational climate and job satisfaction. Schneider (1975) noted that in many instruments designed to measure the "organizational climate" construct, the level-ofanalysis was in fact the individual, and not the organization. Both Guion (1973) and Johannesson (1973) criticized the conceptualization of organizational climate as an individual attribute, essentially labeling this conceptualization as a "rediscovery of the wheel" (Muchinsky, 1977). Payne, Fineman, \& Wall (1976) ask if organizational climate and job satisfaction were the same, and if organization climate was more applicable to organizations or individuals. However, research has argued that job satisfaction and perceived organizational climate, while dynamically related, may provide different sources of related information; that is, climate provides descriptive information (often affected by satisfaction), while satisfaction provides evaluative assessments (James \& Jones, 1974; Li et al., 2017; Muchinsky, 1977).

Thus far, this section of this chapter has explained the background of the literature regarding the organizational climate construct, along with standard measures of the construct that have been developed and used over time in research on this topic. Additionally, this section of this chapter has also introduced a discussion about the levelsof-analysis issue implicit in research about organizational climate. The following 
subsection will provide a general critique of the current state of the organizational climate literature.

\section{Critique of Organizational Climate Literature}

It is readily apparent that many considerations must be taken into account in any current studies about organizational climate. Climate must be seen as a combination of both objective organizational aspects and subjective individual perceptions of those organizational aspects. As a result, measures of climate must assess both distinct facets that make up the construct. The balance between objective organizational conditions and the individual perceptions of those conditions lends itself to a discussion about the levelsof-analysis issue that complicates the organizational climate construct.

Any quantitative data analysis method addressing organizational climate must account for the fact that the construct incorporates variables at both the organizational and individual levels-of-analysis. As James \& Jones (1974) and Muchinsky (1977) noted, studies about organizational climate either focus solely on the organizational level, solely the individual level, or incorrectly integrate both levels-of-analysis. While existing studies employ an Ordinary Least Squares (OLS) regression model, this type of analysis is inappropriate for a construct in which the main issues revolve around levels-ofanalysis. Multi-level modeling data analysis techniques are necessary for any study examining organizational climate in order to adequately address the current issues with existing studies about the construct.

In addition to treatment of the organizational climate construct using multi-level modeling techniques, it is important to consider how this construct relates to other variables. Thus far in this chapter, two major constructs in the literature have been 
discussed: job satisfaction and organizational climate. The following section will describe the relationship between these two constructs that has been established in the existing literature.

\section{Relationship Between Organizational Climate and Job Satisfaction}

A number of studies have examined the relationships between dimensions of organizational climate and dimensions of job satisfaction (Downey et al., 1974; Downey et al., 1975; Johannesson, 1973; LaFollette \& Sims, 1975; Welsch \& LaVan, 1981). These studies span a diverse set of industries and organizations, including automobile manufacturing, research and development, and insurance agencies (Chadha, 1988; Friedlander \& Margulies, 1969; Schneider \& Snyder, 1975). The focus of the existing research about the relationship between these two constructs has treated organizational climate as the independent variable, while job satisfaction is treated as the outcome variable.

Chadha (1988) surveyed 150 supervisors along eight dimensions of organizational climate. The author found that trust, intimacy, and non-hindrance were the three organizational climate constructs that maximized employee job satisfaction. Churchill et al. (1976) used years of experience as a moderating variable between climate and satisfaction. The authors found that closeness of manager supervision was positively related to job satisfaction. As noted earlier in this paper, Churchill et al. (1976) found that $40 \%$ of the variation in job satisfaction was explained by organizational climate variables.

Research shows mixed results regarding the relationship between organizational climate and job satisfaction. Frielander \& Margulies (1969) note that maximum 
satisfaction with work requires different mixes of climate components. Schneider \& Snyder (1975) found that climate and satisfaction correlations exist for some levels of employees, but not for others. The mixed results of the impact of organizational climate on job satisfaction necessitate further investigation of the topic. Given the findings of Schneider \& Snyder (1975), any further research about this relationship requires a data analysis technique that can explore these variables while taking into account different levels-of-analysis. In addition to considering levels-of-analysis, an additional variable of value in a model including both organizational climate and employee job satisfaction is leadership style of supervisors.

\section{Supervisor Leadership Style}

Research has attempted to identify different traits and behaviors exhibited by effective leaders in order to develop leadership capacities and capabilities in all individuals (Bryman, Collinson, Grint, Jackson, \& Uhl-Bien, 2011). While there are numerous leadership theories in the literature, a leading theory that has been utilized in research has been transformational leadership (Bryman et al., 2011; Diaz-Saenz, 2011). Transformational leadership has been linked to a range of work outcomes, including cognitive effort, effectiveness, motivation, engagement, commitment, performance, and turnover (Yukl, 1999). Additionally, transformational leadership has been found to have a favorable impact on positive emotions such as employee happiness, enthusiasm, and sense of pride in work (Zineldin \& Hytter, 2012).

Transformational leadership is focused on the relationship between leaders and followers. Given that the leader-to-follower relationship has the most potential of impacting organizational climate and employee job satisfaction, this dissertation focuses 
specifically on the application of transformational leadership theory. While full-range leadership will be measured and analyzed as part of this dissertation, the transformational leadership construct, particularly in the context of its relationship to the variables previously discussed in this chapter, is the main focus of this research. Therefore, this section of the literature review will focus specifically on transformational leadership.

The following subsections will present and critique the existing transformational leadership literature, instruments to measure transformational leadership, and highlight the links between this leadership style and the capacity of supervisors to create, embed, develop, and change the climate of their organizations/subunits. It will also expand on the relationship between transformational leadership capacity of supervisors and the job satisfaction levels of their subordinates.

\section{Transformational Leadership}

Transformational leadership is the process by which a leader fosters group or organizational performance beyond expectation by virtue of the strong emotional attachment with his or her followers combined with the collective commitment to a higher moral cause (Diaz-Saenz, 2011). Transformational leaders utilize this strong emotional attachment to empower their followers to an awareness of organizational goals, thereby allowing the followers to perform above and beyond their expected roles (Bass \& Riggio, 2006; Burns, 2003; Hartog, Muijen, \& Koopman, 1997; Muenjohn \& Armstrong, 2008; Northouse, 2015). This values-based approach emphasizes the roles and needs of individual followers in realizing the goals and mission of the entire group or organization (Bass \& Riggio, 2006; Crawford, Gould, \& Scott, 2003; Hartog et al., 1997). 
Burns (2003) distinguished between this form of leadership and "transactional leadership", which he suggests is when a leader leads followers on the basis of reciprocal exchange leading to the satisfaction of both the leader's and the follower's self-interests. Bass (1984), in his work on the Full Range Leadership (FRL) model, identified transactional and transformational factors of leadership. Under transactional leadership, he highlighted contingent reward and management-by-exception (both active and passive). Alternatively, for transformational leadership factors, he included idealized influence (both attributed and behaviors), inspirational motivation, intellectual stimulation, and individualized consideration (Bass \& Riggio, 2006; Northouse, 2015). Bass (1984) suggested that the ideal leadership approach is a combination of both transactional and transformational forms of leadership (Diaz-Saenz. 2011).

Leaders with idealized influence become role models that followers want to identify with and emulate (Bass \& Riggio, 2006; Diaz-Saenz, 2011). These leaders are perceived to have extraordinary capabilities, persistence, and determination; as a result, followers admire, respect, and trust the leader, helping build a sense of common purpose within the group (Diaz-Saenz, 2011; Northouse, 2015). By putting the needs of followers first, these leaders develop an identity founded in ethics and shared principles, which contributes to these leaders frequently being described as having charisma (Bass, Avolio, Jung, \& Berson, 2003; Diaz-Saenz, 2011).

Those who create inspirational motivation help their followers identify meaning in their work by painting a clear vision for their followers' future state (Bass et al., 2003; Diaz-Saenz, 2011). They also deliver the momentum to reach that vision through the 
arousal of team spirit by providing meaning, challenge, clearly communicated expectations, and a commitment to set goals (Bass \& Riggio, 2006; Diaz-Saenz, 2011).

Leaders who encourage their followers to be innovative and creative in their work characterize the intellectual stimulation dimension of transformational leadership (Yukl, 1999). Pushing followers to address old problems in new ways and to regularly examine old assumptions to see if they are still viable are common methods transformational leaders use to encourage innovation and creativity (Diaz-Saenz, 2011).

Lastly, when leaders show individual consideration, they serve as mentors in the followers' growth and development by treating each follower as an individual and considering their individual needs, abilities, and aspirations (Bass \& Riggio, 2006; DiazSaenz, 2011; Northouse, 2015). They view each follower as a whole person, assisting them in actualizing their full potential by helping individuals to develop their strengths and spending time coaching and guiding their followers (Avolio, Bass, \& Jung, 1999; Diaz-Saenz, 2011).

The transformational leadership construct has been applied in studies across many fields and industries. In the context of organizations, a number of studies have investigated transformational leadership in CEOs and mid-level managers, as well as the impact of the leadership style on various organizational outcomes (Colbert, KristofBrown, Bradley, \& Barrick, 2008; Pastor \& Mayo, 2008). For example, Jung, Wu, \& Chow (2008), in an investigation of 50 Taiwanese electronics/telecommunications companies, found that there is a direct and positive effect of CEO transformational leadership on organizational innovation. Zhu, Chew, \& Spangler (2005) found that transformational CEOs are more likely to adopt a human-capital-enhancing Human 
Resources Management system than non-transformational systems; further, they found that human-capital-enhancing Human Resources Management systems mediated the relationship between transformational leadership and outcomes such as absenteeism (Diaz-Saenz, 2011).

Empirical studies have found that transformational leadership is equally applicable and relevant to middle-level managers as well as top-level management (DiazSaenz, 2011). Singh \& Krishnan (2008) found that transformational leadership is positively related to followers' collective identity and perceived unit performance. The study also demonstrated that there is a statistically significant, positive relationship between transformational leadership levels and followers' perception of successful unit performance (Diaz-Saenz, 2011).

Research has further linked transformational leadership to follower satisfaction, motivation, and performance (Yukl, 1999). In addition to the relationship between transformational leadership and these outcomes of interest, extensive work has also been done regarding the relationship between transformational leadership and organizational climate (Dragoni, 2005; Liao \& Chuang, 2007; Wang \& Rode, 2010; Zohar \& TenneGazit, 2008). These studies have found strong, positive relationships between leader transformational leadership scores and strength of climate within a subunit. An extension of these connections allows for organizational climate to be regarded as a mediating variable between transformational leadership and outcomes such as employee satisfaction, motivation, engagement, and performance.

This section of the chapter has thus far explained the importance of researching leadership style of supervisors, while making the justification for focusing on 
transformational leadership for this particular study. The definitions and constructs comprising transformational leadership, as well as the consequences of organizational importance stemming from transformational leadership, have also been outlined. In order to fully operationalize the aspects of the aforementioned discussion, existing measures of the transformational leadership need to be explored. The following subsection provides an overview of the considerations in the current literature of how transformational leadership has been measured in the existing literature.

\section{Measuring Transformational Leadership}

Diaz-Saenz (2011) noted that a widely used instrument to assess transformational leadership was the Transformational Leadership Inventory (TLI), developed by Podsakoff, MacKenzie, Moorman, \& Fetter (1990). The authors identified six behaviors known to be associated with transformational leadership: 1) identifying and articulating a vision; 2) providing an appropriate model; 3) fostering the acceptance of group goals; 4) high performance expectations; 5) providing individualized support; and, 6) intellectual stimulation. Podskaoff et al. (1990) characterized the first three behaviors listed above as "core" transformational leader behaviors. In addition to these factors comprising transformational leadership, the researchers included a contingent reward construct in the TLI to measure transactional leadership. The TLI has been administered in a variety of industries and across a number of cultural contexts (Diaz-Saenz, 2011).

Bass (1984) developed the Multifactor Leadership Questionnaire (MLQ), which has become the most widely used instrument to measure transformational leadership (Diaz-Saenz, 2011). This instrument has been used in a diverse set of organizational environments across different cultural contexts (Bass \& Riggio, 2006). The current MLQ 
version $6 \mathrm{~S}$ uses 21 questions to measure the previously mentioned four factors of transformational leadership: idealized influence, inspirational motivation, intellectual stimulation, and individualized consideration (Bass \& Riggio, 2006; Diaz-Saenz, 2011). In addition, the transactional dimensions of the MLQ 6S include two components: contingent reward and management-by-exception (Diaz-Saenz, 2011). Bass (1984) argued that the transactional behaviors were the foundations of the full set of behaviors that transformational leaders perform. The final component of the MLQ 6S is a factor measuring the absence of leadership, otherwise known as laissez-faire leadership (Bass \& Riggio, 2006). Much like the TLI, the MLQ has been administered in a variety of industries and across a number of cultural contexts (Diaz-Saenz, 2011).

The psychometric properties of reliability and validity of both the MLQ and TLI have been well established in the literature due to their consistent use over time, across industries, and between different cultural contexts (Bass \& Riggio, 2006; Crawford et al., 2003; Diaz-Saenz, 2011; Northouse, 2015). Variations of the MLQ have been in use since 1985 (with the most recent MLQ version 6S), while the TLI has been employed in studies since 1990 (Bass \& Riggio, 2006; Diaz-Saenz, 2011). Both the MLQ and the TLI have been used in a diverse set of contexts, including by firemen, sales force, bank teams, manufacturing companies, and universities (Diaz-Saenz, 2011). Diaz-Saenz (2011) noted that the TLI has been used in countries ranging from the USA, Mexico, China, Greece, United Kingdom, and Pakistan, while the MLQ has been translated into many languages, including French, Japanese, Germany, and Hebrew (Bass \& Riggio, 2006).

Despite the common use of both the instruments, several issues must be considered when employing either the MLQ or the TLI. Both instruments do not directly 
address charisma as an important assessment of transformational leadership, though both take into account the charismatic conceptualization in their development (Diaz-Saenz, 2011). Additionally, many researchers employing the TLI in their studies have ignored the previously stated "core" transformational leader behavior identified by Podsakoff et al. (1990), thereby yielding limited interpretations of the study results. Lastly, Bass \& Riggio (2006) cited multicollinearity issues in the MLQ. Despite these considerations, both measures of transformational leadership add value to a study about the construct. One major advantage of utilizing the MLQ 6S instead of the TLI is the short survey administration time, given that the MLQ $6 \mathrm{~S}$ is only 21 total questions to measure four dimensions of transformational leadership, two dimensions of transactional leadership, and laissez-faire leadership.

This subsection of this chapter detailed the primary existing measures of transformational leadership, including their advantages and aspects for consideration. In addition to this subsection, it is important to discuss the relationship between transformational leadership and other variables of interest. The following subsection will explain in detail the established relationship between transformational leadership and the first variable introduced in this chapter: employee job satisfaction.

\section{Relationship Between Transformational Leadership and Job Satisfaction}

The literature about the relationship of these two dimensions has concentrated on using transformational leadership as the independent variable and job satisfaction as the dependent variable. Studies have consistently found that transformational leadership style 
is positively related to job success and career satisfaction (Berson \& Linton, 2005; Gill, Flaschner, Shah, \& Bhutani, 2010; Riaz \& Haider, 2010; Wiratmadja, Govindaraju, \& Rahyuda, 2008). The consistency of these findings extends across cultural boundaries. Riaz \& Haider (2010), in their study conducted in Pakistan, found that transformational leaders have more positive impacts on both job and overall satisfaction than transactional leaders. Additionally, these findings extend across different industries. Medley \& Larochelle (1995) investigated the relationship between head nurse leadership style and staff nurse job satisfaction. Correlations showed a significant positive relationship between those head nurses exhibiting a transformational leadership style and the satisfaction of their staff nurses.

While a general consensus about the impact of transformational leadership on job satisfaction has been built, disagreements have also risen about the nature of this relationship. Lee, Cheng, Yeung, \& Lai (2011) found that only intellectual stimulation is significantly related to employee job satisfaction. However, Hanaysha, Khalid, Mat, Sarassina, Rahman, \& Zakaria (2012) found that both individualized consideration and intellectual stimulation affect followers' job satisfaction. The authors found a positive relationship between intellectual stimulation and follower job satisfaction, but a negative relationship between individualized consideration and employee job satisfaction. Hanaysha et al. (2012) conceded that the negative relationship between individualized consideration and job satisfaction was not supported in past research. It is clear that, despite being heavily studied, inconsistent results appear in the literature about the impact of transformational leadership on job satisfaction. 
In addition to the disagreements in the literature, critiques of transformational leadership have also posited a relationship between the two constructs in the reverse direction. Alternatively stated, researchers have hypothesized that employees who are more satisfied in their jobs tend to attribute more transformational qualities to their supervisors (Van Knippenberg \& Sitkin, 2013). This aligns with studies that note that leadership is an attribution in the eye of the beholder; namely, employees hold mental representations of leadership that color their perceptions of leadership (Eden \& Leviatan, 1975; Lord \& Maher, 2002; Meindl, Ehrlich, \& Dukerich, 1985; Van Knippenberg \& Sitkin, 2013). These studies would model the relationship by treating job satisfaction as the independent variable and transformational leadership as the dependent variable. Studies investigating the relationship between these two constructs should consider this directionality as well when conducting data analysis.

This subsection described the relationship between transformational leadership and job satisfaction. In addition to the job satisfaction construct, this chapter has also expounded on the organizational climate construct. Taken together, these sections suggest the value of introducing organizational climate as a mediating variable between transformational leadership and employee job satisfaction. First, however, an explanation about the relationship between transformational leadership and organizational climate is necessary. The following subsection of this chapter will detail the work that has been done to establish a link between transformational leadership and the organizational climate construct.

\section{Relationship Between Transformational Leadership and Organizational Climate}


As explained in the previous subsection, transformational leadership can directly influence job satisfaction. However, a more realistic model may be to explore an indirect relationship between transformational leadership and job satisfaction through the mediating variable of organizational climate. This more realistic model is justified through the combination of both the established links between organizational climate and job satisfaction that were provided earlier in the paper (Downey et al., 1974; Downey et al., 1975; LaFollette \& Sims, 1975; Johannesson, 1973; Welsch \& LaVan, 1981) and the extensive existing literature on the relationship between transformational leadership and organizational climate that is provided in this current subsection. This part of the literature has focused on transformational leadership as the independent variable and organizational climate as the outcome variable.

Liao \& Chuang (2007) noted that, in addition to influencing follower attitudes and behaviors at the individual level-of-analysis, transformational leadership may also influence follower performance by transforming the general climate at the organizational level. The notion of leadership as a climate antecedent has remained relatively stable across the literature (Dragoni, 2005; Ostroff, Kinicki, \& Tamkins, 2003; Zohar \& TenneGazit, 2008). Schneider (1983) argued that because employees' climate perceptions are more likely to be shaped by their immediate organizational context, leadership of the immediate supervisor serves as a key filter in the interpretations that provide the basis for subordinates' climate perceptions (Kozlowski \& Doherty, 1989). Employees are likely to focus on situations in which the leader faces competing operation demands, informing them about what is prioritized, valued, and supported (Ashforth, 1985; Zohar, 2003; Zohar \& Tenne-Gazit, 2008). When these perceptions are shared due to consistency of 
the leader's messages and practices, they constitute the core meaning of organizational climates (Zohar \& Tenne-Gazit, 2008).

The literature at this level has explored the relationship between transformational leadership and climate for organizational innovation and organizational excellence (Charbonnier-Voirin, El Akremi, \& Vandenberghe, 2010; Eisenebeiss, van Knippenberg, \& Boergner, 2008; Moolenaar, Daly, \& Sleegers, 2010; Sarros, Cooper, \& Santora, 2008; Wang \& Rode, 2010). Additionally, studies have consistently supported the relationship between transformational leadership and group climate perceptions, particularly in terms of safety climate (Barling, Loughlin, \& Kelloway, 2002; Gonzalez-Roma et al., 2002; Hofmann \& Morgeson, 2003; Hofmann, Moregeson, \& Gerras, 2003; Kozlowski \& Doherty, 1989; Zohar, 2002; Zohar \& Luria, 2004; Zohar \& Tenne-Gazit, 2008). A metaanalysis suggested that the estimated correlation between leadership and safety climate is 0.61, suggesting a strong, positive relationship between the two variables (Nahrgang, Morgeson, \& Hofmann, 2006). Additionally, Liao \& Chuang (2007) focused on the effects of transformational leadership on influencing a work unit's service climate.

Zohar \& Tenne-Gazit (2008) posited that climate strength and transformational leadership are related due to a number of reasons. First, they argued that transformational leaders create more opportunities for sharing and clarifying perceptions (Kozlowski \& Doherty, 1989). Additionally, transformational leaders offer better articulation of task cues (Kirkpatrick \& Locke, 1996). Taken together, this provides group members with better information for assessing what is prioritized, valued, and supported, further promoting the development of shared cognitions and thereby creating a stronger climate. Secondly, the authors noted that transformational leaders are expected to exhibit greater 
consistency across situations in terms of their leadership practices. Given the key role of group leaders' practices as a common and unique reference point for group members' climate perceptions, the more consistent a leader's practices in different situations, the more they can reduce variation in group members' perceptions of the organizational climate (Ashforth, 1985). Lastly, Zohar \& Tenne-Gazit (2008) noted that the tendency of transformational leaders to exhibit greater consistency takes place especially when members' safety or welfare is at stake. In a study involving army field units, Zohar \& Luria (2004) found that transformational leaders are more consistent in their choices across a diverse range of situations than low-transformational leaders in prioritizing their soldiers' safety, resulting in a stronger safety climate. Given that the same dilemmas regarding competing demands between accomplishing goals and employee well-being occur in civil organizations, Reason (2016) noted that transformational group leadership will promote a stronger climate in organizations, especially when the focal climate's facet is associated with organizational employees' welfare or safety.

\section{Critique of Transformational Leadership Literature}

As outlined in this section, the use of transformational leadership in the literature is well documented. Because of its focus on the leader-follower relationship, transformational leadership is an appropriate theory to apply in a study researching the effect of leadership style on organizational climate and employee job satisfaction. This leadership theory has been explored deeply in a variety of industries and contexts and has been found to be applicable at various levels of management. As a result, transformational leadership is a strong dimension to include in a study exploring outcomes such as organizational climate and employee job satisfaction. Despite the 
usefulness of the transformational leadership theory, this portion of the literature review highlights that there are issues with operationalizing the dimensions that comprise this construct. The biggest issue that exists with measuring transformational leadership is the lack of focus on charisma in both the TLI and MLQ. As charisma is a core component of the theory, the utilization of the major existing measures in a study will miss out on capturing the charismatic attributes of leaders. Despite this issue, there are no viable alternatives to the TLI and MLQ, given their demonstration of reliability and validity throughout decades of data collection.

The focus of this section was the relationship between transformational leadership and both organizational climate and job satisfaction. An earlier section in this paper outlined the existing literature around the impact of organizational climate on job satisfaction. These three, taken together, justify the use of organizational climate as a mediating variable between transformational leadership and job satisfaction.

In addition to justifying the inclusion of organizational climate as a mediating variable between transformational leadership and job satisfaction, this section also highlighted that these three variables are all measured as different levels-of-analysis. The previously noted studies exploring the relationships between transformational leadership and job satisfaction (Berson \& Linton, 2005; Gill et al., 2010; Riaz \& Haider, 2010; Wiratmadja et al., 2008), leadership style and organizational climate (Dragoni, 2005; Liao \& Chuang, 2007; Ostroff et al., 2003; Zohar \& Tenne-Gazit, 2008), and organizational climate and job satisfaction (Downey et al., 1974; Downey et al., 1975; Johannesson, 1973; LaFollette \& Sims, 1975; Welsch \& LaVan, 1981) all employ OLS regression analysis techniques. 
Given that the level-of-analysis for organizational climate (organizational level) and job satisfaction (individual level) are different, employing an OLS regression methodology to examine the relationship between transformational leadership and these two constructs would be inappropriate. Using OLS regressions would conflate organizational and individual level variables, thereby presenting inaccurate regression coefficients and leading to interpretations of the data that are based on incorrect statistical and methodological assumptions.

Rather, a study investigating the relationship between leadership style, organizational climate, and job satisfaction requires a multilevel modeling method of analysis in order to yield appropriate and accurate findings. A more complex, sophisticated, and robust statistical methodology is necessary in order to improve on the current shortcomings of research about how transformational leadership influences outcomes that exist in different levels-of-analysis. To address this, the following section of this chapter will provide a primer on multi-level modeling techniques.

\section{Multi-Level Modeling Techniques}

Multi-level modeling is a complex form of OLS regression that is used to analyze variance in outcome variables when the predictor variables are at varying hierarchical levels (Woltman, Feldstain, MacKay, \& Rocchi, 2012). Hierarchical/nested data structures are abundant throughout different areas of research. Individuals tend to exist within organizational structures such as families, schools, business organizations, churches, towns, states, and countries (Osborne, 2000). Bryk and Raudenbush (1992) also noted that data hierarchies exist in repeated-measures data and meta-analytic data. Osborne (2000) listed several difficulties hierarchical data presents for analysis. The first 
issue he noted is that people who exist within hierarchies tend to be more similar to each other than people randomly sampled from the entire population. Observations based on individuals who share certain characteristics (environmental, background, experiential, demographic, or otherwise) suffer from a homogeneity issue, due to the fact that these observations are not fully independent of one another.

However, most analytic techniques require independence of observations as a primary assumption for the analysis (DeLeeuw, 1992; Osborne, 2000; Pollack, 1998). Due to hierarchical data violating this assumption, OLS regressions produce standard errors that are underestimated (Hofmann, 1997). As a result, there are higher probabilities of rejecting the null hypothesis using OLS than if an appropriate statistical analysis were performed or the data included truly independent observations (Nezlek \& Zyzniewski, 1998). For example, Berson \& Linton (2005), using OLS regressions, found a statistically significant relationship between transformational leadership and job satisfaction.

However, Braun, Peus, Weisweiler, \& Frey (2013), utilizing multilevel modeling, found relationships between transformational leadership and job satisfaction at some levels of the organization, but not at others. It is clear that the literature has identified multi-level modeling as a more appropriate and robust statistical analysis procedure for addressing hierarchical/nested data.

Pollack (1998) highlighted five major advantages of employing the multi-level modeling technique when using nested data: 1) multi-level modeling provides more precise estimates of the relative strength of relationships between variables at two or more levels-of-analysis; 2) multi-level modeling provides increased power to distinguish between random error and "error" attributed to between-group variance; 3) multi-level 
modeling gives researchers clarity about if and why some group properties might affect the strength of bivariate individual-level relationships; 4) multi-level modeling employs random sampling only at the highest levels-of-analysis, because levels nested within are assumed to be inter-correlated; and, 5) multi-level modeling gives researchers the choice of comparing individuals to the whole population or just those within the same groups. For example, Chadha (1988) correlated dimensions of organizational culture and job satisfaction, but did not employ the multi-level modeling method. Therefore, his analysis was limited, in the sense that he was not able to give clarity around if and why group properties may affect the strength of the relationship. Additionally, this method did not yield an opportunity to compare individuals to either the whole population, or even within the same group. The rest of this section will synthesize the literature about levelsof-analysis and how commonly used statistical analyses are inappropriate for analyzing hierarchical data. A subsection will also highlight studies in which a multi-level modeling technique has been employed to conduct data analysis.

\section{Levels-of-Analysis}

Small group research has explored relationships between groups and individuals. Multi-level models have attracted attention in research due to a number of constructs of interest, such as climate, being investigated at both the individual and the group levels (Moritz \& Watson, 1998; Pollack, 1998). Hoyle and Crawford (1994) noted that researchers who investigate group phenomena could choose either the group as a whole or individuals within groups as a basis for formulating research questions, developing data-gathering strategies, and conducting statistical analyses. Hackman (1990) delineated multiple group effects (ambient stimuli, discretionary stimuli, and norms) on individual- 
level beliefs, behaviors, and attitudes (Pollack, 1998). Most group research has focused on either the individual in groups or the group itself, in turn excluding the other. Neglecting both the individual and group levels-of-analysis while conducting group research is fraught with issues, given that single-level research suffers from three fundamental biases (Rousseau \& House, 1994).

The first bias is that single-level research may overgeneralize, assuming that a concept at one level will have the same relationships as a seemingly similar concept at another level (Mortiz \& Watson, 1998; Rousseau \& House, 1994). Second, single-level research underestimates the cross-level effects; studies of individuals underestimate the effects of groups on individual behavior, while studies of groups underestimate the effects that individuals have on their environments, which lead to serious statistical concerns (DeLeeuw, 1992; Kenny \& La Voie, 1985; Hofmann, 1997; Mortiz \& Watson, 1998). Specifically, Osborne (2000) notes that assigning group level characteristics to all individuals presents the previously stated problem of independence of observations.

Alternatively, aggregating individual characteristics up to the group level presents its own set of problems: 1) much (up to $80 \%-90 \%$ ) of the individual variability on the outcome variable is lost, which can lead to dramatic under- or over-estimation of observed relationships between variables (Bryk \& Raudenbush, 1992); 2) the outcome variable changes significantly and substantively from an individual-level outcome to a group-level outcome; and, 3) all the within-group variance is lost, which could be meaningful or of theoretical interest (DeLeeuw, 1992; Hofmann, 1997; Pollack, 1998). All these issues apply to the aforementioned studies tying transformational leadership to organizational climate, which did not employ a multi-level modeling methodology 
(Charbonnier-Voirin et al., 2010; Dragoni, 2005; Eisenebeiss et al., 2008; Kozlowski \& Doherty, 1989; Moolenaar et al., 2010; Ostroff et al., 2003; Sarros et al., 2008; Wang \& Rode, 2010; Zohar \& Tenne-Gazit, 2008). The final fundamental bias of single-level analysis labeled by Rousseau and House (1994) was that single-level research at the group level might result in the reification of group structures (Mortiz \& Watson, 1998). Mortiz \& Watson (1998) called for a data analysis method that could be used to analyze multilevel data in three ways: 1) to assess the extent of agreement within a single group; 2) to contrast within-group and between-group variance; and, 3) to permit multiple-level analyses.

Pollack (1998) highlighted that, for years, researchers have grappled with the “levels-of-analysis problem" (Sirotnik, 1980; Tetlock, 1986). This issue has been explored in the context of individuals who are nested within groups (Glisson, 1987; Hopkins, 1982; Hoyle \& Crawford, 1994; Morran, Robison, \& Hulse-Killacky, 1990; Pollack, 1998). It has also been investigated through the lens of individuals within organizations (Glick, 1980; Glick, 1985; Glick \& Roberts, 1984; Mossholder \& Bedeian, 1983; Pollack, 1998). In the past, group researchers have attempted to statistically address this methodological issue of levels-of-analysis. The levels-of-analysis issue is highlighted, as explained in earlier sections of this paper, in studies about the interaction between leadership style, organizational climate, and job satisfaction. Recent research has attempted to employ multi-level modeling techniques to address these concepts (Bernhard \& O’Driscoll, 2011; Braun et al., 2013; Glick, 1985; Griffin, Patterson, \& West, 2001; Kidwell, Mossholder, \& Bennett, 1997; Loi, Yang, \& Diefendorff, 2009; 
Lord, Brown, Harvey, \& Hall, 2001; Sauer, 2011; Scott \& Judge, 2006; Yammarino, Dionne, Chun, \& Dansereau, 2005; Zohar \& Luria, 2004).

Kenny and La Voie (1985) developed statistical strategies including computing intra-class correlation, mean squares from a one-way analysis of variance (ANOVA), and cross products from a multivariate analysis of variance (MANOVA). These techniques, while useful, are cumbersome and time consuming to conduct; additionally, these techniques are not intended for groups that are formed without randomization (Kenny \& La Voie, 1985; Pollack, 1998). Another often-utilized technique to separate group from individual variance is the within-and-between-analysis (WABA) (George \& James, 1993; Pollack, 1998; Yammarino \& Markham, 1992). While WABA addresses the units of analysis issue, it approaches the problem differently than other multi-level modeling techniques. WABA was created to determine the appropriate levels-of-analysis in which to measure and test particular variables (Dansereau, Alutto, \& Yammarino, 1984; Pollack, 1998).

This distinguishes WABA from general multi-level modeling techniques such as Hierarchical Linear Modeling (HLM), in that HLM allows researchers to statistically estimate hierarchical relationships between constructs measured at multiple levels-ofanalysis (Bryk \& Raudenbush, 1992; DeLeeuw, 1992; Pollack, 1998). To be more specific, HLM was created to investigate correlational relationships between higher-level and lower-level variables with a hierarchical/nested structure. The HLM procedure enables regression of a lower-level variable (for example, the individual-level) on higherlevel variables (such as the group-level), as well as other lower-level variables (Pollack, 1998). HLM accounts for the interdependence of individuals within the same group and 
model both group-level and individual-level variance in the outcome (Bryk \& Raudenbush, 1992; Hofmann, 1997).

While the literature expands on many advantages of using HLM over other data analysis techniques when working with nested data, Pollack (1998) mentioned two major limitations of the method. First, a large enough sample size is needed for each level analysis; the reality of achieving this in practice is often difficult. The second limitation concerns the type of research questions that can be addressed. HLM was created to predict the impact of higher-level variables on lower-level variables that are embedded in the higher-level context (Bryk \& Raudenbush, 1992; Pollack, 1998). However, HLM cannot be used to answer questions about the impact of lower-level variables on higherlevel ones. For example, the HLM technique cannot answer the question of how group member performance affects group culture. While the latter is certainly an issue in general, it does not pose a serious problem if research questions in a study focus specifically on the impact of higher-level variables on lower-level variables.

\section{Studies Employing HLM Technique}

The HLM procedure has been used heavily in the field of K-12 education (Kennedy, 1992; Kreft, 1993; Lee \& Byrk, 1989; Pollack, 1998). Management and organizational researchers have utilized this methodology as well (Scandura, Williams, Dansereau, Gavin, James, Markham, \& Ostroff, 1995). Recent research studies employing HLM have also addressed the major areas of this current paper. For example, a few studies have used HLM to answer research questions around job satisfaction (Braun et al., 2013; Griffin et al., 2001; Kidwell et al., 1997; Loi et al., 2009; Scott \& Judge, 2006). Additionally, studies investigating organizational climate utilizing 
multilevel modeling techniques are present in the literature (Glick, 1985; Liao \& Chuang, 2007; Zohar \& Luria, 2004).

HLM has also been used to investigate topics around leadership style and its interaction with context, its impact on team performance, and employee attitudes (Bernhard \& O’Driscoll, 2011; Lord et al., 2001; Sauer, 2011; Yammarino et al., 2005). In particular, studies have been conducted to look into the effect of transformational leadership on a number of outcomes of interest, such as the dissemination of organizational goals, job satisfaction/team performance, and employee commitment to change (Berson \& Avolio, 2004; Braun et al., 2013; Herold, Fedor, Caldwell, \& Liu, 2008; Oreg \& Berson, 2011; Sparks \& Schenk, 2001). Griffith (2004) explored the effect of transformational leadership on a variety of outcomes in K-12 education. The author found that transformational leadership by school principals was not directly associated with school staff turnover or school performance, but showed an indirect effect, through staff job satisfaction, on school staff turnover (negative) and school-aggregated student achievement (positive). Griffith (2004) also found that higher levels of school staff job satisfaction were associated with smaller achievement gaps between minority and nonminority students, which was more evident among schools having higher levels of principal transformational leadership. These findings display the potential possibilities when using HLM as the data analysis technique of choice.

\section{Critique of HLM Data Analysis Methodology}


As previously explained, there are inherent limitations with the HLM methodology. HLM cannot be used to predict the impact of lower-level variables on higher-level ones. Additionally, a large sample size (both within and between groups) is required in order to adequately employ HLM. Despite these limitations, the use of HLM is a value-add in any research about organizational climate and job satisfaction, given that it addresses issues present in the existing literature. The usage of HLM in the literature, as well as the positives it brings, has been well documented over time. Being the preferred method to handle hierarchical/nested data, HLM can resolve the levels-ofanalysis issues present in both organizational climate and job satisfaction measurements. Not only can using HLM in a study about these topics assist in a statistical manner, it can also help move the theories of leadership, organizational climate, and job satisfaction forward by providing more accurate findings that are based on more precise statistical assumptions of the data.

\section{Conclusion}

This chapter provided a literature review about three major variables that have been heavily researched: job satisfaction, organizational climate, and transformational leadership. This chapter also provided justification for why these constructs have been studied in such depth. Various sections of this chapter outlined the distinct dyadic relationships between transformational leadership and organizational climate, organizational climate and job satisfaction, and transformational leadership and job satisfaction. While some research has been done around job satisfaction influencing employee perceptions/attributions of transformational properties of their supervisors, the majority of the literature has treated transformational leadership as the precursor to both 
organizational climate and job satisfaction, as well as organizational climate as an antecedent to job satisfaction. Therefore, a logical theoretical framework exists in which organizational climate should be treated as a mediating variable.

This chapter detailed specific measures utilized in the literature to quantify these three distinct variables; therefore, those measures could potentially be utilized to gather data on these three constructs before exploring a model in with organizational climate strength is introduced as a mediating variable between supervisor leadership style and employee job satisfaction.

This chapter also highlighted the need for a new data analysis method to be utilized when investigating the relationships between these three variables, due to the varying levels-of-analysis necessary to properly investigate these constructs. Various sections of the chapter outlined how OLS regression techniques, which have dominated the literature in investigating the relationships between these variables, are inappropriate and fraught with problems. Justifications and rationales for the application of multi-level modeling techniques were given in this chapter, along with a strong endorsement for HLM in particular.

From this literature review, two major areas of opportunity are highlighted in future studies regarding the inter-relationships between employee job satisfaction, organizational climate, and leadership style of supervisors. First, organizational climate should be used as a mediating variable between the leadership variable and the job satisfaction outcome. Second, multi-level modeling techniques should be used in the data analysis portion of the study. The following chapter, focusing on the execution of 
methodology in this dissertation, will outline the details of how I addressed these two areas of improvement in my study. 


\section{CHAPTER THREE}

\section{METHODOLOGY}

\section{Introduction}

This study employed survey and quantitative analysis methods to examine the inter-relationships between supervisor leadership style, organizational climate, and employee job satisfaction. In this chapter, the research site and the procedures for selecting study participants will be discussed. In addition, general data collection procedures, including details about the survey instrument, as well as constructs measured in the survey, will be explained. Finally, a thorough outline of the data analysis procedures executed in this research will be presented.

\section{Research Site}

This study was executed at a small, private, four-year university in Southern California. This university was chosen as the research site because I have an existing relationship with official representatives who work at the university. These representatives were able to assist me in conducting my research at the site. For the purposes of preserving the confidentiality of the research site, further details and information regarding the research site will not be presented. The research site will hereby be referred to as "The University" throughout the remainder of this dissertation.

\section{Participant Selection}

In selecting participants, this study employed a convenience-purposeful sampling strategy. As the name of this hybrid strategy implies, the strategy combines elements of both convenience sampling and purposeful sampling. The elements of convenience sampling came from my existing relationship with official representatives who work for 
The University. I chose The University as the research site due to my ability to leverage my relationships with officials who are employed at The University in order to conduct this study. My prior existing relationship with officials at The University granted me more access to and information about the research site than would have been readily available to me in other organizations. The relationships I have with officials at The University also allowed me to conduct this study within my desired timeframe. My contacts at The University also made me aware that there was a substantial amount of interest from stakeholders at The University in my research topic/proposed study. Therefore, there was a higher probability of this study being executed to my specifications at this research site, rather than in a randomly selected research site in which I have no insight into the level of buy-in from stakeholders within the organization. Because of all of these considerations, elements of convenience sampling were present in this study.

In addition, elements of purposeful sampling were present in my participant selection procedures. One of the major components of this study, as explained in Chapter 1 and detailed in Chapter 2, is employee job satisfaction. Employees at The University can generally be categorized into one of three broad categories: faculty, staff, or administrators. The job requirements, expectations, hierarchy, and overall culture of faculty are all drastically different from those of staff and administrators. As a result, only full-time staff and administrators at The University were included as participants in this study. Given that there is a clear criterion for being either included or omitted from the sample, aspects of purposive sampling were present in this study as well. 
In addition to only including full-time staff and administrator positions in the sample, I worked closely with the Chief Human Resources Officer at The University to ensure that the participants in the sample make practical sense within the context of the topics being investigated in the study. For example, the Chief Human Resources Officer recommended that I only include full-time staff and administrators who are connected to non-academic programs and departments (thereby omitting, for example, staff and administrators from academic programs or schools within The University from my sample). The justification of this recommendation was for me to have a more robust between-group comparison, since staff and administrators in non-academic-related job functions make more sense to make comparisons between, rather than comparing to staff/administrators in academic job functions.

In the prior example, full-time staff and administrators from non-academic departments were the employees who responded to the survey; their supervisors were the Associate/Assistant Vice Presidents (hereby referred to as AVPs) of their respective departments. The Chief Human Resources Officer at the University served as my "subject-matter expert" when composing the list of participants for my study, thereby ensuring that this study was executed in the most robust practical terms. It is important to note that another element of convenience sampling was present in the participant selection procedures. In the aforementioned example, participation by Associate/Assistant Vice Presidents (whose employee roll-up headcounts make sense for the statistical requirements of this study) was voluntary.

The Chief Human Resources Officer and I solicited participation from AVPs, as well as their respective employees, from seven non-academic departments in The 
University. The employee headcounts within each of the departments that participated in my dissertation research ranged from 10 to 171 . If The University where I conducted this research is somehow identified, providing exact employee headcount numbers would make it possible to identify participating departments. Therefore, I will not be providing employee headcounts for each of the seven departments in the presentation of this dissertation. This is a step that I have taken, in agreement with the Chief Human Resources Officer, to ensure that all data collected and analyzed as part of this research remains anonymous.

Once participation of AVPs and their employees was finalized for each of these seven departments, the Chief Human Resources Officer used their subject matter expertise to pare down the list of participants to those who would make the most practical sense to be included in this study; from here, the Chief Human Resources Officer then provided me with the e-mail addresses and the hire date of each of the employees to send the survey to. The final list of employees to include in this study (provided to me by the Chief Human Resources Officer) contained 358 e-mail addresses. A survey invitation was sent to all 358 e-mail addresses; details of the data collection procedures of this study are explained in the following section.

\section{Data Collection Procedures}

The participants in this study were invited to respond to an online survey measuring their job satisfaction, their perceptions of the organizational climate in which they work, and their perceptions of their supervisor's leadership style, including the degree to which their supervisor practices transformational leadership. The survey these 
employees received consisted of three existing survey instruments that have frequently been used in research on the three aforementioned constructs.

Because the survey I sent to study participants will be an amalgamation of excerpts from existing survey instruments whose psychometric properties have been established in the literature, my survey instrument should also have demonstrated reliability and validity. I have contacted the researchers who developed the three instruments that were employed in my study and have confirmed that the psychometric properties of the instruments will hold if I administered sub-scales of the survey instruments in their entirety.

The survey was administered through the Qualtrics online survey platform. The participants in my sample were informed that their individual survey responses will remain confidential, and that data/findings will only be presented at the aggregate level. One main reason this survey was confidential, rather than anonymous, is that confidential surveys allowed me to have the survey instrument focus solely on the variables of interest in this study: supervisor's leadership style, organizational climate, and employee job satisfaction. As a result of keeping this survey confidential, the length of the survey was minimized. Participants in my study were split into two groups: employees (full-time staff/administrators) and supervisors (AVPs). Both groups of participants were surveyed on the three components that comprise this study. Employees were asked about their own job satisfaction, their perception of their department's organizational climate, and their perception of their AVP's leadership style (focusing on transformational leadership). AVPs were surveyed on their own job satisfaction, their perception of their department's 
organizational climate, and their perception of their own leadership style (focusing on transformational leadership).

In an effort to increase the response rate, I sent one weekly reminder for three weeks after the initial survey invitation. In addition, I also e-mailed the participating AVPs in the middle of the one-month open period I set aside to collect survey responses, and I requested them to contact their employees in the most convenient manner and encourage the employees to take the survey. I also spent time e-mailing responses to individual employees who e-mailed me feedback or questions on my survey and, after answering any of their questions, asked if they would encourage their colleagues to take the survey as well. Through these tactics, multiple sources of appeal to take the survey may have been present: 1) study participants may have responded because they wanted to assist me in my dissertation data collection process, or 2) study participants may have been inclined to respond knowing that their AVP and other coworkers were supporting this study.

Details about the survey, including survey questions from the three components of my study, as well as the existing survey instruments they borrow from, are provided in the following section, and the four subsections that comprise it. Further details of specific questions asked in the survey (Appendix A), along with the e-mail invitation and language sent in the automated reminders through Qualtrics (Appendix B).

\section{Survey Instrument}

The final survey instrument used in this study is an amalgamation of excerpts from three existing survey instruments whose psychometric properties have been established in the literature. The three existing survey instruments each measure one of 
the three dimensions that are at the core of this study: employee job satisfaction, organizational climate, and leadership style. The details of the excerpts of the three existing instruments that were used as a part of this study are detailed in the following subsections.

Employee job satisfaction. A scale that has often been used to measure employee job satisfaction is the Job Satisfaction Survey (JSS). Developed by Spector (1985), the JSS uses 36 questions to measure nine facets of employee attitudes about their job and aspects of the job. Each facet is assessed with four items. The JSS is comprised of nine dimensions, including satisfaction with: pay, promotion, supervision, fringe benefits, contingent rewards (performance-based rewards), operating procedures (required rules and procedures), coworkers, nature of work, and communication. Although the JSS was originally developed for use in human service organizations, it is applicable to all organizations in both the private and public sector.

The JSS employs a 6-point Likert Scale, ranging from "Disagree very much" to "Agree very much". Both reliability and validity of the instrument have been established over the course of the past two decades. Thousands of responses from various organization types and industries have been analyzed to ensure strong psychometric properties hold for the instrument. In using the JSS to measure the job satisfaction construct in this study, I am confident that the attributes of reliability and validity will hold in my measurement of this construct. This instrument will be administered to both the full-time staff/administrators and their respective AVPs.

Because length of the survey is related to administration time, and administration time is likely related to response rates, I wanted to ensure that this survey would measure 
the most salient aspects of job satisfaction while also remaining as short as possible. In discussions with the Chief Human Resources Officer and other members of my dissertation committee, we agreed that the four most practical dimensions to measure regarding employee job satisfaction using the JSS are: Supervision, Contingent Rewards, Nature of Work, and Communication. These four seemed to be the dimensions related to satisfaction that would yield the most actionable results from the findings of this study while requiring the respondents to answer only 16 questions regarding job satisfaction. I have contacted and been told by the researcher who developed the JSS that reliability and validity should still hold as long as I administer the four constructs in their entirety (P. Spector, personal communication, April 21, 2018).

Organizational climate. For the purposes of measuring organizational climate, this survey utilized the Organizational Climate Measure (OCM). Researchers in the United Kingdom used Quinn and Rohrbaugh's Competing Values model to create the OCM in 2005. The 82-question survey measures 17 distinct dimensions of organizational climate. The researchers divided these 17 dimensions into four quadrants: human relations, internal process, open systems, and rational goals. Concurrent, predictive, and discriminant validity have all been established with this survey instrument that will be a component of the survey instrument I administered as part of this study.

Administering the complete 82-question survey would increase administration time, which I was certain would greatly decrease response rates. Therefore, I only included a subset of the 17 measured dimensions in the OCM, rather than the entire OCM itself, in order to measure organizational climate in my study. In communication with the researchers who developed the OCM, I have been assured that as long as I maintain all 
the questions measuring a subset of dimensions in their entirety, I can safely administer a subset of dimensions without sacrificing a significant portion of the validity and reliability of the entire instrument (M. Patterson \& J. Dawson, personal communication, March 13, 2018).

I used three considerations to determine which dimensions would comprise the subset of dimensions that I borrow from the OCM. First, I aligned the salient aspects of organizational climate as noted by the existing research (outlined in detail in Chapter 2) with the dimensions measured in the OCM. Next, I considered which of the aforementioned quadrants of the OCM (human relations, internal process, open systems, and rational goals) were represented by the subset of dimensions I had selected as having been aligned with the existing research on organizational climate. It was my goal to have diversity of the dimensions represented in the survey instrument for this study. Lastly, I considered the most parsimonious manner in which to measure dimensions of organizational climate. While I wanted to ensure that I measured enough of the construct, I was also aware of the trade-off between administration time of this survey and response rate to this survey.

As a result of these three considerations, my survey instrument measured the following dimensions of organizational climate as outlined by the OCM: autonomy, innovation \& flexibility, and effort. Three of the four quadrants outlined by the OCM were represented in the subset of dimensions I measured. The human relations quadrant is measured by autonomy, while the open systems quadrant and rational goal quadrant are measured by innovation \& flexibility, and effort, respectively. The aforementioned dimensions of organizational climate that I used in my survey instrument were measured 
by 16 total questions via a 4-point Likert scale, ranging from "Definitely false" to

"Definitely true". This instrument was administered to both the full-time staff/administrators and their respective AVPs.

Supervisor's transformational leadership. In order to measure to what extent supervisors are engaged in transformational leadership, this study employed the Multifactor Leadership Questionnaire Form 6S, also known as the MLQ 6S (Bass \& Riggio, 2006). This instrument measures four dimensions of transformational leadership: idealized influence, inspirational motivation, intellectual stimulation, and individualized consideration. In addition, the MLQ 6S includes a measure of transactional leadership, comprised of two dimensions: contingent reward and management-by-exception. The final component of the MLQ 6S measures the absence of leadership, otherwise known as laissez-faire leadership. While my study is focusing on the effect of transformational leadership, I still measured the transactional leadership and laissez-faire leadership dimensions using the MLQ 6S.

In total, the MLQ 6S is 21 questions and uses a 5-point Likert scale, ranging from "Not at all" to "Frequently if not always". Used heavily in research regarding transformational leadership, the MLQ 6S has demonstrated high reliability and validity scores over the past two decades (Bass \& Riggio, 2006). AVPs of each department were given the MLQ 6S, which is a leader-self assessment of each of the aforementioned leadership styles. The full-time staff/administrators who report into these supervisors were given a 360-version of the MLQ 6S in which the rated the leadership style of their AVP. 
Summary of survey instrument. Taking all three components together, my survey consisted of 53 questions. A combination of 4-point Likert scale, 5-point Likert scale, and 6-point Likert scale questions were used to measure different components of this study. A summary table of the survey instrument that I used in this study is provided in Table 1 (the survey instrument in its entirety, including the specific questions asked, can be found in Appendix A).

Table 1

Survey Instrument Summary

\begin{tabular}{|c|c|c|c|}
\hline Component of Study & $\begin{array}{c}\text { Existing Survey } \\
\text { Instrument Utilized }\end{array}$ & $\begin{array}{c}\text { Number of } \\
\text { Survey Items }\end{array}$ & Type of Questions \\
\hline $\begin{array}{c}\text { Employee Job } \\
\text { Satisfaction }\end{array}$ & JSS & 16 & $\begin{array}{l}\text { 6-point Likert Scale } \\
\text { (Disagree very much to } \\
\text { Agree very much) }\end{array}$ \\
\hline $\begin{array}{c}\text { Organizational } \\
\text { Climate }\end{array}$ & $\mathrm{OCM}$ & 16 & $\begin{array}{l}\text { 4-point Likert Scale } \\
\text { (Definitely false to } \\
\text { Definitely true) }\end{array}$ \\
\hline $\begin{array}{c}\text { Transformational } \\
\text { Leadership }\end{array}$ & MLQ Form 6S & 21 & $\begin{array}{l}\text { 5-point Likert Scale (Not } \\
\text { at all to Frequently if not } \\
\text { always) }\end{array}$ \\
\hline
\end{tabular}

\section{Data Analysis Procedures}

Participant responses to the survey were split into two groups: employees and supervisors (the AVPs). Employees were surveyed about their own job satisfaction, the climate of their organization (defined here as the department in which they work), and the 
extent to which their AVP exhibits different leadership behaviors (focusing on characteristics of transformational leadership). The AVPs of each of the seven departments were surveyed about their own job satisfaction, their perception of the climate of their organization (the department which they supervise), and their own transformational (or non-transformational) leadership style. The survey responses provided total quantitative scores for each of these three dimensions for each individual respondent. This was the final dataset that was manipulated into different datasets to answer the research questions and conduct multiple analyses. All data manipulation to create the datasets utilized in this study used Microsoft Excel.

When cleaning and manipulating the raw data, it was extremely important to consider and strategize how to address missing data. I omitted any respondents for whom there was missing data for any question that comprised the job satisfaction or organizational climate constructs. This was done because job satisfaction was the outcome variable in the main model, while organizational climate was the mediating variable (as such, it is partially treated as an outcome in the modeling procedure). As a result, I could not treat missing data for either of these variables simply by imputing the mean of the scores from each department (as I did with missing data regarding supervisor leadership style, which is always treated as an independent variable in the main regression models). Therefore, any missing data from the job satisfaction or organizational climate constructs required that I omit the respondent entirely from the analysis.

Five major analyses were conducted in this study: descriptive statistics, gap analyses, reverse regressions (utilizing OLS regression techniques), OLS regression 
models to address the main research questions in this study, and multi-level modeling regressions using HLM. The methodologies employed for all five of these analyses in this study are explained in greater depth in the following subsections.

\section{Descriptive Statistics Methods}

Using IBM SPSS Software, descriptive statistics were investigated for the three major components of this study: employee job satisfaction, organizational climate strength, and leadership behaviors of AVPs. The means and standard deviations of the four constructs measured for employee job satisfaction were analyzed and split by each of the seven departments. Organizational climate strength was measured by the standard deviation between employees within the separate departments for their scores on each of the three climate measures. It is important to note that a lower score for organizational climate strength through this method of measurement correlates with a stronger organizational climate within a department. It is also important to note that the score given by the AVP was omitted from the standard deviation between employee scores of organizational climate; alternatively stated, only employee scores (and not AVP scores) were taken into consideration when calculating the organizational climate strength measure.

Lastly, means and standard deviations for each of the four dimensions of Transformational Leadership, both dimensions of Transactional Leadership, and LaissezFaire Leadership, were also split by department and analyzed. In addition, descriptive statistics were investigated regarding the relationship between employee job satisfaction and years of service of employees at The University. Descriptive statistics of similar relationships between organizational climate strength and years of service of employees 
and perceptions of AVP leadership and years of service of employees were also analyzed. These relationships were investigated using both IBM SPSS Software and Microsoft Excel.

\section{Gap Analyses Methods}

The Gap Analyses conducted in this study used both Microsoft Excel and IBM SPSS Software. The Gap Analyses investigated the relationship between the absolute value of the differences in ratings given by employees versus AVPs and employee job satisfaction. The results of these regressions show how differences in employee perceptions of the AVP and AVP self-perceptions relate to employee job satisfaction. In addition, this study looked at how the absolute value of difference in ratings given by employees versus AVPs changes relative to the years of service of employees at The University.

Another Gap Analysis conducted in this study used employee job satisfaction variables as outcome variables, but utilized dummy variables to show whether the differences in perceptions between the employee and AVP were positive (defined in this study as higher ratings given by employees than the AVP gives themselves), negative (defined in this study as higher ratings given by the AVP themselves than the employee gave the AVP), or full agreement (where the ratings given by the employee for the AVP and the AVP self-ratings are equal). The reference group in these regressions was the full agreement group. Therefore, coefficient estimates from those regressions represented how different satisfaction levels were for employees with positive or negative difference scores (as previously defined above) compared to those employees who were in full agreement with the AVPs about AVP leadership style. Taken together, the Gap Analyses 
regression results explained the relationship between difference scores on supervisor leadership style and employee job satisfaction, as well as the relationship between the direction of difference score and satisfaction of employees.

The Gap Analyses used OLS regression methods in which the outcome variables were always the employee job satisfaction measurements from this study, while the independent variables were either the absolute value of difference scores of the seven leadership behaviors measured in this study, or were the dummy variables explained previously (to help answer the question of the relationship between direction of difference score and satisfaction of employees).

\section{Reverse Regression Methods}

As cited in Chapter 2 of this dissertation, researchers have hypothesized a reverse relationship between employee satisfaction and leadership style exists; that is, employees who are more satisfied with their jobs tend to attribute more leadership qualities (specifically, transformational qualities) to their supervisors (Van Knippenberg \& Sitkin, 2013). This aligns with studies that note that leadership is an attribution in the eye of the beholder; namely, employees hold mental representations of leadership that color their perceptions of leadership (Eden \& Leviatan, 1975; Lord \& Maher, 2002; Meindl, Ehrlich, \& Dukerich, 1985; Van Knippenberg \& Sitkin, 2013). The aforementioned studies would model the relationship by treating job satisfaction as the independent variable and transformational leadership as the dependent variable; I have labeled this portion of the analysis conducted in my study as Reverse Regressions. I utilized IBM SPSS Software and OLS methods to conduct this portion of the data analysis. 
For the Reverse Regressions, satisfaction scores with Supervision, Contingent Rewards, Nature of Work, and Communication (along with the control variable of Years of Service) were treated as independent variables, while perceptions of leadership style behaviors of the AVP were treated as the outcome. Nine variables were utilized as separate regression outcomes in this part of the study: Transformational Leadership Overall, the four dimensions of Transformational Leadership (Idealized Influence, Inspirational Motivation, Intellectual Stimulation, and Individualized Consideration), Transactional Leadership Overall, the two dimensions of Transactional Leadership (Contingent Rewards and Management by Exception), and Laissez-Faire Leadership. It is important to note that an entirely different dataset was used to conduct the Reverse Regression analyses than what was used to construct the main regression models of this study and what was used for the descriptive statistics/Gap Analyses. I treated the main regression models as though leadership style was the independent variable (and therefore I could impute means for missing data), while omitting any respondents who had any missing data for job satisfaction or organizational climate questions. For the reverse regressions, I instead omitted respondents who had missing data for any leadership style questions while imputing the means for missing data on job satisfaction and organizational climate questions. After this treatment of the data, the reverse regression models had a sample size of 93 respondents.

\section{OLS Regression Methods}

Chapter 2 of this dissertation argued that methods that are more robust than the OLS methodology should be utilized when investigating the inter-relationships between employee job satisfaction, organizational climate strength, and supervisor leadership 
style. However, having collected data on these three components at a research site, it would be useful to analyze that data through the OLS methods that have been established in the current literature. IBM SPSS Software was used to execute the OLS regressions for this part of the data analysis procedures.

Five different outcomes were utilized in separate regression models: Overall Satisfaction, Supervision Satisfaction, Contingent Rewards Satisfaction, Nature of Work Satisfaction, and Communication Satisfaction. Four distinct regression models were run within regressions containing the five outcome variables. Model 1 included the Years of Service variable as a control variable along with each of the four dimensions of Transformational Leadership, the two dimensions of Transactional Leadership, and Laissez-Faire Leadership (these independent variables were entered separately in each regression). Models 2, 3, and 4 include the same variables of Model 1; in addition, the mediating variables of Autonomy Climate Strength, Innovation and Flexibility Climate Strength, and Effort Strength, were included in the three models, respectively. Regression results from these models, taken together with the regression results from Model 1, yield insights about whether the aforementioned variables in Models 2, 3, and 4 don not at all mediate, partially mediate, or fully mediate the effects of independent variables of interest on the outcome variable.

\section{Multi-Level Modeling (HLM) Regression Methods}

Hierarchical Linear Modeling (HLM), a multi-level modeling technique, was utilized to analyze this dataset. I used the Scientific Software International HLM 7 package to conduct the multi-level modeling regression analyses. This study explored two levels-of-analysis: the individual level and the organizational level. At the individual 
level, the outcome variable was employee job satisfaction. The independent variable at Level 1 was years of service of the employees. These regression results will show the association between the years of service of the employee and employee job satisfaction.

At the organizational-level, the coefficients from the individual-level regressions become the outcome variables (in addition to the Constant from Level-1, which is also an outcome variable). The outcome variables were regressed (in separate regressions) on organizational-level characteristics, mainly represented by leadership behavior ratings of the AVP. In addition, mediating variables of organizational climate strength were included in the Level-2 models. Organizational climate strength was measured by the standard deviation between scores of organizational climate scores within each department. These second-level regressions will answer the research question regarding the direct relationship between supervisor leadership style (focusing on transformational leadership) and employee job satisfaction, as well as the second research question about the indirect relationship between these two variables (through the mediating variable of organizational climate). Details of the math behind the multi-level modeling techniques are available in Appendix C.

Five different outcomes were utilized in separate regression models: Overall Satisfaction, Supervision Satisfaction, Contingent Rewards Satisfaction, Nature of Work Satisfaction, and Communication Satisfaction. Four distinct regression models were run within regressions containing the five outcome variables. Model 1 included the Years of Service variable as a control variable along with each of the four dimensions of Transformational Leadership, the two dimensions of Transactional Leadership, and Laissez-Faire Leadership (these independent variables were entered separately in each 
regression). Models 2, 3, and 4 include the same variables of Model 1; in additional, the mediating variables of Autonomy Climate Strength, Innovation and Flexibility Climate Strength, and Effort Strength, are included in the three models, respectively. Regression results from these models, taken together with the regression results from Model 1, yield insights about whether the aforementioned variables in Models 2, 3, and 4 do not at all mediate, partially mediate, or fully mediate the effects of independent variables of interest on the outcome variable. 


\section{CHAPTER FOUR}

\section{DATA ANALYSIS}

\section{Introduction}

This chapter presents the results of the several data analyses conducted in this study. The chapter begins with an overview of descriptive statistics; specifically, details are given about the descriptive statistics for the constructs of job satisfaction, organizational climate strength, and supervisor leadership style. Next, the results of the Gap Analyses (as described in further depth in Chapter 3) are presented. The results of the OLS Reverse Regressions (also detailed in Chapter 3) are offered immediately following the sub-section explaining the results of the Gap Analyses. The results of OLS regressions of job satisfaction on supervisor leadership style will follow; these results depict the conclusions that would arise if this study had executed the analysis in a lessrobust statistical manner. Results of the HLM regressions of job satisfaction on supervisor leadership style will conclude this chapter and offer a contrast to the findings of the OLS regressions. The results of the HLM regressions will help to answer the three research questions that guide this study:

1) To what degree does a relationship exist between supervisor full-range leadership (in particular, transformational leadership) and employee job satisfaction?

2) To what degree does organizational climate strength mediate the relationship between supervisor full-range leadership and employee job satisfaction?

3) How do findings regarding the interrelationships between supervisor full-range leadership, organizational climate strength, and employee job satisfaction differ 
when utilizing multi-level modeling techniques instead of OLS regression techniques?

\section{Descriptive Statistics}

This section of the chapter provides the descriptive statistics for each of the three major variables included in this study: employee job satisfaction, organizational climate strength, and supervisor leadership style. This section also displays descriptive statistics about the Gap Analyses conducted in this study. Overall descriptive statistics are presented below.

Table 2

Number of Respondents to the Survey by Department/Group

\begin{tabular}{cc}
\hline Department & Number of respondents \\
\hline 1 & 13 \\
3 & 31 \\
4 & 13 \\
5 & 6 \\
6 & 14 \\
7 & 9 \\
AVPs (Second-level group) & 7 \\
Total & $\mathbf{1 0 0}$ \\
\hline
\end{tabular}

Table 2 shows the number of respondents to the survey that was sent out (explained in more detail in Chapter 3) by department, including AVPs. A total of 112 people submitted the survey. However, three respondents clicked through the entirety of 
the survey and submitted it without answering any questions; therefore, these three responses were omitted from the analysis. In addition, I chose to omit nine other responses that contained missing data for any question that comprised the job satisfaction or organizational climate constructs. This was done because job satisfaction is the outcome variable in the main model, while organizational climate is the mediating variable (as such, it is partially treated as an outcome in the modeling procedure). As a result, I could not treat missing data for either of these variables simply by imputing the mean (as I did with missing data regarding supervisor leadership style, which is always treated as an independent variable in the main regression models). Therefore, any missing data from the job satisfaction or organizational climate constructs required that I omit the respondent entirely from the analysis. Following these data treatment procedures, the final dataset used for the main regression models of this study contained 100 total respondents.

As a reminder, confidentiality was of utmost importance to the stakeholders at the research site; as a result, measures were taken to ensure that the departments are not identifiable through the presentation of results in this study. Presenting response rates in the table would allow readers to be able to calculate the total number of people who the survey was sent to, thereby allowing the possibility of the department to be identified based on the number of employees within each department. Accordingly, response rates for each individual department are not provided. However, I can disclose that the response rates for the eight groups shown in Table 2 range from $8 \%-100 \%$. The mean and median response rates of the eight groups were $51 \%$ and $53 \%$, respectively. These mean and median response rate figures indicate a generally high response rate across the 
departments. The number of respondents in each department, while generally small, still allows the intended analyses to be conducted in this study. However, any findings presented in this chapter should be interpreted while keeping the small sample sizes within each department in mind.

Table 3 highlights that the potential range for each of the four job satisfaction dimensions measured in the survey are equal (0-20), as are the ranges for the seven leadership behaviors that are measured (0-12). Two of the dimensions of organizational climate are measured on a range from 0 to 15, while the Innovation and Flexibility dimension can potentially range from 0 to 18 .

Table 3

Ranges for Each Dimension Measured in the Survey

Employee Job Satisfaction Potential Range

Supervision 0-20

Contingent Rewards

0-20

Nature of Work

0-20

Communication

0-20

\section{Organizational Climate}

Autonomy

Innovation and Flexibility

Effort

$\underline{\text { Supervisor Leadership Style }}$

Idealized Influence

Inspirational Motivation
Potential Range

0-15

0-18

$0-15$

Potential Range

0-12

0-12 


$\begin{array}{cc}\text { Intellectual Stimulation } & 0-12 \\ \text { Individual Consideration } & 0-12 \\ \text { Contingent Reward } & 0-12 \\ \text { Management-by-Exception } & 0-12 \\ \text { Laissez-Faire Leadership } & 0-12\end{array}$

\section{Employee Job Satisfaction Descriptive Statistics}

Table 4 shows the mean and standard deviations for each of the four dimensions of employee job satisfaction measured in this study (note that the potential range for levels of satisfaction for each of these constructs is $0-20$ ). While comparing between departments may not be useful given that the departments are anonymized (and, as a result, actionable insights cannot be yielded at the department-level), comparing between the different dimensions of satisfaction is possible. The constructs of satisfaction with Supervision and Nature of Work generally have higher mean scores than the constructs of satisfaction with Contingent Rewards and Communication. Additionally, the standard deviations within departments are generally lower for the Supervision and Nature of Work constructs. This indicates higher levels of agreement between employees within departments regarding the levels of satisfaction with Supervision and Nature of Work when compared to levels of agreement about satisfaction with both Contingent Rewards and Communication.

\section{Table 4}

Employee Job Satisfaction Means and Standard Deviations by Department

\begin{tabular}{|c|c|c|c|c|c|c|c|c|}
\hline \multirow[b]{2}{*}{ Dept. } & \multicolumn{2}{|c|}{ Supervision } & \multicolumn{2}{|c|}{ Contingent Rewards } & \multicolumn{2}{|c|}{ Nature of Work } & \multicolumn{2}{|c|}{ Communication } \\
\hline & Mean & Std. Dev. & Mean & Std. Dev. & Mean & Std. Dev. & Mean & Std. Dev. \\
\hline
\end{tabular}




\begin{tabular}{lllllllll}
\hline 1 & 17.4 & 2.4 & 16.1 & 1.4 & 17.8 & 1.9 & 14.4 & 2.4 \\
2 & 17.3 & 4.0 & 11.9 & 5.1 & 18.1 & 2.8 & 13.0 & 5.3 \\
3 & 16.2 & 4.2 & 10.7 & 5.2 & 15.6 & 3.8 & 13.7 & 4.9 \\
4 & 16.9 & 3.3 & 12.4 & 5.1 & 16.7 & 2.8 & 13.6 & 4.4 \\
5 & 17.3 & 2.9 & 13.6 & 3.6 & 16.1 & 2.4 & 13.4 & 4.4 \\
6 & 15.5 & 5.2 & 12.4 & 5.5 & 16.2 & 4.0 & 10.9 & 5.6 \\
7 & 17.0 & 3.6 & 12.9 & 5.1 & 16.6 & 3.7 & 13.7 & 5.2
\end{tabular}

Note. $\mathrm{N}=100 ;$ Potential range of scores is $0-20$

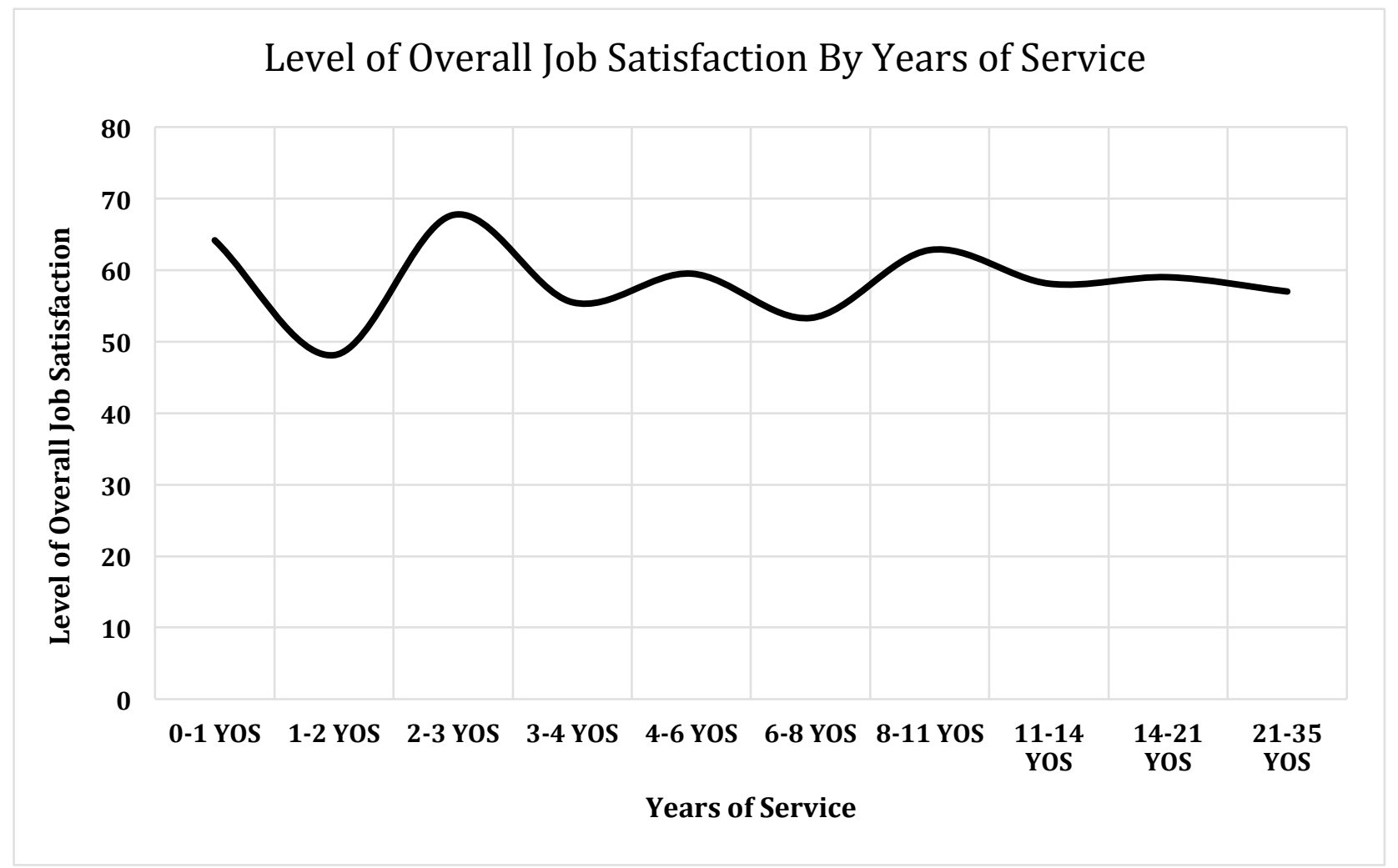

Figure 2. Level of overall employee job satisfaction by years of service deciles.

This figure shows the trend of overall satisfaction for employees over their years of service at The University. It is important to note that Overall Satisfaction is the sum of the satisfaction scores with the four dimensions measured in this study (Supervision, 
Contingent Rewards, Nature of Work, and Communication); therefore, the range of possible scores for Overall Satisfaction is $0-80$.

The figure highlights a substantial decrease in employee job satisfaction for those employees who have been employed at The University for 1-2 years. This decrease is followed by a large increase in overall satisfaction for those employees who have worked for 2-3 years at the research site. It is possible that self-selection effects account for this trend, as dissatisfied employees tend to leave organizations over time. After about three years of service, smaller decreases and increases in levels of satisfaction occur over time. Tables D1 - D4 in Appendix D show the trend of satisfaction levels over years of service for each of the four individual dimensions of satisfaction measured in the survey. The trends of these individual dimensions generally follow the same pattern shown in Figure 2.

\section{Organizational Climate Strength Descriptive Statistics}

Table 5 displays the organizational climate strength of the three climate dimensions measured in this survey (Autonomy, Innovation and Flexibility, and Effort). Organizational climate strength was measured in this study by the standard deviation between employee ratings, within each department, of climate scores for the three dimensions. Therefore, lower standard deviation values presented in the Table 5 are equivalent to stronger climate scores. Generally, the climate strengths for Autonomy and Effort are stronger than the Innovation and Flexibility climates within departments at The University. 
Table 5

Organizational Climate Strength Descriptive Statistics by Department

\begin{tabular}{cccc}
\hline Department & Autonomy & Innovation and & Effort \\
& & Flexibility & \\
\hline 1 & 2.93 & 2.15 & 1.46 \\
3 & 2.25 & 4.40 & 4.11 \\
4 & 3.30 & 4.44 & 2.96 \\
5 & 2.75 & 3.47 & 2.06 \\
6 & 2.58 & 3.08 & 2.58 \\
7 & 3.59 & 2.10 & 1.81 \\
& 3.27 & 2.91 & 2.05
\end{tabular}

Note. Values in this table are standard deviations between employee scores within department (excludes the score from the AVP of the department)

In addition, correlations were run to see whether there is a relationship between average years of service of employees within a department and the strengths of each of the three climates. The correlation between average years of service of employees within a department and the climate strength of Autonomy was 0.51 . The correlation between average years of service of employees within a department and the climate strength of Innovation and Flexibility was -0.28. Lastly, the correlation between average years of service of employees within a department and the climate strength of Effort was -0.02 . These low correlation coefficients, along with the lack of statistical significance between the variables, indicate that no linear relationship exists between average years of service 
of employees within a department at The University and the three climate variables measured in this study.

Furthermore, correlations were run to see whether there is a relationship between the years of service of the AVP of each department and the strengths of each of the three climates. The correlation between the years of service of the AVP and the climate strength of Autonomy was -0.07 . The correlation between the years of service of the AVP and the climate strength of Innovation and Flexibility was -0.29. Lastly, the correlation between years of service of the AVP and the climate strength of Effort was -0.56 (which, while not a small value, was still statistically insignificant). These low correlation coefficients, along with the lack of statistical significance between the variables, indicate that no linear relationship exists between the years of service of the AVP at The University and the three climate variables measured in this study.

\section{Supervisor Leadership Style Descriptive Statistics}

Table 6 shows the mean and standard deviations for each of the four dimensions of Transformational Leadership (note that the potential range for levels of satisfaction for each of these constructs is 0-12). While comparing between departments may not be useful given that the departments are anonymized (and, as a result, actionable insights cannot be yielded at the department-level), comparing between different dimensions of Transformational Leadership is possible. The mean scores for Idealized Influence are slightly higher than those of the other three dimensions. Generally, the mean scores and standard deviations are similar for each of the four dimensions of Transformational Leadership. 
Table 6

Transformational Leadership Means \& Standard Deviations by Department

\begin{tabular}{|c|c|c|c|c|c|c|c|c|}
\hline \multirow[b]{3}{*}{ Dept. } & \multicolumn{2}{|c|}{ Idealized Influence } & \multirow{2}{*}{\multicolumn{2}{|c|}{$\begin{array}{l}\text { Inspirational } \\
\text { Motivation }\end{array}$}} & \multirow{2}{*}{\multicolumn{2}{|c|}{$\begin{array}{l}\text { Intellectual } \\
\text { Stimulation } \\
\end{array}$}} & \multirow{2}{*}{\multicolumn{2}{|c|}{$\begin{array}{l}\text { Individualized } \\
\text { Consideration }\end{array}$}} \\
\hline & & & & & & & & \\
\hline & Mean & Std. Dev. & Mean & Std. Dev. & Mean & Std. Dev. & Mean & Std. Dev. \\
\hline 1 & 11.0 & 1.4 & 9.3 & 1.6 & 7.9 & 2.4 & 8.6 & 1.8 \\
\hline 2 & 7.2 & 3.8 & 6.5 & 3.6 & 6.6 & 3.6 & 5.5 & 3.9 \\
\hline 3 & 10.7 & 1.6 & 8.4 & 2.7 & 8.4 & 2.6 & 7.3 & 2.8 \\
\hline 4 & 9.8 & 2.3 & 8.5 & 2.4 & 8.7 & 2.1 & 7.7 & 2.5 \\
\hline 5 & 10.2 & 1.8 & 7.4 & 3.4 & 7.4 & 3.4 & 7.4 & 3.4 \\
\hline 6 & 9.5 & 2.3 & 7.7 & 2.9 & 8.3 & 2.8 & 7.8 & 3.1 \\
\hline 7 & 8.5 & 2.6 & 7.5 & 3.1 & 7.5 & 3.1 & 7.1 & 3.4 \\
\hline
\end{tabular}

Note. $\mathrm{N}=100 ;$ Potential range of scores is $0-12$

Table 7 shows the mean and standard deviations for the two dimensions of Transactional Leadership (note that the potential range for levels of satisfaction for each of these constructs is 0-12). The mean scores for Management by Exception are higher than those of the Contingent Rewards construct. The standard deviation between scores for each department is lower for the Management by Exception dimension when compared to the Contingent Rewards dimension. While the scores for the Management by Exception construct are generally comparable to the ratings given for each of the four dimensions of Transformational Leadership in Table 6, the mean scores given for the Contingent Rewards construct are much lower. 
Table 7

Transactional Leadership Means \& Standard Deviations by Department

\begin{tabular}{ccccc}
\hline & \multicolumn{2}{c}{ Contingent Rewards } & \multicolumn{2}{c}{ Management by Exception } \\
Dept. & Mean & Std. Dev. & Mean & Std. Dev. \\
\hline 1 & 3.6 & 1.6 & 8.4 & 2.5 \\
2 & 5.7 & 3.7 & 7.2 & 1.7 \\
3 & 5.5 & 3.1 & 8.8 & 2.3 \\
4 & 5.7 & 3.2 & 7.6 & 2.4 \\
5 & 4.8 & 2.7 & 7.7 & 2.2 \\
7 & 6.1 & 4.0 & 7.7 & 1.2 \\
\hline
\end{tabular}

Note. $\mathrm{N}=100$; Potential range of scores is $0-12$

Table 8 shows the mean and standard deviations for Laissez-Faire Leadership (note that the potential range for levels of satisfaction for each of these constructs is 012). The mean score of this dimension is generally lower than the other six leadership dimensions measured in this study. Additionally, the low standard deviation values indicate that this is general agreement between employees within each department about the level of Laissez-Faire Leadership practiced by the AVP of the department.

Table 8

Laissez-Faire Leadership Means \& Standard Deviations by Department

Department $\quad$ Mean $\quad$ Standard Deviation


2

3

4

5

6

7
5.0

5.5

3.6

3.6

4.5

3.2
1.8

2.9

1.8

2.1

2.5

1.8

Note. $\mathrm{N}=100$; Potential range of scores is $0-12$

Taken together, the previous three tables describe higher ratings given by employees to Transformational Leadership behaviors of the AVP, followed by slightly lower ratings assigned to Transactional Leadership behaviors, followed by generally low ratings (both within and between departments) of Laissez-Faire Leadership practices of the AVP. Standard deviation scores indicate generally strong agreement between employees regarding the leadership scores assigned to the AVPs. 


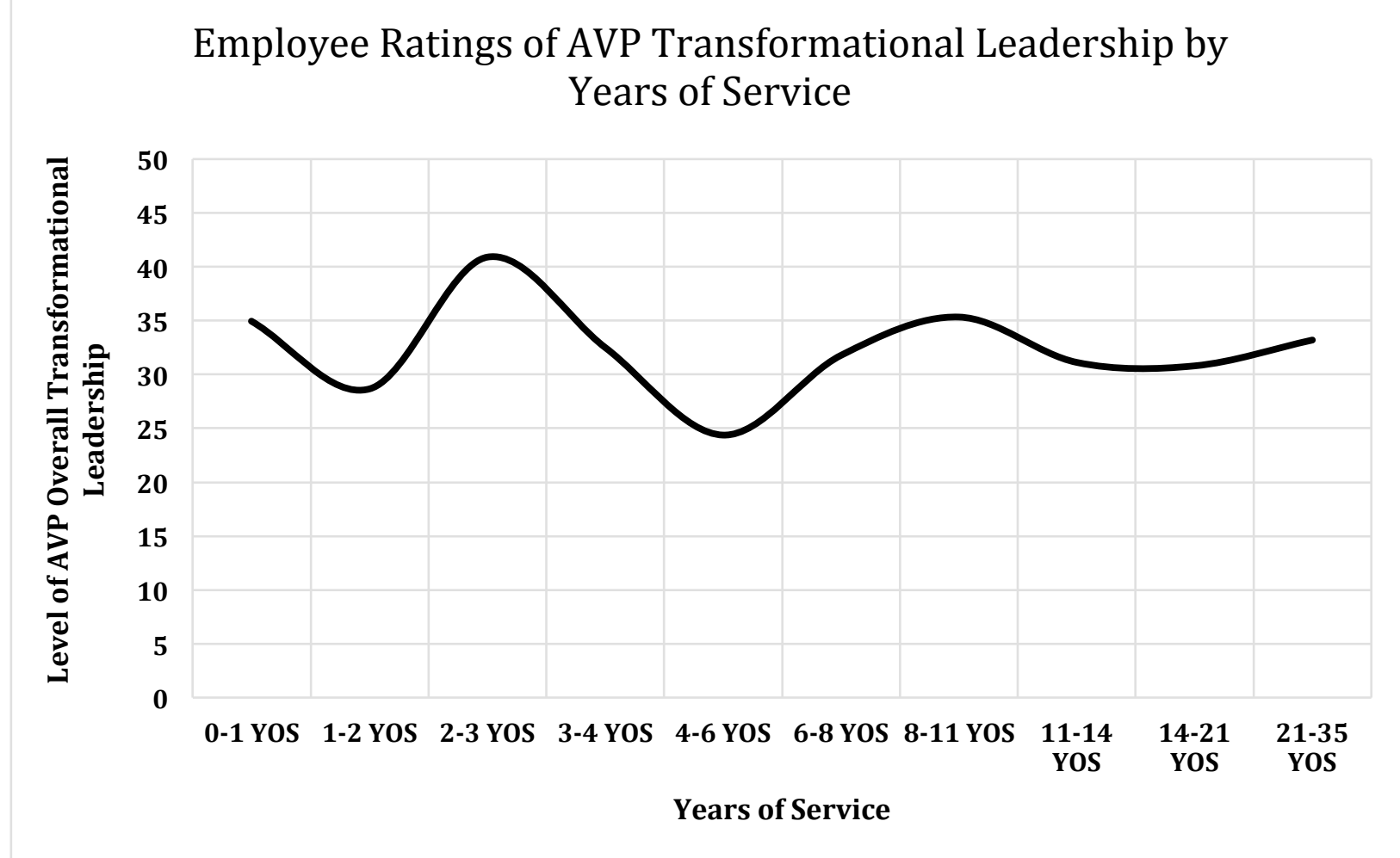

Figure 3. Employee ratings of AVP Transformational Leadership over years of service deciles.

This figure shows the trend of Transformational Leadership ratings from employees about the AVPs of their department over the employees' years of service at The University. It is important to note that the variable of Transformational Leadership is the sum of the leadership scores given by employees for the four dimensions of Transformational Leadership (Idealized Influence, Inspirational Motivation, Intellectual Stimulation, and Individualized Consideration); therefore, the range of possible scores for Transformational Leadership is 0-48.

The figure highlights substantially lower scores for AVP Transformational Leadership given by employees with 1-2 years of service, as well as 4-6 years of service. These local minimums are generally followed by peaks in AVP Transformational 
Leadership ratings given by employees, particularly from those with 2-3 years of service at The University. Tables E1 - E4 in Appendix E show the trend of Transformational Leadership ratings given to AVPs by employees over the employees' years of service for each of the four individual dimensions of Transformational Leadership. The trends of these individual dimensions generally follow the same pattern shown in Figure 3.

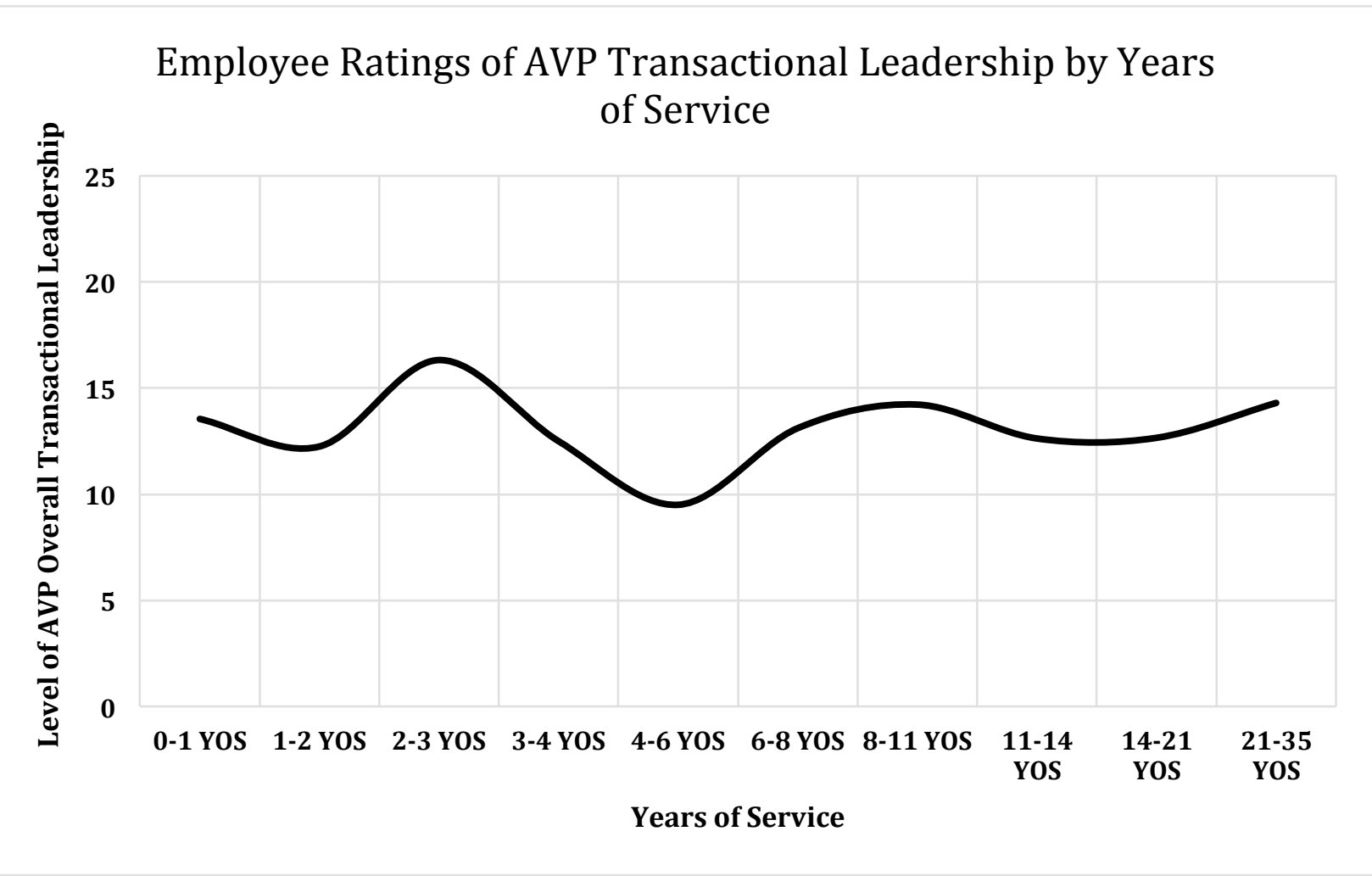

Figure 4. Employee ratings of AVP Transactional Leadership over years of service deciles.

This figure shows the trend of Transactional Leadership ratings from employees about the AVPs of their department over the employees' years of service at The University. It is important to note that the variable of Transactional Leadership is the sum of the leadership scores given by employees for the two dimensions of Transactional 
Leadership (Contingent Rewards and Management by Exception); therefore, the range of possible scores for Transactional Leadership is 0-24.

The trend for AVP Transactional Leadership ratings follows the same pattern previously shown about AVP Transformational Leadership ratings. The figure shows substantially lower scores for AVP Transactional Leadership given by employees with 12 years of service, as well as 4-6 years of service. Tables F1 and F2 in Appendix F show the trend of Transactional Leadership ratings given to AVPs by employees over the employees' years of service for both individual dimensions of Transformational Leadership (Contingent Rewards and Management by Exception). The trends of these individual dimensions generally follow the same pattern shown in Figure 4. In addition, Table G1 in Appendix G shows the trend of the Laissez-Faire Leadership ratings given to AVPs by employees over the employees' years of service. Laissez-Faire Leadership was the seventh and final leadership construct measured in this study. 


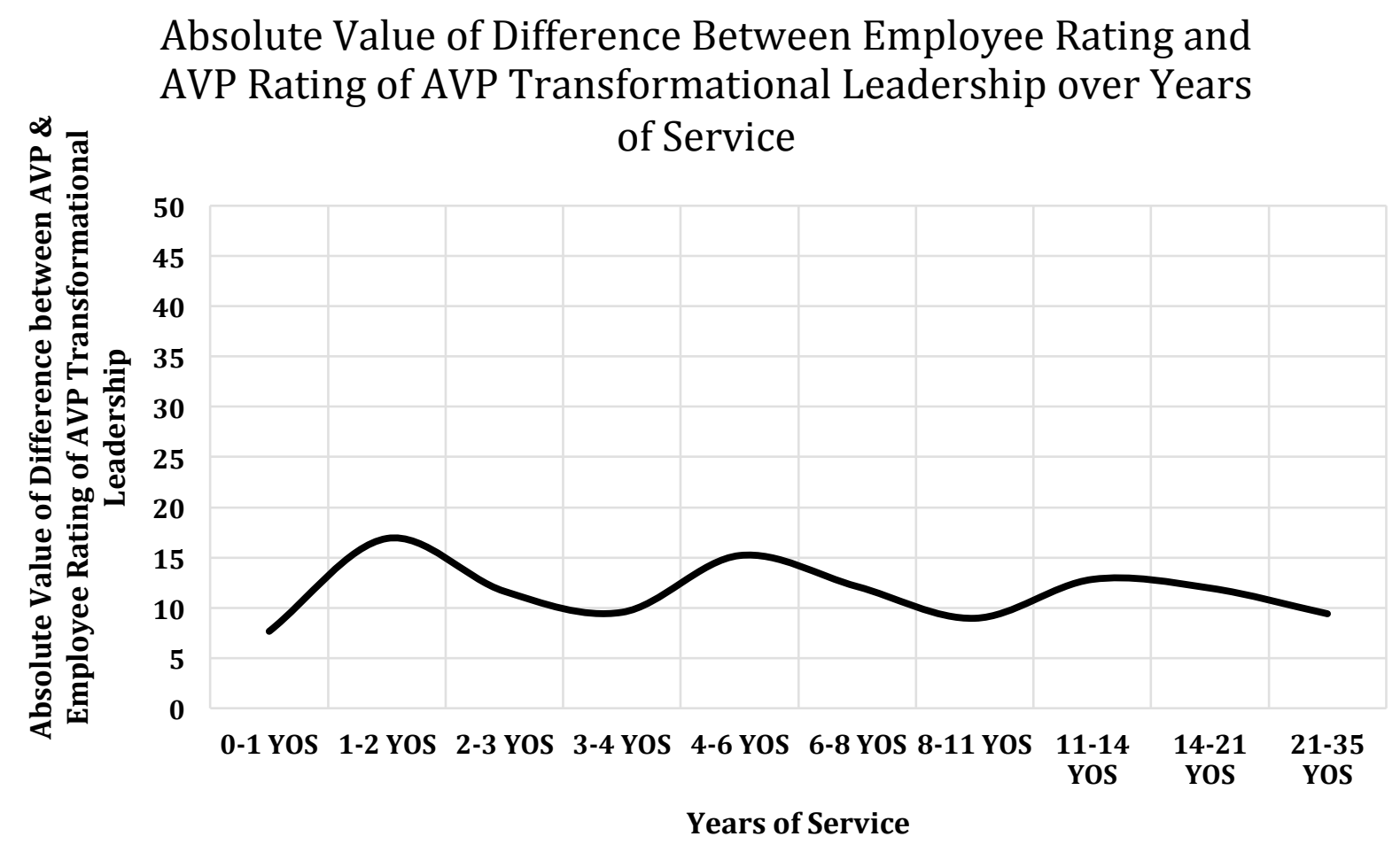

Figure 5. Absolute value of difference in ratings given by employees and by AVPs of the AVPs' Transformational Leadership behaviors over years of service deciles.

This figure shows how the difference in ratings given by employees versus AVPs of the AVPs' Transformational Leadership behaviors changes as the employees' years of service increase. This difference score depicted in this figure is the independent variable in the Gap Analyses described in Chapter 3. It is important to note that the measure of Transformational Leadership is the sum of the leadership scores given by employees for the four dimensions of Transformational Leadership (Idealized Influence, Inspirational Motivation, Intellectual Stimulation, and Individualized Consideration); therefore, the range of possible scores for the difference between ratings given by employees and the self-ratings given by AVPs of AVPs' Transformational Leadership behaviors is 0-48. 
It is also important to note that this figure displays the absolute value of the difference in ratings given by the employee and the self-ratings by AVPs regarding the Transformational Leadership behaviors of AVPs. Because it is the absolute value of this difference, it does not matter whether the employees rated the AVPs higher than the AVPs rated themselves, or vice-versa; the main variable of interest here is the degree to which there is a disagreement between an AVPs self-assessment and the assessment of their Transformational Leadership behaviors by the employees within their department.

The figure highlights the biggest differences in ratings of AVP Transformational Leadership when employees have 1-2 years of service and 4-6 years of service at The University. These smallest differences in ratings given by employees and their respective AVPs come from the employees in the 3-4 years of service and 8-11 years of service deciles. Tables $\mathrm{H} 1-\mathrm{H} 4$ in Appendix $\mathrm{H}$ show the changes in difference in ratings given by employees and AVPs of the AVPs' Transformational Leadership behaviors over employees' years of service for each of the four individual dimensions of Transformational Leadership. The trends of these individual dimensions generally follow the same pattern shown in Figure 5. 


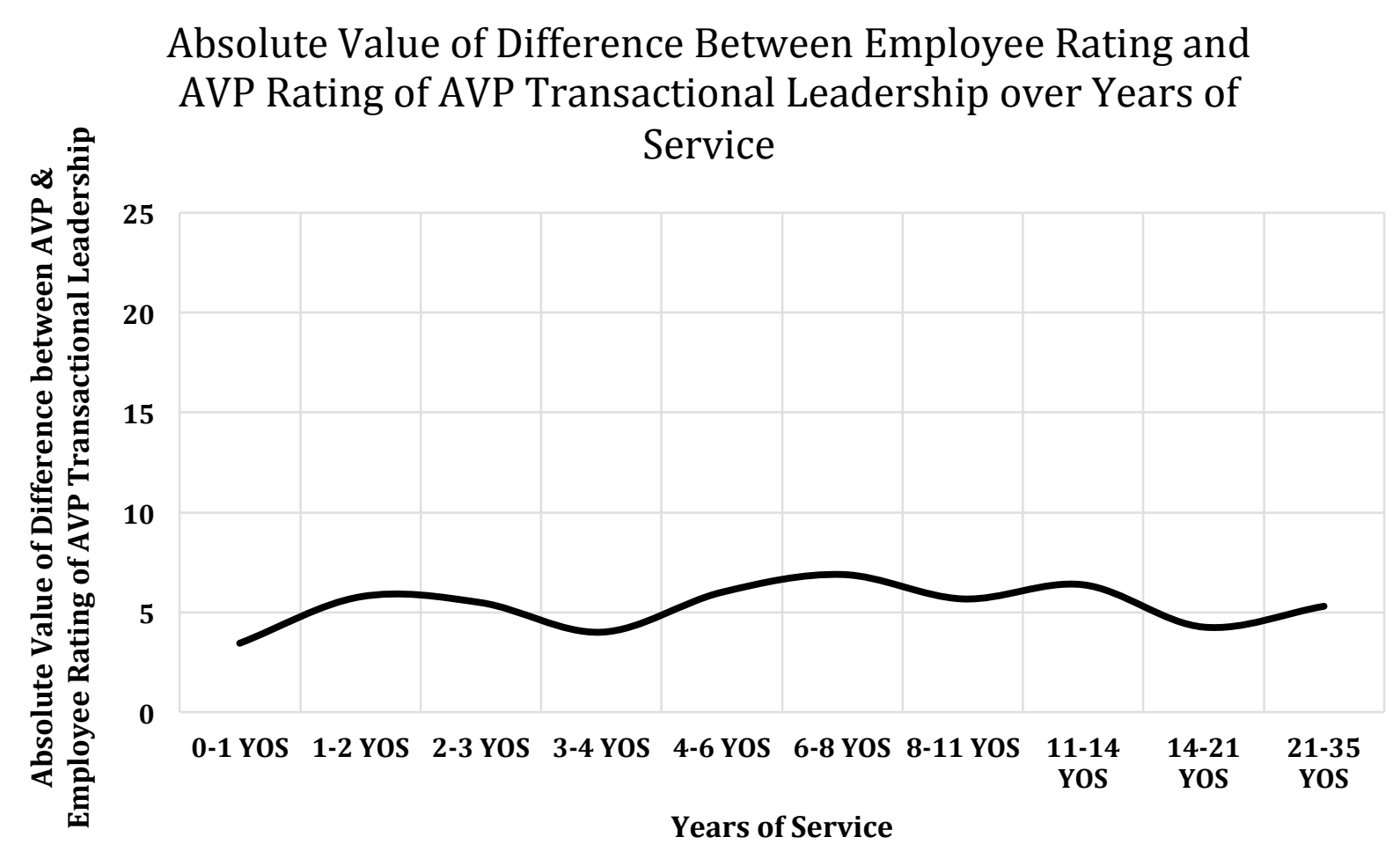

Figure 6. Absolute value of difference in ratings given by employees and by AVPs of the AVPs' Transactional Leadership behaviors over years of service deciles.

This figure shows how the difference in ratings given by employees versus AVPs of the AVPs' Transactional Leadership behaviors changes as the employees' years of service increase. It is important to note that the measure of Transactional Leadership is the sum of the leadership scores given by employees for the two dimensions of Transactional Leadership (Contingent Rewards and Management by Exception); therefore, the range of possible scores for the difference between ratings given by employees and the self-ratings given by AVPs of AVPs' Transactional Leadership behaviors is $0-24$.

It is also important to note that this figure displays the absolute value of the difference in ratings given by the employee and the self-ratings by AVPs regarding the 
Transactional Leadership behaviors of AVPs. Because it is the absolute value of this difference, it does not matter whether the employees rated the AVPs higher than the AVPs rated themselves, or vice-versa; the main variable of interest here is the degree to which there is a disagreement between an AVPs self-assessment and the assessment of their Transactional Leadership behaviors by the employees within their department.

Compared to the trend of how the difference in ratings given by employees versus AVPs of the AVPs' Transformational Leadership behaviors changes as the employees' years of service increase, the Transactional Leadership ratings difference in Figure 6 is much smoother and less volatile. Slight peaks in differences of ratings on AVP Transactional Leadership are seen from employees in the 1-2 years of service, 6-8 years of service, and 11-14 years of service deciles. Tables I1 and I2 in Appendix I show the changes in difference in ratings given by employees and AVPs of the AVPs' Transactional Leadership behaviors over employees' years of service for both of the individual dimensions of Transactional Leadership (Contingent Rewards and Management by Exception). The trends of these individual dimensions generally follow the same pattern shown in Figure 6. In addition, Table J1 in Appendix J shows how the difference in ratings given by employees versus AVPs of the AVPs' Laissez-Faire Leadership changes as the employees' years of service increase. Laissez-Faire Leadership was the seventh and final leadership construct measured in this study.

The previous two figures regarding the difference in ratings given by employees of their AVPs leadership behaviors and the AVPs' self-ratings of their leadership behaviors highlight the Gap Analyses conducted in this study (described in greater depth in Chapter 3). The Gap Analyses attempted to measure how agreement (or lack thereof) 
between employees and the leader (the AVP) regarding the AVPs leadership styles related to employee job satisfaction. The results of the Gap Analyses conducted in this study are presented in the following section of this chapter.

\section{Gap Analyses Regression Results}

This section of this chapter presents the regression results of the Gap Analyses conducted in this study. Further details of the methods for the Gap Analyses are contained in Chapter 3. This section presents findings for two types of Gap Analyses. One type of Gap Analysis conducted in this study utilizes the absolute value of the difference between employee ratings of AVP leadership styles and AVP self-ratings as the independent variables, and the four dimensions of job satisfaction as four separate dependent variables. The results of these regressions show how differences in employee perceptions of the AVP and AVP self-perceptions relate to employee job satisfaction.

Another Gap Analysis conducted in this study uses the same outcome variables as described above, but utilizes dummy variables to show whether the differences in perceptions between the employee and AVP are positive (defined in this study as higher ratings given by employees than the AVP gives themselves), negative (defined in this study as higher ratings given by the AVP themselves than the employee gave the AVP), or full agreement (where the ratings given by the employee for the AVP and the AVP self-ratings are equal). The reference group in these regressions are the full agreement group. Therefore, coefficient estimates presented in these regressions represent how different satisfaction levels are for employees with positive or negative difference scores (as previously defined above) compared to those employees who are in full agreement with the AVPs about AVP leadership style. Taken together, the regression results 
presented in this chapter will explain the relationship between difference scores on supervisor leadership style and employee job satisfaction, as well as the relationship between the direction of difference score and satisfaction of employees.

Table 9

Leadership Difference Scores/Supervision Satisfaction Regression Results

\begin{tabular}{cccc}
\hline Difference variable (absolute & $B$ & $S E B$ & Significance \\
value) & & & \\
Constant & 18.01 & .88 & .00 \\
Idealized Influence & .15 & .23 & .52 \\
Inspirational Motivation & -.53 & .31 & .09 \\
Intellectual Stimulation & -.49 & .27 & .07 \\
Individualized Consideration & .38 & .27 & .16 \\
Contingent Rewards & .26 & .24 & .28 \\
Management by Exception & .05 & .30 & .88 \\
Laissez-Faire Leadership & -.48 & .19 & .01 \\
\hline
\end{tabular}

Note. $\mathrm{N}=100 ;$ adjusted $\mathrm{R}^{2}=.06$

Table 10

Direction of Leadership Difference Scores and Supervision Satisfaction Regression Results

\begin{tabular}{cccc}
\hline Directional difference variable & $B$ & $S E B$ & Significance \\
\hline Constant & 17.80 & 1.00 & .00
\end{tabular}


Laissez-Faire Leadership

Positive

Laissez-Faire Leadership

Negative

Note. $\mathrm{N}=100 ;$ adjusted $\mathrm{R}^{2}=.03$

Table 9 shows the regression results of leadership difference scores on employee job satisfaction. The Constant in this regression is significant, meaning that if all other values of the independent variable in this regression model were equal to zero, the expected level of satisfaction with Supervision would be 18.01 (note that the range for satisfaction with Supervision is 0-20). The only significant variable, aside from the Constant, is the Laissez-Faire Leadership variable. The coefficient estimate on this variable indicates that for a one-point increase in difference between employee rating of AVP Laissez-Faire Leadership and AVP self-rating Laissez-Faire Leadership, there is an associated .48-point decrease in employee satisfaction with Supervision, ceteris paribus.

This means that if there is a gap between employee perceptions of the AVP and AVP self-perceptions regarding the Laissez-Faire Leadership behaviors of the AVP, regardless of direction of that gap (i.e. whether employees rate the AVP higher than the AVP rates themselves on this construct, or vice versa), there is a significant negative relationship with employee levels of satisfaction with Supervision. From these results, another Gap Analysis was conducted to determine whether the direction of the difference between employee perceptions of the AVP and AVP self-perceptions regarding their Laissez-Faire Leadership practices was significantly related to satisfaction with Supervision. 
Table 10 presents the results of this secondary Gap Analysis. The reference group omitted from this dummy variable regression was the group of employees with full agreement with their AVPs about the level of Laissez-Faire Leadership practiced by the AVP. The lack of statistically significant coefficient results for both the Positive and Negative Laissez-Faire Leadership groups indicates that the direction of the difference is not related to Supervision satisfaction; rather, the existence of a difference in the ratings overall is what is related to Supervision satisfaction.

Table 11

Leadership Difference Scores and Contingent Rewards Satisfaction Regression Results

\begin{tabular}{cccc}
\hline Difference variable (absolute & $B$ & SE B & Significance \\
value) & & & .00 \\
Constant & 16.58 & 1.05 & .07 \\
Idealized Influence & -.50 & .27 & .46 \\
Inspirational Motivation & .27 & .37 & .06 \\
Intellectual Stimulation & -.60 & .32 & .38 \\
Individualized Consideration & -.29 & .33 & .23 \\
Contingent Rewards & .35 & .29 & .61 \\
Management by Exception & -.19 & .37 & .00 \\
Laissez-Faire Leadership & -.80 & .23 &
\end{tabular}

Note. $\mathrm{N}=100 ;$ adjusted $\mathrm{R}^{2}=.17$ 
Table 12

Direction of Leadership Difference Scores and Contingent Rewards Satisfaction Regression Results

\begin{tabular}{cccc}
\hline Directional difference variable & $B$ & SE B & Significance \\
\hline Constant & 15.07 & 1.26 & .00 \\
Laissez-Faire Leadership Positive & -3.71 & 1.39 & .01 \\
Laissez-Faire Leadership Negative & -2.26 & 1.64 & .17 \\
\hline
\end{tabular}

Note. $\mathrm{N}=100 ;$ adjusted $\mathrm{R}^{2}=.05$

Comparable to the results with Supervision satisfaction as the outcome, Table 11 shows that, aside from the Constant, the Laissez-Faire Leadership difference variable is the only independent variable significantly associated with Contingent Rewards satisfaction. For every one-point increase in the Laissez-Faire Leadership difference score, there is an associated .80-point decrease in Contingent Reward satisfaction, ceteris paribus. Table 12 differs from the same Gap Analysis with Supervision satisfaction as the outcome, however, as the Positive difference variable for Laissez-Faire Leadership has a statistically significant coefficient estimate. In interpreting this statistically significant coefficient of -3.71 , the findings indicate that when employees rate their AVP higher than AVPs rate themselves on the Laissez-Faire Leadership dimension, these employees are less satisfied (by about 3.7 points, or 18.5\%) with Contingent Rewards than those employees who are in full agreement with their AVPs Laissez-Faire Leadership style of the AVP, ceteris paribus. It is helpful to note that the range for Contingent Rewards satisfaction is $0-20$. 
Table 13

Leadership Difference Scores and Nature of Work Satisfaction Regression Results

\begin{tabular}{cccc}
\hline Difference variable (absolute & $B$ & $S E B$ & Significance \\
value) & & & \\
Constant & 17.94 & .75 & .00 \\
Idealized Influence & -.02 & .19 & .91 \\
Inspirational Motivation & -.28 & .26 & .05 \\
Intellectual Stimulation & -.46 & .23 & .89 \\
Individualized Consideration & -.03 & .23 & .01 \\
Contingent Rewards & .53 & .21 & .96 \\
Management by Exception & .01 & .26 & .01 \\
Laissez-Faire Leadership & -.45 & .16 &
\end{tabular}

Note. $\mathrm{N}=100 ;$ adjusted $\mathrm{R}^{2}=.09$

Table 14

Direction of Leadership Difference Scores and Nature of Work Satisfaction Regression Results

\begin{tabular}{cccc}
\hline Directional difference variable & $B$ & SE B & Significance \\
\hline Constant & 17.84 & 1.08 & .00 \\
Intellectual Stimulation Positive & .15 & 1.12 & .89 \\
Intellectual Stimulation Negative & .21 & 1.02 & .84 \\
Contingent Rewards Positive & .94 & 1.24 & .45 \\
Contingent Rewards Negative & .07 & 1.21 & .95
\end{tabular}


Laissez-Faire Leadership

Positive

Laissez-Faire Leadership

Negative
.04

Note. $\mathrm{N}=100 ;$ adjusted $\mathrm{R}^{2}=.01$

Table 13 shows that differences in AVP Intellectual Stimulation and AVP Laissez-Faire Leadership ratings given by employees and AVPs are significantly and negatively related to satisfaction with Nature of Work, while differences in ratings in AVP Contingent Rewards is positively related to satisfaction with Nature of Work. A one-point increase in Intellectual Stimulation difference scores is associated with a .46point decrease in Nature of Work satisfaction (ceteris paribus), while a one-point increase in Contingent Rewards difference scores is associated with a .53-point increase in Nature of Work satisfaction, ceteris paribus. The negative effect size of Laissez-Faire Leadership difference scores is comparable to the effect size when Supervision satisfaction was the outcome.

While differences in Intellectual Stimulation, Contingent Rewards, and LaissezFaire Leadership were statistically significant in this regression model, only the direction of the difference for Laissez-Faire Leadership had a statistically significant coefficient estimate on Nature of Work satisfaction, as shown in Table 14. The Laissez-Faire Leadership Positive variable yielded a statistically significant coefficient estimate, indicating that when employees rate their AVPs higher on Laissez-Faire Leadership behaviors than the AVPs rate themselves, employees are less satisfied with the nature of their work than those employees who are in full agreement with their AVPs about AVP 
Laissez-Faire Leadership practices. Table Y indicates that a positive difference in AVP Laissez-Faire Leadership ratings (when employee ratings are higher than AVP selfratings) is associated with a 2.34-point lower level of satisfaction for employees with Nature of Work (on a range from 0-20) than those who are in full agreement with their AVP. This difference of 2.34 points is equivalent to about a $12 \%$ lower satisfaction rating than those employees who are in full agreement with their AVPs.

Table 15

Leadership Difference Scores and Communication Satisfaction Regression Results

\begin{tabular}{cccc}
\hline$\underline{\text { Difference variable (absolute }}$ & $B$ & SE B & Significance \\
Vonstant & 16.44 & 1.00 & .00 \\
Idealized Influence & -.45 & .26 & .08 \\
Inspirational Motivation & .66 & .35 & .07 \\
Intellectual Stimulation & -1.06 & .30 & .00 \\
Individualized Consideration & -.22 & .31 & .49 \\
Contingent Rewards & .29 & .28 & .72 \\
Management by Exception & .12 & .35 & .02 \\
Laissez-Faire Leadership & -.52 & .21 & \\
\hline
\end{tabular}

Note. $\mathrm{N}=100 ;$ adjusted $\mathrm{R}^{2}=.19$

Table 16 
Direction of Leadership Difference Scores and Communication Satisfaction Regression Results

\begin{tabular}{cccc}
\hline Directional difference variable & $B$ & SE B & Significance \\
\hline Constant & 15.06 & 1.32 & .00 \\
Intellectual Stimulation Positive & 1.63 & 1.51 & .28 \\
Intellectual Stimulation Negative & -2.18 & 1.28 & .09 \\
Laissez-Faire Leadership & -1.19 & 1.42 & .40 \\
Positive & & & .81 \\
Laissez-Faire Leadership & -.39 & 1.61 & \\
Negative & & & \\
\hline
\end{tabular}

Note. $\mathrm{N}=100 ;$ adjusted $\mathrm{R}^{2}=.09$

Table 15 highlights that differences in AVP Laissez-Faire Leadership behaviors is negatively associated with all four satisfaction outcomes measured in this study (Supervision, Contingent Rewards, Nature of Work, and Communication). As the difference in scores given to the AVP regarding Laissez-Faire Leadership by employees and AVPs increases by one-point, there is an associated .52-point decrease in employee levels of satisfaction with Communication. In addition, for every one-point increase in the difference in scores given to the AVP regarding Intellectual Stimulation by employees and the AVPs, there is an associated 1.06-point (equivalent to about 5\%) decrease in employee levels of satisfaction with Communication.

The direction of the differences for both AVP Intellectual Stimulation and AVP Laissez-Faire Leadership was not significantly related to employee satisfaction with Communication, as shown in Table 16. Therefore, the results of the Gap Analyses 
explained in Table 15 and Table 16 indicate that differences in scores for Intellectual Stimulation and Laissez-Faire Leadership given by employees and AVPs, but not the direction of these differences, are negatively related to employee satisfaction with Communication.

These Gap Analyses were conducted using OLS methodology. This study conducted additional research with the data gathered using OLS methodology. As cited in Chapter 2 of this dissertation, researchers have hypothesized a reverse relationship between employee satisfaction and leadership style exists; that is, employees who are more satisfied with their jobs tend to attribute more leadership qualities (specifically, transformational qualities) to their supervisors (Van Knippenberg \& Sitkin, 2013). This aligns with studies that note that leadership is an attribution in the eye of the beholder; namely, employees hold mental representations of leadership that color their perceptions of leadership (Eden \& Leviatan, 1975; Lord \& Maher, 2002; Meindl, Ehrlich, \& Dukerich, 1985; Van Knippenberg \& Sitkin, 2013). The aforementioned studies would model the relationship by treating job satisfaction as the independent variable and transformational leadership as the dependent variable.

The following section of this chapter discusses the analysis results in which the satisfaction data gathered from the survey was treated as the independent variable and leadership was treated as the outcome. The findings of these Reverse Regressions executed using OLS models will now be presented.

\section{Reverse Regression Results}

This section shows the regression results when satisfaction scores with Supervision, Contingent Rewards, Nature of Work, and Communication (along with the 
control variable of Years of Service) are treated as independent variables, while perceptions of leadership style behaviors of the AVP are treated as the outcome. Nine variables were utilized as separate regression outcomes in this part of the study: Transformational Leadership Overall, the four dimensions of Transformational Leadership (Idealized Influence, Inspirational Motivation, Intellectual Stimulation, and Individualized Consideration), Transactional Leadership Overall, the two dimensions of Transactional Leadership (Contingent Rewards and Management by Exception), and Laissez-Faire Leadership.

It is important to note that an entirely different dataset was used to conduct the reverse regression analyses than what was used to construct the main regression models of this study. As explained earlier, I treated the main regression models as though leadership style was the independent variable (and therefore I could impute means for missing data), while omitting any respondents who had any missing data for job satisfaction or organizational climate questions. For the reverse regressions, I instead omitted respondents who had missing data for any leadership style questions while imputing the means for missing data on job satisfaction and organizational climate questions. After this treatment of the data, the reverse regression models have a sample size of 93 respondents.

Table 17

Satisfaction Ratings and Transformational Leadership Overall Regression Results

$\begin{array}{llll}\text { Satisfaction variable } & B & S E B & \text { Significance }\end{array}$




\begin{tabular}{|c|c|c|c|}
\hline Constant & 26.04 & 7.01 & .00 \\
\hline Supervision & -.74 & .40 & .07 \\
\hline Contingent Rewards & .53 & .31 & .09 \\
\hline Nature of Work & .22 & .38 & .57 \\
\hline Communication & .74 & .30 & .01 \\
\hline Years of Service & -.01 & .12 & .97 \\
\hline \multicolumn{4}{|c|}{ Note. $\mathrm{N}=93 ;$ adjusted $\mathrm{R}^{2}=.18$} \\
\hline \multicolumn{4}{|c|}{ The significant coefficient estimate for the Constant in Table 17 indicates that } \\
\hline \multicolumn{4}{|c|}{ rating of Transformational Leadership Overall of the AVP is expected to be about 26} \\
\hline \multicolumn{4}{|c|}{ points (on a range of 0-48) if satisfaction with the four satisfaction constructs measured in } \\
\hline \multicolumn{4}{|c|}{ this study were zero and an employee had zero years of service, all else held equal. The } \\
\hline \multicolumn{4}{|c|}{ only significant independent variable in this regression model was satisfaction with } \\
\hline \multicolumn{4}{|c|}{ Communication. The coefficient estimate on this variable indicates that for every one- } \\
\hline \multicolumn{4}{|c|}{ point increase in Communication satisfaction, there is an expected .74-point increase } \\
\hline \multicolumn{4}{|c|}{ (equivalent to about a $1.5 \%$ increase) in perception of AVP Transformational Leadership } \\
\hline \multicolumn{4}{|c|}{ Overall, all else held constant. While statistically significant, a $1.5 \%$ expected increase } \\
\hline
\end{tabular}

Table 18

Satisfaction Ratings and Idealized Influence Regression Results

$\begin{array}{llll}\text { Satisfaction variable } & B & S E B & \text { Significance }\end{array}$




$\begin{array}{cccc}\text { Constant } & 10.05 & 1.86 & .00 \\ \text { Supervision } & -.18 & .11 & .11 \\ \text { Contingent Rewards } & .10 & .08 & .22 \\ \text { Nature of Work } & -.06 & .10 & .57 \\ \text { Communication } & .18 & .08 & .03 \\ \text { Years of Service } & .01 & .03 & .76\end{array}$

Note. $\mathrm{N}=93$; adjusted $\mathrm{R}^{2}=.08$

Table 19

Satisfaction Ratings and Inspirational Motivation Regression Results

\begin{tabular}{cccc}
\hline Satisfaction variable & $B$ & $S E B$ & Significance \\
Constant & 6.42 & 2.04 & .00 \\
Supervision & -.18 & .12 & .12 \\
Contingent Rewards & .13 & .09 & .15 \\
Nature of Work & .07 & .11 & .51 \\
Communication & .15 & .09 & .08 \\
Years of Service & -.01 & .03 & .80 \\
\hline
\end{tabular}

Note. $\mathrm{N}=93 ;$ adjusted $\mathrm{R}^{2}=.10$

Table 18 shows that Communication satisfaction is the only variable significantly related to employee perceptions of Idealized Influence behaviors by the AVP. The coefficient estimate shows that, for every one-point increase in satisfaction with Communication, there is an expected .18-point increase in Idealized Influence perception of the AVP, ceteris paribus. The range of Idealized Influence scores is $0-12$; therefore, 
this .18-point change associated with a one-point increase in Communication satisfaction is equivalent to about a $1.5 \%$ increase in Idealized Influence. This is similar to the effect size of Communication satisfaction on perception of Transformational Leadership Overall presented previously.

Table 19 displays the regression results with Inspirational Motivation as the outcome variable. The coefficient on the Constant indicates that if all satisfaction scores were zero and the employee had zero years of service, the rating of Inspirational Motivation of the AVP is expected to be 6.42 (on a range of $0-12$ ), all else held constant. The results explained in Table 19 also show that no variable included in the model yielded statistically significant coefficient estimates, indicating no relationship between the four satisfaction dimensions and Inspirational Motivation.

Table 20

Satisfaction Ratings and Intellectual Stimulation Regression Results

$\begin{array}{llll}\text { Satisfaction variable } & B & S E B & \text { Significance }\end{array}$




\begin{tabular}{cccc} 
Constant & 5.38 & 1.93 & .01 \\
Supervision & -.18 & .11 & .12 \\
Contingent Rewards & .14 & .09 & .11 \\
Nature of Work & .08 & .11 & .47 \\
Communication & .19 & .08 & .02 \\
Years of Service & .02 & .03 & .62 \\
\hline
\end{tabular}

Note. $\mathrm{N}=93 ;$ adjusted $\mathrm{R}^{2}=.17$

Table 21

Satisfaction Ratings \& Individualized Consideration Regression Results

\begin{tabular}{cccc}
\hline Satisfaction variable & $B$ & SE B & Significance \\
Constant & 4.19 & 2.03 & .04 \\
Supervision & -.20 & .12 & .09 \\
Contingent Rewards & .16 & .09 & .09 \\
Nature of Work & .13 & .11 & .26 \\
Communication & .22 & .09 & .01 \\
Years of Service & -.02 & .03 & .52 \\
\hline
\end{tabular}

Note. $\mathrm{N}=93 ;$ adjusted $\mathrm{R}^{2}=.22$

The results in Table 20 and Table 21 display regression results with outcome variables of Intellectual Stimulation and Individualized Consideration, respectively. In both sets of regression models, Communication satisfaction is the only statistically significant variable related to the leadership behavior outcomes. In both regression models, the Communication satisfaction variable is positively related to the outcomes. 
Table 20 shows that a one-point increase in Communication satisfaction is associated with a .19-point (1.6\%) increase in perception of Intellectual Stimulation, ceteris paribus. Table 21 shows that a one-point increase in Communication satisfaction is associated with a .22-point (1.8\%) increase in perception of Individualized Consideration, ceteris paribus. In taking the results of the previous four tables together, Communication satisfaction is more strongly related to Individualized Consideration than the other three dimensions of Transformational Leadership. The relationships between satisfaction scores and Transactional Leadership dimensions are presented in the following three tables.

Table 22

Satisfaction Ratings and Transactional Leadership Behaviors Overall Regression Results

\begin{tabular}{cccc} 
Satisfaction variable & $B$ & SE B & Significance \\
Constant & 10.85 & 3.32 & .00 \\
Supervision & -.37 & .19 & .06 \\
Contingent Rewards & .38 & .15 & .01 \\
Nature of Work & .09 & .18 & .64 \\
Communication & .19 & .14 & .17 \\
Years of Service & .03 & .06 & .58 \\
\hline
\end{tabular}

Note. $\mathrm{N}=93 ;$ adjusted $\mathrm{R}^{2}=.16$

The significant coefficient estimate for the Constant in Table 22 indicates that rating of Transactional Leadership Overall of the AVP is expected to be about 10.9 points (on a range of 0-24) if satisfaction with the four satisfaction constructs measured in this study were zero and an employee had zero years of service, all else held equal. The only 
significant independent variable in this regression model was satisfaction with Contingent Rewards. The coefficient estimate on this variable indicates that for every one-point increase in Contingent Rewards satisfaction, there is an expected .38-point increase (equivalent to about a 1.6\% increase) in perception of AVP Transactional Leadership. Overall, all else held constant. While statistically significant, a 1.6\% expected increase indicates that the relationship does not hold much practical significance. The following two tables present the regression results of the four satisfaction variables on perceptions of AVP leadership behaviors of the two dimensions that comprise Transactional Leadership: Contingent Rewards and Management by Exception.

Table 23

Satisfaction Ratings and Contingent Rewards Regression Results

\begin{tabular}{cccc}
\hline Satisfaction variable & $B$ & SE B & Significance \\
Constant & 3.23 & 2.30 & .17 \\
Supervision & -.16 & .13 & .22 \\
Contingent Rewards & .31 & .10 & .00 \\
Nature of Work & -.02 & .13 & .91 \\
Communication & .11 & .10 & .25 \\
Years of Service & -.00 & .04 & .9 \\
\hline
\end{tabular}

Note. $\mathrm{N}=93 ;$ adjusted $\mathrm{R}^{2}=.18$

Table 24

Satisfaction Ratings and Management by Exception Regression Results

$\begin{array}{llll}\text { Satisfaction variable } & B & S E B & \text { Significance }\end{array}$


Constant

Supervision

Contingent Rewards

Nature of Work

Communication

Years of Service
7.63

$-.20$

.08

.10

.08

.03
1.49

.09

.07

.08

.06

.03
.00

.02

.26

.22

.22

.18

Note. $\mathrm{N}=93$; adjusted $\mathrm{R}^{2}=.08$

The results in Table 23 and Table 24 display regression results with outcome variables of Contingent Rewards and Management by Exception, respectively. Table 23 shows that Contingent Rewards satisfaction is significantly and positively related to perception of Contingent Rewards leadership. Specifically, a one-point increase in Contingent Rewards satisfaction is associated with a .31-point increase in perception of Contingent Rewards leadership behavior, ceteris paribus. Because the range of Contingent Rewards leadership is $0-12$, this is equivalent to about a $2.6 \%$ increase. Table 24 shows that Supervision satisfaction is significantly and negatively related to perception of Management by Exception, where a one-point increase in Supervision satisfaction is associated with a .20-point (1.7\%) decrease in perception of Management by Exception, ceteris paribus. Both these results are understandable, as Contingent Rewards satisfaction theoretically should be related to perception of Contingent Rewards leadership behaviors; additionally, as satisfaction with Supervision increases, it is logical that perceptions of a leader only making interventions when processes deviate from the norm (Management by Exception). The relationships between satisfaction scores and Laissez-Faire Leadership are presented in the following table. 
Table 25

Satisfaction Ratings and Laissez-Faire Leadership Regression Results

\begin{tabular}{cccc}
\hline Satisfaction variable & $B$ & $S E B$ & Significance \\
Constant & 9.38 & 1.81 & .00 \\
Supervision & -.15 & .10 & .15 \\
Contingent Rewards & -.08 & .08 & .34 \\
Nature of Work & -.12 & .10 & .23 \\
Communication & .08 & .08 & .27 \\
Years of Service & -.04 & .03 & .22 \\
\hline
\end{tabular}

Note. $\mathrm{N}=93 ;$ adjusted $\mathrm{R}^{2}=.08$

Table 25 displays the regression results with Laissez-Faire Leadership as the outcome variable. The coefficient on the Constant indicates that if all satisfaction scores were zero and the employee had zero years of service, the rating of Laissez-Faire Leadership of the AVP is expected to be 9.38 (on a range of 0-12), all else held constant. The results explained in Table 25 also show that no variable included in the model yielded statistically significant coefficient estimates. This means that employee satisfaction with any of the four dimensions measured in this study were found to have no relationship with perceptions of Laissez-Faire Leadership behaviors of the AVP.

The regressions results from this section stemmed from OLS regression models. Further OLS regressions were run as a part of this study. Chapter 1 and Chapter 2 of this dissertation highlighted that previous studies investigating the inter-relationships between employee job satisfaction, organizational climate strength, and supervisor leadership style employ OLS methods for the statistical analyses. The following section of this paper 
displays OLS regression results using the data collected as part of this study. In the following section, employee job satisfaction is used as the outcome variable, while supervisor leadership style and organizational climate strength are utilized as the independent and mediating variables, respectively.

\section{OLS Regression Results}

This section of the paper presents the OLS regression model results. As explained in detail in Chapter 3, five different outcomes were utilized in separate regression models: Overall Satisfaction, Supervision Satisfaction, Contingent Rewards Satisfaction, Nature of Work Satisfaction, and Communication Satisfaction. Four distinct regression models were run within regressions containing the five outcome variables. Model 1 included the Years of Service variable as a control variable along with each of the four dimensions of Transformational Leadership, the two dimensions of Transactional Leadership, and Laissez-Faire Leadership (these independent variables were entered separately in each regression). Models 2, 3, and 4 include the same variables of Model 1; in additional, the mediating variables of Autonomy Climate Strength, Innovation and Flexibility Climate Strength, and Effort Strength, are included in the three models, respectively. Regression results from these models, taken together with the regression results from Model 1, will yield insights about whether the aforementioned variables in Models 2, 3, and 4 do not at all mediate, partially mediate, or fully mediate the effects of independent variables of interest on the outcome variable.

The following subsection presents the OLS model results of regressing the variables representing the four dimensions of Transformational Leadership (Idealized 
Influence, Inspirational Motivation, Intellectual Stimulation, and Individualized Consideration) on the five Satisfaction outcomes measured in this study.

\section{Transformational Leadership OLS Regression Results}

This subsection displays the results of the regressions in which Transformational Leadership dimensions (Idealized Influence, Inspirational Motivation, Intellectual Stimulation, and Individualized Consideration) were regressed on five different Satisfaction outcomes (Overall, Supervision, Contingent Rewards, Nature of Work, and Communication). Five separate tables, separated by the five different outcome variables, are used to the present the data. Within each of these tables, four blocks of regression results are presented (one for each of the four dimensions of Transformational Leadership). In addition, the results of four different regression models are presented: Model 1 contains the Constant, one dimension of Transformational Leadership as the explanatory variable, and the control variable of Years of Service; Models 2, 3, and 4 include those variables, along with mediating variables of climate strength (Autonomy, Innovation and Flexibility, and Effort), respectively.

Table 26

Transformational Leadership Behaviors and Overall Satisfaction OLS Regression Results

\begin{tabular}{l|l|l|l|l}
\hline & $\underline{\text { Model 1 }}$ & $\underline{\text { Model 2 }}$ & $\underline{\text { Model 3 }}$ & Model 4
\end{tabular}




\begin{tabular}{|c|c|c|c|c|c|c|c|c|c|c|c|c|}
\hline Variable & $B$ & $\begin{array}{c}S E \\
B\end{array}$ & Sig & $B$ & $S E B$ & Sig & $B$ & $\begin{array}{c}S E \\
B\end{array}$ & Sig & $B$ & $\begin{array}{c}S E \\
B\end{array}$ & Sig \\
\hline Constant & 47.64 & 5.56 & .00 & 64.57 & 10.03 & .00 & 50.26 & 7.80 & .00 & 46.45 & 8.11 & .00 \\
\hline Ideal.Inf. & 1.17 & .54 & .03 & 1.46 & .55 & .01 & 1.16 & .54 & .03 & 1.19 & .55 & .03 \\
\hline YOS & -.05 & .16 & .78 & .00 & .16 & .99 & -.05 & .16 & .75 & -.04 & .16 & .79 \\
\hline Auton. & & & & -6.62 & 3.29 & .05 & & & & & & \\
\hline$I \& F$ & & & & & & & -.71 & 1.48 & .63 & & & \\
\hline Effort & & & & & & & & & & .37 & 1.79 & .84 \\
\hline $\operatorname{adj} .-R^{2}$ & & .03 & & & .06 & & & .02 & & & .02 & \\
\hline
\end{tabular}

\begin{tabular}{|c|c|c|c|c|c|c|c|c|c|c|c|c|}
\hline Constant & 46.27 & 4.21 & .00 & 62.57 & 9.72 & .00 & 48.55 & 6.78 & .00 & 45.10 & 6.61 & .00 \\
\hline Inspi.Mot. & 1.58 & .47 & .00 & 1.69 & .47 & .00 & 1.57 & .47 & .00 & 1.59 & .48 & .00 \\
\hline YOS & -.04 & .16 & .82 & .00 & .16 & .99 & -.04 & .16 & .79 & -.03 & .16 & .83 \\
\hline Auton. & & & & -5.76 & 3.11 & .07 & & & & & & \\
\hline$I \& F$ & & & & & & & -.62 & 1.44 & .67 & & & \\
\hline Effort & & & & & & & & & & .40 & 1.72 & .82 \\
\hline adj. $-R^{2}$ & & .09 & & & .11 & & & .08 & & & .08 & \\
\hline Constant & 43.50 & 4.09 & .00 & 61.46 & 9.34 & .00 & 45.87 & 6.56 & .00 & 42.20 & 6.35 & .00 \\
\hline Intell.Stim. & 1.97 & .47 & .00 & 2.12 & .46 & .00 & 1.97 & .47 & .00 & 1.99 & .47 & .00 \\
\hline YOS & -.08 & .15 & .60 & -.04 & .15 & .78 & -.09 & .15 & .57 & -.08 & .15 & .60 \\
\hline Auton. & & & & -6.42 & 3.01 & .04 & & & & & & \\
\hline$I \& F$ & & & & & & & -.65 & 1.40 & .64 & & & \\
\hline Effort & & & & & & & & & & .45 & 1.66 & .79 \\
\hline adj. $-R^{2}$ & & .14 & & & .17 & & & .13 & & & .13 & \\
\hline
\end{tabular}




\begin{tabular}{c|ccc|ccc|ccc|ccc} 
Constant & 44.85 & 3.79 & .00 & 63.64 & 9.19 & .00 & 43.71 & 6.86 & .00 & 40.80 & 6.49 & .00 \\
Indi.Cons. & 1.84 & .43 & .00 & 2.01 & .43 & .00 & 1.86 & .44 & .00 & 1.93 & .46 & .00 \\
YOS & .03 & .15 & .84 & .08 & .15 & .59 & .03 & .16 & .83 & .04 & .15 & .80 \\
Auton. & & & & -6.73 & 3.01 & .03 & & & & & & \\
I\&F & & & & & & & & .28 & 1.42 & .84 & & \\
Effort
\end{tabular}

Note. $\mathrm{N}=100$

Table 26 displays the regression results that explain the relationship between each of the four dimensions of Transformational Leadership and Overall Satisfaction (the range for Overall Satisfaction scores is 0-80). The first block of regression results shown in Table 26 shows the relationship between Idealized Influence behaviors of the AVP and Overall Satisfaction of the employees. The coefficient estimate of 47.64 for the Constant in Model 1 in this block of regressions indicates the expected Overall Satisfaction level of employees when the value of the explanatory variables in the model are all zero.

Model 1 coefficient estimates across the four blocks of regressions show that Intellectual Stimulation and Individualized Consideration (1.97 and 1.84, respectively) have larger effect sizes associated with Overall Satisfaction than Inspirational Motivation (1.58) and Idealized Influence (1.17). These positive effect sizes indicate that as scores in these four separate leadership behaviors by the AVP increases, Overall Satisfaction of employees increase as well, all else held constant.

The results of Model 2 show that Autonomy Climate Strength is significantly related to Overall Satisfaction in three of the four blocks of regressions. Autonomy 
Climate Strength does not mediate the effect sizes of any of the dimensions of Transformational Leadership on Overall Satisfaction; in fact, the inclusion of the Autonomy Climate Strength variable into the models actually strengthens the relationships between the separate Transformational Leadership behaviors (Idealized Influence, Intellectual Stimulation, and Individualized Consideration) and Overall Satisfaction.

The Autonomy Climate Strength variable has similar effect sizes on Overall Satisfaction in the three of the four blocks of regressions in which it is statistically significant. It is important to note that Autonomy Climate Strength is measured by the standard deviation between the scores given by employees in each department; therefore, a lower score for this (and other climate strength) variables indicates a stronger climate. Therefore, the negative values of the coefficients for Autonomy Climate Strength (in which a one-point decrease in Autonomy Climate Strength score is associated with a decrease in Overall Satisfaction) actually indicate a positive relationship between Autonomy Climate Strength and Overall Satisfaction.

For example, the value of -6.73 for the coefficient estimate on Autonomy Climate Strength in the fourth block of regressions (which includes Individualized Consideration as the explanatory variable of interest) can be interpreted as follows: for every one-point increase in the standard deviation between Autonomy scores given (this increase representing a weaker Autonomy Climate), there is an associated 6.73-point decrease in Overall Satisfaction, ceteris paribus. Conversely, a one-point decrease in the standard deviation between Autonomy scores given (this decrease representing a stronger Autonomy Climate) is associated with a 6.73-point increase (equivalent to about an $8.4 \%$ 
increase) in Overall Satisfaction, ceteris paribus. It is also notable that the results portrayed in Table 26 indicate that neither Innovation and Flexibility Climate Strength and Effort Climate Strength are not significantly related to Overall Satisfaction.

Table 27

Transformational Leadership and Supervision Satisfaction OLS Regression Results

\begin{tabular}{|c|c|c|c|c|c|c|c|c|c|c|c|c|}
\hline \multirow[b]{2}{*}{ Variable } & \multicolumn{3}{|c|}{ Model 1} & \multicolumn{3}{|c|}{ Model 2} & \multicolumn{3}{|c|}{ Model 3} & \multicolumn{3}{|c|}{ Model 4} \\
\hline & $B$ & $S E B$ & Sig & $B$ & $S E B$ & Sig & $B$ & $S E$ & Sig & $B$ & $S E B$ & Sig \\
\hline Constant & 15.73 & 1.59 & .00 & 19.61 & 2.89 & .00 & 15.37 & 2.24 & .00 & 14.86 & 2.32 & .00 \\
\hline Ideal.Inf. & .09 & .15 & .56 & .16 & .16 & .33 & .09 & .16 & .56 & .11 & .16 & .50 \\
\hline YOS & .00 & .05 & .99 & .01 & .05 & .83 & .00 & .05 & .98 & .00 & .05 & .98 \\
\hline Auton. & & & & -1.52 & .95 & .11 & & & & & & \\
\hline$I \& F$ & & & & & & & .10 & .43 & .82 & & & \\
\hline Effort & & & & & & & & & & .27 & .05 & .61 \\
\hline $\operatorname{adj} .-R^{2}$ & & -.02 & & & .00 & & & -.03 & & & -.03 & \\
\hline Constant & 15.23 & 1.24 & .00 & 19.30 & 2.87 & .00 & 14.82 & 1.99 & .00 & 14.37 & 1.94 & .00 \\
\hline Inspi.Mot. & .17 & .14 & .22 & .20 & .14 & .15 & .17 & .14 & .22 & .18 & .14 & .19 \\
\hline YOS & .00 & .05 & .98 & .01 & .05 & .82 & .00 & .05 & .96 & .00 & .05 & .96 \\
\hline Auton. & & & & -1.44 & .92 & .12 & & & & & & \\
\hline $\mathrm{I} \& \mathrm{~F}$ & & & & & & & .11 & .42 & .79 & & & \\
\hline Effort & & & & & & & & & & .29 & .50 & .57 \\
\hline adj.- $R^{2}$ & & .00 & & & .01 & & & -.01 & & & -.01 & \\
\hline Constant & 14.79 & 1.23 & .00 & 19.08 & 2.83 & .00 & 14.39 & 1.97 & .00 & 13.91 & 1.91 & .00 \\
\hline
\end{tabular}




\begin{tabular}{|c|c|c|c|c|c|c|c|c|c|c|c|c|}
\hline Intell.Stim. & .23 & .14 & .10 & .27 & .14 & .06 & .23 & .14 & .10 & .24 & .14 & .09 \\
\hline YOS & .00 & .05 & .93 & .01 & .05 & .91 & .00 & .05 & .95 & .00 & .05 & .95 \\
\hline Auton. & & & & -1.54 & .91 & .10 & & & & & & \\
\hline$I \& F$ & & & & & & & .11 & .42 & .80 & & & \\
\hline Effort & & & & & & & & & & .30 & .50 & .55 \\
\hline adj.- $R^{2}$ & & .01 & & & .03 & & & .00 & & & .00 & \\
\hline Constant & 15.07 & 1.14 & .00 & 19.42 & 2.80 & .00 & 14.21 & 2.07 & .00 & 13.84 & 1.96 & .00 \\
\hline Indi.Cons. & .20 & .13 & .13 & .24 & .13 & .07 & .21 & .13 & .12 & .27 & .14 & .10 \\
\hline YOS & .01 & .05 & .86 & .02 & .05 & .66 & .01 & .05 & .81 & .01 & .05 & .82 \\
\hline Auton. & & & & -1.56 & .92 & .09 & & & & & & \\
\hline $\mathrm{I} \& \mathrm{~F}$ & & & & & & & .22 & .43 & .62 & & & \\
\hline Effort & & & & & & & & & & .40 & .51 & .44 \\
\hline adj. $-\mathrm{R}^{2}$ & & .00 & & & .02 & & & .00 & & & .00 & \\
\hline
\end{tabular}

Note. $\mathrm{N}=100$

Table 27 shows the relationship between the dimensions of Transformational Leadership and Supervision Satisfaction. The range for Supervision Satisfaction scores is 0-20. As shown in this table, aside from the coefficient estimates of the Constant in all four blocks of regressions and within all four models, none of the explanatory or control variables are statistically significant. This indicates that there are no significant relationships between dimensions of Transformational Leadership behaviors by the AVP and the satisfaction of employees at The University with the construct of Supervision. The lack of statistically significant results in displayed in Table 27 also indicates that there is no relationship between climate strength of the three climate constructs measured in this study and employee satisfaction with Supervision. 
Table 28

Transformational Leadership and Contingent Rewards Satisfaction OLS Regression Results

\begin{tabular}{|c|c|c|c|c|c|c|c|c|c|c|c|c|}
\hline \multirow[b]{2}{*}{ Variable } & \multicolumn{3}{|c|}{ Model 1} & \multicolumn{3}{|c|}{ Model 2} & \multicolumn{3}{|c|}{ Model 3} & \multicolumn{3}{|c|}{ Model 4} \\
\hline & $B$ & $S E B$ & Sig & $B$ & $\begin{array}{c}S E \\
B\end{array}$ & Sig & $B$ & $\begin{array}{c}S E \\
B\end{array}$ & Sig & $B$ & $S E B$ & Sig \\
\hline Constant & 8.38 & 1.97 & 4.26 & 12.04 & 3.60 & .00 & 12.79 & 2.69 & .00 & 11.09 & 2.86 & .00 \\
\hline Ideal.Inf. & .44 & .19 & .02 & .50 & .20 & .01 & .43 & .19 & .02 & .38 & .20 & .05 \\
\hline YOS & -.05 & .06 & .42 & -.04 & .06 & .52 & -.06 & .06 & .30 & -.05 & .06 & .39 \\
\hline Auton. & & & & -1.43 & 1.18 & .23 & & & & & & \\
\hline $\mathrm{I} \& \mathrm{~F}$ & & & & & & & -1.20 & .51 & .02 & & & \\
\hline Effort & & & & & & & & & & -.82 & .63 & .19 \\
\hline adj.- $R^{2}$ & & .04 & & & .04 & & & .08 & & & .05 & \\
\hline Constant & 8.50 & 1.51 & .00 & 11.60 & 3.53 & .00 & 12.82 & 2.37 & .00 & 10.96 & 2.35 & .00 \\
\hline Inspi.Mot. & .52 & .17 & .00 & .54 & .17 & .00 & .50 & .16 & .00 & .48 & .17 & .01 \\
\hline YOS & -.04 & .06 & .44 & -.04 & .06 & .53 & -.06 & .06 & .32 & -.05 & .06 & .41 \\
\hline Auton. & & & & -1.10 & 1.13 & .33 & & & & & & \\
\hline $\mathrm{I} \& \mathrm{~F}$ & & & & & & & -1.17 & .50 & .02 & & & \\
\hline Effort & & & & & & & & & & -.83 & .61 & .18 \\
\hline adj. $-R^{2}$ & & .08 & & & .08 & & & .12 & & & .08 & \\
\hline Constant & 7.50 & 1.47 & .00 & 11.19 & 3.41 & .00 & 11.82 & 2.29 & .00 & 9.84 & 2.26 & .00 \\
\hline Intell.Stim. & .66 & .17 & .00 & .69 & .17 & .00 & .65 & .16 & .00 & .63 & .17 & .00 \\
\hline YOS & -.06 & .06 & .29 & -.05 & .06 & .36 & -.07 & .05 & .19 & -.06 & .06 & .27 \\
\hline Auton. & & & & -1.32 & 1.10 & .23 & & & & & & \\
\hline
\end{tabular}




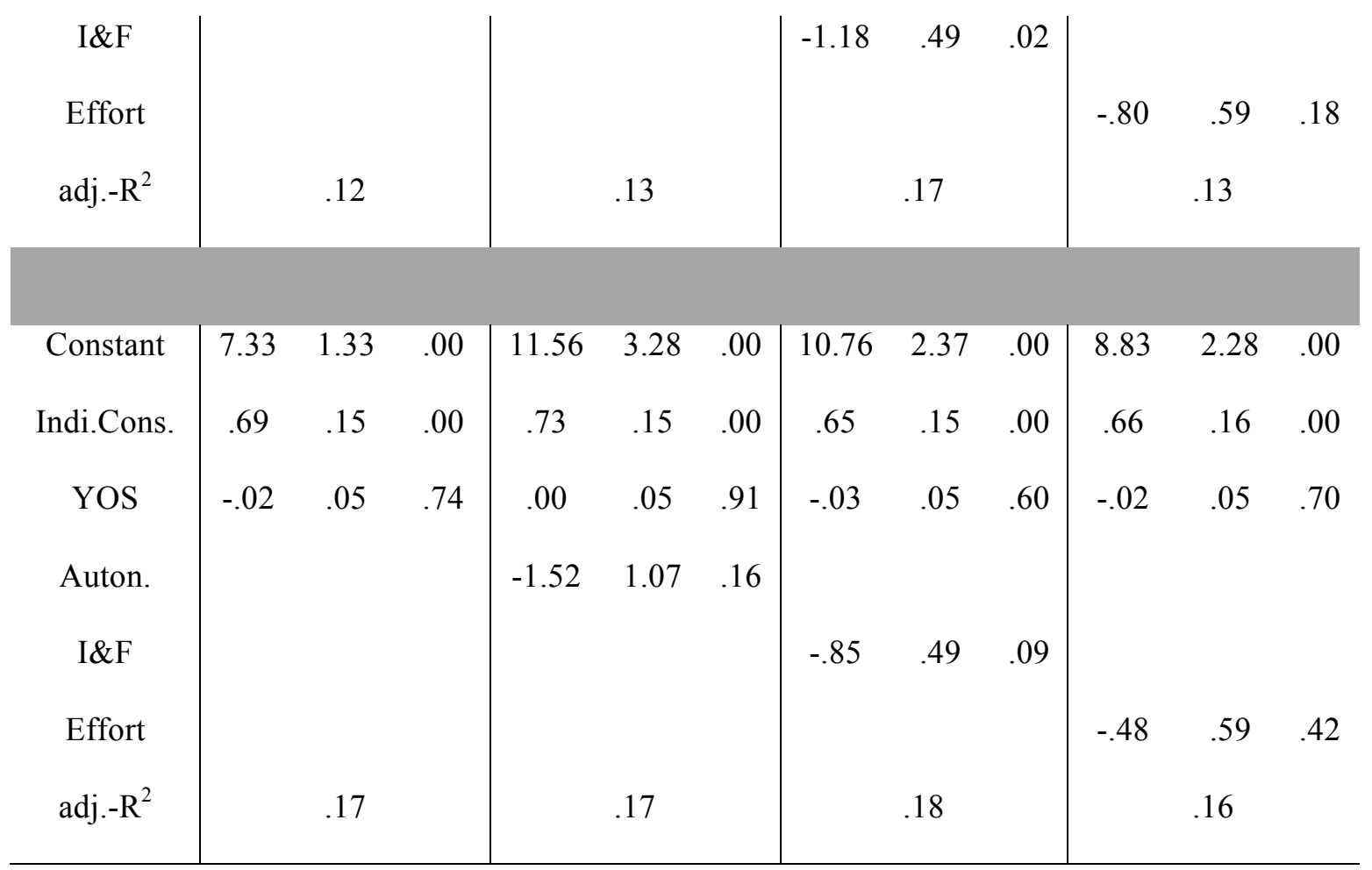

Note. $\mathrm{N}=100$

Table 28 shows the regression results for the relationships between dimensions of Transformational Leadership and Contingent Rewards Satisfaction. The range of Contingent Rewards Satisfaction scores is 0-20. From the results displayed from Model 1, all four dimensions of Transformational Leadership are statistically significant and positively related to Contingent Rewards Satisfaction. The coefficient estimates of Intellectual Stimulation (.66) and Individualized Consideration (.69) are notably bigger than the coefficient estimates of Inspirational Motivation and Idealized Influence (.52 and .44 , respectively). This means that Intellectual Stimulation and Individualized Consideration have stronger positive associations with Contingent Rewards Satisfaction than Inspirational Motivation and Idealized Influence leadership behaviors do. These findings are similar to the findings from Table 26, in which Overall Satisfaction is the outcome variable. The biggest effect size of these four dimensions (Individualized 
Consideration) indicates that for every one-point increase in Individualized Consideration scores, there is an associated .69-point (equivalent to about a 3.5\%) increase in Contingent Rewards Satisfaction, ceteris paribus.

In addition, the Innovation and Flexibility Climate Strength variable is significantly and positively related to Contingent Rewards Satisfaction in the blocks of regressions including Intellectual Stimulation and Inspirational Motivation variables as independent variables (as a reminder, keep in mind that a negative coefficient estimate for any of the three climate variables indicates that stronger climates are associated with higher satisfaction scores, as the climate strength variables are measured by the standard deviations between scores from employees regarding the climate). The Innovation and Flexibility Climate Strength variables in the two blocks of regressions in which it is statistically significant is not a strong mediator whatsoever. The coefficient estimate of the Innovation and Flexibility Climate Strength variable in the third block of regressions (utilizing Intellectual Stimulation as the independent variable of interest) indicates that a one-point decrease in Innovation and Flexibility Climate Strength (yielding a stronger climate) is associated with a 1.18-point increase (equivalent to about 5.9\%) in Contingent Rewards Satisfaction, ceteris paribus.

Table 29

Transformational Leadership and Nature of Work Satisfaction OLS Regression Results

\begin{tabular}{|c|c|c|c|c|c|c|c|c|c|c|c|c|}
\hline \multirow[b]{2}{*}{ Variable } & \multicolumn{3}{|c|}{ Model 1} & \multicolumn{3}{|c|}{ Model 2} & \multicolumn{3}{|c|}{ Model 3} & \multicolumn{3}{|c|}{ Model 4} \\
\hline & $B$ & $S E B$ & Sig & $B$ & $S E B$ & Sig & $B$ & $S E B$ & Sig & $B$ & $S E B$ & Sig \\
\hline
\end{tabular}




\begin{tabular}{|c|c|c|c|c|c|c|c|c|c|c|c|c|}
\hline Constant & 15.51 & 1.38 & .00 & 20.31 & 2.47 & .00 & 15.98 & 1.93 & .00 & 14.47 & 2.00 & .00 \\
\hline Ideal.Inf. & .09 & .13 & .52 & .17 & .14 & .21 & .09 & .13 & .52 & .11 & .14 & .43 \\
\hline YOS & .02 & .04 & .64 & .03 & .04 & .08 & .02 & .04 & .66 & .02 & .04 & .62 \\
\hline Auton. & & & & -1.88 & .81 & .02 & & & & & & \\
\hline$I \& F$ & & & & & & & -.13 & .37 & .73 & & & \\
\hline Effort & & & & & & & & & & .32 & .44 & .48 \\
\hline adj. $-R^{2}$ & & -.01 & & & .03 & & & -.02 & & & -.02 & \\
\hline Constant & 14.11 & 1.05 & .00 & 19.42 & 2.39 & .00 & 14.51 & 1.69 & .00 & 12.93 & 1.64 & .00 \\
\hline Inspi.Mot. & .28 & .12 & .02 & .31 & .11 & .01 & .28 & .12 & .02 & .30 & .12 & .01 \\
\hline YOS & .02 & .04 & .61 & .03 & .04 & .40 & .02 & .04 & .63 & .02 & .04 & .58 \\
\hline Auton. & & & & -1.88 & .76 & .02 & & & & & & \\
\hline$I \& F$ & & & & & & & -.11 & .36 & .77 & & & \\
\hline Effort & & & & & & & & & & .40 & .43 & .35 \\
\hline $\operatorname{adj} .-R^{2}$ & & .04 & & & .09 & & & .03 & & & .04 & \\
\hline Constant & 13.69 & 1.04 & .00 & 19.26 & 2.33 & .00 & 14.10 & 1.66 & .00 & 12.51 & 1.60 & .00 \\
\hline Intell.Stim. & .34 & .12 & .01 & .39 & .12 & .00 & .34 & .12 & .01 & .36 & .12 & .00 \\
\hline YOS & .01 & .04 & .75 & .03 & .04 & .52 & .01 & .04 & .77 & .01 & .04 & .73 \\
\hline Auton. & & & & -1.99 & .75 & .01 & & & & & & \\
\hline$I \& F$ & & & & & & & -.11 & .35 & .75 & & & \\
\hline Effort & & & & & & & & & & .40 & .42 & .34 \\
\hline adj. $-R^{2}$ & & .06 & & & .12 & & & .05 & & & .06 & \\
\hline Constant & 14.15 & .97 & .00 & 19.78 & 2.32 & .00 & 14.03 & 1.75 & .00 & 12.49 & 1.65 & .00 \\
\hline
\end{tabular}




\begin{tabular}{|c|c|c|c|c|c|c|c|c|c|c|c|c|}
\hline Indi.Cons. & .29 & .11 & .01 & .34 & .11 & .00 & .29 & .11 & .01 & .32 & .11 & .01 \\
\hline YOS & .03 & .04 & .44 & .05 & .04 & .24 & .03 & .04 & .44 & .03 & .04 & .39 \\
\hline Auton. & & & & -2.01 & .76 & .01 & & & & & & \\
\hline$I \& F$ & & & & & & & .03 & .36 & .93 & & & \\
\hline Effort & & & & & & & & & & .54 & .43 & .21 \\
\hline $\operatorname{adj} .-R^{2}$ & & .05 & & & .10 & & & .04 & & & .05 & \\
\hline
\end{tabular}

Note. $\mathrm{N}=100$

Table 29 shows the regression results of the relationship between

Transformational Leadership dimensions and Nature of Work Satisfaction (the range of satisfaction scores for Nature of Work is 0-20). The first block of regressions indicates that the Idealized Influence dimension is not significantly related to Nature of Work Satisfaction; however, from the second, third, and fourth blocks of regressions, the dimensions of Inspirational Motivation, Intellectual Stimulation, and Individualized Consideration are all significantly and positively related to Nature of Work Satisfaction. The effect sizes on the coefficient estimates of these three variables throughout the four different models are all generally comparable and similar. The coefficient estimate of .34 for Intellectual Stimulation in Model 1 (third block of regression) indicates that for every one-point increase in Intellectual Stimulation score given by employees in rating their AVP on this leadership dimension, there is an associated .34-point increase (equivalent to about a $1.7 \%$ increase) in employee satisfaction with Nature of Work, ceteris paribus.

In addition, Autonomy Climate Strength is significantly and positively related to employee satisfaction. The strongest relationship between Autonomy Climate Strength and Nature of Work Satisfaction is in the model including Individualized Consideration (coefficient estimate of -2.01), followed by the models including Intellectual Stimulation 
(-1.99) and Inspirational Motivation (-1.88). The coefficient estimate of Autonomy Climate Strength in the regression utilizing Individualized Consideration as the independent variable of interest shows that a one-point decrease in Autonomy Climate Strength score (indicating a stronger climate score) is associated with a 2.01-point increase (equivalent to about a $10.1 \%$ increase) in employee satisfaction with Nature of Work, all else held constant. The Autonomy Climate Strength variable does not mediate, but in fact strengthens, the effect sizes of the different dimensions of Transformational Leadership on Nature of Work Satisfaction.

Table 30

Transformational Leadership Behaviors and Communication Satisfaction OLS Regression Results

\begin{tabular}{|c|c|c|c|c|c|c|c|c|c|c|c|c|}
\hline \multirow[b]{2}{*}{ Variable } & \multicolumn{3}{|c|}{ Model 1} & \multicolumn{3}{|c|}{ Model 2} & \multicolumn{3}{|c|}{ Model 3} & \multicolumn{3}{|c|}{ Model 4} \\
\hline & $B$ & $S E B$ & Sig & $B$ & $S E B$ & Sig & $B$ & $S E B$ & Sig & $B$ & $S E B$ & Sig \\
\hline Constant & 8.03 & 1.87 & .00 & 12.61 & 3.40 & .00 & 6.13 & 2.62 & .02 & 6.03 & 2.72 & .03 \\
\hline Ideal.Inf. & .55 & .18 & .00 & .63 & .19 & .00 & .55 & .18 & .00 & .59 & .19 & .00 \\
\hline YOS & -.02 & .06 & .74 & -.01 & .06 & .91 & -.01 & .06 & .82 & -.02 & .06 & .77 \\
\hline Auton. & & & & -1.79 & 1.12 & .11 & & & & & & \\
\hline$I \& F$ & & & & & & & .52 & .50 & .30 & & & \\
\hline Effort & & & & & & & & & & .61 & .60 & .31 \\
\hline adj. $-R^{2}$ & & .07 & & & .08 & & & .07 & & & .07 & \\
\hline Constant & 8.43 & 1.42 & .00 & 12.24 & 3.32 & .00 & 6.41 & 2.28 & .01 & 6.84 & 2.23 & .00 \\
\hline Inspi.Mot. & .61 & .16 & .00 & .64 & .16 & .00 & .62 & .16 & .00 & .64 & .16 & .00 \\
\hline YOS & -.01 & .05 & .79 & -.01 & .05 & .93 & -.01 & .05 & .88 & -.01 & .05 & .82 \\
\hline
\end{tabular}




\begin{tabular}{|c|c|c|c|c|c|c|c|c|c|c|c|c|}
\hline Auton. & & & & -1.35 & 1.06 & .21 & & & & & & \\
\hline $\mathrm{I} \& \mathrm{~F}$ & & & & & & & .55 & .49 & .26 & & & \\
\hline Effort & \multirow{2}{*}{\multicolumn{3}{|c|}{.12}} & \multirow{2}{*}{\multicolumn{3}{|c|}{.12}} & \multirow{2}{*}{\multicolumn{3}{|c|}{.12}} & .54 & .58 & .35 \\
\hline adj.- $R^{2}$ & & & & & & & & & & & .12 & \\
\hline Constant & 7.53 & 1.38 & .00 & 11.93 & 3.19 & .00 & 5.57 & 2.20 & .01 & 5.94 & 2.13 & .01 \\
\hline Intell.Stim. & .74 & .16 & .00 & .78 & .16 & .00 & .75 & .16 & .00 & .77 & .16 & .00 \\
\hline YOS & -.03 & .05 & .55 & -.02 & .05 & .68 & -.03 & .05 & .62 & -.03 & .05 & .57 \\
\hline Auton. & & & & -1.57 & 1.03 & .13 & & & & & & \\
\hline$I \& F$ & & & & & & & .54 & .47 & .26 & & & \\
\hline Effort & & & & & & & & & & .55 & .56 & .33 \\
\hline adj. $-R^{2}$ & & .17 & & & .18 & & & .17 & & & .17 & \\
\hline Constant & 8.30 & 1.29 & .00 & 12.89 & 3.18 & .00 & 4.72 & 2.30 & .04 & 5.65 & 2.20 & .01 \\
\hline Indi.Cons. & .66 & .15 & .00 & .70 & .15 & .00 & .71 & .15 & .00 & .72 & .15 & .00 \\
\hline YOS & .01 & .05 & .85 & .02 & .05 & .68 & .02 & .05 & .69 & .02 & .05 & .78 \\
\hline Auton. & & & & -1.64 & 1.04 & .12 & & & & & & \\
\hline $\mathrm{I} \& \mathrm{~F}$ & & & & & & & .89 & .48 & .06 & & & \\
\hline Effort & & & & & & & & & & .85 & .57 & .14 \\
\hline adj. $-R^{2}$ & & .16 & & & .17 & & & .18 & & & .17 & \\
\hline
\end{tabular}

Note. $\mathrm{N}=100$

Table 30 shows the regression results of the relationships between

Transformational Leadership dimensions and Communication Satisfaction (the range for Communication Satisfaction scores is 0-20). All four dimensions of Transformational Leadership are significantly and positively related to Communication Satisfaction. 
Intellectual Stimulation had the biggest effect size of the four blocks of regressions run for Model 1. The .74 coefficient estimate of Intellectual Stimulation indicates that for every one-point increase in Intellectual Stimulation score given by employees for an AVP, there is an associate .74-point increase (equivalent to about a $3.7 \%$ increase) in Communication Satisfaction, ceteris paribus. None of the three climate strength variables measured in this study are shown to be significantly related to Communication Satisfaction.

In taking the results shown in the previous five tables together, the findings imply that the relationship between Autonomy Climate Strength and Overall Satisfaction (Table 26) stems primarily from the strong relationship between Autonomy Climate Strength and Nature of Work Satisfaction (Table 29). In addition, the effect sizes of the four dimensions of Transformational Leadership are biggest for the outcomes of satisfaction with Contingent Rewards and Communication (Table 28 and Table 30, respectively), compared to the effect sizes of the four dimensions of Transformational Leadership when the outcomes are satisfaction with Supervision and Nature of Work (Table 27 and Table 29 , respectively).

The following subsection presents the OLS model results of regressing the variables representing the two dimensions of Transactional Leadership (Contingent Rewards and Management by Exception) on the five Satisfaction outcomes measured in this study.

\section{Transactional Leadership OLS Regression Results}

This subsection displays the results of the regressions in which Transactional Leadership dimensions (Contingent Rewards and Management by Exception) were 
regressed on five different Satisfaction outcomes (Overall, Supervision, Contingent Rewards, Nature of Work, and Communication). Five separate tables, separated by the five different outcome variables, are used to the present the data. Within each of these tables, two blocks of regression results are presented (one for both of the dimensions of Transactional Leadership). In addition, the results of four different regression models are presented: Model 1 contains the Constant, one dimension of Transactional Leadership as the explanatory variable, and the control variable of Years of Service; Models 2, 3, and 4 include those variables, along with mediating variables of climate strength (Autonomy, Innovation and Flexibility, and Effort), respectively.

Table 31

Transactional Leadership and Overall Satisfaction OLS Regression Results

\begin{tabular}{|c|c|c|c|c|c|c|c|c|c|c|c|c|}
\hline \multirow[b]{2}{*}{ Variable } & \multicolumn{3}{|c|}{ Model 1} & \multicolumn{3}{|c|}{ Model 2} & \multicolumn{3}{|c|}{ Model 3} & \multicolumn{3}{|c|}{ Model 4} \\
\hline & $B$ & $\begin{array}{c}S E \\
B\end{array}$ & Sig & $B$ & $S E B$ & Sig & $B$ & $\begin{array}{c}S E \\
B\end{array}$ & Sig & $B$ & $\begin{array}{c}S E \\
B\end{array}$ & Sig \\
\hline Constant & 50.28 & 2.85 & .00 & 63.98 & 9.42 & .00 & 54.15 & 5.70 & .00 & 52.66 & 5.07 & .00 \\
\hline Cont.Rew. & 1.60 & .40 & .00 & 1.61 & .39 & .00 & 1.61 & .40 & .00 & 1.61 & .40 & .00 \\
\hline YOS & -.03 & .15 & .84 & .00 & .15 & .99 & -.04 & .16 & .79 & -.03 & .15 & .83 \\
\hline Auton. & & & & -4.63 & 3.03 & .13 & & & & & & \\
\hline $\mathrm{I} \& \mathrm{~F}$ & & & & & & & -1.10 & 1.40 & .44 & & & \\
\hline Effort & & & & & & & & & & -.94 & 1.66 & .57 \\
\hline adj.- $\mathrm{R}^{2}$ & & .13 & & & .14 & & & .12 & & & .12 & \\
\hline Constant & 50.87 & 5.78 & .00 & 65.05 & 10.60 & .00 & 54.19 & 7.54 & .00 & 52.07 & 7.48 & .00 \\
\hline MgmtByEx & 1.04 & .70 & .14 & 1.22 & .71 & .09 & 1.10 & .71 & .13 & 1.04 & .71 & .15 \\
\hline
\end{tabular}




\begin{tabular}{|c|c|c|c|c|c|c|c|c|c|c|c|c|}
\hline YOS & -.08 & .17 & .64 & -.05 & .17 & .76 & -.09 & .17 & .59 & -.08 & .17 & .63 \\
\hline Auton. & & & & -5.21 & 3.28 & .12 & & & & & & \\
\hline$I \& F$ & & & & & & & -1.04 & 1.51 & .49 & & & \\
\hline Effort & & & & & & & & & & -.45 & 1.78 & .80 \\
\hline $\operatorname{adj} .-R^{2}$ & & .00 & & & .02 & & & .00 & & & -.01 & \\
\hline
\end{tabular}

Note. $\mathrm{N}=100$

Table 31 shows the regression results of the relationships between the dimensions of Transactional Leadership and Overall Satisfaction (the range of Overall Satisfaction scores is $0-80$ ). The coefficient estimate of the Constant in the first block of the Model 1 estimates in Table 31 indicates that if the value of the explanatory variables included in the model are all zero, the expected Overall Satisfaction score is about 51 points. The only variable significantly related to Overall Satisfaction is the Contingent Rewards dimension. The results indicate that for every one-point increase in Contingent Rewards score, there is an associated 1.60-point increase (equivalent to about a $2 \%$ increase) in Overall Satisfaction, ceteris paribus. None of the climate strength variables measured in this study returned statistically significant coefficient estimates, indicating that none of these variables are related to employee satisfaction overall, and that these variables do not mediate the relationships between Transactional Leadership dimensions and Overall Satisfaction.

Table 32

Transactional Leadership Behaviors and Supervision Satisfaction OLS Regression Results

\begin{tabular}{|c|c|c|c|c|c|c|c|c|c|c|c|c|}
\hline \multirow[b]{2}{*}{ Variable } & \multicolumn{3}{|c|}{ Model 1} & \multicolumn{3}{|c|}{ Model 2} & \multicolumn{3}{|c|}{ Model 3} & \multicolumn{3}{|c|}{ Model 4} \\
\hline & $B$ & $S E B$ & Sig & $B$ & $S E B$ & Sig & $B$ & $S E$ & Sig & $B$ & $S E B$ & Sig \\
\hline
\end{tabular}




\begin{tabular}{|c|c|c|c|c|c|c|c|c|c|c|c|c|}
\hline & & & & & & & \multicolumn{3}{|c|}{$B$} & & & \\
\hline Constant & 15.49 & .85 & .00 & 19.37 & 2.81 & .00 & 15.30 & 1.51 & .00 & 15.16 & 1.51 & .00 \\
\hline Cont.Rew. & .21 & .12 & .09 & .21 & .12 & .08 & .20 & .12 & .09 & .20 & .12 & .09 \\
\hline YOS & .00 & .05 & .96 & .01 & .05 & .82 & .00 & .05 & .96 & .00 & .05 & .96 \\
\hline Auton. & & & & -1.31 & .91 & .15 & & & & & & \\
\hline $\mathrm{I} \& \mathrm{~F}$ & & & & & & & .05 & .42 & .90 & & & \\
\hline Effort & & & & & & & & & & .13 & .50 & .79 \\
\hline adj.- $R^{2}$ & & .01 & & & .02 & & & .00 & & & .00 & \\
\hline Constant & 17.41 & 1.63 & .00 & 20.75 & 3.01 & .00 & 17.02 & 2.14 & .00 & 16.92 & 2.12 & .00 \\
\hline MgmtByEx & -.11 & .20 & .60 & -.06 & .20 & .75 & -.11 & .20 & .58 & -.10 & .20 & .60 \\
\hline YOS & .00 & .05 & .93 & .01 & .05 & .82 & .01 & .05 & .90 & .01 & .05 & .92 \\
\hline Auton. & & & & -1.23 & .93 & .19 & & & & & & \\
\hline $\mathrm{I} \& \mathrm{~F}$ & & & & & & & .12 & .43 & .78 & & & \\
\hline Effort & & & & & & & & & & .18 & .50 & .72 \\
\hline adj. $-R^{2}$ & & -.02 & & & -.01 & & & -.03 & & & -.03 & \\
\hline
\end{tabular}

Note. $\mathrm{N}=100$

Table 32 shows the relationship between Transactional Leadership dimensions and Supervision Satisfaction. Outside of the Constant in each of the models and blocks of regressions, none of the variables are statistically significant. The lack of statistically significant coefficient results in this table is comparable to the lack of statistically significant findings of the relationship between Transformational Leadership and Supervision Satisfaction (as seen in Table 27).

Table 33 
Transactional Leadership and Contingent Rewards Satisfaction OLS Regression Results

\begin{tabular}{|c|c|c|c|c|c|c|c|c|c|c|c|c|}
\hline \multirow[b]{2}{*}{ Variable } & \multicolumn{3}{|c|}{ Model 1} & \multicolumn{3}{|c|}{ Model 2} & \multicolumn{3}{|c|}{ Model 3} & \multicolumn{3}{|c|}{ Model 4} \\
\hline & $B$ & $S E B$ & Sig & $B$ & $S E B$ & Sig & $B$ & $S E B$ & Sig & $B$ & $S E B$ & Sig \\
\hline Constant & 9.18 & .99 & .00 & 11.43 & 3.30 & .00 & 13.95 & 1.91 & .00 & 12.42 & 1.72 & .00 \\
\hline Cont.Rew. & .64 & .14 & .00 & .64 & .14 & .00 & .66 & .13 & .00 & .66 & .14 & .00 \\
\hline YOS & -.04 & .05 & .45 & -.04 & .05 & .51 & -.06 & .05 & .29 & -.05 & .05 & .39 \\
\hline Auton. & & & & -.76 & 1.06 & .48 & & & & & & \\
\hline $\mathrm{I} \& \mathrm{~F}$ & & & & & & & -1.36 & .47 & .01 & & & \\
\hline Effort & & & & & & & & & & -1.28 & .56 & .03 \\
\hline adj.- $R^{2}$ & & .17 & & & .17 & & & .23 & & & .20 & \\
\hline Constant & 9.19 & 2.04 & .00 & 11.88 & 3.78 & .00 & 13.50 & 2.58 & .00 & 12.08 & 2.60 & .00 \\
\hline MgmtByEx & .45 & .25 & .08 & .49 & .25 & .06 & .52 & .24 & .04 & .44 & .25 & .08 \\
\hline YOS & -.06 & .06 & .30 & -.06 & .06 & .35 & -.08 & .06 & .18 & -.07 & .06 & .27 \\
\hline Auton. & & & & -.99 & 1.17 & .40 & & & & & & \\
\hline $\mathrm{I} \& \mathrm{~F}$ & & & & & & & -1.34 & .52 & .01 & & & \\
\hline Effort & & & & & & & & & & -1.08 & .62 & .08 \\
\hline adj. $-R^{2}$ & & .02 & & & .02 & & & .07 & & & .04 & \\
\hline
\end{tabular}

Note. $\mathrm{N}=100$

Table 33 shows the regression results of the relationship between Transactional Leadership dimensions and Contingent Rewards Satisfaction. The construct of Contingent Rewards is significantly, positively related to Contingent Rewards Satisfaction. In addition, the Management by Exception construct is significantly, positively related to Contingent Rewards Satisfaction when Innovation and Flexibility Climate Strength is included in the model (Model 3). In this model, the coefficient results 
show that for every one-point increase in Management by Exception ratings given by employees about the AVP, there is an associated .52-point increase (equivalent to about a $2.6 \%$ increase) in satisfaction with Contingent Rewards, all else held constant.

The Innovation and Flexibility Climate Strength construct is positively and significantly related to Contingent Rewards Satisfaction (because climate strength is measured by standards deviation between scores, a negative coefficient estimate of one of the climate strength variables indicates a positive relationship between climate strength and the satisfaction outcome). For example, the coefficient estimate of -1.34 for the Innovation and Flexibility Climate Strength variable in the second block of regression results (where Management by Exception is the independent variable of interest) indicates that for every one-point decrease in Innovation and Flexibility Climate Strength, there is an associated 1.34-point increase (equivalent to about a $6.7 \%$ increase) in satisfaction with Contingent Rewards, ceteris paribus.

Another notable observation is that the relationship between Innovation and Flexibility Climate Strength and Contingent Rewards Satisfaction shown in Table 33 is similar to the relationship between these two variables shown from the Transformational Leadership regression results shown in the previous subsection (Table 28). This indicates that the relationship between this particular climate strength variable and Contingent Rewards Satisfaction is unrelated to the type of leadership behavior being employed in the OLS regression models.

Table 34

Transactional Leadership and Nature of Work Satisfaction OLS Regression Results

\begin{tabular}{l|l|l|l|l}
\hline & $\underline{\text { Model 1 }}$ & $\underline{\text { Model 2 }}$ & $\underline{\text { Model 3 }}$ & Model 4
\end{tabular}




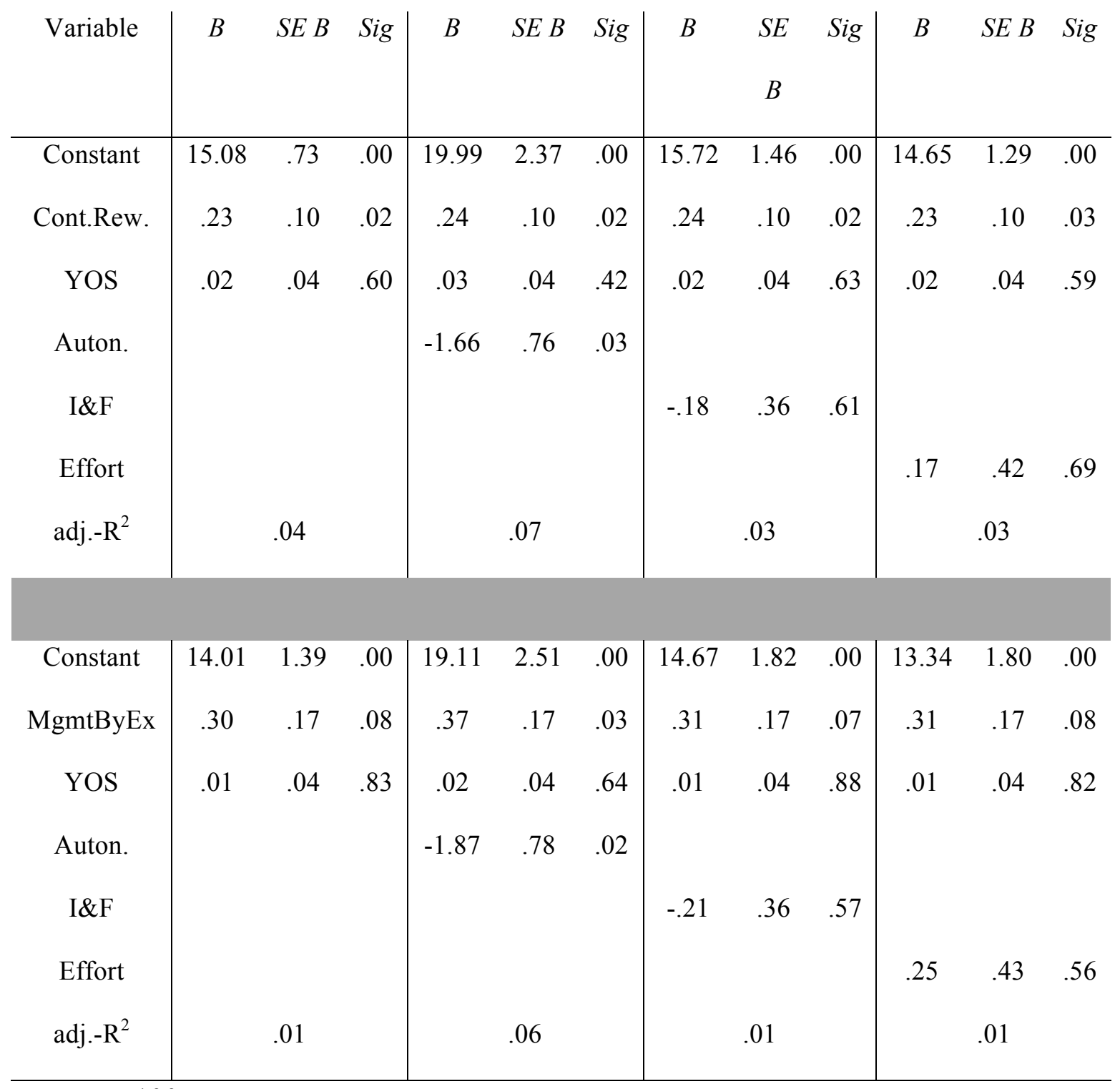

Note. $\mathrm{N}=100$

Table 34 shows the regression results of the relationship between Transactional Leadership dimensions and Nature of Work Satisfaction. Contingent Rewards is significantly and positively related to Nature of Work Satisfaction (coefficient estimate of .23), as is Autonomy Climate Strength (though it does not mediate the relationship between Contingent Rewards and Nature of Work Satisfaction). The Management by Exception construct is also significantly and positively related to Nature of Work Satisfaction, as seen in the second block of regression results. For every one-unit increase 
in Management by Exception score, there is an associated .30-point increase (equivalent to a $1.5 \%$ increase) in Nature of Work Satisfaction, ceteris paribus. The coefficient of Autonomy Climate Strength in Model 2 of the second block of regression indicates that for every one-point decrease in Autonomy Climate Strength score, there is an associated 1.87-point increase (or about a 9.4\% increase) in Nature of Work Satisfaction, all else held equal. No other climate strength variables were statistically significant in these regressions.

The relationship between Autonomy Climate Strength and Nature of Work Satisfaction is comparable to the relationship between these two variables in the set of regressions for Transformational Leadership and Nature of Work Satisfaction (Table 29). This indicates that the relationship between this particular climate strength variable and Nature of Work Satisfaction is unrelated to the type of leadership behavior being employed in the OLS regression models.

Table 35

Transactional Leadership and Communication Satisfaction OLS Regression Results

\begin{tabular}{|c|c|c|c|c|c|c|c|c|c|c|c|c|}
\hline \multirow[b]{2}{*}{ Variable } & \multicolumn{3}{|c|}{ Model 1} & \multicolumn{3}{|c|}{ Model 2} & \multicolumn{3}{|c|}{ Model 3} & \multicolumn{3}{|c|}{ Model 4} \\
\hline & $B$ & $S E B$ & Sig & $B$ & $S E B$ & Sig & $B$ & $S E B$ & Sig & B & $S E B$ & Sig \\
\hline Constant & 10.53 & .99 & .00 & 13.19 & 3.30 & .00 & 9.18 & 1.98 & .00 & 10.43 & 1.76 & .00 \\
\hline Cont.Rew. & .52 & .14 & .00 & .52 & .14 & .00 & .52 & .14 & .00 & .52 & .14 & .00 \\
\hline YOS & -.01 & .05 & .81 & -.01 & .05 & .90 & -.01 & .05 & .87 & -.01 & .05 & .81 \\
\hline Auton. & & & & -.90 & 1.06 & .40 & & & & & & \\
\hline $\mathrm{I} \& \mathrm{~F}$ & & & & & & & .38 & .49 & .44 & & & \\
\hline Effort & & & & & & & & & & .04 & .58 & .95 \\
\hline
\end{tabular}




\begin{tabular}{|c|c|c|c|c|c|c|c|c|c|c|c|c|}
\hline adj. $-R^{2}$ & \multicolumn{3}{|c|}{.11} & \multicolumn{3}{|c|}{.11} & \multicolumn{3}{|c|}{.11} & \multicolumn{3}{|c|}{.10} \\
\hline Constant & 10.27 & 1.98 & .00 & 13.32 & 3.67 & .00 & 9.00 & 2.59 & .00 & 9.73 & 2.57 & .00 \\
\hline MgmtByEx & .40 & .24 & .10 & .44 & .24 & .08 & .38 & .24 & .12 & .40 & .24 & .10 \\
\hline YOS & -.03 & .06 & .59 & -.02 & .06 & .67 & -.03 & .06 & .66 & -.03 & .06 & .60 \\
\hline Auton. & & & & -1.12 & 1.13 & .33 & & & & & & \\
\hline $\mathrm{I} \& \mathrm{~F}$ & & & & & & & .40 & .52 & .45 & & & \\
\hline Effort & & & & & & & & & & .20 & .61 & .74 \\
\hline adj. $-\mathrm{R}^{2}$ & & .01 & & & .01 & & & .00 & & & .00 & \\
\hline
\end{tabular}

Note. $\mathrm{N}=100$

Table 35 shows the regression results of the relationships between dimensions of Transactional Leadership and Communication Satisfaction. As seen in Model 1, the Contingent Rewards dimension is significantly and positively related with Communication Satisfaction. For every one-point increase in Contingent Rewards, there is an associated .52-point increase (equivalent to about a $2.6 \%$ increase) in Communication Satisfaction, all else held equal. The Management by Exception construct is not significantly related to Communication Satisfaction. In addition, none of the three climate strength variables measured in this study were found to be significantly related to satisfaction with Communication.

In comparing the previous five tables together, the effect sizes for the Contingent Rewards construct are biggest in the regressions where the outcomes were satisfaction with Contingent Rewards and Communication (Table 33 and Table 35, respectively), compared to the effect sizes of Contingent Rewards when the outcomes are satisfaction with Supervision and Nature of Work (Table 32 and Table 34, respectively). These 
differences follow the same pattern as the effect size differences for the four dimensions of Transformational Leadership and the separate outcome dimensions measured in this study.

The following subsection presents the OLS model results of regressing the Laissez-Faire Leadership variable on the five Satisfaction outcomes measured in this study.

\section{Laissez-Faire Leadership OLS Regression Results}

This subsection displays the results of the regressions in which Laissez-Faire Leadership was regressed on five different Satisfaction outcomes (Overall, Supervision, Contingent Rewards, Nature of Work, and Communication). Five separate tables, separated by the five different outcome variables, are used to the present the data. Within each of these tables, the results of four different regression models are presented: Model 1 contains the Constant, Laissez-Faire Leadership as the explanatory variable, and the control variable of Years of Service; Models 2, 3, and 4 include those variables, along with mediating variables of climate strength (Autonomy, Innovation and Flexibility, and Effort), respectively. It is important to remember that climate strength scores are measured using the standard deviation between scores of employees within different departments; therefore, a lower climate strength score represents a stronger climate. As a result, negative coefficient estimates for climate strength scores imply a positive relationship between the climate strength in the model and the outcome variable of each table.

Table 36

Laissez-Faire Leadership Behaviors and Overall Satisfaction OLS Regression Results 


\begin{tabular}{|c|c|c|c|c|c|c|c|c|c|c|c|c|}
\hline \multirow[b]{2}{*}{ Variable } & \multicolumn{3}{|c|}{ Model 1} & \multicolumn{3}{|c|}{ Model 2} & \multicolumn{3}{|c|}{ Model 3} & \multicolumn{3}{|c|}{ Model 4} \\
\hline & $B$ & $S E B$ & Sig & $B$ & $S E B$ & Sig & $B$ & $S E B$ & Sig & $B$ & $S E B$ & Sig \\
\hline Constant & 66.87 & 3.34 & .00 & 77.54 & 9.81 & .00 & 66.58 & 5.86 & .00 & 65.75 & 5.26 & .00 \\
\hline L-F Lead & -1.65 & .56 & .00 & -1.60 & .56 & .01 & -1.66 & .58 & .01 & -1.68 & .58 & .00 \\
\hline YOS & -.09 & .16 & .56 & -.07 & .16 & .68 & -.09 & .16 & .57 & -.09 & .16 & .57 \\
\hline Auton. & & & & -3.66 & 3.17 & .25 & & & & & & \\
\hline$I \& F$ & & & & & & & .09 & 1.49 & .95 & & & \\
\hline Effort & & & & & & & & & & .48 & 1.75 & .78 \\
\hline adj.- $R^{2}$ & & .06 & & & .07 & & & .05 & & & .05 & \\
\hline
\end{tabular}

Note. $\mathrm{N}=100$

Table 36 shows the regression results of the relationship between Laissez-Faire Leadership and Overall Satisfaction (the range of Overall Satisfaction scores is 0-80). The coefficient estimate of the Constant in Model 1 shows that the expected score of Overall Satisfaction would be 66.87 if the values of all the independent variables in the regression were zero. Laissez-Faire Leadership is statistically significant and is negatively related to Overall Satisfaction. As seen in the results from Model 1, for every one-point increase in the Laissez-Faire Leadership score of the AVP, there is an associated 1.65-point decrease (or about a 2.1\% decrease) in Overall Satisfaction, all else held constant. None of the three climate strength variables measured in this study were found to be significantly related to Overall Satisfaction. In addition, the control variable of Years of Service was also found to have no significant relationship with Overall Satisfaction.

Table 37

Laissez-Faire Leadership \& Supervision Satisfaction OLS Regression Results 


\begin{tabular}{|c|c|c|c|c|c|c|c|c|c|c|c|c|}
\hline \multirow[b]{2}{*}{ Variable } & \multicolumn{3}{|c|}{ Model 1} & \multicolumn{3}{|c|}{ Model 2} & \multicolumn{3}{|c|}{ Model 3} & \multicolumn{3}{|c|}{ Model 4} \\
\hline & $B$ & $S E$ & Sig & $B$ & $S E B$ & Sig & $B$ & $S E B$ & Sig & $B$ & $S E B$ & Sig \\
\hline Constant & 18.95 & .93 & .00 & 22.07 & 2.73 & .00 & 17.77 & 1.63 & .00 & 17.82 & 1.46 & .00 \\
\hline L-F Lead & -.49 & .16 & 00 & -.47 & .16 & .00 & -.52 & .16 & .00 & -.52 & .16 & .00 \\
\hline YOS & -.01 & .05 & .75 & -.01 & .05 & .88 & -.01 & .05 & .80 & -.01 & .05 & .76 \\
\hline Auton. & & & & -1.07 & .88 & .23 & & & & & & \\
\hline$I \& F$ & & & & & & & .36 & .41 & .38 & & & \\
\hline Effort & & & & & & & & & & .49 & .49 & .32 \\
\hline adj.- $\mathrm{R}^{2}$ & & .07 & & & .08 & & & .07 & & & .07 & \\
\hline
\end{tabular}

Note. $\mathrm{N}=100$

Table 37 shows the regression results of the relationship between Laissez-Faire Leadership and Supervision Satisfaction (the range of Supervision Satisfaction scores is 0-20). For every one-point increase in Laissez-Faire Leadership, there is an associated .49-point decrease in Supervision Satisfaction, ceteris paribus. This .49-point decrease is equivalent to about a $2.5 \%$ decrease in Supervision Satisfaction. Compared to the Transformational Leadership and Transactional Leadership tables with Supervision Satisfaction as the outcome that were previously presented (Table 27 and Table 32, respectively), Laissez-Faire Leadership is the only dimension to be related to Supervision Satisfaction using OLS regression techniques. As seen in Table 37, no climate strength variables measured in this study are significantly related to Supervision Satisfaction. In addition, the control variable of Years of Service is not significantly related to Supervision Satisfaction.

Table 38 
Laissez-Faire Leadership and Contingent Rewards Satisfaction OLS Regression Results

\begin{tabular}{|c|c|c|c|c|c|c|c|c|c|c|c|c|}
\hline \multirow[b]{2}{*}{ Variable } & \multicolumn{3}{|c|}{ Model 1} & \multicolumn{3}{|c|}{ Model 2} & \multicolumn{3}{|c|}{ Model 3} & \multicolumn{3}{|c|}{ Model 4} \\
\hline & $B$ & $S E B$ & Sig & $B$ & $S E B$ & Sig & $B$ & $S E B$ & Sig & $B$ & $S E B$ & Sig \\
\hline Constant & 15.39 & 1.19 & .00 & 16.57 & 3.51 & .00 & 18.49 & 2.05 & .00 & 17.23 & 1.86 & .00 \\
\hline L-F Lead & -.57 & .20 & .01 & -.57 & .20 & .01 & -.50 & .20 & .02 & -.52 & .20 & .01 \\
\hline YOS & -.06 & .06 & .27 & -.06 & .06 & .30 & -.07 & .06 & .21 & -.06 & .06 & .26 \\
\hline Auton. & & & & -.41 & 1.13 & .72 & & & & & & \\
\hline $\mathrm{I} \& \mathrm{~F}$ & & & & & & & -.96 & .52 & .07 & & & \\
\hline Effort & & & & & & & & & & -.80 & .62 & .20 \\
\hline adj. $-R^{2}$ & & .06 & & & .06 & & & .09 & & & .07 & \\
\hline
\end{tabular}

Note. $\mathrm{N}=100$

Table 38 shows the regression results of the relationship between Laissez-Faire Leadership and Contingent Rewards Satisfaction (the range of Contingent Rewards Satisfaction scores is 0-20). For every one-point increase in Laissez-Faire Leadership scores of the AVP, there is an associated .57-point decrease (equivalent to about a $2.9 \%$ decrease) in Contingent Rewards Satisfaction, all else held constant. This effect size for Laissez-Faire Leadership is consistent across the four regression models. Similar to the Laissez-Faire Leadership regression results presented with outcomes of Overall Satisfaction and Supervision Satisfaction, none of the three climate strength variables measured in this study returned statistically significant coefficient estimates. In addition, the control variable of Years of Service does not return any statistically significant coefficient estimates when included in models regressing Laissez-Faire Leadership on Contingent Rewards Satisfaction. 
Table 39

Laissez-Faire Leadership Behaviors and Nature of Work Satisfaction OLS Regression Results

\begin{tabular}{|c|c|c|c|c|c|c|c|c|c|c|c|c|}
\hline \multirow[b]{2}{*}{ Variable } & \multicolumn{3}{|c|}{ Model 1} & \multicolumn{3}{|c|}{ Model 2} & \multicolumn{3}{|c|}{ Model 3} & \multicolumn{3}{|c|}{ Model 4} \\
\hline & $B$ & $\begin{array}{c}S E \\
B\end{array}$ & Sig & $B$ & $S E B$ & Sig & $B$ & $S E B$ & Sig & $B$ & $S E B$ & Sig \\
\hline Constant & 17.89 & .82 & .00 & 22.21 & 2.39 & .00 & 17.78 & 1.44 & .00 & 16.87 & 1.29 & .00 \\
\hline L-F Lead & -.32 & .14 & .02 & -.30 & .14 & .03 & -.32 & .14 & .03 & -.35 & .14 & .02 \\
\hline YOS & .01 & .04 & .82 & .02 & .04 & .62 & .01 & .04 & .81 & .01 & .04 & .80 \\
\hline Auton. & & & & -1.49 & .77 & .06 & & & & & & \\
\hline$I \& F$ & & & & & & & .03 & .37 & .93 & & & \\
\hline Effort & & & & & & & & & & .44 & .43 & .31 \\
\hline adj. $-R^{2}$ & & .04 & & & .06 & & & .03 & & & .04 & \\
\hline
\end{tabular}

Note. $\mathrm{N}=100$ 
Table 39 shows the regression results of the relationship between Laissez-Faire Leadership and Nature of Work Satisfaction (the range of Nature of Work Satisfaction scores is 0-20). For every one-point increase in Laissez-Faire Leadership scores of the AVP, there is an associated .32-point decrease (equivalent to about a $1.6 \%$ decrease) in Nature of Work Satisfaction, all else held constant. This effect size for Laissez-Faire Leadership is relatively consistent across the four regression models. Similar to the Laissez-Faire Leadership regression results presented with outcomes of Overall Satisfaction, Supervision Satisfaction, and Contingent Rewards Satisfaction, none of the three climate strength variables measured in this study returned statistically significant coefficient estimates. In addition, the control variable of Years of Service does not return any statistically significant coefficient estimates when included in models regressing Laissez-Faire Leadership on Nature of Work Satisfaction.

Table 40

Laissez-Faire Leadership Behaviors and Communication Satisfaction OLS Regression Results

\begin{tabular}{|c|c|c|c|c|c|c|c|c|c|c|c|c|}
\hline \multirow[b]{2}{*}{ Variable } & \multicolumn{3}{|c|}{ Model 1} & \multicolumn{3}{|c|}{ Model 2} & \multicolumn{3}{|c|}{ Model 3} & \multicolumn{3}{|c|}{ Model 4} \\
\hline & $B$ & $S E B$ & Sig & $B$ & $S E B$ & Sig & $B$ & $S E B$ & Sig & $B$ & $S E B$ & Sig \\
\hline Constant & 14.67 & 1.19 & .00 & 16.69 & 3.51 & .00 & 12.54 & 2.07 & .00 & 13.83 & 1.87 & .00 \\
\hline L-F Lead & -.27 & .20 & .18 & -.26 & .20 & .19 & -.33 & .20 & .11 & -.30 & .21 & .15 \\
\hline YOS & -.03 & .06 & .66 & -.02 & .06 & .73 & -.02 & .06 & .73 & -.02 & .06 & .67 \\
\hline Auton. & & & & -.70 & 1.13 & .54 & & & & & & \\
\hline $\mathrm{I} \& \mathrm{~F}$ & & & & & & & .66 & .53 & .22 & & & \\
\hline Effort & & & & & & & & & & .36 & .62 & .57 \\
\hline adj. $-\mathrm{R}^{2}$ & & .00 & & & -.01 & & & .01 & & & -.01 & \\
\hline
\end{tabular}


Note. $\mathrm{N}=100$

Table 40 shows the regression results of the relationship between Laissez-Faire Leadership and Communication Satisfaction (the range of Communication Satisfaction scores is $0-20$ ). Outside of the Constant in each of the models and blocks of regressions, none of the variables are statistically significant.

In comparing the previous five tables together, the effect sizes for the LaissezFaire Leadership construct was biggest in the regressions where the outcome was satisfaction with Contingent Rewards (Table 38), compared to the effect sizes of LaissezFaire Leadership when the outcomes are satisfaction with Supervision, Nature of Work, and Communication (Table 37, Table 39, and Table 40, respectively). These differences follow the same pattern as the effect size differences for the four dimensions of Transformational Leadership and the separate outcome dimensions measured in this study, as well as the effect size differences for the two dimensions of Transactional Leadership and the separate outcome dimensions measured in this study.

This section of this chapter has displayed the regression results and interpretations when OLS regression techniques were utilized to analyze the data gathered from this study. The fifteen tables presented in this section have highlighted the significant relationships between different leadership behaviors and employee satisfaction with different aspects of their jobs. In addition, this section has also highlighted the significant relationships between climate strength levels employee satisfaction with the different satisfaction measures included in this study.

Chapter 1 and Chapter 2 of this dissertation argued that OLS techniques to investigate the inter-relationships between leadership styles of supervisors, organizational 
climate strength, and employee job satisfaction fall short of delivering complete and accurate answers. Instead, these chapters emphasized the need for multi-level modeling techniques to be employed when investigating these inter-relationships. The following section of this chapter displays the results of the HLM regressions of job satisfaction on supervisor leadership style. The following section will conclude this chapter and offer a contrast to the findings of the OLS regressions presented in this section.

\section{Multi-Level Modeling (HLM) Regression Results}

This section of the paper presents the HLM regression model results. As explained in detail in Chapter 3, five different outcomes were utilized in separate regression models: Overall Satisfaction, Supervision Satisfaction, Contingent Rewards Satisfaction, Nature of Work Satisfaction, and Communication Satisfaction. Four distinct regression models were run within regressions containing the five outcome variables. Model 1 included the Years of Service variable as a control variable along with each of the four dimensions of Transformational Leadership, the two dimensions of Transactional Leadership, and Laissez-Faire Leadership (these independent variables were entered separately in each regression). Models 2, 3, and 4 include the same variables of Model 1; in additional, the mediating variables of Autonomy Climate Strength, Innovation and Flexibility Climate Strength, and Effort Strength, are included in the three models, respectively. Regression results from these models, taken together with the regression results from Model 1, will yield insights about whether the aforementioned variables in Models 2, 3, and 4 do not at all mediate, partially mediate, or fully mediate the effects of independent variables of interest on the outcome variable. 
As explained in Chapter 2, the HLM methodology is utilized for within-andbetween group analyses. Anonymity of the seven different groups included in this study is of utmost importance to stakeholders at the research site; therefore, between-group comparisons of anonymous groups will not yield actionable or insightful data. The between-group HLM regression results are presented in Appendix K for all the independent variables measured for Transformational Leadership (Tables K1 - K5), Appendix L for all the independent variables measured for Transactional Leadership (Tables L1 - L5), and in Appendix M for Laissez-Faire Leadership (Tables M1 - M5).

The following subsection presents the within-group HLM model results of regressing the variables representing the four dimensions of Transformational Leadership (Idealized Influence, Inspirational Motivation, Intellectual Stimulation, and Individualized Consideration) on the Overall Satisfaction outcome measured in this study.

\section{Transformational Leadership HLM Regression Results}

This subsection displays the results of the regressions in which Transformational Leadership dimensions (Idealized Influence, Inspirational Motivation, Intellectual Stimulation, and Individualized Consideration) were regressed on Overall Satisfaction using multi-level modeling techniques. Within the table displaying the results, four blocks of regression results are presented (one for each of the four dimensions of Transformational Leadership). In addition, the results of four different regression models are presented: Model 1 contains the Constant, one dimension of Transformational Leadership as the explanatory variable, and the control variable of Years of Service; 
Models 2, 3, and 4 include those variables, along with mediating variables of climate strength (Autonomy, Innovation and Flexibility, and Effort), respectively.

Table 41

Transformational Leadership and Overall Satisfaction HLM Fixed Effects Estimation

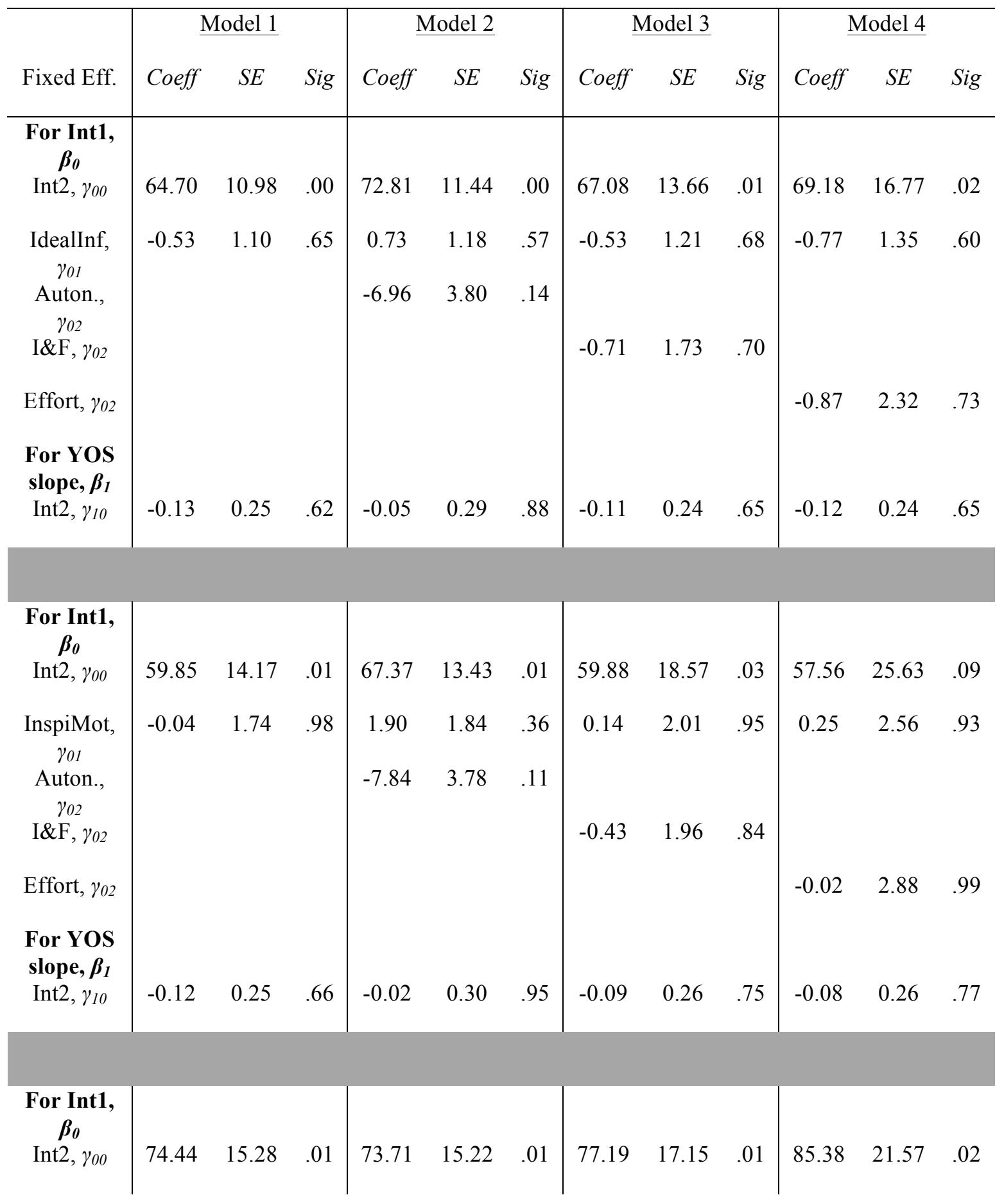




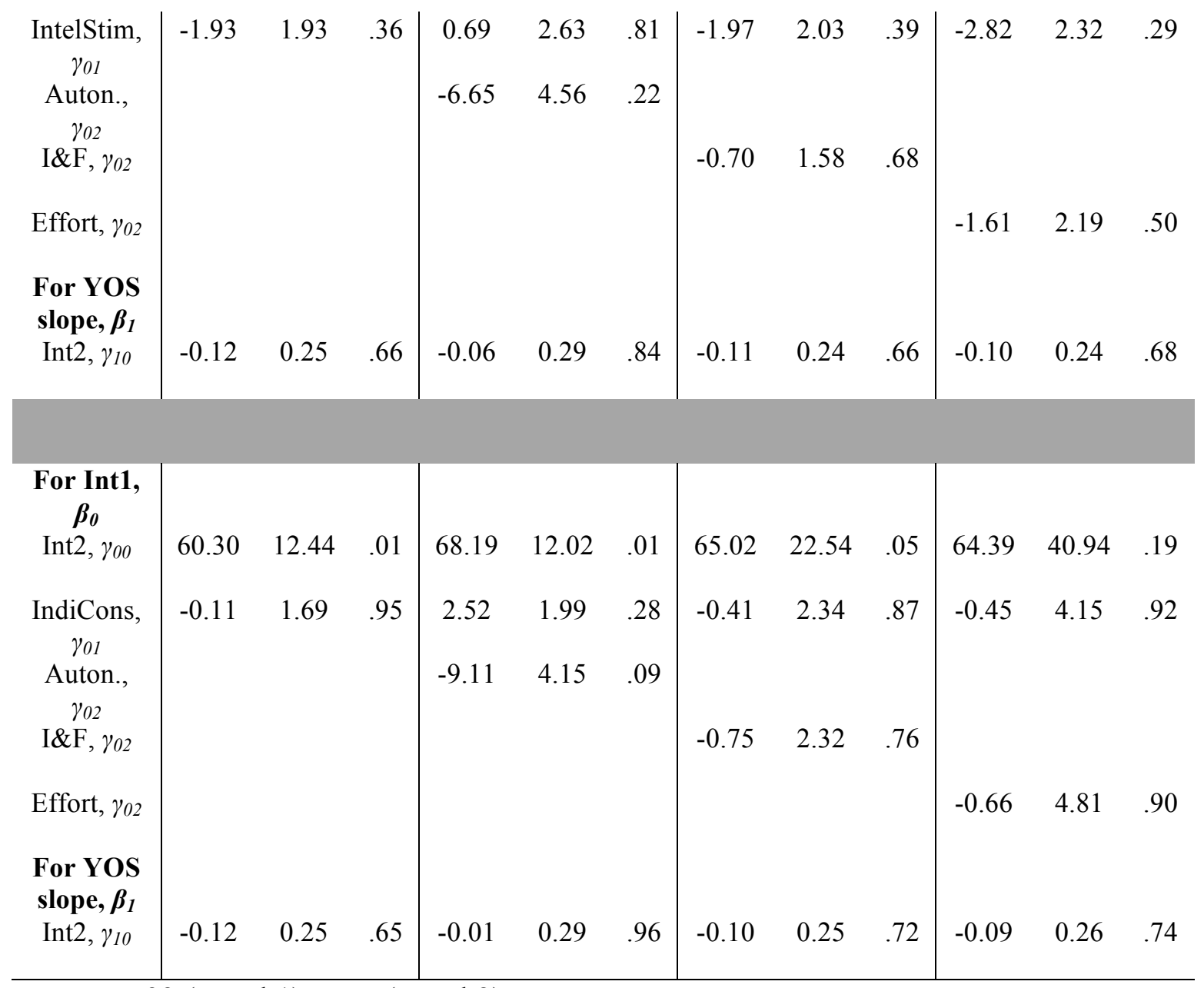

Note. $\mathrm{N}=93$ (Level 1); $\mathrm{N}=7$ (Level 2)

Table 41 displays the HLM regression results that explain the relationship between each of the four dimensions of Transformational Leadership and Overall Satisfaction (the range for Overall Satisfaction scores is $0-80$ ). While the coefficient estimates of the Constants are statistically significant, the independent variables of interest (the four dimensions of Transformational Leadership and three climate strength variables) are not significantly related to Overall Satisfaction. When other satisfaction measures (Supervision, Contingent Rewards, Nature of Work, and Communication) were used as the outcome variables in the regression models, no independent variables were 
found to be statistically significant; tables displaying the coefficient estimates of these regressions are presented in Tables N1 - N5 in Appendix N.

The following subsection presents the HLM model results of regressing the variables representing the two dimensions of Transactional Leadership (Contingent Rewards and Management by Exception) on the Overall Satisfaction variable measured in this study.

\section{Transactional Leadership HLM Regression Results}

Table 42 displays the HLM regression results that explain the relationship between each of the two dimensions of Transactional Leadership and Overall Satisfaction (the range for Overall Satisfaction scores is 0-80). While the coefficient estimates of the Constants are statistically significant, the independent variables of interest (the two dimensions of Transactional Leadership and three climate strength variables) are not significantly related to Overall Satisfaction.

Table 42

Transactional Leadership and Overall Satisfaction HLM Fixed Effects Estimation

\begin{tabular}{|c|c|c|c|c|c|c|c|c|c|c|c|c|}
\hline \multirow[b]{2}{*}{ Fixed Eff. } & \multicolumn{3}{|c|}{ Model 1} & \multicolumn{3}{|c|}{ Model 2} & \multicolumn{3}{|c|}{ Model 3} & \multicolumn{3}{|c|}{ Model 4} \\
\hline & Coeff & $S E$ & Sig & Coeff & $S E$ & Sig & Coeff & $S E$ & Sig & Coeff & $S E$ & Sig \\
\hline $\begin{array}{c}\text { For Int1, } \\
\boldsymbol{\beta}_{\mathbf{0}} \\
\text { Int } 2, \gamma_{00}\end{array}$ & 77.79 & 9.24 & .00 & 86.43 & 11.95 & .00 & 77.40 & 9.71 & .00 & 77.24 & 9.61 & .00 \\
\hline ContRew, & -3.74 & 1.75 & .09 & -3.01 & 1.79 & .17 & -4.62 & 1.93 & .07 & -4.03 & 1.82 & .09 \\
\hline Auton., & & & & -4.09 & 3.25 & .28 & & & & & & \\
\hline $\begin{array}{c}\gamma_{02} \\
\mathrm{I} \& \mathrm{~F}, \gamma_{02}\end{array}$ & & & & & & & 1.34 & 1.68 & .47 & & & \\
\hline Effort, $\gamma_{02}$ & & & & & & & & & & 0.78 & 1.82 & .69 \\
\hline $\begin{array}{c}\text { For YOS } \\
\text { slope, } \beta_{1}\end{array}$ & & & & & & & & & & & & \\
\hline
\end{tabular}




\begin{tabular}{|c|c|c|c|c|c|c|c|c|c|c|c|c|}
\hline $\operatorname{Int} 2, \gamma_{10}$ & -0.02 & 0.27 & .96 & -0.02 & .28 & .96 & 0.02 & 0.28 & .95 & -0.01 & 0.28 & .98 \\
\hline For Int1, & & & & & & & & & & & & \\
\hline Int $2, \gamma_{00}$ & 81.76 & 20.66 & .01 & 75.70 & 19.43 & .02 & 82.68 & 21.57 & .02 & 84.31 & 22.54 & .02 \\
\hline MgtbEx, & -2.80 & 2.59 & .33 & 0.11 & 3.00 & .97 & -2.88 & 2.88 & .37 & -3.00 & 2.72 & .33 \\
\hline Auton., & & & & -5.83 & 4.12 & .23 & & & & & & \\
\hline $\begin{array}{c}\gamma_{02} \\
\mathrm{I} \& \mathrm{~F}, \gamma_{02}\end{array}$ & & & & & & & -.08 & 1.73 & .97 & & & \\
\hline Effort, $\gamma_{02}$ & & & & & & & & & & -0.39 & 2.00 & .86 \\
\hline $\begin{array}{c}\text { For YOS } \\
\text { slope, } \boldsymbol{\beta}_{1} \\
\text { Int } 2, \gamma_{10}\end{array}$ & -0.11 & 0.25 & .67 & -0.06 & 0.28 & .83 & -0.11 & 0.25 & .67 & -0.11 & 0.24 & .68 \\
\hline
\end{tabular}

Note. $\mathrm{N}=93$ (Level 1); $\mathrm{N}=7$ (Level 2)

When other satisfaction measures (Supervision, Contingent Rewards, Nature of Work, and Communication) were used as the outcome variables in the regression models, no independent variables were found to be statistically significant; tables displaying the coefficient estimates of these regressions are presented in Tables O1-O5 in Appendix O. This same lack of significant relationship is reflected in the previous subsection presenting the HLM regression results of the relationship between Transformational Leadership and Satisfaction outcomes. Thus far, utilizing HLM techniques has shown a lack of relationship between the measured leadership behaviors in the study and the satisfaction outcomes measured in this study; this is in stark contrast to the results of the data analysis conducted with OLS regression techniques and presented in the previous section of this chapter. The following subsection presents the HLM model results of regressing Laissez-Faire Leadership on the Overall Satisfaction variable measured in this study.

\section{Laissez-Faire Leadership HLM Regression Results}


Table 43 displays the HLM regression results that explain the relationship between Laissez-Faire Leadership and Overall Satisfaction (the range for Overall Satisfaction scores is 0-80). While the coefficient estimates of the Constants are statistically significant, the independent variables of interest (Laissez-Faire Leadership and three climate strength variables) are not significantly related to Overall Satisfaction.

Table 43

Laissez-Faire Leadership and Overall Satisfaction HLM Fixed Effects Estimation

\begin{tabular}{|c|c|c|c|c|c|c|c|c|c|c|c|c|}
\hline \multirow[b]{2}{*}{ Fixed Eff. } & \multicolumn{3}{|c|}{ Model 1} & \multicolumn{3}{|c|}{ Model 2} & \multicolumn{3}{|c|}{ Model 3} & \multicolumn{3}{|c|}{ Model 4} \\
\hline & Coeff & $S E$ & Sig & Coeff & $S E$ & Sig & Coeff & $S E$ & Sig & Coeff & $S E$ & Sig \\
\hline $\begin{array}{c}\text { For Int1, } \\
\boldsymbol{\beta}_{\boldsymbol{0}} \\
\text { Int } 2, \gamma_{00}\end{array}$ & 64.84 & 7.59 & .00 & 79.39 & 11.51 & .00 & 64.17 & 8.51 & .00 & 64.31 & 7.92 & .00 \\
\hline LFLead, & -1.20 & 1.55 & .48 & -0.85 & 1.54 & .61 & -1.21 & 2.00 & .58 & -1.48 & 1.85 & .47 \\
\hline $\begin{array}{c}\text { Auton., } \\
\gamma_{02} \\
\mathrm{I} \& \mathrm{~F}, \gamma_{02}\end{array}$ & & & & -5.47 & 3.32 & .17 & 0.20 & 1.99 & .92 & & & \\
\hline Effort, $\gamma_{02}$ & & & & & & & & & & 0.72 & 2.17 & .76 \\
\hline $\begin{array}{c}\text { For YOS } \\
\text { slope, } \boldsymbol{\beta}_{1} \\
\text { Int } 2, \gamma_{10}\end{array}$ & -0.10 & 0.25 & .69 & -0.06 & 0.28 & .85 & -0.09 & 0.26 & .74 & -0.10 & 0.26 & .70 \\
\hline
\end{tabular}

Note. $\mathrm{N}=93$ (Level 1); $\mathrm{N}=7$ (Level 2)

When other satisfaction measures (Supervision, Contingent Rewards, Nature of Work, and Communication) were used as the outcome variables in the regression models, no independent variables were found to be statistically significant; tables displaying the coefficient estimates of these regressions are presented in Tables P1 - P5 in Appendix P. Taken together, the three tables presented in this section of the chapter (along with the HLM regression result tables presented in the Appendix) show that, when utilizing HLM regression methods, no significant relationships exist between 
Transformational/Transactional/Laissez-Faire Leadership and the outcomes of Satisfaction measured in this study. These results are far different than the results displayed when analyzing this data using OLS methods (presented in the previous section of this chapter).

The following chapter will express the results displayed in this chapter in meaningful and actionable terms. The significance of the findings highlighted in this chapter will be explained in greater depth, as will potential next steps for future studies looking to investigate the inter-relationships between supervisor leadership style, organizational climate strength, and employee job satisfaction.

\section{CHAPTER FIVE}

\section{DISCUSSION OF FINDINGS AND CONCLUSION}

\section{Introduction}

The research conducted in this dissertation employed organizational climate strength as a mediating variable between supervisor leadership style and employee job satisfaction. Moreover, this study employed multi-level modeling techniques to investigate the interrelationships between supervisor leadership style, organizational climate strength, and employee job satisfaction. The following research questions guided the study:

1) To what degree does a relationship exist between supervisor full-range leadership (in particular, transformational leadership) and employee job satisfaction? 
2) To what degree does organizational climate strength mediate the relationship between supervisor full-range leadership and employee job satisfaction?

3) How do findings regarding the interrelationships between supervisor full-range leadership, organizational climate strength, and employee job satisfaction differ when utilizing multi-level modeling techniques instead of OLS regression techniques?

Overall, certain relationships between supervisor leadership style and employee job satisfaction were found when using OLS techniques. However, no significant relationships were found when employing HLM methods. This indicates that major differences in findings can exist when utilizing OLS techniques rather than multi-level modeling methods. Organizational climate strength was not found to mediate these relationships, irrespective of the regression technique used. These summarized findings will be explained in greater depth in this chapter, along with interpretations for how these findings can be proactively leveraged in practice.

This chapter begins with a review of the findings outlined in the previous chapter. This review of findings will be divided into four subsections: Descriptive Statistics, Gap Analyses, Reverse Regressions, and OLS/HLM Regression Results. The review of findings includes discussion around how these findings fit into the existing literature about supervisor leadership style, organizational climate strength, and employee job satisfaction. This chapter then proceeds to explore the implications for policy/practice based on the findings of this study. This section includes recommendations for specific actions to be taken as a result of the findings of this research. Following the section focusing on implications for policy/practice, a discussion about implications for future 
research is provided. Limitations of this study will be interspersed throughout all of these sections. A summary section to conclude this chapter will highlight the significance of this study.

\section{Review of Findings}

This section provides an overview of the findings discussed in Chapter 4. It is split into four sections based on the analysis method used to derive the findings: Descriptive Statistics, Gap Analyses, Reverse Regressions, and OLS/HLM Regressions. Connections of the findings from this study to the extant literature are interspersed throughout these subsections.

\section{Descriptive Statistics}

As shown in Chapter 4, Supervision and Nature of Work Satisfaction were generally given higher scores and had lower standard deviations than those of Contingent Rewards and Communication Satisfaction. This means that employees at the research site are more satisfied with Supervision and Nature of Work (than with Contingent Rewards and Communication) in their roles, and that there is high agreement amongst employees on their high satisfaction levels with these two constructs. The University can leverage high satisfaction and agreement levels with Supervision and Nature of Work, while spending its time more efficiently to focus on increasing employee satisfaction with Contingent Rewards and Communication. To increase employee satisfaction with Contingent Rewards, The University would benefit from encouraging supervisors to increase appreciation and feedback to employees for a job well done. This is connected to increasing Communication satisfaction of employees, as improving Contingent Rewards satisfaction should be done through increasing communication of positive feedback. 
In terms of climate strength, the findings indicate that the departments that responded to the survey have a stronger Autonomy climate and stronger Effort climate than they do an Innovation \& Flexibility climate. This means that employees at The University have higher agreement levels around the behaviors that are expected and supported within their departments relating to Autonomy and Effort than that of Innovation \& Flexibility. Employees tend to agree more about whether Autonomy and Effort behaviors are expected, supported, and rewarded at The University. The research site would benefit from standardizing, at least within different departments, the degree to which Innovation \& Flexibility is valued in the work of their employees.

When comparing the full-range leadership style ratings of AVPs given by employees, the highest scores were given for Transformational Leadership behaviors. Slightly lower scores were given for Transactional Leadership behaviors, and employees gave very low ratings for Laissez-Faire Leadership behaviors by AVPs at The University. These findings are consistent with full-range leadership leadership research conducted in various industries in that organizations often find that their leaders are practicing Trasnformational Leadership at the highest rates, followed by Transactional Leadership.

The Descriptive Statistics analyses included an investigation of how survey responses differed as years of service at The University changed. Figure 2 in Chapter 4 showed that the lowest levels of satisfaction came from employees who had 1-2 years of service. Employees from that same 1-2 years of service range also gave lower ratings of AVP Transformational Leadership and Transactional Leadership behaviors than employees in other years of service ranges (as shown by Figure 3 and Figure 4). Furthermore, the biggest absolute value of difference between ratings given by 
employees and self-ratings by AVPs of AVPs' Leadership behaviors occurs in the 1-2 years of service range of employees (as seen in Figure 5 and Figure 6). Anecdotally, these findings follow similar trends across industries and contexts about the job experience of employees at different years of service, particularly at 1-2 years.

Taken together, the findings about employees based on years of service indicate that there is an area of opportunity to address regarding employee job satisfaction and perceptions of leadership amongst employees with 1-2 years of service. Trends indicate that satisfaction levels and perceptions of supervisor leadership are at a higher level when employees first begin their careers at The University; in addition, there are higher levels of alignment between employees and supervisors about supervisor leadership. These satisfaction and leadership ratings decrease after employees have spent enough time working within the organization and have conceivably developed a better understanding of their job responsibilities (1-2 years). Furthermore, less alignment between employees and supervisors about supervisor leadership behaviors develops in this time frame. It stands to reason that those who continue with the organization have a higher level of satisfaction, more positive feelings of supervisor leadership, and more alignment with their supervisors about supervisor leadership, since more positive outlooks on these three metrics arise after the second year of employment at The University. These changes occur either because these employees either resolve their areas of dissatisfaction, or those who are dissatisfied leave The University.

Methods to address these areas of opportunity include: 1) taking steps to increase employee job satisfaction for employees with 1-2 years of service; 2) developing positive leadership behaviors in supervisors to address the low leadership ratings given by 
employees with 1-2 years of service; and, 3) encouraging supervisors and employees, specifically those with 1-2 years of service, to take steps become more aligned on perceptions of the leadership style of the supervisor.

However, it is important to note that these years of service findings are not investigated with longitudinal data, meaning that the changes in ratings over time are not for the same individual. Rather, the ratings by years of service are one-time averages of different employees within the same years of service group at time of data collection. These findings would be more powerful and more conclusive if they followed the same employees over different points in time during their careers. However, the findings from this portion of the study are based on aggregate averages of employees within distinct years of service deciles. Therefore, conclusions drawn about ratings changes over years of service should be approached with caution. Despite this limitation, these findings can still help to inform future decisions regarding employees with 1-2 years of service.

\section{Gap Analyses}

The results of the Gap Analyses indicate that differences between employee ratings and AVP self-ratings of AVP Laissez-Faire Leadership and AVP Intellectual Stimulation (one of the four Transformational Leadership behaviors) have the strongest relationships with employee job satisfaction. Differences in ratings by employees and AVPs of AVP Laissez-Faire Leadership levels were found to be negatively associated with Supervision, Contingent Rewards, Nature of Work, and Communication Satisfaction. This means that low levels of alignment between employees and supervisors about the perceptions of supervisors not practicing leadership behaviors is related to lower levels of satisfaction for employees. Therefore, higher levels of satisfaction for 
employees can be achieved simply by having supervisors understand what their employees think of their leadership behaviors (particularly in terms of absence of leadership). If supervisors can achieve a more realistic outlook about their own shortcomings of leadership practices, employees may take this as a sign of high selfawareness and ultimately be happier in their roles within their department.

When the outcomes were either Supervision Satisfaction or Communication Satisfaction, the direction of the difference in Laissez-Faire Leadership ratings (whether employee ratings were higher than AVP self-ratings, or vice versa) did not have a significant effect on employee satisfaction with either of these constructs. When the outcomes were Contingent Rewards or Nature of Work Satisfaction, the findings indicated that employees were less satisfied when employees rated the AVP higher on Laissez-Faire Leadership levels than AVP self-ratings. This means that if employees felt that supervisors did not practice leadership more often than supervisors felt that they were absentee leaders, employees were less satisfied in their roles. Therefore, it is important for supervisors to be more modest about their assessment of their own lack of leadership practices if their employees feel that the supervisors are not practicing leadership. The findings about perceptions of leader Laissez-Faire Leadership behaviors and its relationship to employee job satisfaction are consistent with the findings from the existing literature.

Differences in ratings by employees and AVPs regarding AVP Intellectual Stimulation were negatively related to both Nature of Work Satisfaction and Communication Satisfaction. In the case of both outcome variables, direction of the difference in Intellectual Stimulation ratings (whether employee ratings were higher than 
AVP self-ratings, or vice versa) did not have a significant effect on employee satisfaction with either of these constructs. This means that not having alignment between employees and supervisors about perceptions of supervisor Intellectual Stimulation decreased employee job satisfaction, but it does not matter whether the employee rates the supervisor higher than the supervisor rates themselves, or if the supervisor rates themselves higher than the employee reates them. This finding indicates that employees would more satisfied if actions were taken to align employee and AVP perceptions of AVP Intellectual Stimulation behaviors. The simple effort of getting on the same page about perceptions of this leadership behavior would have positive returns to employee job satisfaction. This finding about the positive returns to alignment between employee and leader perceptions of Intellectual Stimulation behaviors of the leader adds to the current literature, which has identified Intellectual Stimulation as a positive leader attribute connected to positive outcomes for followers.

\section{Reverse Regressions}

This study employed a Reverse Regression technique in which satisfaction scores with Supervision Contingent Rewards, Nature of Work, and Communication (along with the control variable of Years of Service) are treated as independent variables, while perceptions of leadership style behaviors of the AVP are treated as the outcome. Findings from these Reverse Regressions highlight that there is a positive relationship between Communication Satisfaction and Transformational Leadership. This finding aligns with previous research that has hypothesized that employees who are more satisfied in their jobs tend to attribute more transformational qualities to their supervisors (Van Knippenberg \& Sitkin, 2013). In addition, a positive relationship was found between 
Contingent Rewards Satisfaction and Transactional Leadership. Taken together, these findings support existing research that has noted that leadership is an attribution in the eye of the beholder; namely, employees hold mental representations of leadership that color their perceptions of leadership (Eden \& Leviatan, 1975; Lord \& Maher, 2002; Meindl et al., 1985; Van Knippenberg \& Sitkin, 2013).

An entirely different dataset was used to conduct the reverse regression analyses than what was used to construct the main regression models of this study. Main regression models were treated with leadership style as the independent variable (and therefore means were imputed for missing data), while respondents who had any missing data for job satisfaction or organizational climate questions were omitted. For the reverse regressions, I instead omitted respondents who had missing data for any leadership style questions while imputing means for missing data on job satisfaction and organizational climate questions. Despite this consideration, it is important to note the limitations of the reverse regressions. These reverse regressions were not investigated in a longitudinal manner that would adequately address questions of how satisfaction affects perceptions of supervisor leadership. In other words, the focus of this study is not to answer the reverse regression relationship. Therefore, the limitations of how this reverse relationship was explored means that these findings should not be taken as anything more than preliminary evidence that a reverse relationship may exist, and that further, dedicated research on this reverse relationship is needed to adequately address this directionality.

Future studies can use the preliminary findings of these reverse regressions as grounded theory for investigating whether more satisfied employees tend to look at aspects of their work more favorably, including viewing the climates within their 
departments as stronger and seeing their leaders as more transformational. Organizations would then be able to leverage employee job satisfaction, not just for increases in employee performance and decrases in employee turnover, but also to have compounding positive effects due to happier employees viewing multiple aspects of their jobs more favorably.

\section{OLS and HLM Regressions}

When using OLS regression techniques to investigate the relationships between Transformational Leadership and Job Satisfaction, Intellectual Stimulation and Individualized Consideration were found to have a larger, positive association with Overall Satisfaction than Inspirational Motivation and Idealized Influence behaviors. This finding supports research on the positive relationships between Intellectual Stimulation and Individualized Consideration and employee job satisfaction (Hanaysha et al., 2012; Lee et al., 2011). Alternatively stated, the critical findings form the OLS regressions are not surprising, as they are consistent with existing research. It appears that leaders who are perceived as stimulating and providing consideration tend to have more satisfied employees. It is interesting to note that the two Transformational Leadership behaviors with the strongest associations to employee job satisfaction were the two specific behaviors that are more easily developed (Intellectual Stimulation and Individualized Consideration) than the two more intangible aspects of the theory (Inspirational Motivation and Idealized Influence).

Transformational Leadership behaviors were found to have larger positive associations with the outcomes of Contingent Rewards Satisfaction and Communication Satisfaction than with the outcomes of Supervision Satisfaction and Nature of Work 
Satisfaction. This finding aligns with existing research that has found a consistent, positive relationship between transformational leadership style and career satisfaction (Berson \& Linton, 2005; Gill et al., 2010; Riaz \& Haider, 2010; Wiratmadja et al., 2008). These findings address the first research question guiding this study: To what degree does a relationship exist between supervisor full-range leadership (in particular, transformational leadership) and employee job satisfaction? It appears a strong relationship does in fact exist between transformational leadership constructs and employee job satisfaction, and this relationship exists to a high degree.

While this study focused on Transformational Leadership, supervisor full-range leadership was also measured. As a result, Transactional Leadership behaviors were also regressed on employee job satisfaction. The Contingent Rewards behavior of Transactional Leadership was found to be positively related to job satisfaction outcomes, particularly Contingent Rewards Satisfaction and Communication Satisfaction, meaning that when supervisors express appreciation and recognition for hard work, employees tend to be more satisfied. Contingent Rewards behaviors also include leaders being clear about what rewards are in store for employees when they deliver on their work responsibilities; practicing this behavior also yields more satisfied employees. These relationships follow the same pattern of associations between Transformational Leadership and satisfaction with Contingent Rewards and Communication; however, the effect sizes of the Transformational Leadership behaviors on these two outcomes were bigger than the effect sizes of the Contingent Rewards behavior.

This finding is in line with the work of Riaz \& Haider (2010), who found that transformational leaders have more positive impacts on job satisfaction than transactional 
leaders. In addition to Transactional Leadership, Laissez-Faire Leadership was also measured in this study. Laissez-Faire Leadership was found to be negatively related to Overall Satisfaction. Furthermore, the strongest negative association of Laissez-Faire Leadership behaviors was when the outcome was Contingent Rewards Satisfaction. These findings are consistent with the existing research on the negative impact of Laissez-Faire Ledership.

Based on these findings, supervisors should strive to develop their Transformational Leadership capacities, particularly in terms of Intellectual Stimulation and Individualized Consideration. Reciprocal leadership practices inherent in Transacational Leadership is also valuable in certain situations, particularly in the context of Contingent Rewards and Communication satisfaction. This means that when rewards for achieving work goals are clearly stated by supervisors, employees are more satisfied both with the acknowledgment they receive for a job well done, but also with the communication levels and processes within their departments.

None of the three organizational climate strength variables were found to mediate the relationship between supervisor leadership behaviors and employee job satisfaction when using OLS techniques. This means that the link between the leadership of a supervisor and employee job satisfaction does not go through the intermediate step of the leader first creating a strong organizational climate, thereby influencing the job satisfaction of employees. This lack of statistically significant findings is in disagreement with the established links between organizational climate and job satisfaction (Downey et al., 1974; Downey et al., 1975; Johannesson, 1973; LaFollette \& Sims, 1975; Welsch \& LaVan, 1981) or the links between transformational leadership and organizational climate 
(Dragoni, 2005; Ostroff et al., 2003; Zohar \& Tenne-Gazit, 2008). This finding answers the second research question guiding this study: To what degree does organizational climate strength mediate the relationship between supervisor full-range leadership and employee job satisfaction? The data analysis methods from this study found that organizational climate strength does not at all mediate the relationship between supervisor leadership and employee job satisfaction. This means that this research study did not find that organizational climate strength was a mechanism or variable through which leadership style of the supervisor can indirectly influence employee job satisfaction.

However, this finding does not mean that organizational climate plays no role in the relationship between supervisor leadership style and employee job satisfaction. Rather, it could be that organizational climate strength specifically is not a mediating variable between these constructs. Alternatively stated, this study only measured three different climate constructs (Autonomy, Innovation \& Flexibility, and Effort). While these were not found to be related to both leadership and job satisfaction, other types of climates (and their respective climate strengths) could potentially be related to both leadership and job satisfaction. Furthermore, limitations in the measurement of the variables in this study may have contributed to the lack of statistically significant results when introducing organizational climate strength as a mediating variable. It may be that organizational climate strength does not mediate the relationship between the specific leadership behaviors and the specific job satisfaction variables (which are a subset of the various leadership behaviors and job satisfaction variables that could potentially have been measured). In other words, this study was not all-inclusive of every aspect of job 
satisfaction and organizational climate, nor did it include all types of leadership behaviors and attributes. Therefore, the relationships found in this study (as well as the lack of relationships) should be take this into consideration, and that different results (particularly stronger relationships) may have been found if different types of leadership, climate, and job satisfaction were included in this study.

The discussion of findings in this subsection has focused on results from OLS regression techniques. This study also introduced multi-level modeling techniques (through HLM) to investigate the interrelationships between supervisor leadership style, organizational climate strength, and employee job satisfaction. As explained in Chapter 4, no statistically significant coefficient estimates were found when using the HLM regression techniques. These results are far different than the results displayed when analyzing the data using OLS methods, which answers the third research question guiding this study: How do findings regarding the interrelationships between supervisor full-range leadership, organizational climate strength, and employee job satisfaction differ when utilizing multi-level modeling techniques instead of OLS regression techniques? The implications of this are that the results from both the OLS and HLM regression models should be interpreted with some caution.

The lack of statistically significant findings when utilizing HLM may be due to inherent limitations of this study. For example, 100 total respondents split between seven departments yields a small sample size, both for within-and-between-group analyses. As a result of the small sample sizes within each department, it is difficult to see statistically significant results from the HLM analytical technique (a method that has strict parameters and assumptions behind its execution). 


\section{Implications for Policy/Practice}

Several policy and practice recommendations stem from the data collected and analyzed in this study. However, it would prudent to start with acknowledging one of the limitations to consider when interpreting the findings from this study. There are generalizability concerns with this study given that the research was conducted with a relatively small sample size and within a narrow context/industry. Despite these external validity concerns, the findings from this study yield actionable insights for the specific research site. While there are no statistically significant results from the HLM methodology, the findings from the OLS regression techniques can be utilized by The University for the purposes of data-driven decision making. An important finding from the OLS regressions was that Laissez-Faire Leadership is negatively related to Overall Satisfaction of employees. This finding indicates that general leadership development trainings that focus on identifying what is considered Laissez-Faire leadership and training leaders to avoid such behaviors can be a worthwhile investment in order to ensure the satisfaction of employees.

Limited time and resources (specifically funding) drive the need to be efficient when determining which specific leadership capacities to develop in supervisors. The University can use the data from this study to determine which leadership capabilities to focus on developing in their supervisors by concentrating on the behaviors that are found to have the greatest returns to employee job satisfaction. Intellectual Stimulation and Individualized Consideration were found to have the strongest positive associations with employee job satisfaction; that is, as Intellectual Stimulation and Individualized Consideration scores for AVPs increased, employee job satisfaction levels increased as 
well. The findings from this study specify that stakeholders at The University can expect the greatest increases in Contingent Rewards Satisfaction and Communication Satisfaction if supervisors work to improve their capacities of Intellectual Stimulation and Individualized Consideration.

The University should develop the capacity of Intellectual Stimulation in their supervisors by teaching the supervisors how to encourage their employees to be innovative and creative in their work (Yukl, 1999). Supervisors should look to push their employees to address old problems in new ways and to regularly examine old assumptions to see if they are still viable (Diaz-Saenz, 2011). To help supervisors develop Individualized Consideration behaviors, leadership trainings should focus on advancing supervisor abilities to serve as mentors in employee growth and development by treating each follower as an individual and considering their individual needs, abilities, and aspirations (Bass \& Riggio, 2006; Diaz-Saenz, 2011; Northouse, 2015). Through growing this Individualized Consideration competence, supervisors will view their employee as a whole person and assist them in actualizing their full potential by helping individuals to develop their strengths and spending time coaching and guiding their employees (Avolio et al., 1999; Diaz-Saenz, 2011).

The findings from this study indicate that actions other than developing supervisor leadership capacities can be taken to increase employee job satisfaction at The University. The results of the Gap Analyses indicate that, in addition to developing Intellectual Stimulation behaviors in supervisors, employee job satisfaction can be increased by making concentrated efforts to better align employee perceptions of AVP Intellectual Stimulation capacities and AVP self-perceptions of Intellectual Stimulation 
capabilities. The findings from the Gap Analyses showed that employees were less satisfied as the difference between employee ratings and AVP self-ratings increased on this construct; therefore, better alignment between employee and AVP perceptions on AVP Intellectual Stimulation behaviors can yield positive returns on employee job satisfaction, particularly with Nature of Work Satisfaction and Communication Satisfaction.

A few specific actions can be taken to better align employee perceptions and AVP self-perceptions of this specific construct. One action is to improve self-awareness skills of supervisors, particularly when considering Intellectual Stimulation. By improving selfawareness, supervisor perceptions of their own behaviors may be better aligned with employee perceptions of the supervisor's capabilities, specifically around Intellectual Stimulation. The University can also encourage supervisors to solicit more feedback from their employees (both in terms of quality and frequency) about the leadership skills of the supervisor. Increased frequency and greater depth of feedback about supervisor leadership by employees can help to mitigate any gaps between employee perceptions of supervisor leadership abilities and supervisor self-assessments. This study has found that, as a result of this diminished gap between the two ratings, employee job satisfaction can be expected to increase.

One final area of opportunity for the research site to address is with employees who have 1-2 years of service at The University. This research identified that employees with 1-2 years of service at The University provided low satisfaction scores, low ratings of AVP leadership behaviors, and had large differences between employee ratings of AVP leadership skills and AVP self-assessments of their own leadership. Taken together, 
these three findings indicate that The University would be well served to focus on improving the experiences of employees with 1-2 years of service. A few considerations should be taken into account in order to best address the experiences of employees with 1-2 years of service.

First, it is possible that ratings given by employees improve after 1-2 years due to full benefits vesting after two years of service at the research site. Once these benefits fully vest, employees may be more satisfied in their jobs or have more positive perceptions of the leadership behaviors of their supervisors. Another consideration is turnover trends by years of service of employees. I was not given turnover data to include in the analysis. Therefore, I would recommend that my point of contact at The University investigate the turnover trends of employees based on their years of service. If a disproportionate number of employees leave The University from the 1-2 years of service group, that could help to explain why ratings of employees increase after 1-2 years of service.

The aforementioned considerations are important to have the full picture of how best to address improving the work experience of employees with 1-2 years of service. However, there are standard steps that can be taken regardless of these considerations. For example, The University can send an automated survey to employees on the one-year anniversary of that employee's start date. This survey can solicit feedback on the onboarding process and how the new hire experience can be improved. In addition, the survey can used to collect data about the work experiences within the first year of an employee's tenure at The University. This data can yield actionable insights of how to improve the employee experience, thereby increasing employee satisfaction and 
improving employee perceptions of leadership within their department. Supervisors can also be alerted to the unique experiences of employees with 1-2 years of service and be given training of how best to address the needs of these employees.

Specific behaviors for supervisors can also be suggested, such as holding more frequent one-on-one meetings with employees with 1-2 years of experience. These meetings can assist in improving employee satisfaction within their roles and also to help better align these employees and their supervisors regarding perceptions of leadership within the department. Supervisors being aware of the area of opportunity that exists to improve the work experience of employees at this specific level of years of service can assist in improving overall job satisfaction at The University.

This section has focused on policy/practice implications at the specific research site where this study was conducted. Another goal of this dissertation was to have an impact on general literature and studies related to supervisor full-range leadership, organizational climate, or employee job satisfaction. With this goal in mind, the following section of this chapter will expand upon the implications this study has for future research.

\section{Implications for Future Research}

As acknowledged previously, generalizability is a limitation of this dissertation. However, this study certainly carries implications for future research on the topics of supervisor full-range leadership, organizational climate, and employee job satisfaction. This study provides a framework for future research to utilize when investigating these three constructs. The core of this framework centers on two main contributions from this study: 1) using organizational climate strength as a mediating variable between 
supervisor transformational leadership capacities and employee job satisfaction; and, 2) employing multi-level modeling techniques to investigate interrelationships between these three variables.

While HLM methods did not produce any statistically significant coefficient estimates in this study, the usage of multi-level modeling techniques to investigate the research questions guiding this study should be duplicated in future research. The practical implications of HLM are limited in this study due to the commitment to preserving the anonymity of both the research site and the departments that participated. As a result, while between-group findings presented statistically significant differences, there are no actions that can be taken as a result of these findings. If future studies are not limited by the commitment to anonymity, research sites in which these studies take place can address findings of differences between-groups to present unique, targeted, and specific solutions to different departments based on the results of the study.

This study was limited in its explanatory power due to small sample sizes, both within-and-between-groups. If future studies can address this small sample size issue, HLM methods can be used, perhaps to yield greater insights. Aspects of this study can also be recreated in future research that takes place in different industries/sectors. This research was conducted at a small, private, four-year university. Future studies can expand to the nonprofit sector, K-12 education, corporate settings, or even different types of higher education institutions. Incorporating core aspects of this study in various sectors will help to make findings more generalizable. In addition, organizations within different industries may lend themselves more to HLM methods due to having more delineated and hierarchical structures. 
This study uses methods that commit to addressing levels of analysis issues that are present within the current literature examining relationships between variables that exist at various levels of analysis. The lack of statistically significant findings as a result of the multi-level modeling techniques used in this study to address the levels of analysis issue should not be taken as an indication of unimportance of addressing levels of analysis. Future studies should look to employ techniques and methods that address levels of analysis issues and can use this study as a framework for doing so, not just through the execution of the study, but also through the justification provided in the literature review portion of this paper. It is advisable for future studies to consider the sample size and organizational structure aspects of study design when attempting to address the levels of analysis issues of cross-level variable relationship analysis.

If the sample size and organizational hierarchical structure issues can be addressed in future research, aspects of this study can not only be borrowed from, but also expanded upon. Future studies can look to measure more leadership behaviors/theories than the three measured in this study. If these future studies have the ability to measure even more aspects of organizational climate (instead of the subset of three measured in my research) and more aspects of job satisfaction (in addition to the four job satisfaction variables measured in this study), more robust research can be used to correlate a vast array of leadership behaviors with a number of climate and satisfaction outcomes. Again, these future studies can use organizational climate strength as a mediating variable between any new leadership variables measured and any new satisfaction variables operationalized in the study. 
This study was also limited by having only one control variable (years of service) in its regression models. If researchers have more access to data in different research sites, additional control/demographic variables can be used in future models. These potential control variables can include years in level, years in a specific department, and years reporting to a particular supervisor. These control variables would not only contribute to a more realistic regression model, but they would also more accurately measure relevant employee work demographics that are related to employee job satisfaction. More traditional demographic variables such as gender, race/ethnicity, and marital status could also be included in these models. If future research can adequately increase sample sizes, there is room to add more demographic control variables to the regression models.

The findings from this study provide a quantitative framework that has investigated the interrelationships between supervisor full-range leadership, organizational climate strength, and employee job satisfaction. This study can provide a springboard for future research to employ qualitative research methods to supplement the work done in this study. Qualitative research on these variables can add in-depth, rich descriptions to the literature that is not provided from the findings in this dissertation. This study, in conjunction with future research using qualitative methods, can provide a number of useful findings to organizations about supervisor leadership capacities, organizational climate, and employee job satisfaction.

Additional findings from this study that have implications for future research are the results from the Reverse Regressions. Findings from these Reverse Regressions highlight that there is a positive relationship between Communication Satisfaction and 
Transformational Leadership. In addition, a positive relationship was found between Contingent Rewards Satisfaction and Transactional Leadership. These findings support extant research that has noted that leadership is an attribution in the eye of the beholder; namely, employees hold mental representations of leadership that color their perceptions of leadership (Eden \& Leviatan, 1975; Lord \& Maher, 2002; Meindl et al., 1985; Van Knippenberg \& Sitkin, 2013). However, as noted previously, it is important to note the limitations of the reverse regressions. These reverse regressions were not investigated in a longitudinal manner that would adequately address questions of how satisfaction affects perceptions of supervisor leadership. In other words, the focus of this study is not to answer the reverse regression relationship. While the findings from the Reverse Regressions can be taken as preliminary evidence that a reverse relationship may exist, further, dedicated research on the reverse relationship is needed to adequately address this directionality. Leaders could use findings from dedicated research addressing this hypothesis to build stronger climates and develop organizational cultures due to more buy-in from employees and increased levels of favorable outlooks on a number of individual- and organizational-level aspects of work.

\section{Summary}

This dissertation research investigated the interrelationships between supervisor transformational leadership, organizational climate strength, and employee job satisfaction. This study made two major contributions to the existing literature. First, it utilized organizational climate strength as a mediating variable between supervisor transformational leadership and employee job satisfaction. Second, this study employed 
multi-level modeling techniques as part of its data analysis procedures. The following research questions guided the study:

1) To what degree does a relationship exist between supervisor full-range leadership (in particular, transformational leadership) and employee job satisfaction?

2) To what degree does organizational climate strength mediate the relationship between supervisor full-range leadership and employee job satisfaction?

3) How do findings regarding the interrelationships between supervisor full-range leadership, organizational climate strength, and employee job satisfaction differ when utilizing multi-level modeling techniques instead of OLS regression techniques?

The findings that Intellectual Stimulation and Individualized Consideration behaviors are positively related to job satisfaction and that Laissez-Faire Leadership is negatively related to job satisfaction address the first research question. The results from this study found that no climate strength variables mediate the relationship between supervisor transformational leadership and employee job satisfaction; this finding answers the second research question. The answer to the third research question is that OLS regression techniques found a positive relationship between Intellectual Stimulation and Individualized Consideration behaviors and employee job satisfaction and negative relationship between Laissez-Faire Leadership and job satisfaction, while HLM techniques found no relationship between leadership variables and job satisfaction outcomes. Both methods found no mediating effect of organizational climate strength between the two variables. 
The limitations of this study should be considered when interpreting the findings. This study contained small sample sizes, both within-and-between groups, which severely limit its generalizability. This external validity concern is compounded by the fact that this research took place in a limited context of a small, private, four-year university. Longitudinal data collection would have strengthened the findings in this study, particularly the results of the analyses concerning the reverse regressions and the ones that split employees by years of service groups. Years of service was the only control variable included in the regression models; this study would have been more robust if additional demographic variables had been provided and if it had been possible to measure more than just a subset of leadership, climate, and satisfaction constructs. Additional data including turnover and performance metrics would have supplemented the findings and interpretations that stemmed from this study. Lastly, this study used purely quantitative methods. Qualitative research would have provided the opportunity for insights that were not possible in this research.

Despite these limitations, this research provides significant contributions to both the research site as well as to the existing literature. As explained in the Implications for Policy/Practice section, a number of the findings can be used for data-driven decisionmaking by The University and operationalized into targeted action items. General stakeholder benefits from this study are displayed in Figure 7.

\section{AVPs}

- Time away from work for leadership development is more efficient and goals of training are clear

- Concentrating on developing specific capacities/practicing specific behaviors, based on research
Human Resources

- Money is spent more effectively and efficiently as a result of datadriven decision-making

- Tangible and measurable outcomes after sending supervisors to leadership training 
Figure 7. Stakeholder benefits from this study.

The findings from this research benefit a number of constituents at The University, including the Human Resources department, AVPs/supervisors, employees, and the consultants conducting the leadership training workshops. Human Resources can utilize the findings from this study to request focused trainings on leadership development. Supervisors and AVPs will spend their time in trainings developing skills and capacities that have been linked to satisfaction outcomes of their subordinates. Employees were given the opportunity to provide feedback on their work experiences in this study; from this feedback, they can expect improvements to be made in aspects of their work experience. In addition, the leadership-consulting group that is contracted to provide leadership development trainings will be given parameters for the content that they are providing, which allows for more focused/efficient planning meetings.

In addition to improvements in practice, this study also provides a framework for future research. The two significant contributions to the literature from this study are the justification to include organizational climate strength as a mediating variable between 
supervisor leadership and employee job satisfaction, and the usage of multi-level modeling to explore the interrelationships between these variables. As outlined in the Implications for Future Research section, a number of adjustments to this study can be made in future research. The contributions provided by this study for both the research site and overall future research opportunities highlight the significance of this dissertation. 


\section{REFERENCES}

Armknecht, P. A., \& Early, J. F. (1972). Quits in manufacturing: A study of their causes. Monthly Lab. Rev., 95, 31.

Ashforth, B. E. (1985). Climate formation: Issues and extensions. Academy of management review, 10(4), 837-847.

Ashkanasy, N. M., Wilderom, C. P., \& Peterson, M. F. (2000). Handbook of organizational culture and climate. Sage.

Atchison, T., \& Lefferts, E. A. (1972). The prediction of turnover using Herzberg's job satisfaction technique. Personnel Psychology, 25(1), 53-64.

Avolio, B. J., Bass, B. M., \& Jung, D. I. (1999). Re examining the components of transformational and transactional leadership using the Multifactor Leadership. Journal of occupational and organizational psychology, 72(4), 441462.

Barker, R. G. (1965). Explorations in ecological psychology. American Psychologist, 20(1), 1 .

Barling, J., Loughlin, C., \& Kelloway, E. K. (2002). Development and test of a model linking safety-specific transformational leadership and occupational safety. Journal of applied psychology, 87(3), 488.

Bass, B. M. (1984). Transformational leadership and performance beyond expectations. Division of Research, Harvard Business School.

Bass, B. M., \& Riggio, R. E. (2006). Transformational leadership. Psychology Press.

Bass, B. M., Avolio, B. J., Jung, D. I., \& Berson, Y. (2003). Predicting unit performance by assessing transformational and transactional leadership. Journal of applied psychology, 88(2), 207. 
Bernhard, F., \& O'Driscoll, M. P. (2011). Psychological ownership in small family owned businesses: Leadership style and nonfamily-employees' work attitudes and behaviors. Group \& Organization Management, 36(3), 345-384.

Berson, Y., \& Avolio, B. J. (2004). Transformational leadership and the dissemination of organizational goals: A case study of a telecommunication firm. The leadership quarterly, 15(5), 625-646.

Berson, Y., \& Linton, J. D. (2005). An examination of the relationships between leadership style, quality, and employee satisfaction in $R \& D$ versus administrative environments. $R \& D$ Management, 35(1), 51-60.

Braun, S., Peus, C., Weisweiler, S., \& Frey, D. (2013). Transformational leadership, job satisfaction, and team performance: A multilevel mediation model of trust. The Leadership Quarterly, 24(1), 270-283.

Brayfield, A. H., \& Crockett, W. H. (1955). Employee attitudes and employee performance. Psychological bulletin, 52(5), 396.

Bryk, A. S., \& Raudenbush, S. W. (1992). Hierarchical linear models for social and behavioral research: Applications and data analysis methods.

Bryman, A., Collinson, D., Grint, K., Jackson, B., \& Uhl-Bien, M. (Ed.). (2011). The SAGE handbook of leadership. Sage Publications.

Burns, J. M. (2003). Transforming leadership: A new pursuit of happiness (Vol. 213). Grove Press.

Campbell, J. J., Dunnette, M. D., Lawler, E. E., \& Weick, K. E. (1970). Managerial behavior, performance, and effectiveness.

Carlos Pastor, J., \& Mayo, M. (2008). Transformational leadership among Spanish upper echelons: the role of managerial values and goal orientation. Leadership \& Organization Development Journal, 29(4), 340-358. 
Chadha, N. K. (1988). Organizational climate and job satisfaction. Psychologia: An International Journal of Psychology in the Orient.

Charbonnier-Voirin, A., El Akremi, A., \& Vandenberghe, C. (2010). A multilevel model of transformational leadership and adaptive performance and the moderating role of climate for innovation. Group \& Organization Management, 35(6), 699-726.

Cherrington, D. J., Reitz, H. J., \& Scott, W. E. (1971). Effects of contingent and noncontingent reward on the relationship between satisfaction and task performance. Journal of applied psychology, 55(6), 531.

Churchill Jr, G. A., Ford, N. M., \& Walker Jr, O. C. (1976). Organizational climate and job satisfaction in the salesforce. Journal of Marketing Research, 323-332.

Cohen, A. M. (1974). Community college faculty job satisfaction. Research in Higher Education, 2(4), 369-376.

Colbert, A. E., Kristof-Brown, A. L., Bradley, B. H., \& Barrick, M. R. (2008). CEO transformational leadership: The role of goal importance congruence in top management teams. Academy of management journal, 51(1), 81-96.

Couger, J. D. (1988). Motivators vs. demotivators in the IS environment. Journal of Systems Management, 39(6), 36.

Crawford, C. B., Gould, L. V., \& Scott, R. F. (2003). Transformational leader as champion and techie: Implications for leadership educators. Journal of Leadership Education, 2(1), 1-12.

Dansereau, F., Alutto, J. A., \& Yammarino, F. J. (1984). Theory testing in organizational behavior: The varient approach. Prentice Hall.

Dawson, J. F., González-Romá, V., Davis, A., \& West, M. A. (2008). Organizational climate and climate strength in UK hospitals. European Journal of Work and Organizational Psychology, 17(1), 89-111. 
De Leeuw, J. (1992). Series editor's introduction to hierarchical linear models. Hierarchical linear models: Applications and data analysis methods, xiiixvi.

Denison, D. R. (1996). What is the difference between organizational culture and organizational climate? A native's point of view on a decade of paradigm wars. Academy of management review, 21(3), 619-654.

Diaz-Saenz, H. R. (2011). Transformational leadership. The SAGE handbook of leadership, 299-310.

Downey, H. K., Don, H., \& Slocum, J. W. (1975). Congruence Between Individual Needs, Organizational Climate, Job Satisfaction and Performance1. Academy of Management Journal, 18(1), 149-155.

Downey, H. K., Hellriegel, D., Phelps, M., \& Slocum, J. W. (1974). Organizational climate and job satisfaction: A comparative analysis. Journal of Business Research, 2(3), 233-248.

Dragoni, L. (2005). Understanding the emergence of state goal orientation in organizational work groups: the role of leadership and multilevel climate perceptions. Journal of Applied Psychology, 90(6), 1084.

Drexler, J. A. (1977). Organizational climate: Its homogeneity within organizations. Journal of Applied Psychology, 62(1), 38.

Dunnette, M. D., Campbell, J. P., \& Hakel, M. D. (1967). Factors contributing to job satisfaction and job dissatisfaction in six occupational groups. Organizational behavior and human performance, 2(2), 143-174.

Ehrhart, M. G., Schneider, B., \& Macey, W. H. (2013). Organizational climate and culture: An introduction to theory, research, and practice. Routledge.

Eisenbeiss, S. A., van Knippenberg, D., \& Boerner, S. (2008). Transformational leadership and team innovation: integrating team climate principles. Journal of applied psychology, 93(6), 1438. 
Fisher, C. D. (1980). On the dubious wisdom of expecting job satisfaction to correlate with performance. Academy of management review, 5(4), 607-612.

Friedlander, F., \& Margulies, N. (1969). Multiple impacts of organizational climate and individual value systems upon job satisfaction. Personnel psychology, 22(2), 171183.

George, J. M., \& James, L. R. (1993). Personality, affect, and behavior in groups revisited: Comment on aggregation, levels of analysis, and a recent application of within and between analysis.

Glenn, N. D., \& Weaver, C. N. (1982). Further evidence on education and job satisfaction. Social Forces, 61(1), 46-55.

Glick, W. (1980). Problems in cross-level inferences. Issues in aggregation, 17-30.

Glick, W. H. (1985). Conceptualizing and measuring organizational and psychological climate: Pitfalls in multilevel research. Academy of management review, 10(3), 601-616.

Glick, W. H. (1988). Response: Organizations are not central tendencies: Shadowboxing in the dark, round 2. Academy of Management Review, 13(1), 133-137.

Glisson, C. (1987). The group versus the individual as the unit of analysis in small group research. Social Work With Groups, 9(3), 15-30.

Gill, A., Flaschner, A. B., Shah, C., \& Bhutani, I. (2010). The relations of transformational leadership and empowerment with employee job satisfaction: A study among Indian restaurant employees. Business and Economics Journal, 18, $1-10$.

González-Romá, V., Peiró, J. M., \& Tordera, N. (2002). An examination of the antecedents and moderator influences of climate strength. Journal of applied psychology, 87(3), 465. 
Greene, C. N. (1973). Causal connections among managers' merit pay, job satisfaction, and performance. Journal of Applied Psychology, 58(1), 95.

Greene, C. N., \& Craft Jr, R. E. (1979). The satisfaction-performance controversy revisited. Organizational behavior: A reader. St. Paul: West Publishing Co, 187201.

Griffin, M. A., Patterson, M. G., \& West, M. A. (2001). Job satisfaction and teamwork: The role of supervisor support. Journal of organizational behavior, 22(5), 537550 .

Griffith, J. (2004). Relation of principal transformational leadership to school staff job satisfaction, staff turnover, and school performance. Journal of Educational Administration, 42(3), 333-356.

Guion, R. M. (1973). A note on organizational climate. Organizational behavior and human performance, 9(1), 120-125.

Hackman, J. R. (1992). Group influences on individuals in organizations. Consulting Psychologists Press.

Hackman, J. R., \& Oldham, G. R. (1980). Work redesign.

Hanaysha, J. R., Khalid, K., Mat, N. K., Sarassina, F., Rahman, M. Y., \& Zakaria, A. S. (2012). Transformational leadership and job satisfaction. American Journal of Economics, Special Issue, 145-148.

Hanson, S. L., Martin, J. K., \& Tuch, S. A. (1987). Economic sector and job satisfaction. Work and Occupations, 14(2), 286-305.

Hartog, D. N., Muijen, J. J., \& Koopman, P. L. (1997). Transactional versus transformational leadership: An analysis of the MLQ. Journal of occupational and organizational psychology, 70(1), 19-34.

Hellriegel, D., \& Slocum, J. W. (1974). Organizational climate: Measures, research and contingencies. Academy of management Journal, 17(2), 255-280. 
Henne, D., \& Locke, E. A. (1985). Job dissatisfaction: what are the consequences?. International Journal of Psychology, 20(2), 221-240.

Herold, D. M., Fedor, D. B., Caldwell, S., \& Liu, Y. (2008). The effects of transformational and change leadership on employees' commitment to a change: a multilevel study. Journal of applied psychology, 93(2), 346.

Herzberg, F. (1987). One more time: How do you motivate employees? Harvard Business Review, 109-120.

Herzberg, F., Mausner, B., \& Snyderman, B. B. (2011). The motivation to work (Vol. 1). Transaction publishers.

Herzberg, F., Mausner, P., Peterson, R. O., \& Capwell, D. F. (1968). Job Attitudes: A Review of the Research and Opinion, Pittsburgh 1957; F. Herzberg, Work and the Nature of Man, Cleveland 1966; ders., One more Time: How do you motivate Employees. Harvard Business Review, 46, 53-62.

Hofmann, D. A. (1997). An overview of the logic and rationale of hierarchical linear models. Journal of management, 23(6), 723-744.

Hofmann, D. A., \& Morgeson, F. P. (2003). The role of leadership in safety. The psychology of workplace safety, 159-180.

Hofmann, D. A., Morgeson, F. P., \& Gerras, S. J. (2003). Climate as a moderator of the relationship between leader-member exchange and content specific citizenship: safety climate as an exemplar. Journal of Applied Psychology, 88(1), 170.

Hopkins, K. D. (1982). The unit of analysis: Group means versus individual observations. American Educational Research Journal, 19(1), 5-18.

Hoppock, R. (1935). Job satisfaction.

Hoyle, R. H., \& Crawford, A. M. (1994). Use of individual-level data to investigate group phenomena issues and strategies. Small Group Research, 25(4), 464-485. 
Igbaria, M., \& Guimaraes, T. (1993). Antecedents and consequences of job satisfaction among information center employees. Journal of Management Information Systems, 9(4), 145- 174.

Iiacqua, J. A., Schumacher, P., \& Li, H. C. (1995). Factors contributing to job satisfaction in higher education. Education, 116(1), 51-62.

James, L. R. (1982). Aggregation bias in estimates of perceptual agreement. Journal of applied psychology, 67(2), 219.

James, L. R., \& Jones, A. P. (1974). Organizational climate: A review of theory and research. Psychological bulletin, 81(12), 1096.

Johannesson, R. E. (1973). Some problems in the measurement of organizational climate. Organizational Behavior and Human Performance, 10(1), 118-144.

Judge, T. A., Thoresen, C. J., Bono, J. E., \& Patton, G. K. (2001). The job satisfaction job performance relationship: A qualitative and quantitative review.

Jung, D. D., Wu, A., \& Chow, C. W. (2008). Towards understanding the direct and indirect effects of CEOs' transformational leadership on firm innovation. The Leadership Quarterly, 19(5), 582-594.

Kahn, R. L. (1960). 3. PRODUCTIVITY AND JOB SATISFACTION. Personnel psychology, 13(3), 275-287.

Kalleberg, A. L. (1977). Work values and job rewards: A theory of job satisfaction. American sociological review, 124-143.

Kalleberg, A. L., \& Loscocco, K. A. (1983). Aging, values, and rewards: Explaining age differences in job satisfaction. American sociological review, 78-90.

Kennedy, E. (1992). A multilevel study of elementary male black students and white students. The Journal of Educational Research, 86(2), 105-110. 
Kenny, D. A., \& La Voie, L. (1985). Separating individual and group effects. Journal of Personality and Social Psychology, 48(2), 339.

Kidwell, R. E., Mossholder, K. W., \& Bennett, N. (1997). Cohesiveness and organizational citizenship behavior: A multilevel analysis using work groups and individuals. Journal of management, 23(6), 775-793.

Kihm, J. A., Smith, P. C., \& Irwin, J. L. (1997). Update for users of the JDI: New national norms for the Job Descriptive Index. The Industrial-Organizational Psychologist, 35(1), 26-30.

Kinicki, A. J., McKee-Ryan, F. M., Schriesheim, C. A., \& Carson, K. P. (2002). Assessing the construct validity of the job descriptive index: a review and meta analysis.

Kirkpatrick, S. A., \& Locke, E. A. (1996). Direct and indirect effects of three core charismatic leadership components on performance and attitudes. Journal of applied psychology, 81(1), 36.

Kozlowski, S. W., \& Doherty, M. L. (1989). Integration of climate and leadership: Examination of a neglected issue. Journal of applied psychology, 74(4), 546.

Kraut, A. I. (1975). Predicting turnover of employees from measured job attitudes. Organizational Behavior and Human Performance, 13(2), 233-243.

Kreft, I. G. (1993). Using multilevel analysis to assess school effectiveness: A study of Dutch secondary schools. Sociology of education, 104-129.

LaFollette, W. R., \& Sims, H. P. (1975). Is satisfaction redundant with organizational climate?. Organizational behavior and human performance, 13(2), 257-278.

Lambert, E. G., Hogan, N. L., \& Barton, S. M. (2001). The impact of job satisfaction on turnover intent: a test of a structural measurement model using a national sample of workers. The Social Science Journal, 38(2), 233-250. 
Lawler, E. E. (1969). 3. Job design and employee motivation. Personnel Psychology, $22(4), 426-435$.

Lawler, E. E., Hall, D. T., \& Oldham, G. R. (1974). Organizational climate: Relationship to organizational structure, process and performance. Organizational Behavior and Human Performance, 11(1), 139-155.

Lee, V. E., \& Bryk, A. S. (1989). A multilevel model of the social distribution of high school achievement. Sociology of education, 172-192.

Lee, P. K., Cheng, T. E., Yeung, A. C., \& Lai, K. H. (2011). An empirical study of transformational leadership, team performance and service quality in retail banks. Omega, 39(6), 690-701.

Lewin, K. (1951). Field theory in social science.

Lewin, K., Lippitt, R., \& White, R. K. (1939). Patterns of aggressive behavior in experimentally created "social climates". The Journal of social psychology, 10(2), 269-299.

Liao, H., \& Chuang, A. (2007). Transforming service employees and climate: a multilevel, multisource examination of transformational leadership in building long-term service relationships. Journal of applied psychology, 92(4), 1006.

Likert, R. (1961). New patterns of management.

Likert, R. (1967). The human organization: Its management and values.

Litwin, G. H., \& Stringer Jr, R. A. (1968). Motivation and organizational climate.

Locke, E. A. (1969). What is job satisfaction?. Organizational behavior and human performance, 4(4), 309-336.

Locke, E. A. (1970). Job satisfaction and job performance: A theoretical analysis. Organizational behavior and human performance, 5(5), 484-500. 
Locke, E. A. (1975). Personnel attitudes and motivation. Annual review of psychology, 26(1), 457-480.

Locke, E. A. (1985). A New Look at Work Motivation: Theory V (No. GS-12). MARYLAND UNIV COLLEGE PARK COLL OF BUSINESS AND MANAGEMENT.

Loi, R., Yang, J., \& Diefendorff, J. M. (2009). Four-factor justice and daily job satisfaction: a multilevel investigation. Journal of Applied Psychology, 94(3), 770 .

Lord, R. G., Brown, D. J., Harvey, J. L., \& Hall, R. J. (2001). Contextual constraints on prototype generation and their multilevel consequences for leadership perceptions. The Leadership Quarterly, 12(3), 311-338.

Maidani, E. A. (1991). Comparative study of Herzberg's two-factor theory of job satisfaction among public and private sectors. Public personnel management, 20(4), 441-448.

March, J. G., \& Simon, H. A. (1958). Organizations.

Martin, J. K., \& Hanson, S. L. (1985). Sex, family wage-earning status, and satisfaction with work. Work and Occupations, 12(1), 91-109.

Martin, J. K., \& Shehan, C. L. (1989). Education and job satisfaction: The influences of gender, wage-earning status, and job values. Work and Occupations, 16(2), 184199.

Medley, F., \& Larochelle, D. R. (1995). Transformational leadership and job satisfaction. Nursing management, 26(9), 64JJ.

Michela, J. L., \& Burke, W. W. (2000). Organizational culture and climate in transformations for quality and innovation. Handbook of organizational culture and climate, 225-244.

Miner, J. B. (1980). Theories of organizational behavior. Dryden Press. 
Mobley, W. H. (1977). Intermediate linkages in the relationship between job satisfaction and employee turnover. Journal of applied psychology, 62(2), 237.

Moolenaar, N. M., Daly, A. J., \& Sleegers, P. J. (2010). Occupying the principal position: Examining relationships between transformational leadership, social network position, and schools' innovative climate. Educational administration quarterly, $46(5), 623-670$.

Moritz, S. E., \& Watson, C. B. (1998). Levels of analysis issues in group psychology: Using efficacy as an example of a multilevel model. Group Dynamics: Theory, Research, and Practice, 2(4), 285.

Morran, D. K., Robison, F. F., \& Hulse-Killacky, D. (1990). Group research and the unit of analysis problem: The use of ANOVA designs with nested factors. Journal for Specialists in Group Work, 15(1), 10-14.

Mortimer, J. T. (1979). Changing attitudes toward work (Vol. 11). Work in Amer Inst.

Mossholder, K. W., \& Bedeian, A. G. (1983). Cross-level inference and organizational research: Perspectives on interpretation and application. Academy of Management Review, 8(4), 547-558.

Muchinsky, P. M. (1977). Organizational communication: Relationships to organizational climate and job satisfaction. Academy of Management Journal, 20(4), 592-607.

Muenjohn, N., \& Armstrong, A. (2008). Evaluating the structural validity of the multifactor leadership questionnaire (MLQ), capturing the leadership factors of transformational \& transactional leadership. Contemporary Management Research, 4(1).

Nahrgang, J. D., Morgeson, F. P., \& Hofmann, D. A. (2006, April). Predicting safety performance: a meta-analysis of safety and organizational constructs. In $22^{\text {nd }}$ annual conference of the society for industrial and organizational psychology, New York. 
Nathanson, C. A., \& Becker, M. H. (1973). Job satisfaction and job performance: An empirical test of some theoretical propositions. Organizational Behavior and Human Performance, 9(2), 267-279.

Nezlek, J. B., \& Zyzniewski, L. E. (1998). Using hierarchical linear modeling to analyze grouped data. Group Dynamics: Theory, Research, and Practice, 2(4), 313.

Northouse, P. G. (2015). Leadership: Theory and practice. Sage publications.

Oreg, S., \& Berson, Y. (2011). LEADERSHIP AND EMPLOYEES'REACTIONS TO CHANGE: THE ROLE OF LEADERS'PERSONAL ATTRIBUTES AND TRANSFORMATIONAL LEADERSHIP STYLE. Personnel psychology, 64(3), 627-659.

Organ, D. W. (1977). A reappraisal and reinterpretation of the satisfaction-causes performance hypothesis. Academy of management review, 2(1), 46-53.

Osborne, J. W. (2000). The advantages of hierarchical linear modeling.

Ostroff, C., Kinicki, A. J., \& Tamkins, M. M. (2003). Organizational culture and climate. John Wiley \& Sons, Inc..

Payne, R. L., Fineman, S., \& Wall, T. D. (1976). Organizational climate and job satisfaction: A conceptual synthesis. Organizational behavior and human performance, 16(1), 45-62.

Payne, R., \& Pugh, D. S. (1976). Organizational structure and climate. Handbook of industrial and organizational psychology, 1125, 1173.

Podsakoff, P. M., MacKenzie, S. B., Moorman, R. H., \& Fetter, R. (1990). Transformational leader behaviors and their effects on followers' trust in leader, satisfaction, and organizational citizenship behaviors. The leadership quarterly, 1(2), 107-142. 
Pollack, B. N. (1998). Hierarchical linear modeling and the" unit of analysis" problem: A solution for analyzing responses of intact group members. Group dynamics: Theory, research, and practice, 2(4), 299.

Poole, M. S. (1985). Communication and organizational climates: Review, critique, and a new perspective. Organizational communication: Traditional themes and new directions, 13, 79-108.

Poole, M. S., \& McPhee, R. D. (1983). A structurational analysis of organizational climate. Communication and organizations: An interpretive approach, 195, 220.

Porter, L. W., \& Lawler, E. E. (1968). Managerial attitudes and performance.

Porter, L. W., \& Steers, R. M. (1973). Organizational, work, and personal factors in employee turnover and absenteeism. Psychological bulletin, 80(2), 151.

Porter, L. W., Steers, R. M., Mowday, R. T., \& Boulian, P. V. (1974). Organizational commitment, job satisfaction, and turnover among psychiatric technicians. Journal of applied psychology, 59(5), 603.

Pritchard, R. D., \& Karasick, B. W. (1973). The effects of organizational climate on managerial job performance and job satisfaction. Organizational behavior and human performance, $9(1), 126-146$.

Reason, J. (2016). Managing the risks of organizational accidents. Routledge.

Reichers, A. E., \& Schneider, B. (1990). Climate and culture: An evolution of constructs. Organizational climate and culture, 1, 5-39.

Riaz, A., \& Haider, M. H. (2010). Role of transformational and transactional leadership on job satisfaction and career satisfaction. Business and Economic Horizons, 1(1), 29-38.

Rosenfeld, M., \& Zdep, S. M. (1971). Intrinsic-extrinsic aspects of work and their demographic correlates. Psychological Reports, 28(2), 359-362. 
Rousseau, D. M., \& House, R. J. (1994). Meso organizational behavior: Avoiding three fundamental biases. Journal of Organizational Behavior (1986-1998), 13.

Sarros, J. C., Cooper, B. K., \& Santora, J. C. (2008). Building a climate for innovation through transformational leadership and organizational culture. Journal of Leadership \& Organizational Studies, 15(2), 145-158.

Sauer, S. J. (2011). Taking the reins: the effects of new leader status and leadership style on team performance. Journal of Applied Psychology, 96(3), 574.

Scandura, T. A., Williams, L., Dansereau, F., Gavin, M., James, L., Markham, S. E., \& Ostroff, C. (1995). Multiple levels in organizational research: Analysisoptions and Interpretation issues. In Symposium presented at the Tenth Annual Conference of the Society for industrial and organizational psychology, Orlando, FL.

Schneider, B. (1975). Organizational climates: An essay. Personnel psychology, 28(4), 447-479.

Schneider, B. (1983). Interactional psychology and organizational behavior. MICHIGAN STATE UNIV EAST LANSING DEPT OF PSYCHOLOGY.

Schneider, B. (1987). The people make the place. Personnel psychology, 40(3), 437-453.

Schneider, B., \& Reichers, A. E. (1983). On the etiology of climates. Personnel psychology, 36(1), 19-39.

Schneider, B., \& Snyder, R. A. (1975). Some relationships between job satisfaction and organization climate. Journal of applied psychology, 60(3), 318.

Scott, B. A., \& Judge, T. A. (2006). Insomnia, emotions, and job satisfaction: A multilevel study. Journal of Management, 32(5), 622-645.

Seybolt, J. W. (1976). Work satisfaction as a function of the person-environment interaction. Organizational Behavior and Human Performance, 17(1), 66-75. 
Siegel, J. P., \& Bowen, D. (1971). Satisfaction and performance: Causal relationships and moderating effects. Journal of Vocational Behavior, 1(3), 263-269.

Singh, N., \& Krishnan, V. R. (2008). Self-sacrifice and transformational leadership: mediating role of altruism. Leadership \& Organization Development Journal, 29(3), 261-274.

Sirotnik, K. A. (1980). Psychometric implications of the unit of analysis problem (with examples from the measurement of organizational climate). Journal of Educational Measurement, 17(4), 245-282.

Smith, P. C. (1969). The measurement of satisfaction in work and retirement: A strategy for the study of attitudes.

Smith, P. C., Balzer, W., Brannick, M., Chia, W., Eggleston, S., Gibson, W., ... \& Whalen, M. (1987). The revised JDI: A facelift for an old friend. The Industrial Organizational Psychologist, 24(4), 31-33.

Smith, P. C., Kendall, L. M., \& Hulin, C. (1969). The measurement of satisfaction in work and behavior. Chicago: Raud McNally.

Sparks, J. R., \& Schenk, J. A. (2001). Explaining the effects of transformational leadership: An investigation of the effects of higher order motives in multilevel marketing organizations. Journal of Organizational Behavior, 22(8), 849-869.

Spector, P. E. (1985). Measurement of human service staff satisfaction: Development of the Job Satisfaction Survey. American journal of community psychology, 13(6), 693-713.

Spector, P. E. (1994). Job satisfaction survey. Tampa, Florida: Department of Psychology, University of South Florida.

Spector, P. E. (1997). Job satisfaction: Application, assessment, causes, and consequences (Vol. 3). Sage publications. 
Tagiuri, R., Litwin, G. H., \& Barnes, L. B. (1968). Organizational climate: Explorations of a concept. Division of Research, Graduate School of Business Administration, Harvard University.

Tetlock, P. E. (1986). Is self categorization theory the solution to the level of analysis problem?. British journal of social psychology, 25(3), 255-256.

Umstot, D. D., Bell, C. H., \& Mitchell, T. R. (1976). Effects of job enrichment and task goals on satisfaction and productivity: Implications for job design. Journal of Applied Psychology, 61(4), 379.

Vroom, V. H. (1982). Work and motivation. Robert E. Krieger Publishing Company.

Wang, P., \& Rode, J. C. (2010). Transformational leadership and follower creativity: The moderating effects of identification with leader and organizational climate. Human relations, 63(8), 1105-1128.

Warr, P., Cook, J., \& Wall, T. (1979). Scales for the measurement of some work attitudes and aspects of psychological well being. Journal of Occupational and Organizational Psychology, 52(2), 129-148.

Welsch, H. P., \& LaVan, H. (1981). Inter-relationships between organizational commitment and job characteristics, job satisfaction, professional behavior, and organizational climate. Human Relations, 34(12), 1079-1089.

Wiratmadja, I. I., Govindaraju, R., \& Rahyuda, A. G. (2008). The influence of transformational leadership style and compensation system on the performance of university lecturer: A case at a State University in Indonesia. In 9th Asia Pacific Industrial Engineering \& Management Systems Conference, Nusa Dua, Bali Indonesia.

Woltman, H., Feldstain, A., MacKay, J. C., \& Rocchi, M. (2012). An introduction to hierarchical linear modeling. Tutorials in Quantitative Methods for Psychology, $8(1), 52-69$.

Yammarino, F. J., \& Markham, S. E. (1992). On the application of within and between analysis: Are absence and affect really group-based phenomena?. 
Yammarino, F. J., Dionne, S. D., Chun, J. U., \& Dansereau, F. (2005). Leadership and levels of analysis: A state-of-the-science review. The Leadership Quarterly, 16(6), 879-919.

Yang, J. T. (2010). Antecedents and consequences of job satisfaction in the hotel industry. International Journal of Hospitality Management, 29(4), 609-619.

Yukl, G. (1999). An evaluation of conceptual weaknesses in transformational and charismatic leadership theories. The leadership quarterly, 10(2), 285-305.

Zhu, W., Chew, I. K., \& Spangler, W. D. (2005). CEO transformational leadership and organizational outcomes: The mediating role of human-capital-enhancing human resource management. The leadership quarterly, 16(1), 39-52.

Zineldin, M., \& Hytter, A. (2012). Leaders' negative emotions and leadership styles influencing subordinates' well-being. The International Journal of Human Resource Management, 23(4), 748-758.

Zohar, D. (2002). The effects of leadership dimensions, safety climate, and assigned priorities on minor injuries in work groups. Journal of Organizational Behavior, 23(1), 75-92.

Zohar, D. (2003). The influence of leadership and climate on occupational health and safety. Health and safety in organizations: A multilevel perspective, 201-230.

Zohar, D., \& Luria, G. (2004). Climate as a social-cognitive construction of supervisory safety practices: scripts as proxy of behavior patterns. Journal of applied psychology, 89(2), 322 .

Zohar, D., \& Tenne-Gazit, O. (2008). Transformational leadership and group interaction as climate antecedents: a social network analysis. Journal of Applied Psychology, 93(4), 74 


\section{APPENDIX A}

Sample of Survey Used in Study 
My name is Bharat Mohan and I am a Ph.D. Candidate in Leadership Studies at the University of San Diego. I am currently conducting my dissertation research. You are receiving an invitation to participate in this survey because the Assistant/Associate Vice President (AVP) of your department has agreed to assist me in my data collection efforts.

Your responses to this survey are very important. Your responses will not only contribute to my advancement in pursuing my degree, but it will also contribute to generating new best practices for leadership. This survey will take less than $\mathbf{1 0}$ minutes to complete.

Your participation in this survey is entirely voluntary and you will be giving your informed consent by participating in this survey. Your responses will be anonymous and data will only be presented at the aggregate level.

Should you have any questions or comments, please do not hesitate to contact me at bmohan@sandiego.edu or (609) 529-1441. You can also contact my Dissertation Chair, Professor Fred Galloway, at galloway@sandiego.edu or (619) 260-7435.

I sincerely appreciate your time and thoughtful responses in completing the survey. Thank you! 
There are three sections that make up this entire survey.

This first section consists of 16 total questions.

Please select your level of agreement to each of the following statements:

\begin{tabular}{|c|c|c|c|c|c|c|}
\hline & $\begin{array}{l}\text { Disagree } \\
\text { Very } \\
\text { Much (0) }\end{array}$ & $\begin{array}{c}\text { Disagree } \\
\text { Moderately } \\
\text { (1) }\end{array}$ & $\begin{array}{l}\text { Disagree } \\
\text { Slightly } \\
\text { (2) }\end{array}$ & $\begin{array}{c}\text { Agree } \\
\text { Slightly } \\
\text { (3) }\end{array}$ & $\begin{array}{c}\text { Agree } \\
\text { Moderately } \\
\text { (4) }\end{array}$ & $\begin{array}{c}\text { Agree } \\
\text { Very } \\
\text { Much (5) }\end{array}$ \\
\hline \multicolumn{7}{|c|}{ Supervisor Satisfaction } \\
\hline $\begin{array}{l}\text { My } \\
\text { supervisor is } \\
\text { quite } \\
\text { competent in } \\
\text { doing his/her } \\
\text { job. }\end{array}$ & O & $\mathrm{O}$ & $\mathrm{O}$ & $\mathrm{O}$ & O & $\mathrm{O}$ \\
\hline $\begin{array}{l}\text { My } \\
\text { supervisor is } \\
\text { unfair to me. }\end{array}$ & O & $\mathrm{O}$ & $\mathrm{O}$ & $\mathrm{O}$ & O & $\mathrm{O}$ \\
\hline $\begin{array}{c}\text { My } \\
\text { supervisor }\end{array}$ & & & & & & \\
\hline $\begin{array}{l}\text { little interest } \\
\text { in the feelings } \\
\text { of } \\
\text { subordinates. }\end{array}$ & $\mathrm{O}$ & $\mathrm{O}$ & $\mathrm{O}$ & $\mathrm{O}$ & $\mathrm{O}$ & $\mathrm{O}$ \\
\hline $\begin{array}{l}\text { I like my } \\
\text { supervisor. }\end{array}$ & $\mathrm{O}$ & O & $\mathrm{O}$ & $\mathrm{O}$ & $\mathrm{O}$ & $\mathrm{O}$ \\
\hline \multicolumn{7}{|c|}{ Contingent Rewards Satisfaction } \\
\hline $\begin{array}{l}\text { When I do a } \\
\text { good job, I } \\
\text { receive the } \\
\text { recognition } \\
\text { for it that I } \\
\text { should } \\
\text { receive. }\end{array}$ & $\mathrm{O}$ & $\mathrm{O}$ & $\mathrm{O}$ & $\mathrm{O}$ & O & $\mathrm{O}$ \\
\hline $\begin{array}{l}\text { I do not feel } \\
\text { that the work } \\
\text { I do is } \\
\text { appreciated. }\end{array}$ & $\mathrm{O}$ & $\mathrm{O}$ & $\mathrm{O}$ & $\mathrm{O}$ & O & $\mathrm{O}$ \\
\hline $\begin{array}{c}\text { There are few } \\
\text { rewards for } \\
\text { those who } \\
\text { work here. }\end{array}$ & $\mathrm{O}$ & $\mathrm{O}$ & $\mathrm{O}$ & $\mathrm{O}$ & O & $\mathrm{O}$ \\
\hline I don't feel & O & $\mathrm{O}$ & $\mathrm{O}$ & O & 0 & $\mathrm{O}$ \\
\hline
\end{tabular}




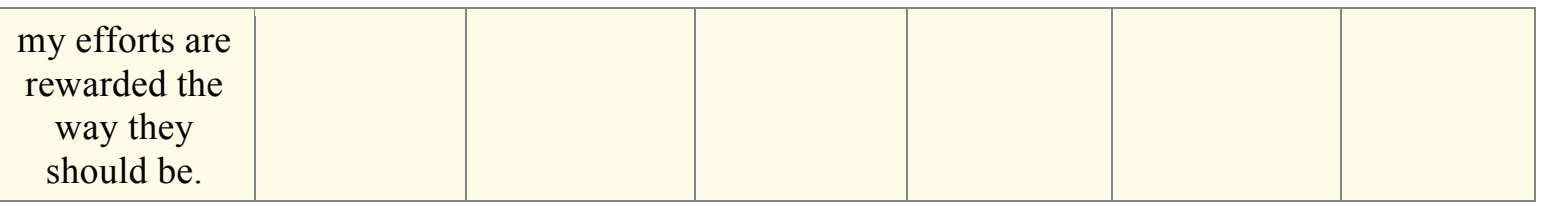

Please select your level of agreement to each of the following statements:

\begin{tabular}{|c|c|c|c|c|c|c|}
\hline & $\begin{array}{l}\text { Disagree } \\
\text { Very } \\
\text { Much }(0)\end{array}$ & $\begin{array}{l}\text { Disagree } \\
\text { Moderately } \\
\text { (1) }\end{array}$ & $\begin{array}{l}\text { Disagree } \\
\text { Slightly } \\
\text { (2) }\end{array}$ & $\begin{array}{l}\text { Agree } \\
\text { Slightly } \\
\text { (3) }\end{array}$ & $\begin{array}{c}\text { Agree } \\
\text { Moderately } \\
\text { (4) }\end{array}$ & $\begin{array}{l}\text { Agree } \\
\text { Very } \\
\text { Much } \\
(5)\end{array}$ \\
\hline \multicolumn{7}{|c|}{ Nature of Work Satisfaction } \\
\hline $\begin{array}{l}\text { I sometimes feel } \\
\text { my job is } \\
\text { meaningless. }\end{array}$ & 0 & 0 & 0 & 0 & 0 & 0 \\
\hline $\begin{array}{l}\text { I like doing the } \\
\text { things I do at } \\
\text { work. }\end{array}$ & 0 & 0 & 0 & 0 & 0 & 0 \\
\hline $\begin{array}{l}\text { I feel a sense of } \\
\text { pride in doing my } \\
\text { job. }\end{array}$ & O & $\mathrm{O}$ & O & O & O & 0 \\
\hline $\begin{array}{l}\text { My job is } \\
\text { enjoyable. }\end{array}$ & O & O & O & O & O & O \\
\hline \multicolumn{7}{|c|}{ Communication Satisfaction } \\
\hline $\begin{array}{l}\text { Communications } \\
\text { seem good within } \\
\text { my department. }\end{array}$ & 0 & O & 0 & 0 & 0 & 0 \\
\hline $\begin{array}{l}\text { The goals of my } \\
\text { department are } \\
\text { not clear to me. }\end{array}$ & O & 0 & O & O & O & $\mathrm{O}$ \\
\hline $\begin{array}{l}\text { I often feel that I } \\
\text { do not know } \\
\text { what is going on } \\
\text { with my } \\
\text { department. }\end{array}$ & 0 & 0 & 0 & 0 & 0 & 0 \\
\hline $\begin{array}{c}\text { Work } \\
\text { assignments are } \\
\text { not fully } \\
\text { explained. }\end{array}$ & 0 & 0 & 0 & 0 & 0 & 0 \\
\hline
\end{tabular}

There are three sections that make up this entire survey.

This second section consists of 16 total questions. 
Please select the level to which, in your opinion, each of the following statements are true:

\title{
Definitely False $\quad$ Mostly False (1) $\quad$ Mostly True (2)
} (0)

\begin{abstract}
Supervisors in my department let people make their own decisions much of the time.

Supervisors in my department trust people to make workrelated decisions without getting permission first.

People at the top of my department tightly control the work of those below them.

Supervisors in my department keep too tight a reign on the way things are done around here.

It's important to check things first with my supervisor before taking a decision.
\end{abstract}

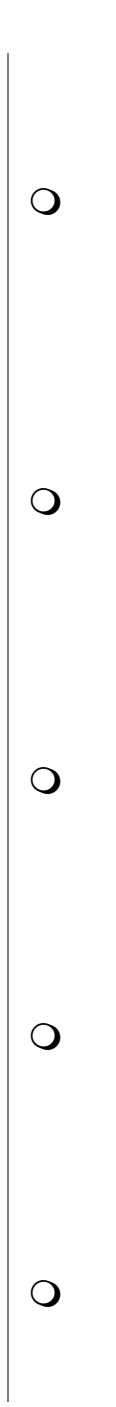

\section{Autonomy Climate}

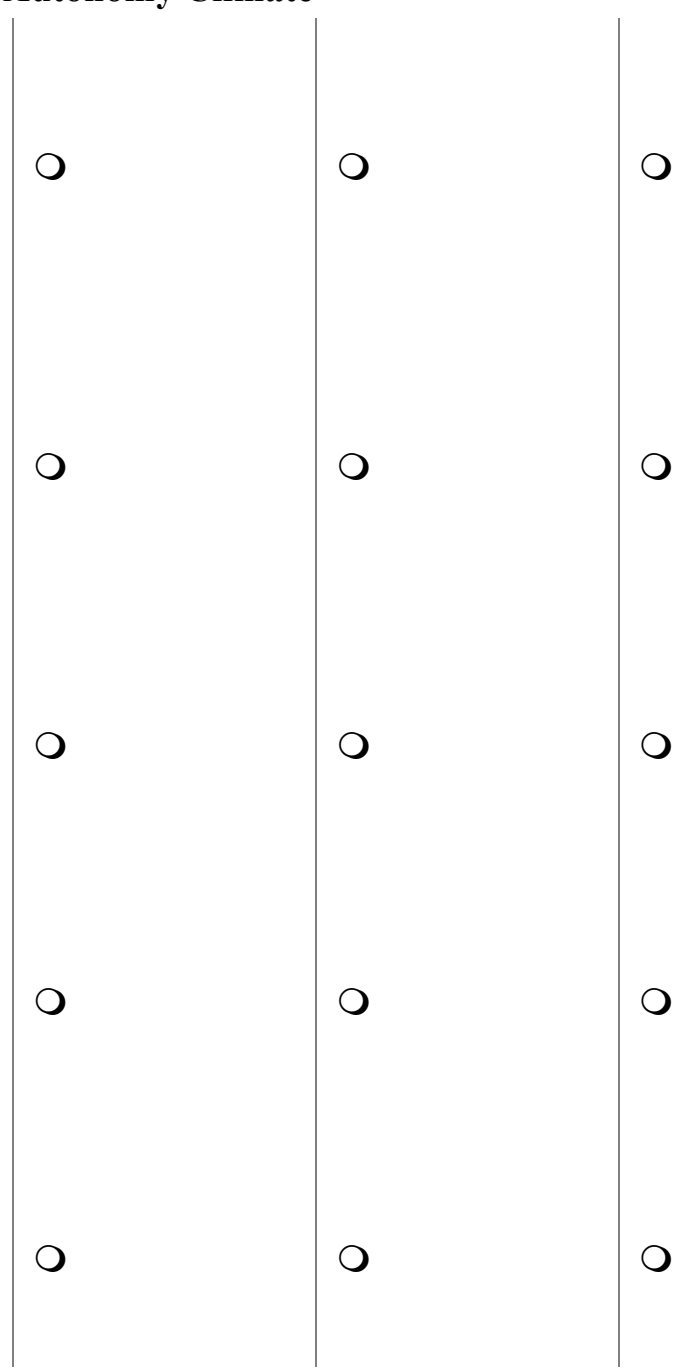

Innovation and Flexibility Climate

New ideas are readily accepted in my department.

My department is quick to respond when changes need to be made.

Supervisors in my department

\begin{tabular}{|l|l|l|l|}
0 & 0 & 0 & 0 \\
0 & 0 & 0 & 0 \\
\hline 0 & 0 & 0 & 0 \\
\hline
\end{tabular}


are quick to spot

the need to do

things differently.

Please select the level to which, in your opinion, each of the following statements are true:

\begin{tabular}{|c|c|c|c|c|}
\hline & $\begin{array}{c}\text { Definitely False } \\
\text { (0) }\end{array}$ & Mostly False (1) & Mostly True (2) & $\begin{array}{c}\text { Definitely True } \\
\text { (3) }\end{array}$ \\
\hline \multicolumn{5}{|c|}{ Innovation and Flexibility Climate (Continued) } \\
\hline $\begin{array}{l}\text { My department is } \\
\text { very flexible; it } \\
\text { can quickly } \\
\text { change } \\
\text { procedures to } \\
\text { meet new } \\
\text { conditions and } \\
\text { solve problems as } \\
\text { they arise. }\end{array}$ & $\mathrm{O}$ & $\mathrm{O}$ & $\mathrm{O}$ & $\mathrm{O}$ \\
\hline $\begin{array}{c}\text { Assistance in } \\
\text { developing new } \\
\text { ideas is readily } \\
\text { available. }\end{array}$ & $\mathrm{O}$ & $\mathrm{O}$ & $\mathrm{O}$ & $\mathrm{O}$ \\
\hline $\begin{array}{l}\text { People in my } \\
\text { department are } \\
\text { always searching } \\
\text { for new ways of } \\
\text { looking at } \\
\text { problems. }\end{array}$ & $\mathrm{O}$ & $\mathrm{O}$ & $\mathrm{O}$ & $\mathrm{O}$ \\
\hline \multicolumn{5}{|c|}{ Effort Climate } \\
\hline $\begin{array}{l}\text { People in my } \\
\text { department } \\
\text { always want to } \\
\text { perform to the } \\
\text { best of their } \\
\text { ability. }\end{array}$ & $\mathrm{O}$ & $\mathrm{O}$ & $\mathrm{O}$ & $\mathrm{O}$ \\
\hline $\begin{array}{c}\text { People in my } \\
\text { department are } \\
\text { enthusiastic } \\
\text { about their work. }\end{array}$ & $\mathrm{O}$ & $\mathrm{O}$ & $\mathrm{O}$ & $\mathrm{O}$ \\
\hline $\begin{array}{c}\text { People in my } \\
\text { department get } \\
\text { by with doing as } \\
\text { little as possible. }\end{array}$ & $\mathrm{O}$ & $\mathrm{O}$ & $\mathrm{O}$ & $\mathrm{O}$ \\
\hline $\begin{array}{c}\text { People in my } \\
\text { department are } \\
\text { prepared to make }\end{array}$ & $\mathrm{O}$ & O & $\mathrm{O}$ & $\mathrm{O}$ \\
\hline
\end{tabular}




\begin{tabular}{|c|c|c|c|c|}
\hline $\begin{array}{l}\text { a special effort to } \\
\text { do a good job. }\end{array}$ & & & & \\
\hline $\begin{array}{l}\text { People in my } \\
\text { department don't } \\
\text { put more effort } \\
\text { into their work } \\
\text { than they have to. }\end{array}$ & 0 & $O$ & 0 & 0 \\
\hline
\end{tabular}

This is the final section of this survey. Please finish this final section of the survey. Clicking the "Next" button at the bottom of this page will submit your survey responses once you are finished.

\section{This section consists of 21 total questions.}

For this section, please answer the questions about the leadership style of the AVP of your department: <insert name of AVP>

Idealized Influence: All items marked (1)

Inspirational Motivation: All items marked (2)

Intellectual Stimulation: All items marked (3)

Individualized Consideration: All items marked (4)

Contingent Reward: All items marked (5)

Management-by-Exception: All items marked (6)

Laissez-Faire Leadership: All items marked (7) 
Please select how frequently, in your opinion, the following statements describe the AVP of your department (AVP Name):

\begin{tabular}{|c|c|c|c|c|c|}
\hline & $\begin{array}{l}\text { Not At All } \\
(0)\end{array}$ & $\begin{array}{l}\text { Once In A } \\
\text { While (1) }\end{array}$ & Sometimes (2) & $\begin{array}{l}\text { Fairly Often } \\
\text { (3) }\end{array}$ & $\begin{array}{c}\text { Frequently, If } \\
\text { Not Always } \\
\text { (4) }\end{array}$ \\
\hline $\begin{array}{l}\text { My AVP } \\
\text { makes } \\
\text { department } \\
\text { members feel } \\
\text { good to be } \\
\text { around them. } \\
\text { (1) }\end{array}$ & 0 & 0 & 0 & 0 & 0 \\
\hline $\begin{array}{c}\text { My AVP } \\
\text { expresses with } \\
\text { a few simple } \\
\text { words what } \\
\text { department } \\
\text { members } \\
\text { could and } \\
\text { should do. (2) }\end{array}$ & 0 & 0 & 0 & 0 & 0 \\
\hline $\begin{array}{c}\text { My AVP } \\
\text { enables } \\
\text { department } \\
\text { members to } \\
\text { think about } \\
\text { old problems } \\
\text { in new ways. } \\
\text { (3) }\end{array}$ & 0 & 0 & 0 & 0 & 0 \\
\hline $\begin{array}{c}\text { My AVP } \\
\text { helps } \\
\text { department } \\
\text { members } \\
\text { develop } \\
\text { themselves. } \\
\text { (4) }\end{array}$ & 0 & 0 & 0 & 0 & 0 \\
\hline $\begin{array}{l}\text { My AVP tells } \\
\text { department } \\
\text { members what } \\
\text { to do if they } \\
\text { want to be } \\
\text { rewarded for } \\
\text { their work. (5) }\end{array}$ & 0 & 0 & 0 & 0 & 0 \\
\hline $\begin{array}{l}\text { My AVP is } \\
\text { satisfied when } \\
\text { department } \\
\text { members meet } \\
\text { agreed-upon }\end{array}$ & 0 & 0 & 0 & 0 & 0 \\
\hline
\end{tabular}




\begin{tabular}{|c|c|c|c|c|c|}
\hline standards. (6) & & & & & \\
\hline $\begin{array}{l}\text { My AVP is } \\
\text { content to let } \\
\text { department } \\
\text { members } \\
\text { continue } \\
\text { working in the } \\
\text { same ways } \\
\text { always. (7) }\end{array}$ & O & O & O & O & O \\
\hline
\end{tabular}

Please select how frequently, in your opinion, the following statements describe the AVP of your department (AVP Name):

\begin{tabular}{|c|c|c|c|c|c|}
\hline & $\begin{array}{c}\text { Not At All } \\
(0)\end{array}$ & $\begin{array}{l}\text { Once In A } \\
\text { While (1) }\end{array}$ & $\begin{array}{l}\text { Sometimes } \\
\text { (2) }\end{array}$ & $\begin{array}{l}\text { Fairly Often } \\
\text { (3) }\end{array}$ & $\begin{array}{l}\text { Frequently, If } \\
\text { Not Always } \\
\text { (4) }\end{array}$ \\
\hline $\begin{array}{l}\text { Department } \\
\text { members have } \\
\text { complete faith in } \\
\text { my AVP. (1) }\end{array}$ & 0 & 0 & O & 0 & 0 \\
\hline $\begin{array}{l}\text { My AVP provides } \\
\text { appealing images } \\
\text { of what department } \\
\text { members can do. } \\
\text { (2) }\end{array}$ & 0 & O & 0 & 0 & 0 \\
\hline $\begin{array}{l}\text { My AVP provides } \\
\text { department } \\
\text { members with new } \\
\text { ways of looking at } \\
\text { puzzling things. (3) }\end{array}$ & 0 & 0 & O & 0 & 0 \\
\hline $\begin{array}{c}\text { My AVP lets } \\
\text { department } \\
\text { members know } \\
\text { how he/she thinks } \\
\text { they are doing. (4) }\end{array}$ & 0 & O & O & O & O \\
\hline $\begin{array}{l}\text { My AVP provides } \\
\text { recognition/rewards } \\
\text { when department } \\
\text { members reach } \\
\text { their goals. }(5)\end{array}$ & 0 & 0 & 0 & 0 & 0 \\
\hline $\begin{array}{l}\text { As long as things } \\
\text { are working, my } \\
\text { AVP does not try to } \\
\text { change anything. } \\
\text { (6) }\end{array}$ & 0 & 0 & O & O & O \\
\hline $\begin{array}{l}\text { Whatever } \\
\text { department }\end{array}$ & 0 & 0 & 0 & 0 & 0 \\
\hline
\end{tabular}


members want to

do is OK with my

AVP. (7)

Please select how frequently, in your opinion, the following statements describe the AVP of your department (AVP Name):

\begin{tabular}{|c|c|c|c|c|c|}
\hline & $\begin{array}{c}\text { Not At All } \\
(0)\end{array}$ & $\begin{array}{l}\text { Once In A } \\
\text { While (1) }\end{array}$ & Sometimes (2) & $\begin{array}{c}\text { Fairly Often } \\
\text { (3) }\end{array}$ & $\begin{array}{c}\text { Frequently, If } \\
\text { Not Always } \\
\text { (4) }\end{array}$ \\
\hline $\begin{array}{l}\text { Department } \\
\text { members are } \\
\text { proud to be } \\
\text { associated } \\
\text { with my AVP. } \\
\text { (1) }\end{array}$ & 0 & 0 & 0 & 0 & 0 \\
\hline $\begin{array}{l}\text { My AVP } \\
\text { helps } \\
\text { department } \\
\text { members find } \\
\text { meaning in } \\
\text { their work. (2) }\end{array}$ & 0 & 0 & 0 & 0 & 0 \\
\hline $\begin{array}{c}\text { My AVP gets } \\
\text { department } \\
\text { members to } \\
\text { rethink ideas } \\
\text { that they had } \\
\text { never } \\
\text { questioned } \\
\text { before. (3) }\end{array}$ & 0 & 0 & 0 & 0 & 0 \\
\hline $\begin{array}{l}\text { My AVP } \\
\text { gives personal } \\
\text { attention to } \\
\text { department } \\
\text { members who } \\
\text { seem rejected. } \\
\text { (4) }\end{array}$ & 0 & 0 & 0 & 0 & 0 \\
\hline $\begin{array}{l}\text { My AVP calls } \\
\text { attention to } \\
\text { what } \\
\text { department } \\
\text { members can } \\
\text { get for what } \\
\text { they } \\
\text { accomplish. } \\
\text { (5) }\end{array}$ & 0 & 0 & 0 & 0 & 0 \\
\hline My AVP tells & 0 & 0 & 0 & 0 & 0 \\
\hline
\end{tabular}




\begin{tabular}{|c|c|c|c|c|c|}
\hline $\begin{array}{l}\text { department } \\
\text { members the } \\
\text { standards they } \\
\text { have to know } \\
\text { to carry out } \\
\text { their work. (6) }\end{array}$ & & & & & \\
\hline $\begin{array}{c}\text { My AVP asks } \\
\text { no more of } \\
\text { department } \\
\text { members than } \\
\text { what is } \\
\text { absolutely } \\
\text { essential. (7) }\end{array}$ & 0 & 0 & 0 & 0 & 0 \\
\hline
\end{tabular}




\section{APPENDIX B}

Survey E-mail Invitation and Reminder 
$\$\{\mathrm{~m}: / /$ FirstName $\}$

My name is Bharat Mohan and I am a Ph.D. student at the University of San Diego. You are invited to participate in a survey as part of my dissertation research. The Human Resources department at < research site $>$ is supporting this dissertation research project.

Please use the following link to the take the survey: $\$\{1: / /$ SurveyLink? $d=$ Take the Survey\}

Participation in this survey is completely voluntary. However, your participation in the survey will help me tremendously in completing my Ph.D. Your responses will also help the Human Resources department both understand and improve the employee experience $<$ research site $>$. The survey will take less than 10 minutes to complete.

I will be the only person to have access to the data. Your responses will remain anonymous and the data will only be presented at the aggregate level. If you have any questions, I would be more than happy to connect with you. You can reach me either at (609) 529-1441 or at bmohan@sandiego.edu.

Sincerely,

Bharat Mohan

Follow the link to opt out of future emails:

$\$\{1: / / O p t O u t L i n k ? d=$ Click here to unsubscribe $\}$ 


\section{APPENDIX C}

Multi-Level Modeling Technical Explanation 
The general hierarchical form of a simple two-level model using HLM is:

(1.1) $Y_{i j}=\beta_{0 j}+\beta_{1 j} X_{i j}+r_{i j}$,

(2.1) $\beta_{0 \mathrm{j}}=\gamma_{00}+\gamma_{01} \mathrm{~W}_{\mathrm{j}}+v_{0 \mathrm{j}}$,

(3.1) $\beta_{1 \mathrm{j}}=\gamma_{10}+\gamma_{11} \mathrm{~W}_{\mathrm{j}}+v_{\mathrm{ij}}$,

where Equation (1.1) is the Level-1 model and Equations (2.1) and (3.1) are the Level-2 models. There are $i=1, \ldots, n_{j}$ Level-1 units nested within $j=1, \ldots, J$ Level-2 units.

Following the general hierarchical form of a simple two-level model using HLM, the specific hierarchical form used in this study is:

(1.2) $\mathrm{JS}_{\mathrm{ij}}=\beta_{0 \mathrm{j}}+\beta_{1 \mathrm{j}} \mathrm{YOS}_{\mathrm{ij}}+\mathrm{r}_{\mathrm{ij}}$,

(2.2) $\beta_{0 \mathrm{j}}=\gamma_{00}+\gamma_{01}$ LEAD $_{\mathrm{j}}+\gamma_{02}$ CLIMSTRENGTH $_{\mathrm{j}}+v_{0 \mathrm{j}}$,

(3.2) $\beta_{1 \mathrm{j}}=\gamma_{10}+\gamma_{11}$ LEAD $_{\mathrm{j}}+\gamma_{12}$ CLIMSTRENGTH $_{\mathrm{j}}+v_{1 \mathrm{j}}$,

where Equation (1.2) is the Level-1 model and Equations (2.2) and (3.2) are the Level-2 models. In these models, $\mathrm{JS}_{\mathrm{ij}}$ is the employee job satisfaction variable; $\mathrm{YOS}_{\mathrm{ij}}$ represents the Years of Service of the employee; $\mathrm{LEAD}_{\mathrm{j}}$ is the leadership rating of the AVP (in this case, different leadership styles are utilized in the models, consisting of the four different transformational leadership dimensions, the two dimensions of transactional leadership, and Laissez-Faire leadership); and CLIMSTRENGTH $\mathrm{H}_{\mathrm{j}}$ represents the organizational climate strength variable (in different models, climate strength measures of Autonomy, Innovation and Flexibility, or Effort were included in the model). 
Given that this study analyzes employees within different departments at the research site, it can also be stated that this study analyzes employee $i$ within department $j$ when investigating the inter-relationships between supervisor leadership style, organizational climate strength, and employee job satisfaction. Both $\beta_{0 \mathrm{j}}$ and $\beta_{1 \mathrm{j}}$ are Level1 coefficients. In this study, these Level-1 coefficients are random Level-1 coefficients; as expressed in Equations (2.2) and (3.2), this study utilizes the intercepts- and slopes-asoutcomes model of HLM. The general hierarchical form takes on the following combined form:

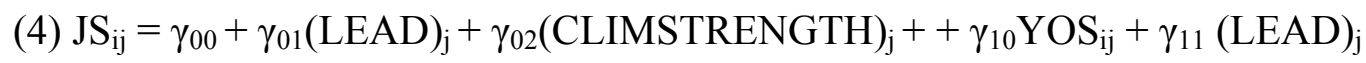

$$
\begin{aligned}
& (\text { YOS })_{i j}+\gamma_{12}(\text { CLIMSTRENGTH })_{j}(Y O S)_{i j}+v_{0 j}+v_{1 j}(Y O S)_{i j}+r_{i j} .
\end{aligned}
$$

Equation (4) illustrates that this outcome of employee-level job satisfaction may be viewed as a function of the overall intercept $\left(\gamma_{00}\right)$, the main effect of supervisor leadership style $\left(\gamma_{01}\right)$, the main effect of organizational climate strength $\left(\gamma_{02}\right)$, the main effect of years of service $\left(\gamma_{10}\right)$, and two cross-level interactions involving supervisor leadership style with employee years of service $\left(\gamma_{11}\right)$ and organizational climate strength with employee years of service $\left(\gamma_{12}\right)$, plus a random error $\left(v_{0 j}+v_{1 j}(Y O S)_{i j}+r_{i j}\right)$.

In the location treatment of the Level-1 independent variable of Years of Service, I centered the variable around the Natural-X Metric. This centering decision was made because the beta-coefficient estimate when Years of Service was equal to 0 would still be meaningful. I utilized the grand-mean centering technique for the Level-2 independent variables of supervisor leadership style and organizational climate strength, as this was the general recommendation for location treatment of Level-2 variables when utilizing HLM by Bryk and Raudenbush (1992). 


\section{APPENDIX D}

Level of Satisfaction on Dimensions over Years of Service 


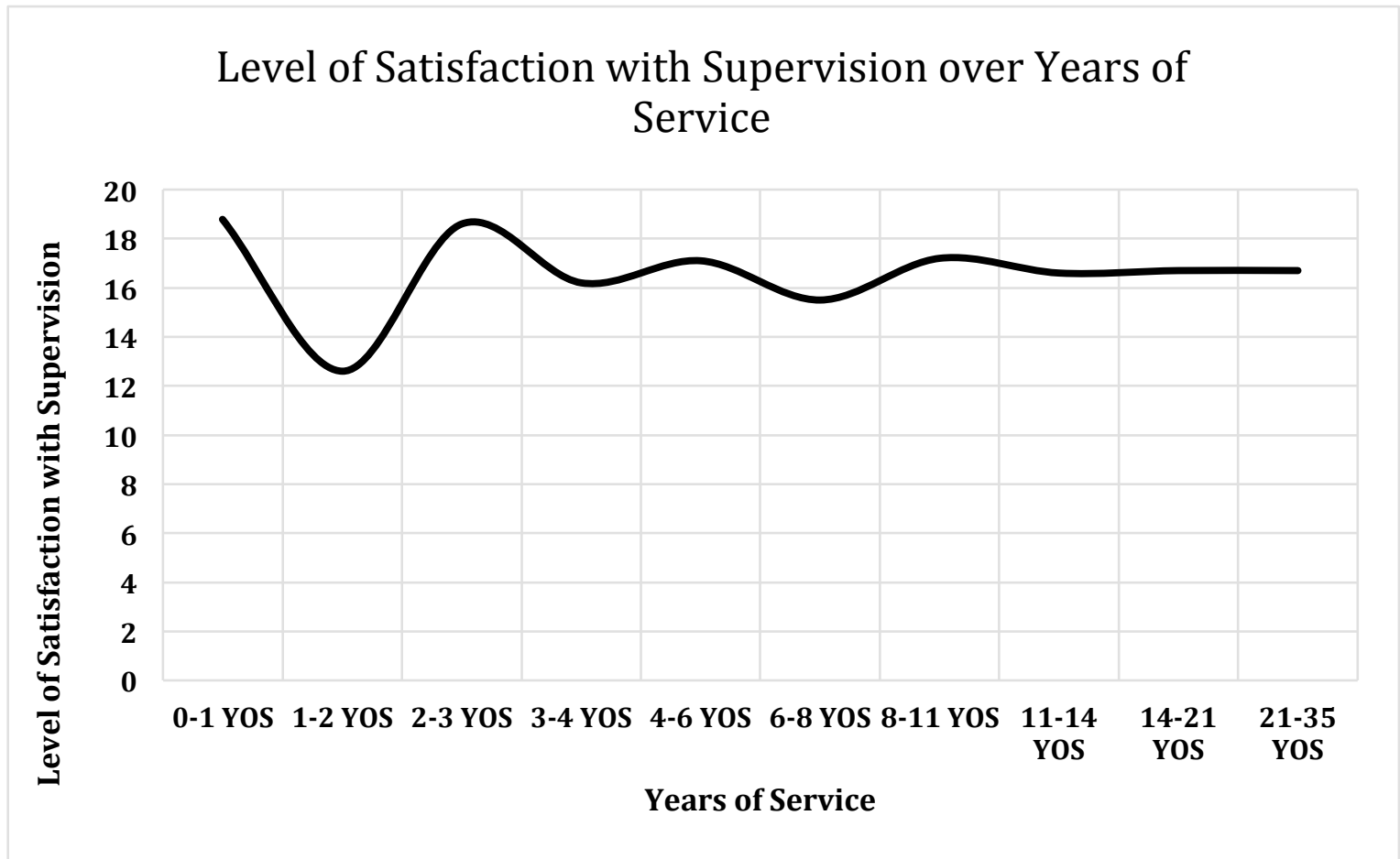

Figure D1. Level of satisfaction with Supervision over years of service.

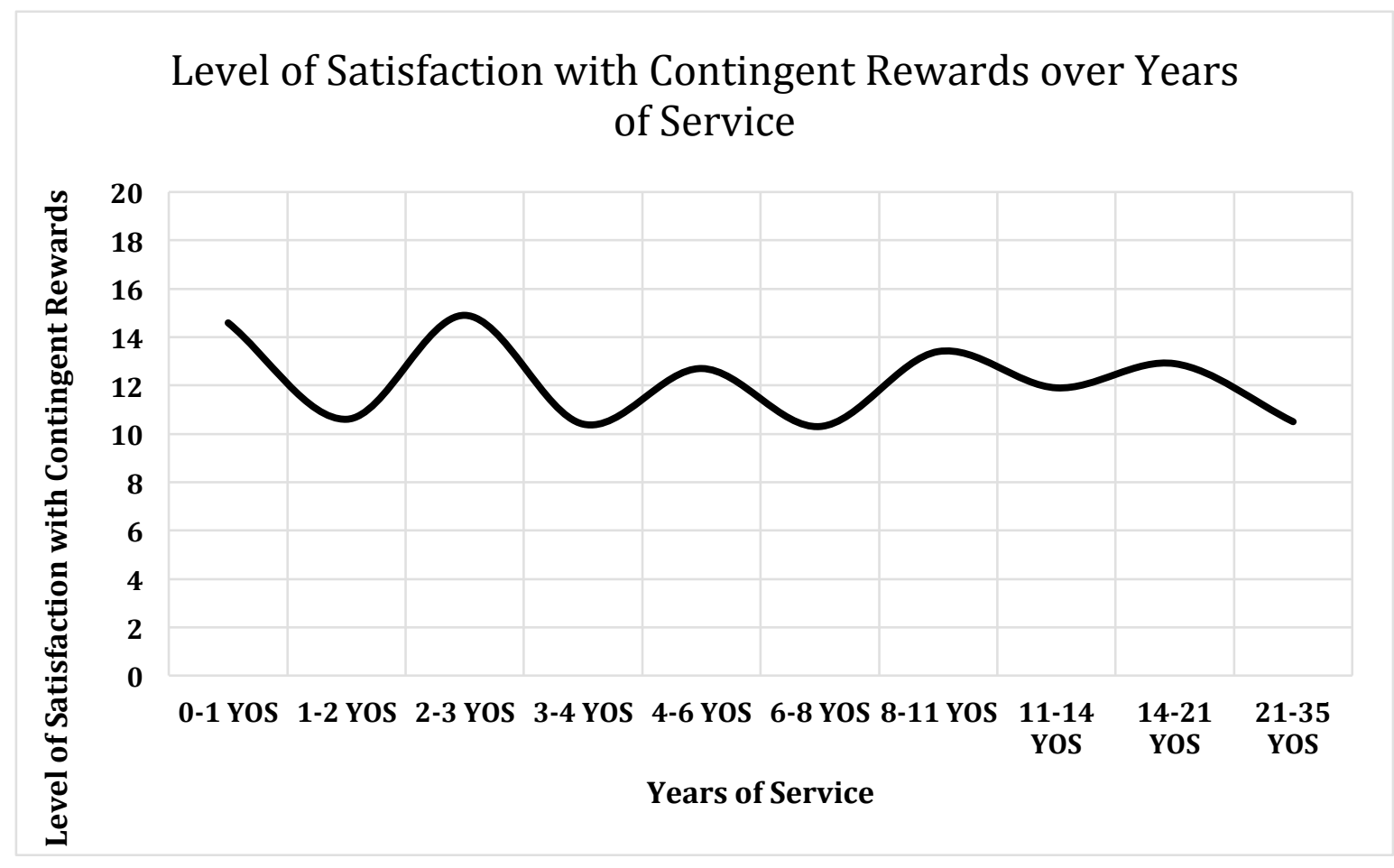


Figure D2. Level of satisfaction with Contingent Rewards over years of service.

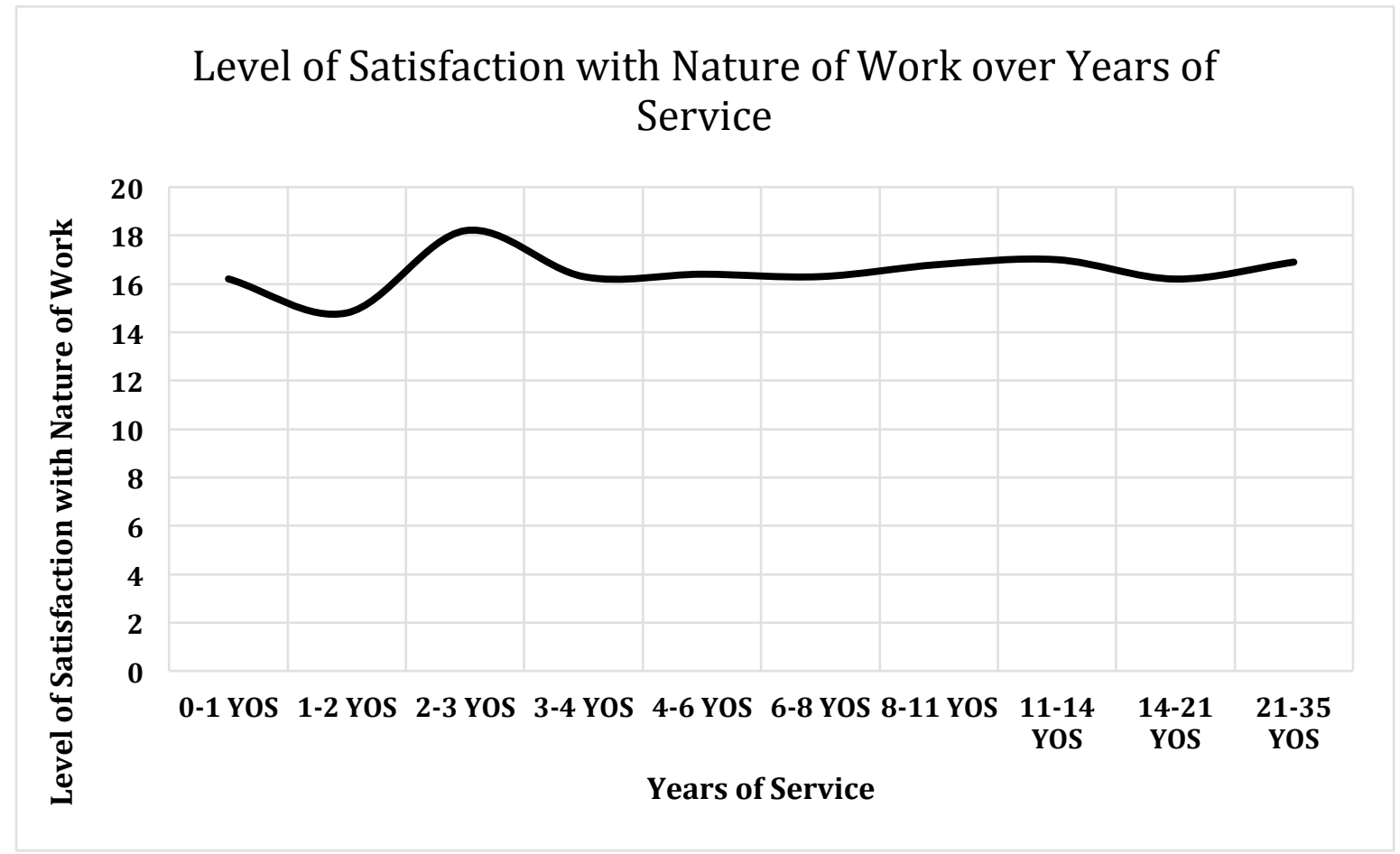

Figure D3. Level of satisfaction with Nature of Work over years of service.

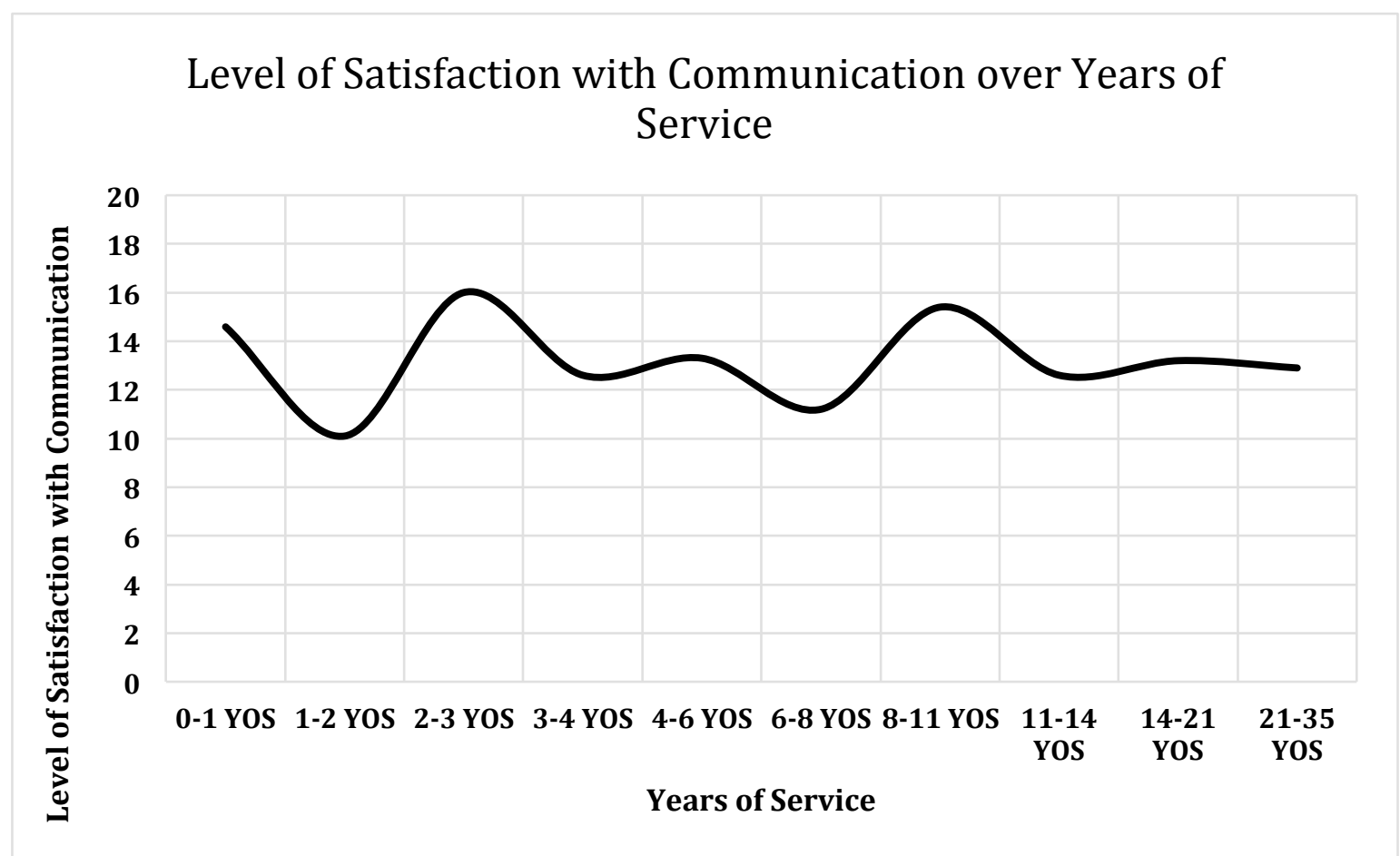


Figure D4. Level of satisfaction with Communication over years of service.

\section{APPENDIX E}

Transformational Leadership Dimension Ratings of AVP over Years of Service 


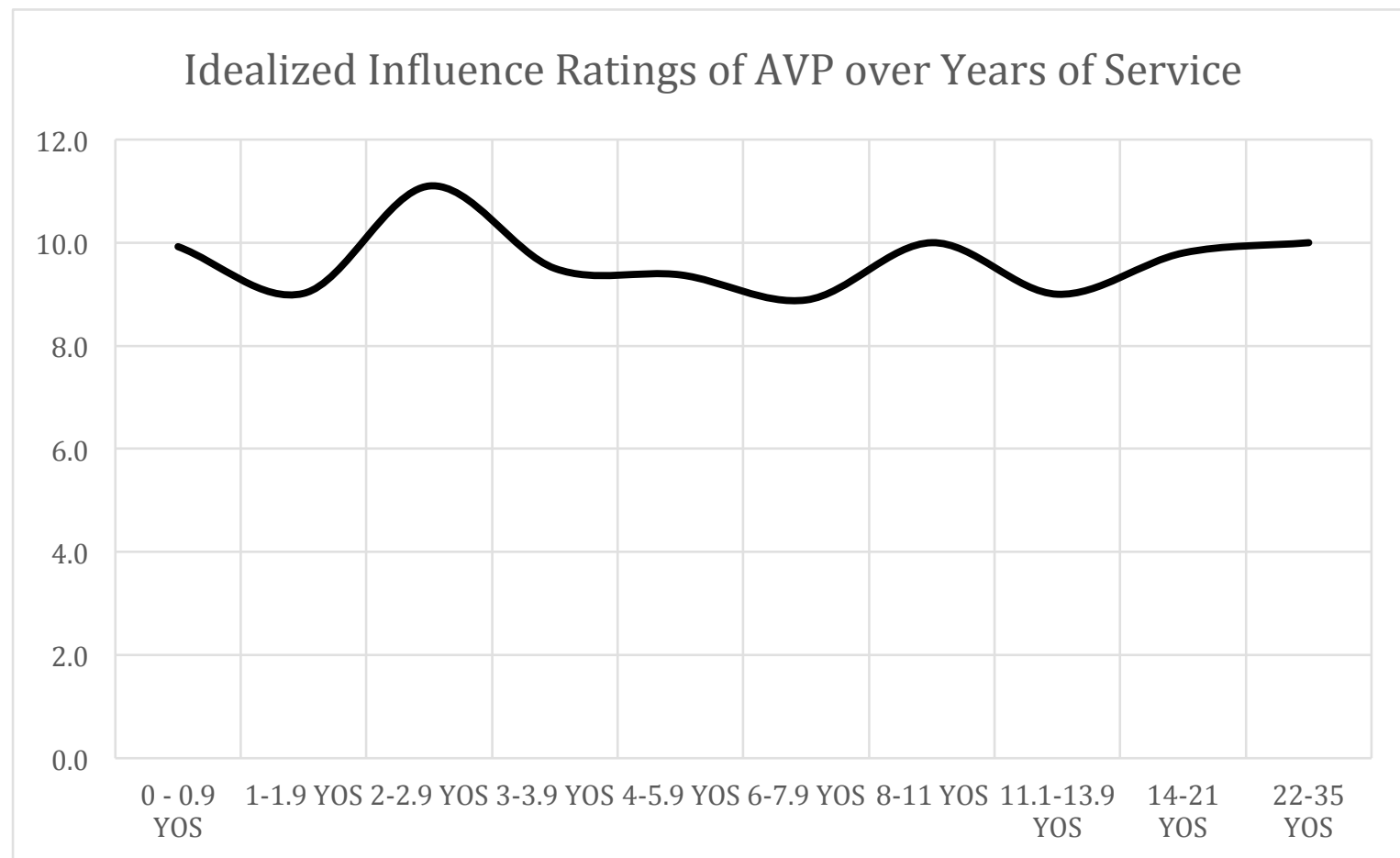

Figure E1. Idealized Influence ratings of AVP over years of service.

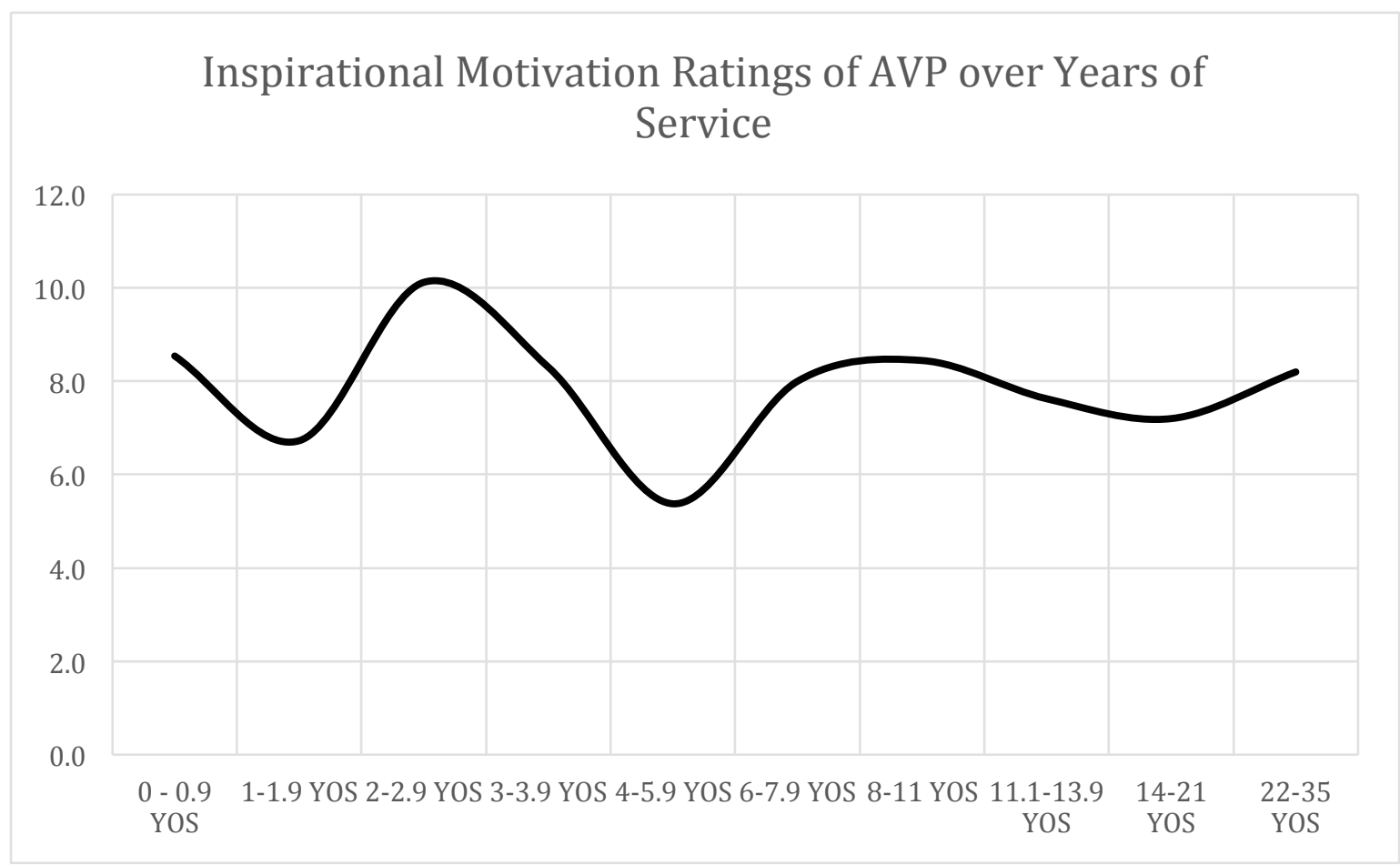


Figure E2. Inspirational Motivation ratings of AVP over years of service.

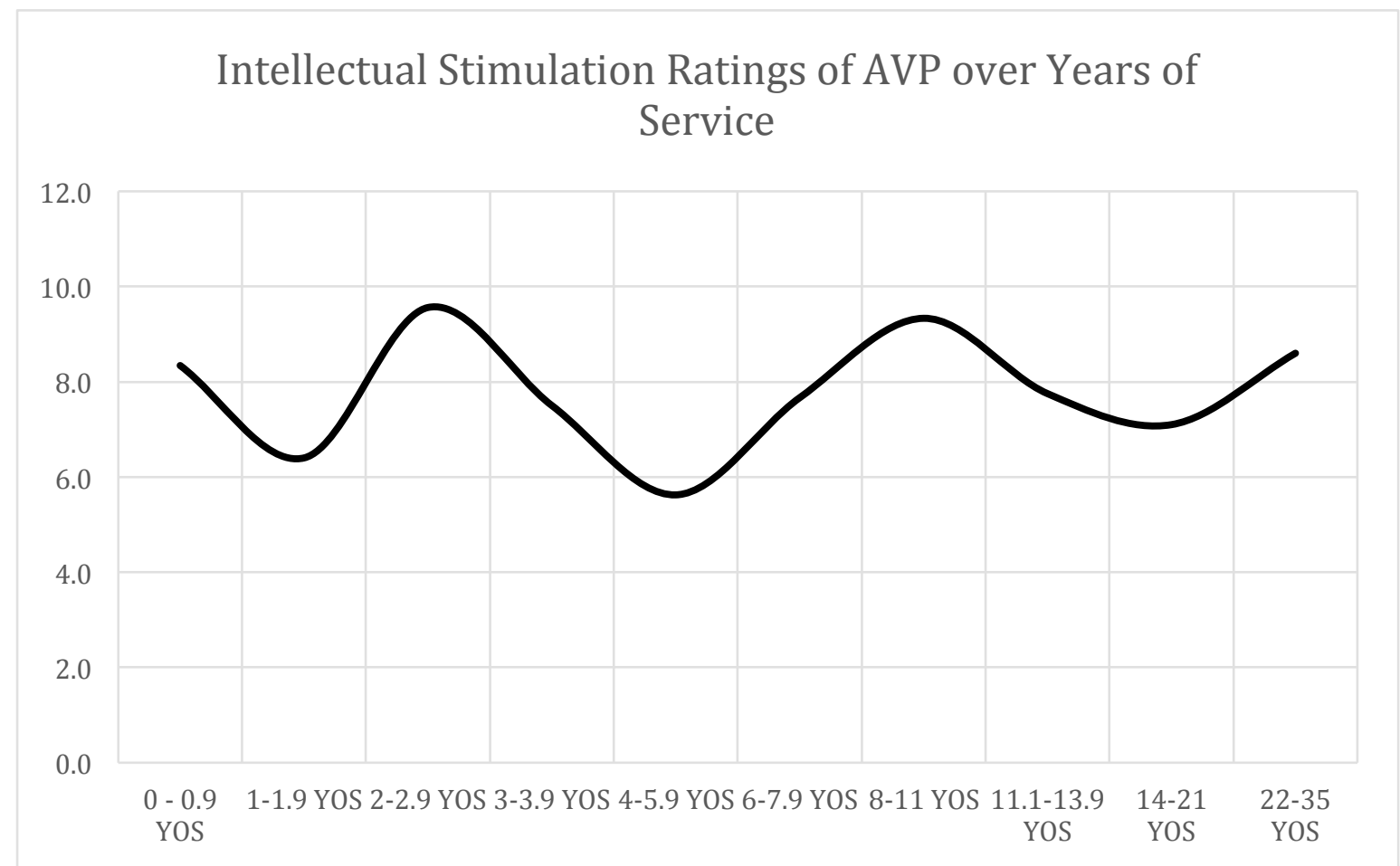

Figure E3. Intellectual Stimulation ratings of AVP over years of service.

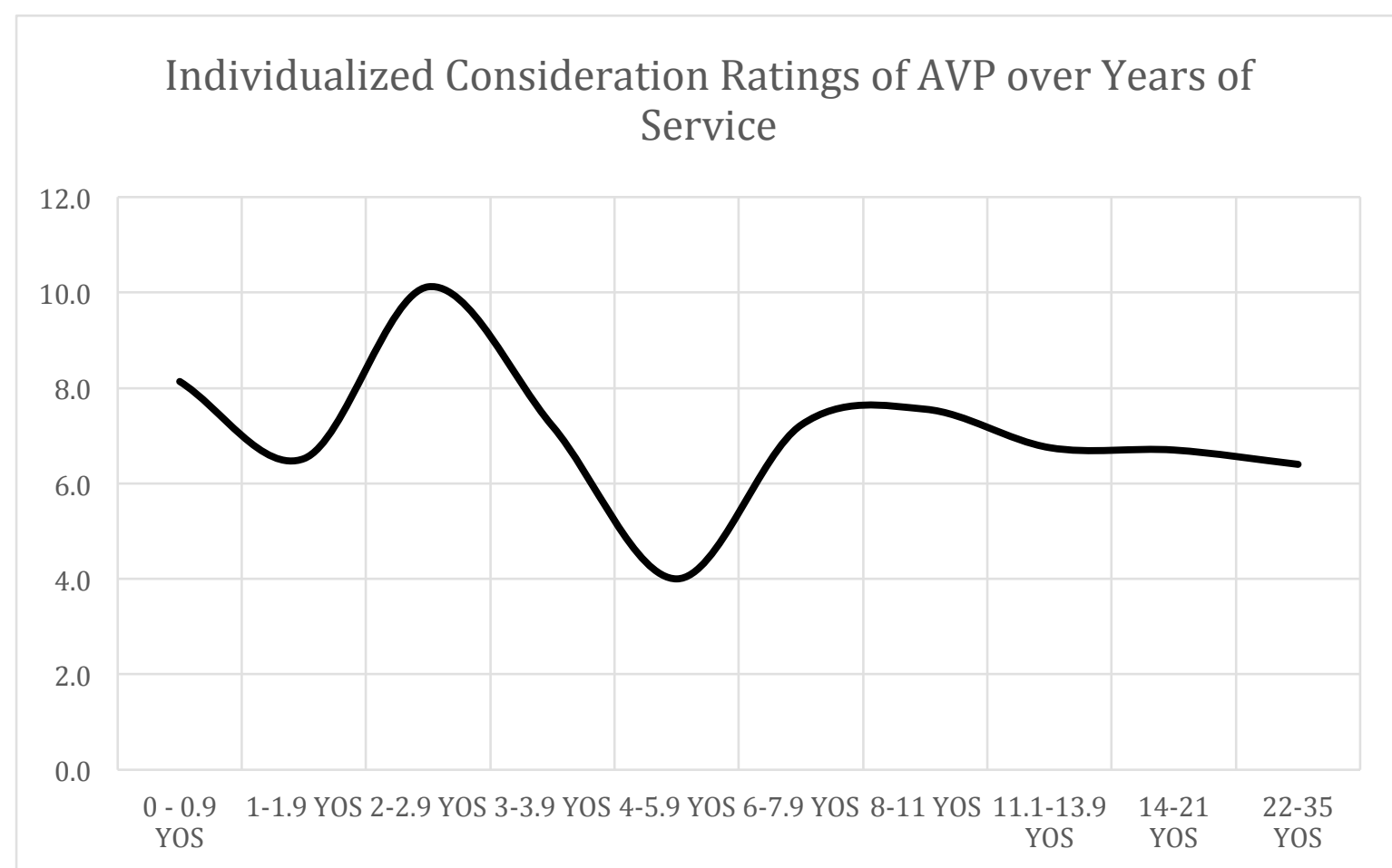


Figure E4. Individualized Consideration ratings of AVP over years of service APPENDIX F

Transactional Leadership Dimension Ratings of AVP over Years of Service 


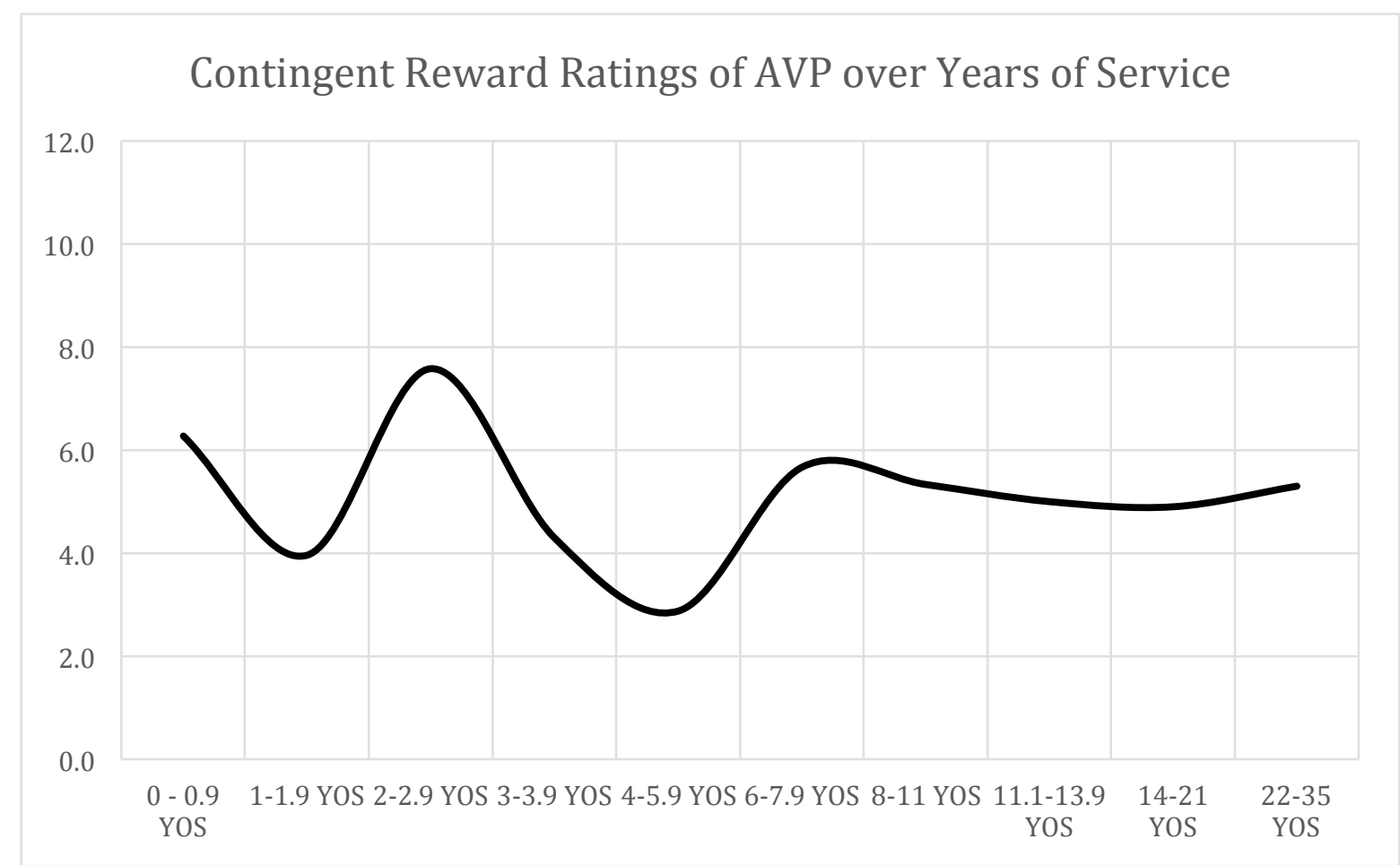

Figure F1. Contingent Reward ratings of AVP over years of service.

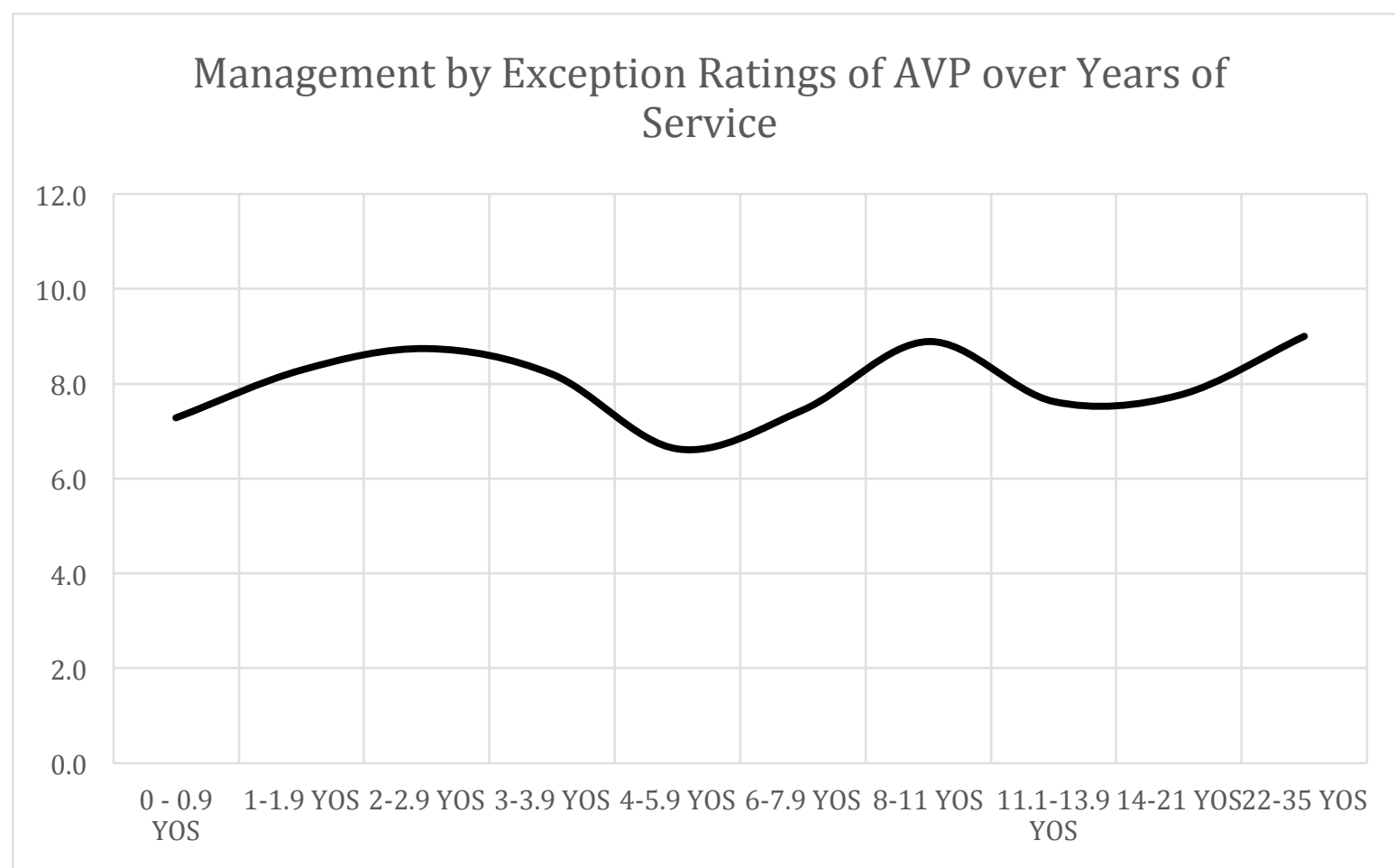


Figure F2. Management by Exception ratings of AVP over years of service.

APPENDIX G

Laissez-Faire Ratings of AVP over Years of Service 


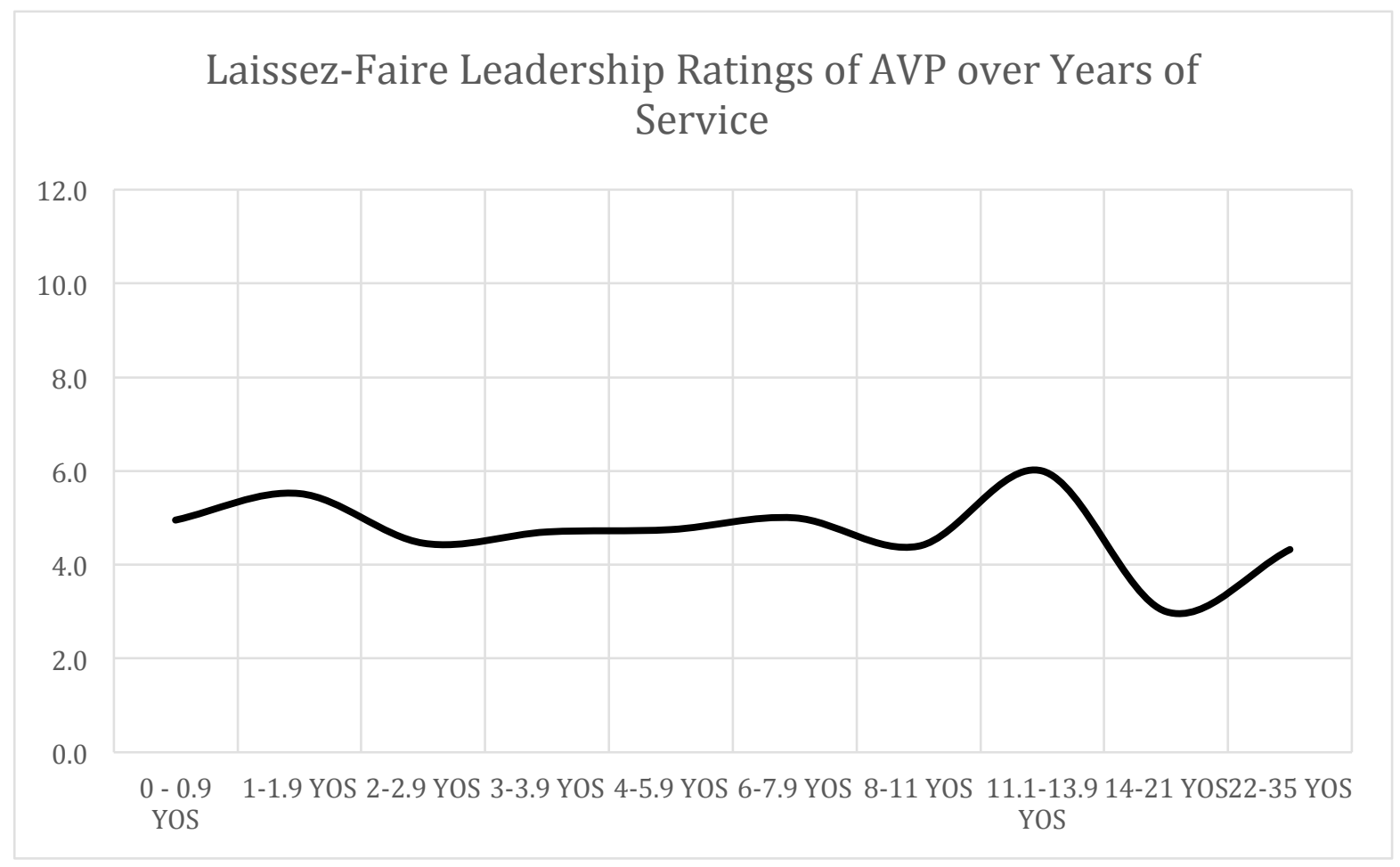

Figure G1. Laissez-Faire Leadership ratings of AVP over years of service 


\section{APPENDIX H}

Absolute Value of Difference Between Employee Ratings and AVP Rating of Transformational Leadership Dimensions over Years of Service 


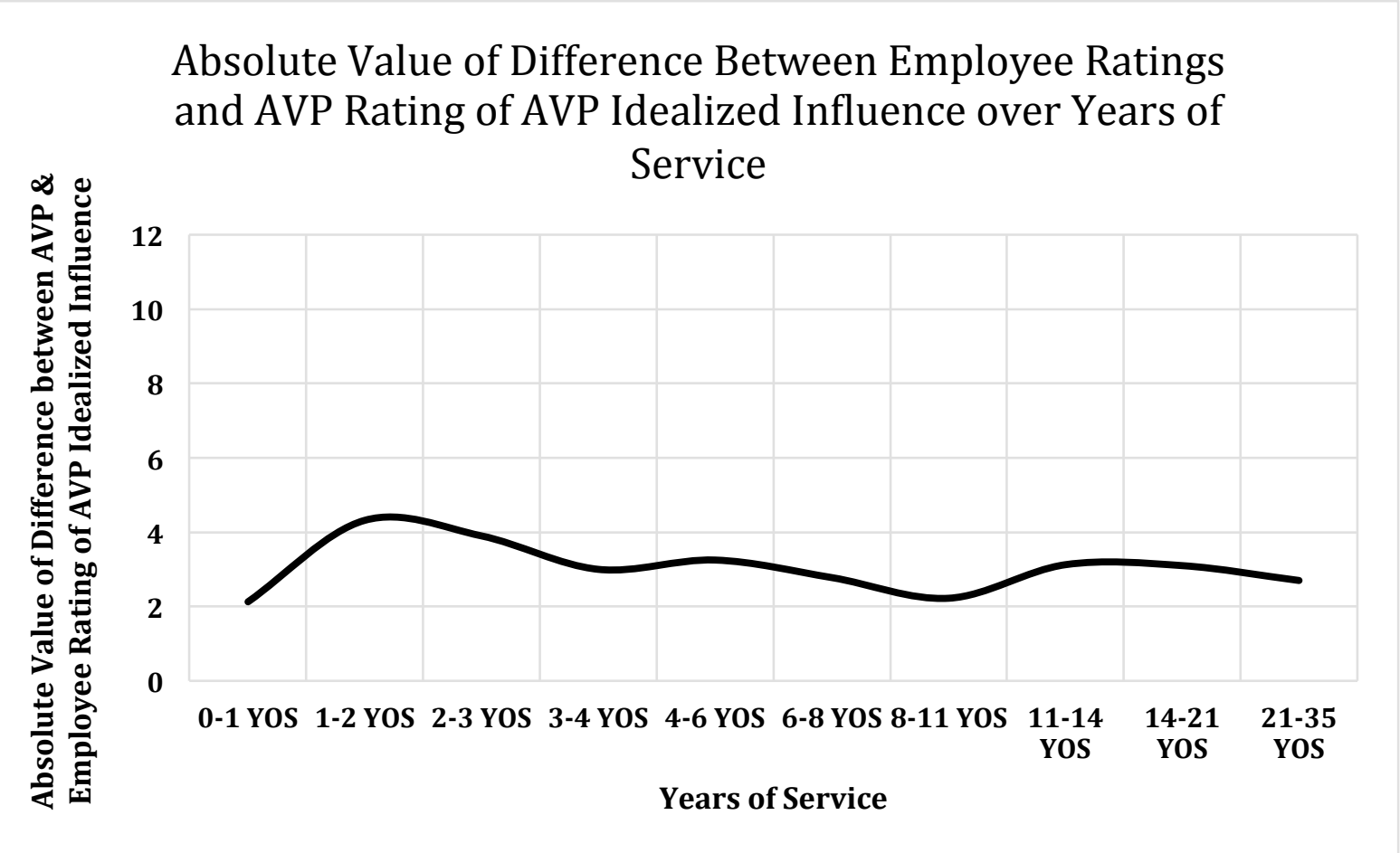

Figure H1. Absolute value of difference between employee ratings and AVP rating of AVP Idealized Influence over years of service. 


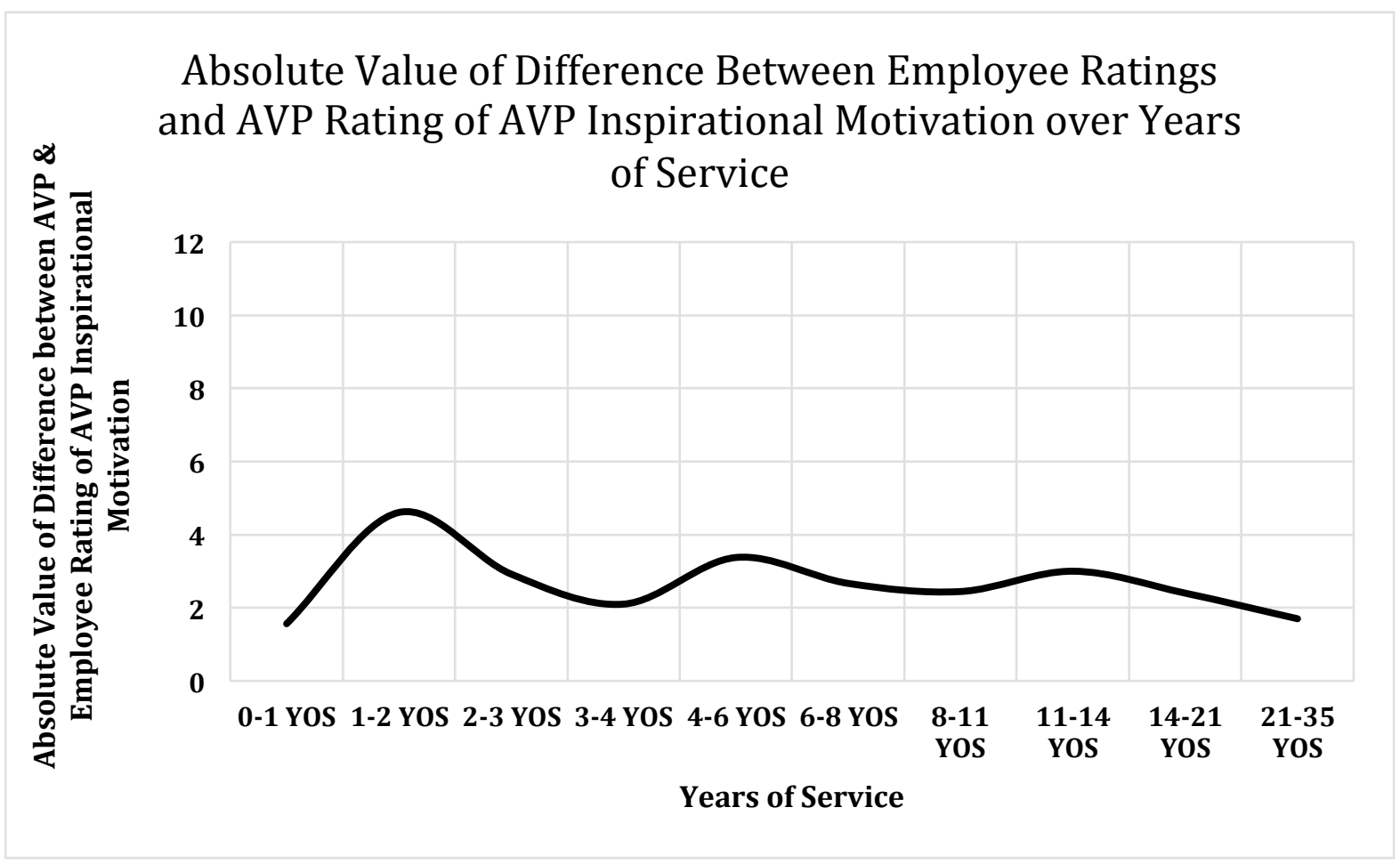

Figure H2. Absolute value of difference between employee ratings and AVP rating of AVP Inspirational Motivation over years of service. 


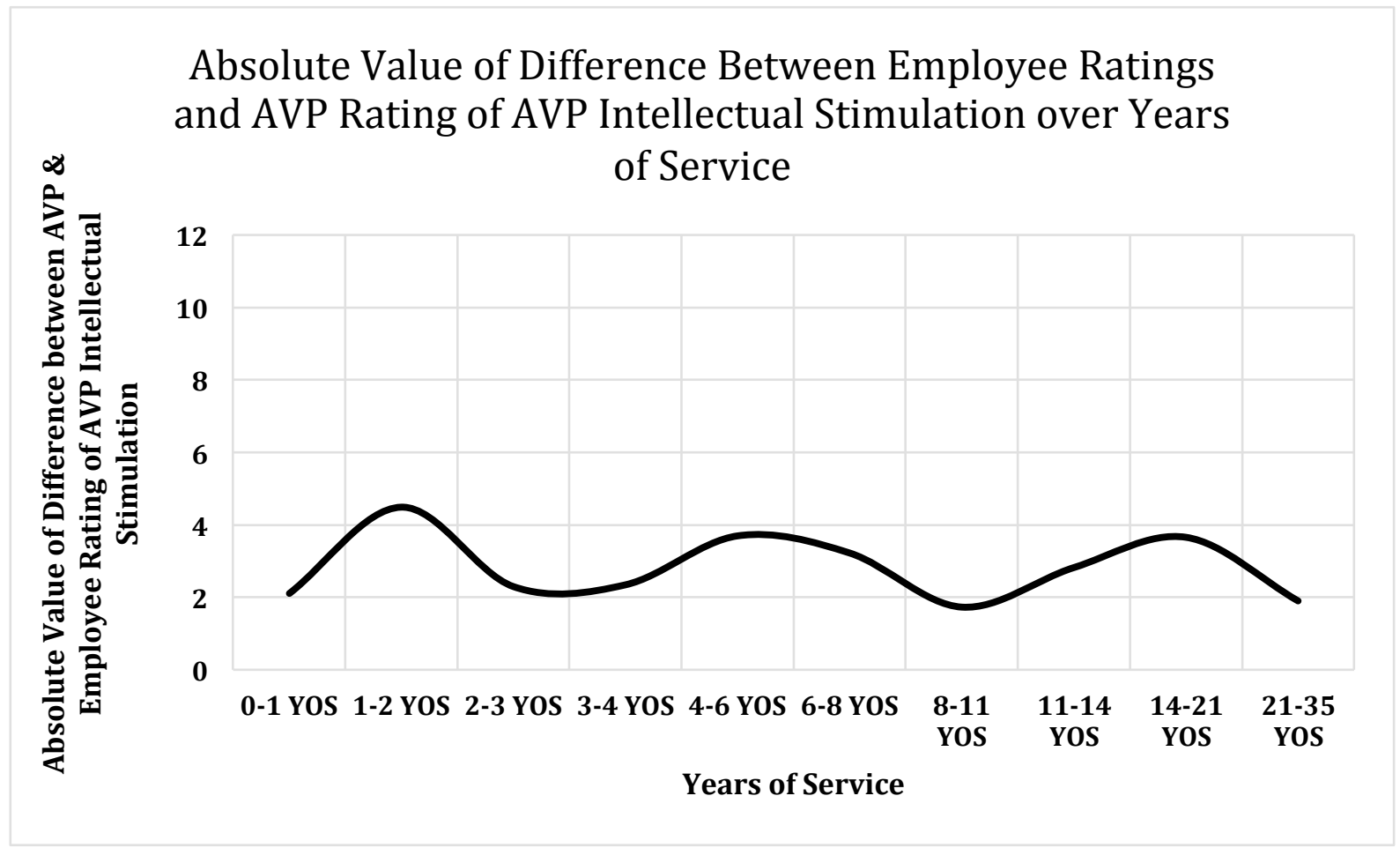

Figure H3. Absolute value of difference between employee ratings and AVP rating of AVP Intellectual Stimulation over years of service. 


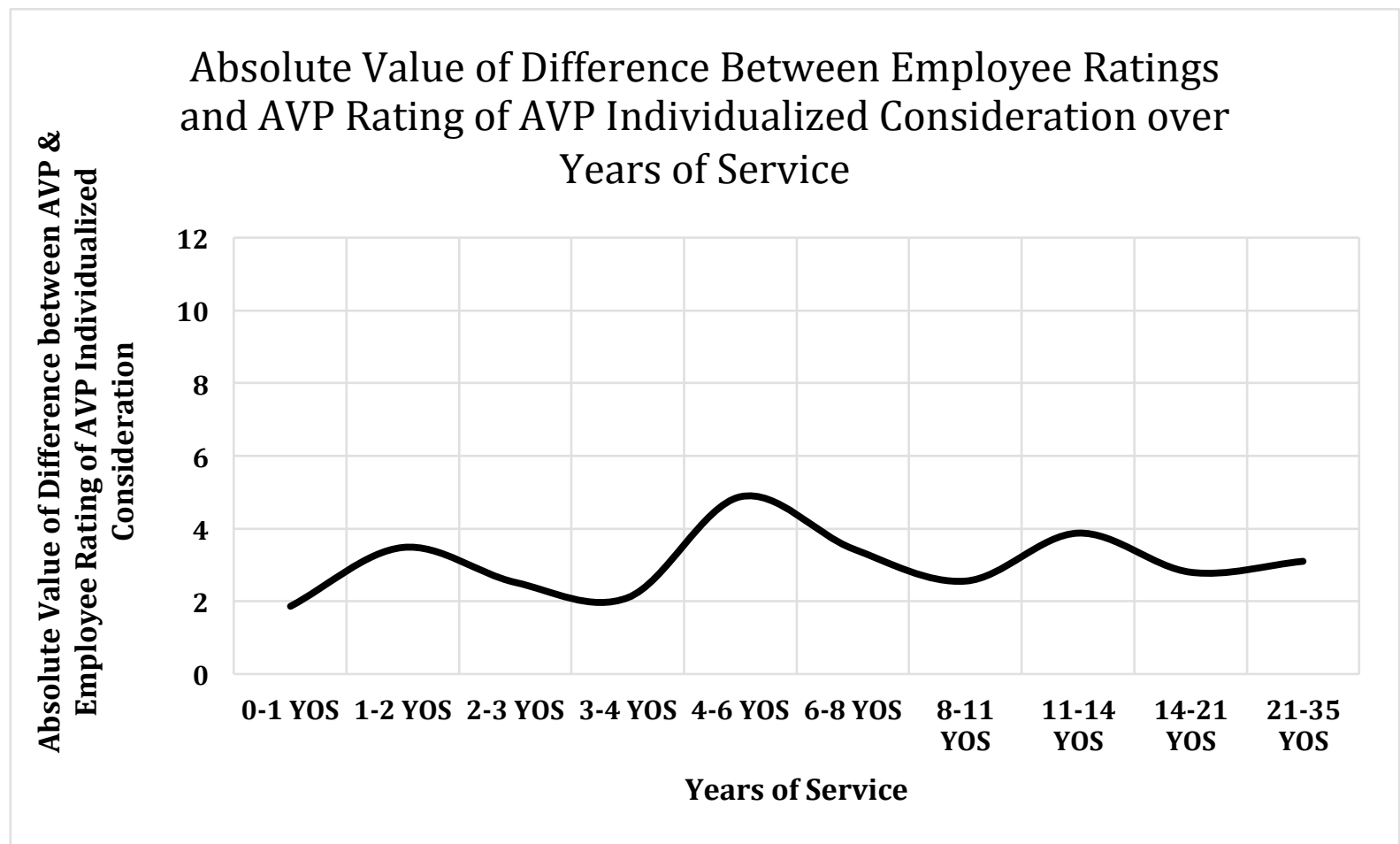

Figure H4. Absolute value of difference between employee ratings and AVP rating of AVP Individualized Consideration over years of service. 


\section{APPENDIX I}

Absolute Value of Difference Between Employee Ratings and AVP Rating of Transactional Leadership Dimensions over Years of Service 


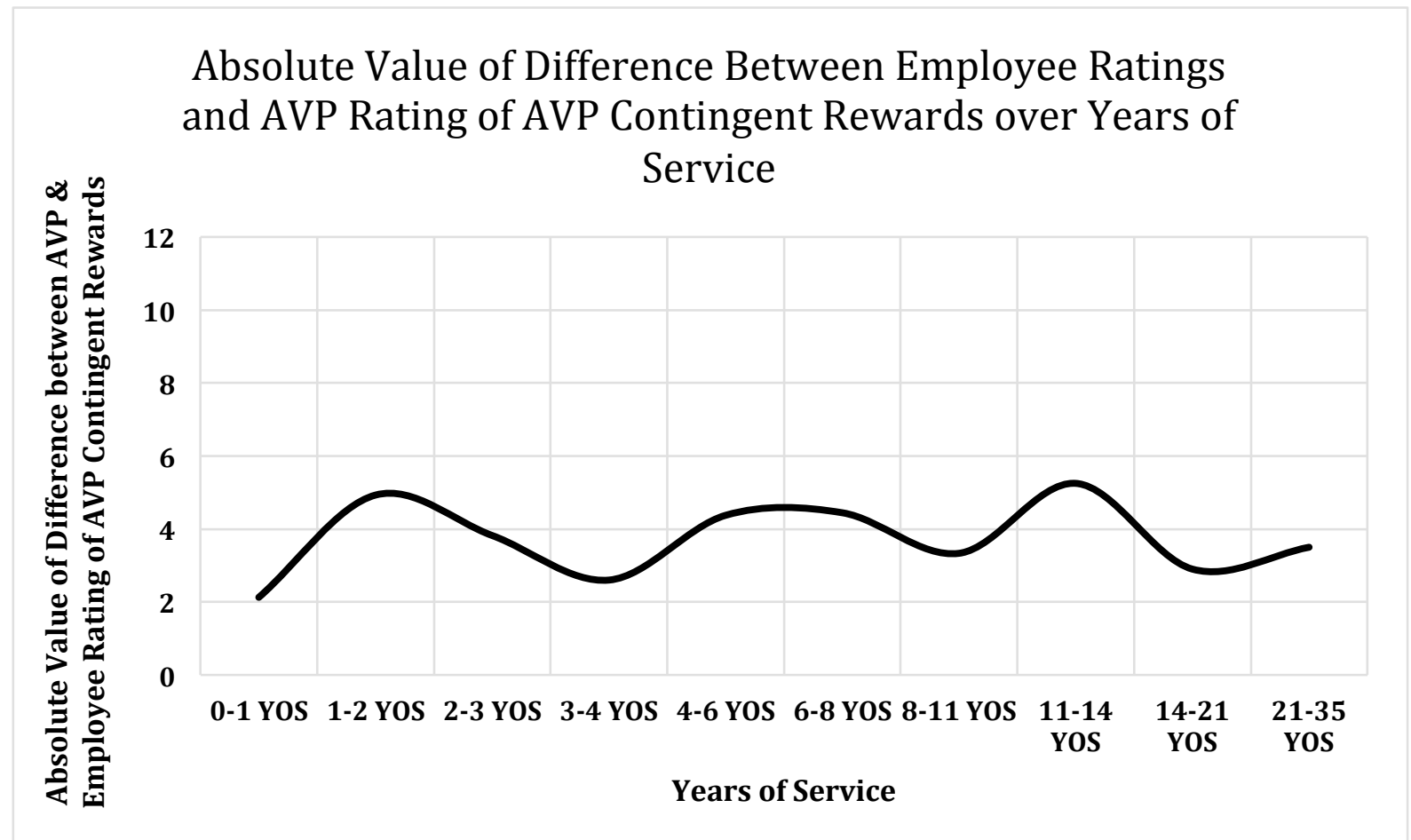

Figure I1. Absolute value of difference between employee ratings and AVP rating of AVP Contingent Rewards over years of service. 


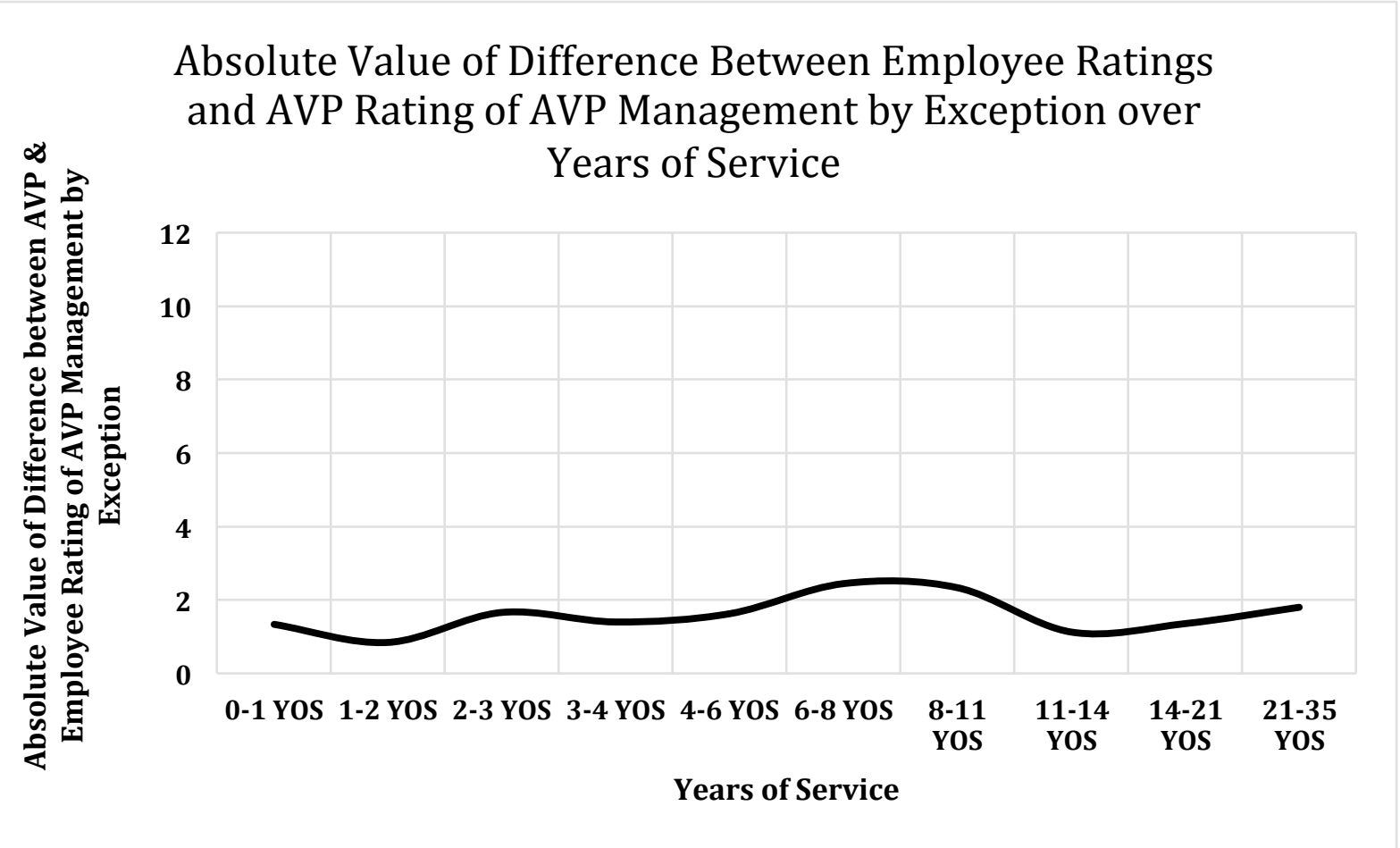

Figure I2. Absolute value of difference between employee ratings and AVP rating of AVP Management by Exception over years of service. 


\section{APPENDIX J}

Absolute Value of Difference Between Employee Ratings and AVP Rating of AVP

Laissez-Faire Leadership over Years of Service 


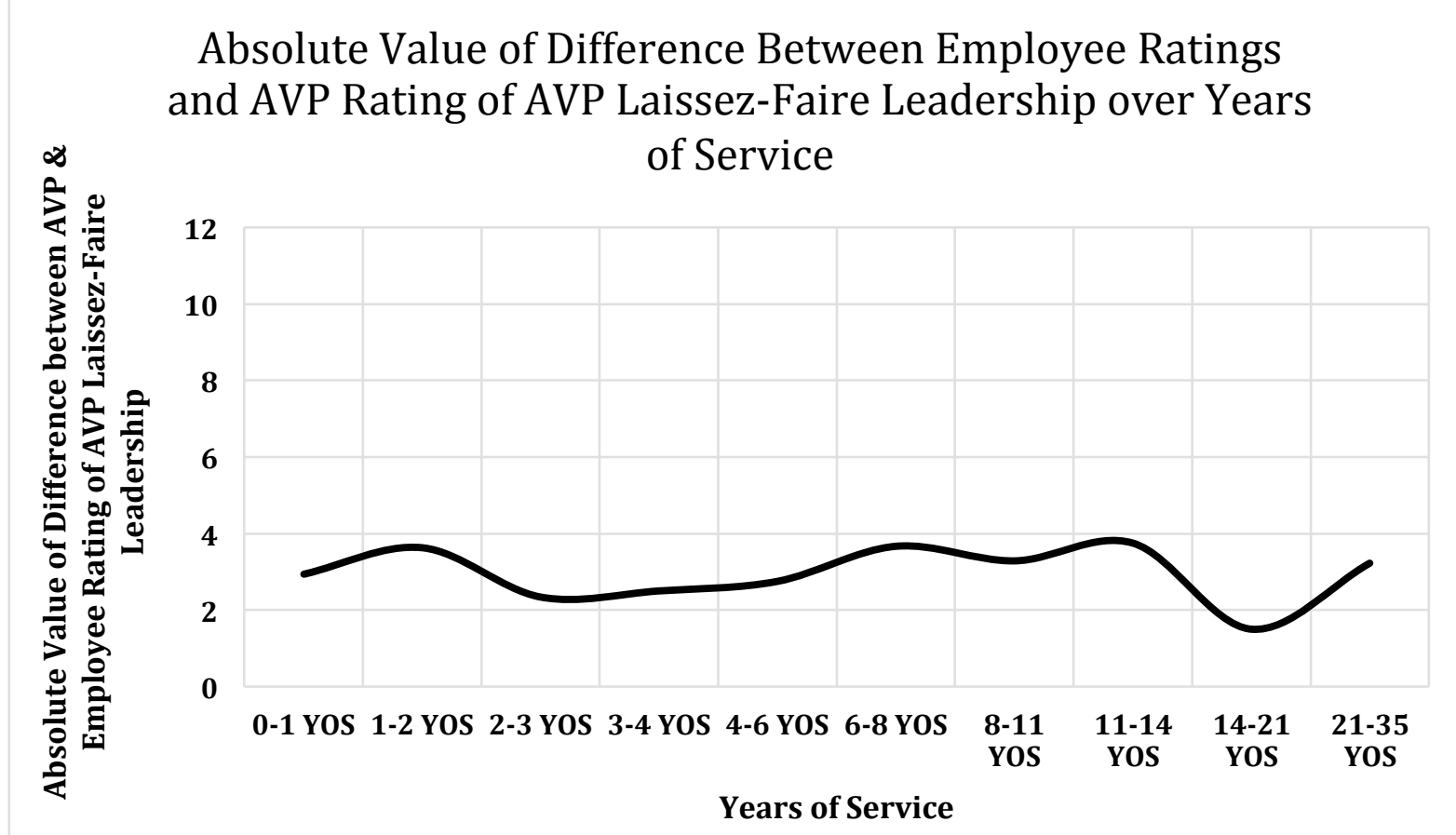

Figure J1. Absolute value of difference between employee ratings and AVP rating of AVP Laissez-Faire Leadership over years of service. 


\section{APPENDIX K}

Transformational Leadership and Dimensions of Satisfaction HLM Fixed Effects Components Estimation 
Table K1

Transformational Leadership and Overall Satisfaction HLM Fixed Effects Estimation

\begin{tabular}{|c|c|c|c|c|c|c|c|c|c|c|c|c|}
\hline \multirow[b]{2}{*}{ Fixed Eff. } & \multicolumn{3}{|c|}{ Model 1} & \multicolumn{3}{|c|}{ Model 2} & \multicolumn{3}{|c|}{ Model 3} & \multicolumn{3}{|c|}{ Model 4} \\
\hline & Coeff & $S E$ & Sig & Coeff & $S E$ & Sig & Coeff & $S E$ & Sig & Coeff & $S E$ & Sig \\
\hline $\begin{array}{c}\text { For Int1, } \\
\boldsymbol{\beta}_{\boldsymbol{0}} \\
\text { Int } 2, \gamma_{00}\end{array}$ & 64.70 & 10.98 & .00 & 72.81 & 11.44 & .00 & 67.08 & 13.66 & .01 & 69.18 & 16.77 & .02 \\
\hline $\begin{array}{c}\text { IdealInf, } \\
\gamma_{01} \\
\text { Auton., } \\
\gamma_{02} \\
\text { I\&F, } \gamma_{02}\end{array}$ & -0.53 & 1.10 & .65 & $\begin{array}{l}0.73 \\
-6.96\end{array}$ & $\begin{array}{l}1.18 \\
3.80\end{array}$ & $\begin{array}{l}.57 \\
.14\end{array}$ & -0.53 & 1.21 & .68 & -0.77 & 1.35 & .60 \\
\hline $\begin{array}{c}\text { Effort, } \gamma_{02} \\
\text { For YOS } \\
\text { slope, } \boldsymbol{\beta}_{1} \\
\text { Int } 2, \gamma_{10}\end{array}$ & -0.13 & 0.25 & .62 & -0.05 & 0.29 & .88 & -0.11 & 0.24 & .65 & -0.87 & 2.32 & .73 \\
\hline $\begin{array}{c}\text { For Int1, } \\
\boldsymbol{\beta}_{0} \\
\text { Int } 2, \gamma_{00}\end{array}$ & 59.85 & 14.17 & .01 & 67.37 & 13.43 & .01 & 59.88 & 18.57 & .03 & 57.56 & 25.63 & .09 \\
\hline $\begin{array}{c}\text { InspiMot, } \\
\gamma_{01} \\
\text { Auton., } \\
\gamma_{02} \\
\text { I\&F, } \gamma_{02}\end{array}$ & -0.04 & 1.74 & .98 & $\begin{array}{l}1.90 \\
-7.84\end{array}$ & $\begin{array}{l}1.84 \\
3.78\end{array}$ & $\begin{array}{l}.36 \\
.11\end{array}$ & 0.14 & 2.01 & .95 & 0.25 & 2.56 & .93 \\
\hline $\begin{array}{c}\text { Effort, } \gamma_{02} \\
\text { For YOS } \\
\text { slope, } \boldsymbol{\beta}_{1} \\
\text { Int } 2, \gamma_{10}\end{array}$ & -0.12 & 0.25 & .66 & -0.02 & 0.30 & .95 & -0.09 & 0.26 & .75 & -0.02 & 2.88 & .99 \\
\hline
\end{tabular}




\begin{tabular}{|c|c|c|c|c|c|c|c|c|c|c|c|c|}
\hline $\begin{array}{c}\text { For Int1, } \\
\boldsymbol{\beta}_{\mathbf{0}} \\
\text { Int } 2, \gamma_{00}\end{array}$ & 74.44 & 15.28 & .01 & 73.71 & 15.22 & .01 & 77.19 & 17.15 & .01 & 85.38 & 21.57 & .02 \\
\hline $\begin{array}{c}\text { IntelStim, } \\
\gamma_{01} \\
\text { Auton., } \\
\gamma_{02} \\
\text { I\&F, } \gamma_{02}\end{array}$ & -1.93 & 1.93 & .36 & $\begin{array}{l}0.69 \\
-6.65\end{array}$ & $\begin{array}{l}2.63 \\
4.56\end{array}$ & $\begin{array}{l}.81 \\
.22\end{array}$ & -1.97 & 2.03 & .39 & -2.82 & 2.32 & .29 \\
\hline $\begin{array}{c}\text { Effort, } \gamma_{02} \\
\text { For YOS } \\
\text { slope, } \boldsymbol{\beta}_{1} \\
\operatorname{Int} 2, \gamma_{10}\end{array}$ & -0.12 & 0.25 & .66 & -0.06 & 0.29 & .84 & -0.11 & 0.24 & .66 & -1.61 & 2.19 & .50 \\
\hline $\begin{array}{c}\text { For Int1, } \\
\boldsymbol{\beta}_{\mathbf{0}} \\
\operatorname{Int} 2, \gamma_{00}\end{array}$ & 60.30 & 12.44 & .01 & 68.19 & 12.02 & .01 & 65.02 & 22.54 & .05 & 64.39 & 40.94 & .19 \\
\hline $\begin{array}{c}\text { IndiCons, } \\
\gamma_{01} \\
\text { Auton., } \\
\gamma_{02} \\
\text { I\&F, } \gamma_{02}\end{array}$ & -0.11 & 1.69 & .95 & $\begin{array}{l}2.52 \\
-9.11\end{array}$ & $\begin{array}{l}1.99 \\
4.15\end{array}$ & $\begin{array}{l}.28 \\
.09\end{array}$ & -0.41 & 2.34 & .87 & -0.45 & 4.15 & .92 \\
\hline $\begin{array}{c}\text { Effort, } \gamma_{02} \\
\text { For YOS } \\
\text { slope, } \boldsymbol{\beta}_{1} \\
\text { Int } 2, \gamma_{10}\end{array}$ & -0.12 & 0.25 & .65 & -0.01 & 0.29 & .96 & -0.10 & 0.25 & .72 & -0.66 & 4.81 & .90 \\
\hline
\end{tabular}

Note. $\mathrm{N}=93$ (Level 1); $\mathrm{N}=7$ (Level 2)

Table K2

Transformational Leadership and Supervision Satisfaction HLM Fixed Effects Estimation

\begin{tabular}{|c|c|c|c|c|c|c|c|c|c|c|c|c|}
\hline \multirow[b]{2}{*}{ Fixed Eff. } & \multicolumn{3}{|c|}{ Model 1} & \multicolumn{3}{|c|}{ Model 2} & \multicolumn{3}{|c|}{ Model 3} & \multicolumn{3}{|c|}{ Model 4} \\
\hline & Coeff & $S E$ & Sig & Coeff & $S E$ & Sig & Coeff & $S E$ & Sig & Coeff & $S E$ & Sig \\
\hline $\begin{array}{c}\text { For Int1, } \\
\boldsymbol{\beta}_{0} \\
\text { Int } 2, \gamma_{00}\end{array}$ & 17.94 & 2.88 & .00 & 20.10 & 3.24 & .00 & 17.66 & 3.46 & .01 & 17.40 & 4.41 & .02 \\
\hline
\end{tabular}




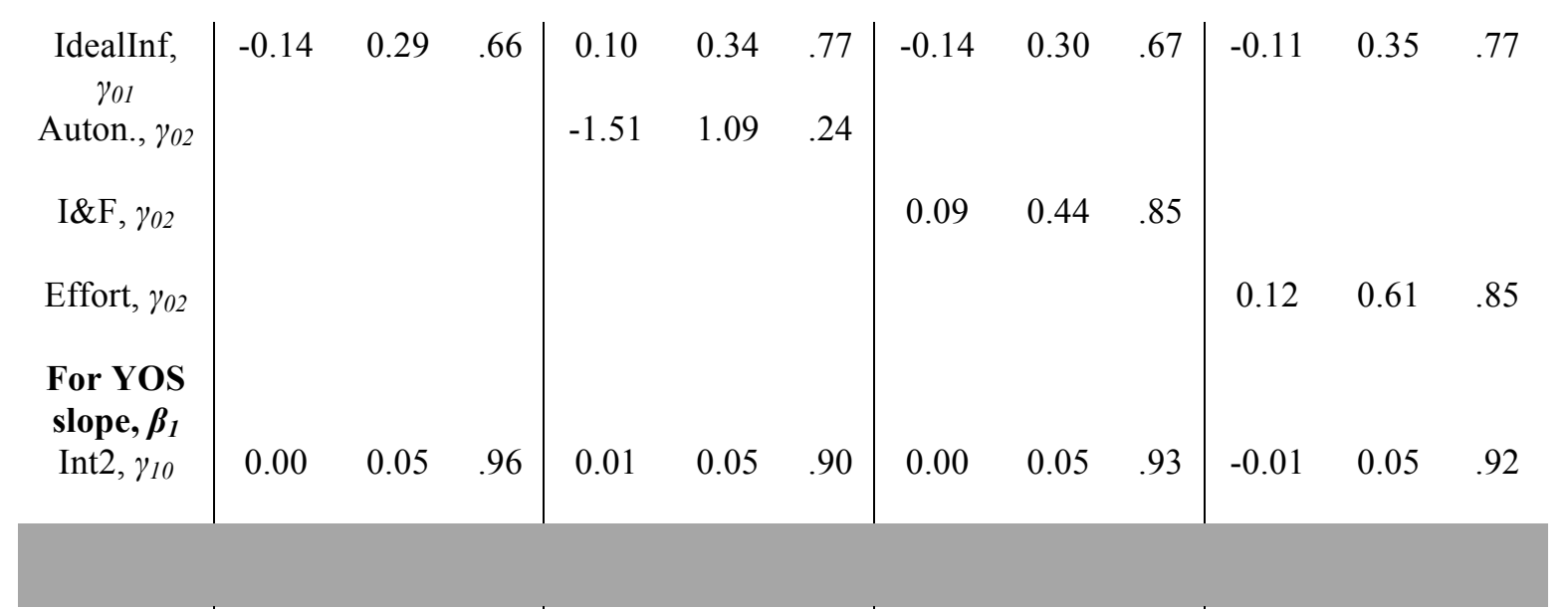

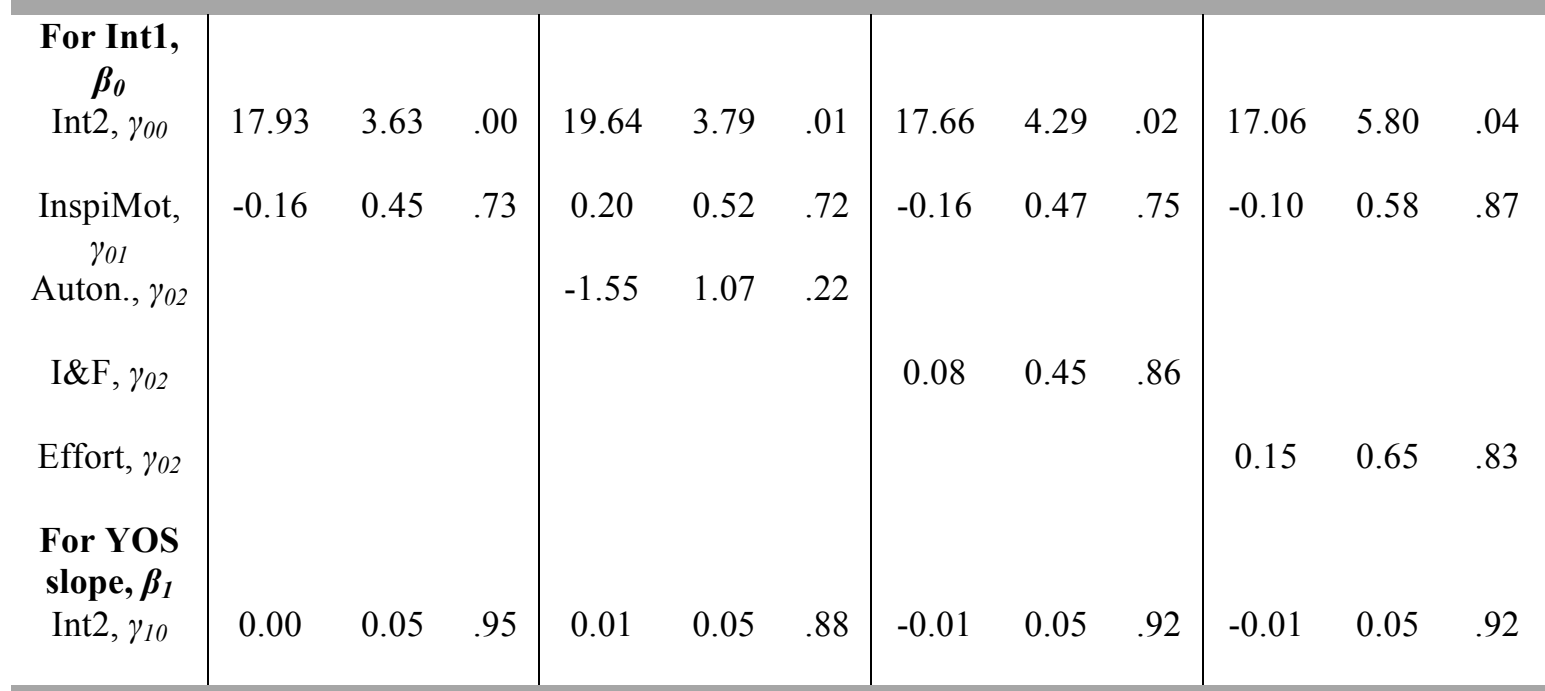

\begin{tabular}{|c|c|c|c|c|c|c|c|c|c|c|c|c|}
\hline $\begin{array}{c}\text { For Int1, } \\
\boldsymbol{\beta}_{0} \\
\text { Int } 2, \gamma_{00}\end{array}$ & 20.40 & 4.14 & .00 & 20.58 & 4.20 & .01 & 20.13 & 4.58 & .01 & 20.88 & 5.97 & .03 \\
\hline $\begin{array}{c}\text { IntelStim, } \\
\gamma_{01} \\
\text { Auton., } \gamma_{02}\end{array}$ & -0.49 & 0.53 & .40 & $\begin{array}{c}0.01 \\
-1.36\end{array}$ & $\begin{array}{l}0.71 \\
1.25\end{array}$ & $\begin{array}{l}.99 \\
.34\end{array}$ & -0.49 & 0.54 & .42 & -0.53 & 0.64 & .46 \\
\hline $\mathrm{I} \& \mathrm{~F}, \gamma_{02}$ & & & & & & & 0.08 & 0.43 & .86 & & & \\
\hline Effort, $\gamma_{02}$ & & & & & & & & & & -0.06 & 0.61 & .92 \\
\hline $\begin{array}{c}\text { For YOS } \\
\text { slope, } \boldsymbol{\beta}_{1} \\
\text { Int } 2, \gamma_{10}\end{array}$ & 0.00 & 0.05 & .98 & 0.01 & 0.05 & .93 & 0.00 & 0.05 & .97 & 0.00 & 0.05 & 0.96 \\
\hline
\end{tabular}

For Int1, $\boldsymbol{\beta}_{0}$ 


\begin{tabular}{|c|c|c|c|c|c|c|c|c|c|c|c|c|}
\hline Int $2, \gamma_{00}$ & 18.17 & 3.19 & .00 & 19.83 & 3.37 & .00 & 18.50 & 5.29 & .03 & 18.84 & 9.51 & .12 \\
\hline $\begin{array}{c}\text { IndiCons, } \\
\gamma_{01}\end{array}$ & -0.22 & 0.44 & .64 & 0.24 & 0.55 & .69 & -0.24 & 0.55 & .68 & -0.28 & 0.96 & .79 \\
\hline $\begin{array}{c}\gamma_{01} \\
\text { Auton., } \gamma_{02}\end{array}$ & & & & -1.65 & 1.17 & .23 & & & & & & \\
\hline $\mathrm{I} \& \mathrm{~F}, \gamma_{02}$ & & & & & & & -0.03 & 0.54 & .96 & & & \\
\hline Effort, $\gamma_{02}$ & & & & & & & & & & -0.07 & 1.11 & .95 \\
\hline $\begin{array}{c}\text { For YOS } \\
\text { slope, } \boldsymbol{\beta}_{1} \\
\text { Int } 2, \gamma_{10}\end{array}$ & 0.00 & 0.05 & .95 & 0.01 & 0.05 & .89 & -0.01 & 0.05 & .92 & -0.01 & 0.05 & .92 \\
\hline
\end{tabular}

Note. $\mathrm{N}=93$ (Level 1); $\mathrm{N}=7$ (Level 2)

\section{Table K3}

Transformational Leadership and Contingent Reward Satisfaction HLM Fixed Effects Estimation

\begin{tabular}{|c|c|c|c|c|c|c|c|c|c|c|c|c|}
\hline \multirow[b]{2}{*}{ Fixed Eff. } & \multicolumn{3}{|c|}{ Model 1} & \multicolumn{3}{|c|}{ Model 2} & \multicolumn{3}{|c|}{ Model 3} & \multicolumn{3}{|c|}{ Model 4} \\
\hline & Coeff & $S E$ & Sig & Coeff & $S E$ & Sig & Coeff & $S E$ & Sig & Coeff & $S E$ & Sig \\
\hline $\begin{array}{c}\text { For Int1, } \\
\boldsymbol{\beta}_{0} \\
\text { Int } 2, \gamma_{00}\end{array}$ & 10.64 & 4.88 & .08 & 12.88 & 5.81 & .09 & 17.54 & 4.37 & .02 & 19.39 & 6.23 & .04 \\
\hline $\begin{array}{c}\text { IdealInf, } \\
\gamma_{01} \\
\text { Auton., } \gamma_{02}\end{array}$ & 0.25 & 0.50 & .64 & $\begin{array}{l}0.47 \\
-1.49\end{array}$ & $\begin{array}{l}0.57 \\
1.83\end{array}$ & $\begin{array}{l}.46 \\
.46\end{array}$ & -0.02 & 0.39 & .96 & -0.30 & 0.50 & .57 \\
\hline $\mathrm{I} \& \mathrm{~F}, \gamma_{02}$ & & & & & & & -1.27 & 0.56 & .08 & & & \\
\hline Effort, $\gamma_{02}$ & & & & & & & & & & -1.38 & 0.85 & .18 \\
\hline $\begin{array}{c}\text { For YOS } \\
\text { slope, } \boldsymbol{\beta}_{1} \\
\text { Int } 2, \gamma_{10}\end{array}$ & -0.06 & 0.09 & .54 & -0.05 & 0.09 & .61 & -0.08 & 0.08 & .34 & -0.07 & 0.08 & .43 \\
\hline $\begin{array}{c}\text { For Int1, } \\
\boldsymbol{\beta}_{\mathbf{0}} \\
\text { Int } 2, \gamma_{00}\end{array}$ & 9.50 & 5.88 & .17 & 11.39 & 6.40 & .15 & 16.91 & 5.43 & .04 & 19.91 & 8.40 & .08 \\
\hline $\begin{array}{c}\text { InspiMot, } \\
\gamma_{01} \\
\text { Auton., } \gamma_{02}\end{array}$ & 0.44 & 0.73 & .57 & $\begin{array}{r}0.80 \\
-1.58\end{array}$ & $\begin{array}{l}0.84 \\
1.79\end{array}$ & $\begin{array}{l}.40 \\
.43\end{array}$ & 0.05 & 0.61 & .94 & -0.43 & 0.84 & .64 \\
\hline
\end{tabular}




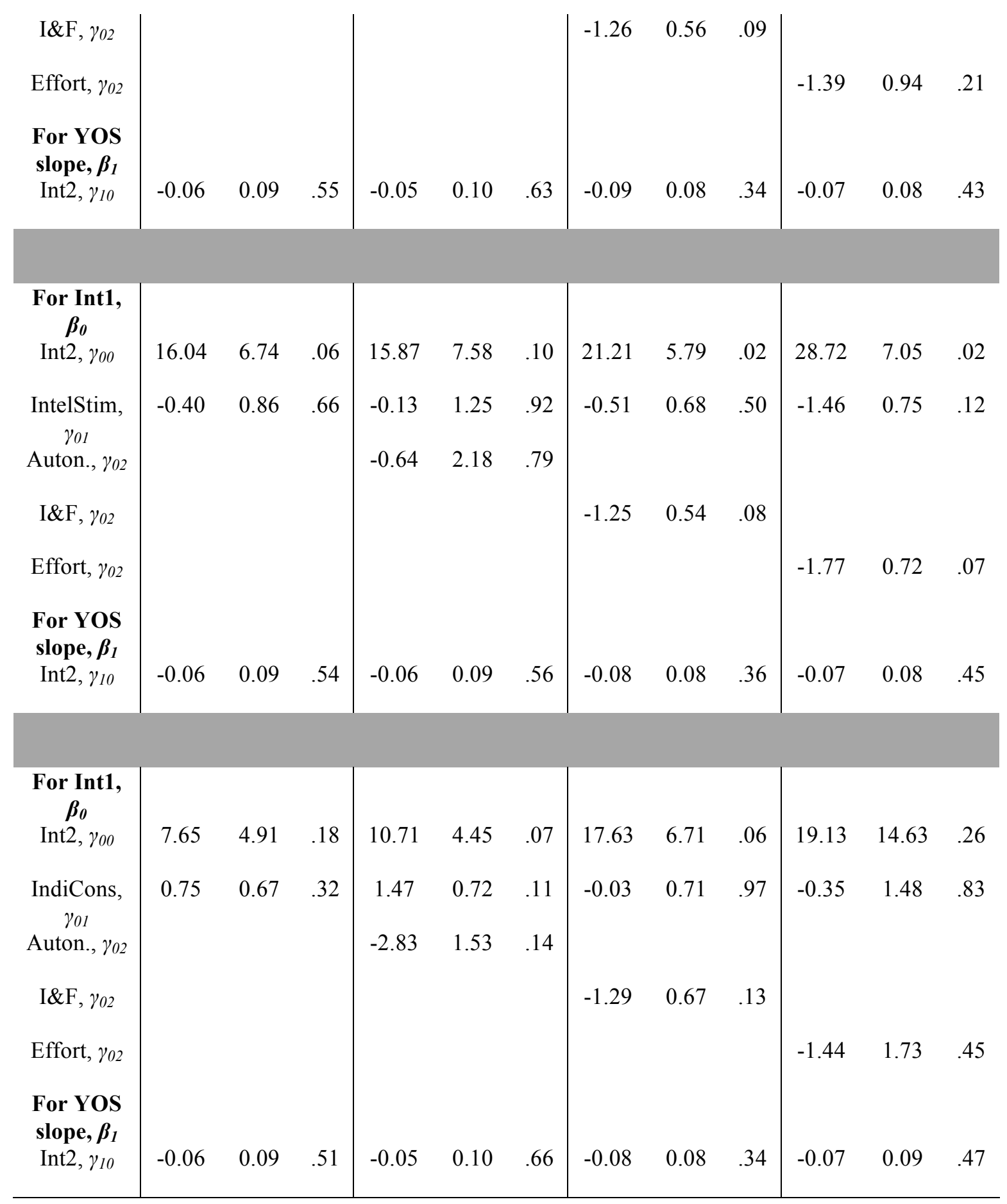

Note. $\mathrm{N}=93$ (Level 1); N=7 (Level 2)

\section{Table K4}

Transformational Leadership and Nature of Work Satisfaction HLM Fixed Effects Estimation 


\begin{tabular}{|c|c|c|c|c|c|c|c|c|c|c|c|c|}
\hline \multirow[b]{2}{*}{ Fixed Eff. } & \multicolumn{3}{|c|}{ Model 1} & \multicolumn{3}{|c|}{ Model 2} & \multicolumn{3}{|c|}{ Model 3} & \multicolumn{3}{|c|}{ Model 4} \\
\hline & Coeff & $S E$ & Sig & Coeff & $S E$ & Sig & Coeff & $S E$ & Sig & Coeff & $S E$ & Sig \\
\hline $\begin{array}{c}\text { For Int1, } \\
\boldsymbol{\beta}_{\boldsymbol{0}} \\
\text { Int } 2, \gamma_{00}\end{array}$ & 20.63 & 2.45 & .00 & 22.95 & 2.67 & .00 & 20.36 & 3.53 & .00 & 20.38 & 4.46 & .01 \\
\hline $\begin{array}{c}\text { IdealInf, } \\
\gamma_{01} \\
\text { Auton., } \gamma_{02}\end{array}$ & -0.43 & 0.24 & .14 & $\begin{array}{l}-0.17 \\
-1.61\end{array}$ & $\begin{array}{l}0.28 \\
0.90\end{array}$ & $\begin{array}{l}.57 \\
.15\end{array}$ & -0.39 & 0.30 & .26 & -0.39 & 0.35 & .33 \\
\hline $\mathrm{I} \& \mathrm{~F}, \gamma_{02}$ & & & & & & & -0.04 & 0.45 & .94 & & & \\
\hline Effort, $\gamma_{02}$ & & & & & & & & & & -0.03 & 0.60 & .96 \\
\hline $\begin{array}{c}\text { For YOS } \\
\text { slope, } \boldsymbol{\beta}_{1} \\
\text { Int } 2, \gamma_{10}\end{array}$ & 0.00 & 0.07 & .97 & 0.01 & 0.08 & .94 & 0.00 & 0.07 & .97 & 0.00 & 0.07 & .97 \\
\hline
\end{tabular}

\begin{tabular}{|c|c|c|c|c|c|c|c|c|c|c|c|c|}
\hline $\begin{array}{c}\text { For Int1, } \\
\boldsymbol{\beta}_{0} \\
\text { Int2, } \gamma_{00}\end{array}$ & 18.97 & 3.63 & .00 & 21.94 & 3.12 & .00 & 18.50 & 5.04 & .02 & 16.93 & 6.99 & .07 \\
\hline $\begin{array}{c}\text { InspiMot, } \\
\gamma_{01} \\
\text { Auton.. } \gamma_{02}\end{array}$ & -0.31 & 0.45 & .52 & $\begin{array}{l}0.04 \\
-1.95\end{array}$ & $\begin{array}{l}0.42 \\
0.88\end{array}$ & $\begin{array}{l}.92 \\
.09\end{array}$ & -0.26 & 0.53 & .65 & -0.13 & 0.69 & .86 \\
\hline $\mathrm{I} \& \mathrm{~F}, \gamma_{02}$ & & & & & & & 0.02 & 0.55 & .97 & & & \\
\hline Effort, $\gamma_{02}$ & & & & & & & & & & 0.24 & 0.79 & .78 \\
\hline $\begin{array}{c}\text { For YOS } \\
\text { slope, } \boldsymbol{\beta}_{1} \\
\text { Int } 2, \gamma_{10}\end{array}$ & 0.01 & 0.07 & .94 & 0.01 & 0.08 & .89 & 0.01 & 0.07 & .91 & 0.01 & 0.07 & .91 \\
\hline $\begin{array}{c}\text { For Int1, } \\
\boldsymbol{\beta}_{0} \\
\text { Int } 2, \gamma_{00}\end{array}$ & 23.33 & 3.47 & .00 & 23.51 & 3.40 & .00 & 23.34 & 4.09 & .01 & 24.90 & 5.07 & .01 \\
\hline $\begin{array}{c}\text { IntelStim, } \\
\gamma_{01} \\
\text { Auton., } \gamma_{02}\end{array}$ & -0.89 & 0.43 & .10 & $\begin{array}{l}-0.33 \\
-1.49\end{array}$ & $\begin{array}{l}0.57 \\
1.01\end{array}$ & $\begin{array}{l}.59 \\
.22\end{array}$ & -0.87 & 0.47 & .14 & -1.01 & 0.53 & .13 \\
\hline $\mathrm{I} \& \mathrm{~F}, \gamma_{02}$ & & & & & & & -0.03 & 0.40 & .94 & & & \\
\hline Effort, $\gamma_{02}$ & & & & & & & & & & -0.23 & 0.51 & .67 \\
\hline
\end{tabular}




\begin{tabular}{|c|c|c|c|c|c|c|c|c|c|c|c|c|}
\hline $\begin{array}{c}\text { For YOS } \\
\text { slope, } \boldsymbol{\beta}_{1} \\
\text { Int } 2, \gamma_{10}\end{array}$ & 0.01 & 0.07 & .93 & 0.01 & 0.08 & .92 & 0.01 & 0.07 & .91 & 0.01 & 0.07 & .91 \\
\hline $\begin{array}{c}\text { For Int1, } \\
\boldsymbol{\beta}_{\mathbf{0}} \\
\operatorname{Int} 2, \gamma_{00}\end{array}$ & 19.34 & 3.14 & .00 & 21.80 & 2.79 & .00 & 21.33 & 5.81 & .02 & 21.71 & 10.72 & .11 \\
\hline $\begin{array}{l}\text { IndiCons, } \\
\qquad \gamma_{01} \\
\text { Auton., } \gamma_{02}\end{array}$ & -0.40 & 0.43 & .40 & $\begin{array}{l}0.11 \\
-2.05\end{array}$ & $\begin{array}{l}0.45 \\
0.95\end{array}$ & $\begin{array}{l}.82 \\
.10\end{array}$ & -0.54 & 0.59 & .41 & -0.61 & 1.08 & .60 \\
\hline $\mathrm{I} \& \mathrm{~F}, \gamma_{02}$ & & & & & & & -0.28 & 0.62 & .68 & & & \\
\hline Effort, $\gamma_{02}$ & & & & & & & & & & -0.32 & 1.27 & .81 \\
\hline $\begin{array}{c}\text { For YOS } \\
\text { slope, } \boldsymbol{\beta}_{\boldsymbol{1}} \\
\text { Int } 2, \gamma_{10}\end{array}$ & 0.01 & 0.07 & .94 & 0.01 & 0.08 & .88 & 0.01 & 0.07 & .94 & 0.01 & 0.07 & .92 \\
\hline
\end{tabular}

Note. $\mathrm{N}=93$ (Level 1); $\mathrm{N}=7$ (Level 2)

Table K5

Transformational Leadership and Communication Satisfaction HLM Fixed Effects Estimation

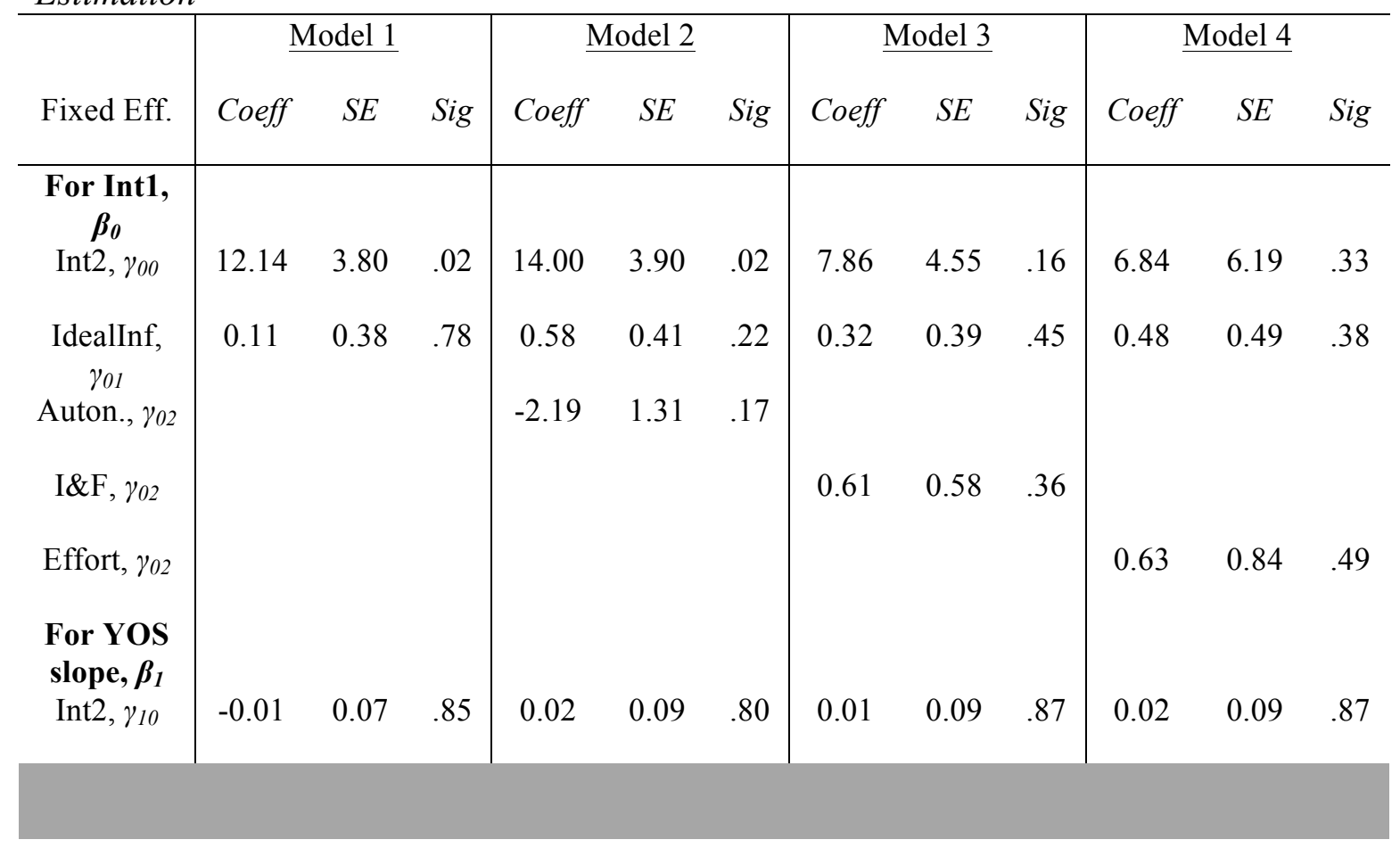




\begin{tabular}{|c|c|c|c|c|c|c|c|c|c|c|c|c|}
\hline $\begin{array}{c}\text { For Int1, } \\
\boldsymbol{\beta}_{\boldsymbol{0}} \\
\text { Int2, } \gamma_{00}\end{array}$ & 10.47 & 4.76 & .08 & 12.57 & 4.80 & .06 & 6.97 & 5.28 & .26 & 4.56 & 7.31 & .57 \\
\hline $\begin{array}{c}\text { InspiMot, } \\
\gamma_{01} \\
\text { Auton., } \gamma_{02}\end{array}$ & 0.35 & 0.59 & .58 & $\begin{array}{c}0.99 \\
-2.47\end{array}$ & $\begin{array}{l}0.66 \\
1.35\end{array}$ & $\begin{array}{l}.21 \\
.14\end{array}$ & 0.51 & 0.57 & .43 & 0.83 & 0.73 & .32 \\
\hline $\mathrm{I} \& \mathrm{~F}, \gamma_{02}$ & & & & & & & 0.61 & 0.56 & .33 & & & \\
\hline Effort, $\gamma_{02}$ & & & & & & & & & & 0.79 & 0.82 & .39 \\
\hline $\begin{array}{c}\text { For YOS } \\
\text { slope, } \boldsymbol{\beta}_{1} \\
\text { Int } 2, \gamma_{10}\end{array}$ & -0.01 & 0.07 & .89 & 0.03 & 0.09 & .75 & 0.01 & 0.08 & .93 & 0.00 & 0.08 & .96 \\
\hline $\begin{array}{c}\text { For Int1, } \\
\boldsymbol{\beta}_{\boldsymbol{0}} \\
\operatorname{Int} 2, \gamma_{00}\end{array}$ & 14.43 & 5.80 & .06 & 14.05 & 5.59 & .07 & 12.26 & 6.04 & .11 & 13.12 & 8.43 & .19 \\
\hline $\begin{array}{c}\text { IntelStim, } \\
\gamma_{01} \\
\text { Auton., } \gamma_{02}\end{array}$ & -0.15 & .74 & .84 & $\begin{array}{l}0.83 \\
-2.46\end{array}$ & $\begin{array}{l}0.97 \\
1.66\end{array}$ & $\begin{array}{l}.44 \\
.21\end{array}$ & -0.09 & 0.72 & .91 & -0.06 & 0.92 & .95 \\
\hline $\mathrm{I} \& \mathrm{~F}, \gamma_{02}$ & & & & & & & 0.48 & 0.56 & .44 & & & \\
\hline Effort, $\gamma_{02}$ & & & & & & & & & & 0.22 & 0.85 & .81 \\
\hline $\begin{array}{c}\text { For YOS } \\
\text { slope, } \boldsymbol{\beta}_{\boldsymbol{1}} \\
\text { Int } 2, \gamma_{10}\end{array}$ & -0.01 & 0.07 & .86 & 0.01 & 0.09 & .88 & -0.01 & 0.08 & .89 & -0.02 & 0.07 & .85 \\
\hline $\begin{array}{c}\text { For Int1, } \\
\boldsymbol{\beta}_{\boldsymbol{0}} \\
\operatorname{Int} 2, \gamma_{00}\end{array}$ & 13.64 & 4.42 & .03 & 15.52 & 4.52 & .03 & 5.90 & 6.68 & .43 & 3.43 & 12.94 & .80 \\
\hline $\begin{array}{l}\text { IndiCons, } \\
\quad \gamma_{01} \\
\text { Auton., } \gamma_{02}\end{array}$ & -0.06 & 0.60 & .93 & $\begin{array}{l}0.58 \\
-2.20\end{array}$ & $\begin{array}{l}0.76 \\
1.57\end{array}$ & $\begin{array}{l}.49 \\
.23\end{array}$ & 0.58 & 0.69 & .45 & 0.94 & 1.31 & .51 \\
\hline $\mathrm{I} \& \mathrm{~F}, \gamma_{02}$ & & & & & & & 0.88 & 0.69 & .27 & & & \\
\hline Effort, $\gamma_{02}$ & & & & & & & & & & 1.18 & 1.52 & .48 \\
\hline $\begin{array}{c}\text { For YOS } \\
\text { slope, } \boldsymbol{\beta}_{1} \\
\text { Int } 2, \gamma_{10}\end{array}$ & -0.02 & 0.07 & .85 & 0.02 & 0.08 & .86 & 0.01 & 0.09 & .91 & 0.00 & 0.08 & .99 \\
\hline
\end{tabular}


Note. $\mathrm{N}=93$ (Level 1); $\mathrm{N}=7$ (Level 2)

APPENDIX L

Transactional Leadership and Dimensions of Satisfaction HLM Fixed Effects

Components Estimation 


\section{Table L1}

Transactional Leadership and Overall Satisfaction HLM Fixed Effects Estimation

\begin{tabular}{|c|c|c|c|c|c|c|c|c|c|c|c|c|}
\hline \multirow[b]{2}{*}{ Fixed Eff. } & \multicolumn{3}{|c|}{ Model 1} & \multicolumn{3}{|c|}{ Model 2} & \multicolumn{3}{|c|}{ Model 3} & \multicolumn{3}{|c|}{ Model 4} \\
\hline & Coeff & $S E$ & Sig & Coeff & $S E$ & Sig & Coeff & $S E$ & Sig & Coeff & $S E$ & Sig \\
\hline $\begin{array}{c}\text { For Int1, } \\
\boldsymbol{\beta}_{0} \\
\text { Int } 2, \gamma_{00}\end{array}$ & 77.79 & 9.24 & .00 & 86.43 & 11.95 & .00 & 77.40 & 9.71 & .00 & 77.24 & 9.61 & .00 \\
\hline $\begin{array}{c}\text { ContRew, } \\
\gamma_{01} \\
\text { Auton., } \\
\gamma_{02} \\
\text { I\&F, } \gamma_{02}\end{array}$ & -3.74 & 1.75 & .09 & $\begin{array}{l}-3.01 \\
-4.09\end{array}$ & $\begin{array}{l}1.79 \\
3.25\end{array}$ & $\begin{array}{l}.17 \\
.28\end{array}$ & -4.62 & 1.93 & .07 & -4.03 & 1.82 & .09 \\
\hline $\begin{array}{c}\text { Effort, } \gamma_{02} \\
\text { For YOS } \\
\text { slope, } \boldsymbol{\beta}_{1} \\
\text { Int } 2, \gamma_{10}\end{array}$ & -0.02 & 0.27 & .96 & -0.02 & .28 & .96 & 0.02 & 0.28 & .95 & 0.78 & 1.82 & .69 \\
\hline $\begin{array}{c}\text { For Int1, } \\
\boldsymbol{\beta}_{0} \\
\text { Int } 2, \gamma_{00}\end{array}$ & 81.76 & 20.66 & .01 & 75.70 & 19.43 & .02 & 82.68 & 21.57 & .02 & 84.31 & 22.54 & .02 \\
\hline $\begin{array}{c}\text { MgtbEx, } \\
\gamma_{01} \\
\text { Auton., } \\
\gamma_{02} \\
\text { I\&F, } \gamma_{02}\end{array}$ & -2.80 & 2.59 & .33 & $\begin{array}{l}0.11 \\
-5.83\end{array}$ & $\begin{array}{l}3.00 \\
4.12\end{array}$ & $\begin{array}{l}.97 \\
.23\end{array}$ & -2.88 & 2.88 & .37 & -3.00 & 2.72 & .33 \\
\hline $\begin{array}{c}\text { Effort, } \gamma_{02} \\
\text { For YOS } \\
\text { slope, } \boldsymbol{\beta}_{1}\end{array}$ & & & & & & & & & & -0.39 & 2.00 & .86 \\
\hline
\end{tabular}




\begin{tabular}{l|lll|lll|lll|lll} 
Int2, $\gamma_{10}$ & -0.11 & 0.25 & .67 & -0.06 & 0.28 & .83 & -0.11 & 0.25 & .67 & -0.11 & 0.24 & .68 \\
\hline
\end{tabular}

Note. $\mathrm{N}=93$ (Level 1); $\mathrm{N}=7$ (Level 2)

Table L2

Transactional Leadership and Supervision Satisfaction HLM Fixed Effects Estimation

\begin{tabular}{|c|c|c|c|c|c|c|c|c|c|c|c|c|}
\hline \multirow[b]{2}{*}{ Fixed Eff. } & \multicolumn{3}{|c|}{ Model 1} & \multicolumn{3}{|c|}{ Model 2} & \multicolumn{3}{|c|}{ Model 3} & \multicolumn{3}{|c|}{ Model 4} \\
\hline & Coeff & $S E$ & Sig & Coeff & $S E$ & Sig & Coeff & $S E$ & Sig & Coeff & $S E$ & Sig \\
\hline $\begin{array}{c}\text { For Int1, } \\
\boldsymbol{\beta}_{\mathbf{0}} \\
\text { Int } 2, \gamma_{00}\end{array}$ & 19.38 & 2.62 & .00 & 22.01 & 3.41 & .00 & 18.97 & 2.74 & .00 & 18.90 & 2.74 & .00 \\
\hline $\begin{array}{c}\text { ContRew, } \\
\gamma_{01} \\
\text { Auton., } \gamma_{02}\end{array}$ & -0.55 & 0.51 & .33 & $\begin{array}{l}-0.40 \\
-1.14\end{array}$ & $\begin{array}{l}0.52 \\
0.95\end{array}$ & $\begin{array}{l}.49 \\
.30\end{array}$ & -0.68 & 0.54 & .28 & -0.63 & 0.52 & .30 \\
\hline $\mathrm{I} \& \mathrm{~F}, \gamma_{02}$ & & & & & & & 0.30 & 0.45 & .55 & & & \\
\hline Effort, $\gamma_{02}$ & & & & & & & & & & 0.33 & 0.51 & .55 \\
\hline $\begin{array}{c}\text { For YOS } \\
\text { slope, } \boldsymbol{\beta}_{1} \\
\text { Int } 2, \gamma_{10}\end{array}$ & 0.01 & 0.05 & .92 & 0.01 & 0.05 & .86 & 0.01 & 0.05 & .88 & 0.01 & 0.05 & .90 \\
\hline $\begin{array}{c}\text { For Int1, } \\
\boldsymbol{\beta}_{\mathbf{0}} \\
\text { Int } 2, \gamma_{00}\end{array}$ & 20.67 & 5.58 & .01 & 19.69 & 5.49 & .02 & 21.00 & 5.76 & .02 & 20.27 & 6.17 & .03 \\
\hline $\begin{array}{c}\text { MgtbEx, } \\
\gamma_{01} \\
\text { Auton., } \gamma_{02}\end{array}$ & -0.51 & 0.70 & .50 & $\begin{array}{l}0.16 \\
-1.47\end{array}$ & $\begin{array}{l}0.86 \\
1.18\end{array}$ & $\begin{array}{l}.86 \\
.28\end{array}$ & -0.65 & 0.76 & .44 & -0.51 & 0.74 & .52 \\
\hline $\mathrm{I} \& \mathrm{~F}, \gamma_{02}$ & & & & & & & 0.23 & 0.47 & .64 & & & \\
\hline $\begin{array}{c}\text { Effort, } \gamma_{02} \\
\text { For YOS } \\
\text { slope, } \boldsymbol{\beta}_{1}\end{array}$ & & & & & & & & & & 0.19 & 0.53 & .75 \\
\hline
\end{tabular}




\begin{tabular}{l|lll|lll|lll|lll} 
Int $2, \gamma_{10}$ & 0.00 & 0.05 & .95 & 0.01 & 0.05 & .90 & 0.00 & 0.05 & .95 & -0.01 & 0.05 & .93 \\
\hline
\end{tabular}

Note. $\mathrm{N}=93$ (Level 1); $\mathrm{N}=7$ (Level 2)

Table L3

Transactional Leadership and Contingent Reward Satisfaction HLM Fixed Effects Estimation

\begin{tabular}{|c|c|c|c|c|c|c|c|c|c|c|c|c|}
\hline \multirow[b]{2}{*}{ Fixed Eff. } & \multicolumn{3}{|c|}{ Model 1} & \multicolumn{3}{|c|}{ Model 2} & \multicolumn{3}{|c|}{ Model 3} & \multicolumn{3}{|c|}{ Model 4} \\
\hline & Coeff & $S E$ & Sig & Coeff & $S E$ & Sig & Coeff & $S E$ & Sig & Coeff & $S E$ & Sig \\
\hline $\begin{array}{c}\text { For Int1, } \\
\boldsymbol{\beta}_{\mathbf{0}} \\
\text { Int } 2, \gamma_{00}\end{array}$ & 21.72 & 3.33 & .00 & 22.66 & 4.58 & .01 & 22.01 & 3.35 & .00 & 22.09 & 3.40 & .00 \\
\hline $\begin{array}{c}\text { ContRew, } \\
\gamma_{01} \\
\text { Auton., } \gamma_{02}\end{array}$ & -1.78 & 0.63 & .04 & $\begin{array}{l}-1.76 \\
-0.34\end{array}$ & $\begin{array}{l}0.66 \\
1.26\end{array}$ & $\begin{array}{l}.06 \\
.80\end{array}$ & -1.46 & 0.66 & .09 & -1.62 & 0.65 & .07 \\
\hline $\mathrm{I} \& \mathrm{~F}, \gamma_{02}$ & & & & & & & -0.53 & 0.58 & .41 & & & \\
\hline Effort, $\gamma_{02}$ & & & & & & & & & & -0.46 & 0.66 & .52 \\
\hline $\begin{array}{c}\text { For YOS } \\
\text { slope, } \boldsymbol{\beta}_{1} \\
\text { Int } 2, \gamma_{10}\end{array}$ & -0.04 & 0.09 & .69 & -0.04 & 0.09 & .69 & -0.05 & 0.09 & .61 & -0.04 & 0.09 & .67 \\
\hline $\begin{array}{c}\text { For Int1, } \\
\boldsymbol{\beta}_{\mathbf{0}} \\
\text { Int } 2, \gamma_{00}\end{array}$ & 18.54 & 9.15 & .10 & 15.78 & 11.38 & .24 & 20.92 & 7.33 & .05 & 26.23 & 7.57 & .03 \\
\hline $\begin{array}{c}\text { MgtbEx, } \\
\gamma_{01} \\
\text { Auton., } \gamma_{02}\end{array}$ & -0.70 & 1.15 & .57 & $\begin{array}{l}-0.08 \\
-0.71\end{array}$ & $\begin{array}{l}1.77 \\
2.15\end{array}$ & $\begin{array}{l}.97 \\
.76\end{array}$ & -0.50 & 0.98 & .64 & -1.28 & 0.91 & .23 \\
\hline $\mathrm{I} \& \mathrm{~F}, \gamma_{02}$ & & & & & & & -1.17 & 0.59 & .12 & & & \\
\hline Effort, $\gamma_{02}$ & & & & & & & & & & -1.25 & 0.67 & .14 \\
\hline $\begin{array}{c}\text { For YOS } \\
\text { slope, } \boldsymbol{\beta}_{1} \\
\text { Int } 2, \gamma_{10}\end{array}$ & -0.07 & 0.09 & .49 & -0.06 & 0.09 & .57 & -0.08 & 0.08 & .36 & -0.07 & 0.08 & .43 \\
\hline
\end{tabular}


Note. $\mathrm{N}=93$ (Level 1); $\mathrm{N}=7$ (Level 2)

Table L4

Transactional Leadership and Nature of Work Satisfaction HLM Fixed Effects Estimation

\begin{tabular}{|c|c|c|c|c|c|c|c|c|c|c|c|c|}
\hline \multirow[b]{2}{*}{ Fixed Eff. } & \multicolumn{3}{|c|}{ Model 1} & \multicolumn{3}{|c|}{ Model 2} & \multicolumn{3}{|c|}{ Model 3} & \multicolumn{3}{|c|}{ Model 4} \\
\hline & Coeff & $S E$ & Sig & Coeff & $S E$ & Sig & Coeff & $S E$ & Sig & Coeff & $S E$ & Sig \\
\hline $\begin{array}{c}\text { For Int1, } \\
\boldsymbol{\beta}_{\mathbf{0}} \\
\text { Int } 2, \gamma_{00}\end{array}$ & 20.45 & 2.36 & .00 & 23.58 & 2.90 & .00 & 20.13 & 2.55 & .00 & 19.91 & 2.45 & .00 \\
\hline $\begin{array}{c}\text { ContRew, } \\
\gamma_{01} \\
\text { Auton., } \gamma_{02}\end{array}$ & -0.82 & 0.45 & .13 & $\begin{array}{l}-0.45 \\
-1.64\end{array}$ & $\begin{array}{l}0.43 \\
0.78\end{array}$ & $\begin{array}{l}.35 \\
.11\end{array}$ & -1.02 & 0.52 & .12 & -0.98 & 0.47 & .11 \\
\hline $\mathrm{I} \& \mathrm{~F}, \gamma_{02}$ & & & & & & & 0.38 & 0.46 & .46 & & & \\
\hline Effort, $\gamma_{02}$ & & & & & & & & & & 0.52 & 0.49 & .35 \\
\hline $\begin{array}{c}\text { For YOS } \\
\text { slope, } \boldsymbol{\beta}_{1} \\
\text { Int } 2, \gamma_{10}\end{array}$ & 0.03 & 0.07 & .72 & 0.02 & 0.08 & .83 & 0.03 & 0.07 & .67 & 0.03 & 0.07 & .69 \\
\hline $\begin{array}{c}\text { For Int1, } \\
\boldsymbol{\beta}_{\mathbf{0}} \\
\text { Int } 2, \gamma_{00}\end{array}$ & 25.30 & 4.53 & .00 & 24.18 & 4.48 & .01 & 25.54 & 4.66 & .01 & 24.47 & 4.93 & .01 \\
\hline $\begin{array}{c}\text { MgtbEx, } \\
\quad \gamma_{01} \\
\text { Auton., } \gamma_{02}\end{array}$ & -1.10 & 0.56 & .11 & $\begin{array}{l}-0.37 \\
-1.59\end{array}$ & $\begin{array}{l}0.71 \\
0.98\end{array}$ & $\begin{array}{l}.63 \\
.18\end{array}$ & -1.24 & 0.61 & .11 & -1.09 & 0.58 & .14 \\
\hline $\mathrm{I} \& \mathrm{~F}, \gamma_{02}$ & & & & & & & 0.24 & 0.38 & .56 & & & \\
\hline Effort, $\gamma_{02}$ & & & & & & & & & & 0.28 & 0.43 & .55 \\
\hline $\begin{array}{c}\text { For YOS } \\
\text { slope, } \boldsymbol{\beta}_{\mathbf{1}} \\
\text { Int } 2, \gamma_{10}\end{array}$ & 0.00 & 0.07 & .98 & 0.01 & 0.08 & .92 & 0.00 & 0.07 & .97 & -0.01 & 0.07 & .95 \\
\hline
\end{tabular}


Note. $\mathrm{N}=93$ (Level 1); $\mathrm{N}=7$ (Level 2)

\section{Table L5}

Transactional Leadership and Communication Satisfaction HLM Fixed Effects Estimation

\begin{tabular}{|c|c|c|c|c|c|c|c|c|c|c|c|c|}
\hline \multirow[b]{2}{*}{ Fixed Eff. } & \multicolumn{3}{|c|}{ Model 1} & \multicolumn{3}{|c|}{ Model 2} & \multicolumn{3}{|c|}{ Model 3} & \multicolumn{3}{|c|}{ Model 4} \\
\hline & Coeff & $S E$ & Sig & Coeff & $S E$ & Sig & Coeff & $S E$ & Sig & Coeff & $S E$ & Sig \\
\hline $\begin{array}{c}\text { For Int1, } \\
\boldsymbol{\beta}_{\boldsymbol{0}} \\
\text { Int } 2, \gamma_{00}\end{array}$ & 16.91 & 3.37 & .00 & 19.26 & 4.42 & .01 & 15.70 & 3.32 & .01 & 16.24 & 3.56 & .01 \\
\hline $\begin{array}{c}\text { ContRew, } \\
\gamma_{01} \\
\text { Auton., } \gamma_{02}\end{array}$ & -0.74 & 0.65 & .31 & $\begin{array}{l}-0.55 \\
-1.13\end{array}$ & $\begin{array}{l}0.70 \\
1.26\end{array}$ & $\begin{array}{l}.48 \\
.42\end{array}$ & -1.12 & 0.65 & .16 & -0.83 & 0.67 & .29 \\
\hline $\mathrm{I} \& \mathrm{~F}, \gamma_{02}$ & & & & & & & 0.88 & 0.54 & .18 & & & \\
\hline Effort, $\gamma_{02}$ & & & & & & & & & & 0.43 & 0.66 & .55 \\
\hline $\begin{array}{c}\text { For YOS } \\
\text { slope, } \boldsymbol{\beta}_{1} \\
\text { Int } 2, \gamma_{10}\end{array}$ & 0.00 & 0.08 & .99 & 0.01 & 0.08 & .89 & 0.02 & 0.09 & .83 & 0.00 & 0.08 & .98 \\
\hline $\begin{array}{c}\text { For Int1, } \\
\boldsymbol{\beta}_{\boldsymbol{0}} \\
\text { Int } 2, \gamma_{00}\end{array}$ & 11.57 & 7.42 & .18 & 7.13 & 6.55 & .34 & 11.77 & 7.52 & .19 & 10.80 & 8.82 & .29 \\
\hline $\begin{array}{c}\text { MgtbEx } \\
\gamma_{01} \\
\text { Auton., } \gamma_{02}\end{array}$ & 0.21 & 0.93 & .83 & $\begin{array}{r}1.73 \\
-2.62\end{array}$ & $\begin{array}{l}1.03 \\
1.43\end{array}$ & $\begin{array}{l}.17 \\
.14\end{array}$ & -0.03 & 0.99 & .98 & 0.23 & 1.06 & .84 \\
\hline $\mathrm{I} \& \mathrm{~F}, \gamma_{02}$ & & & & & & & 0.50 & 0.60 & .46 & & & \\
\hline Effort, $\gamma_{02}$ & & & & & & & & & & 0.24 & 0.74 & .76 \\
\hline $\begin{array}{c}\text { For YOS } \\
\text { slope, } \boldsymbol{\beta}_{1} \\
\text { Int } 2, \gamma_{10}\end{array}$ & -0.02 & 0.07 & .84 & 0.02 & 0.09 & .81 & -0.01 & 0.08 & .91 & -0.01 & 0.08 & .91 \\
\hline
\end{tabular}


Note. $\mathrm{N}=93$ (Level 1); $\mathrm{N}=7$ (Level 2)

APPENDIX M

Laissez-Faire Leadership and Dimensions of Satisfaction HLM Fixed Effects

Components Estimation 


\section{Table M1}

Laissez-Faire Leadership and Overall Satisfaction HLM Fixed Effects Estimation

\begin{tabular}{|c|c|c|c|c|c|c|c|c|c|c|c|c|}
\hline \multirow[b]{2}{*}{ Fixed Eff. } & \multicolumn{3}{|c|}{ Model 1} & \multicolumn{3}{|c|}{ Model 2} & \multicolumn{3}{|c|}{ Model 3} & \multicolumn{3}{|c|}{ Model 4} \\
\hline & Coeff & $S E$ & Sig & Coeff & $S E$ & Sig & Coeff & $S E$ & Sig & Coeff & $S E$ & Sig \\
\hline $\begin{array}{c}\text { For Int1, } \\
\boldsymbol{\beta}_{\boldsymbol{0}} \\
\text { Int } 2, \gamma_{00}\end{array}$ & 64.84 & 7.59 & .00 & 79.39 & 11.51 & .00 & 64.17 & 8.51 & .00 & 64.31 & 7.92 & .00 \\
\hline LFLead, & -1.20 & 1.55 & .48 & -0.85 & 1.54 & .61 & -1.21 & 2.00 & .58 & -1.48 & 1.85 & .47 \\
\hline $\begin{array}{c}\text { Auton., } \\
\gamma_{02} \\
\mathrm{I} \& \mathrm{~F}, \gamma_{02}\end{array}$ & & & & -5.47 & 3.32 & .17 & 0.20 & 1.99 & .92 & & & \\
\hline Effort, $\gamma_{02}$ & & & & & & & & & & 0.72 & 2.17 & .76 \\
\hline $\begin{array}{c}\text { For YOS } \\
\text { slope, } \boldsymbol{\beta}_{1} \\
\text { Int } 2, \gamma_{10}\end{array}$ & -0.10 & 0.25 & .69 & -0.06 & 0.28 & .85 & -0.09 & 0.26 & .74 & -0.10 & 0.26 & .70 \\
\hline
\end{tabular}

Note. $\mathrm{N}=93$ (Level 1); N=7 (Level 2)

Table M2

Laissez-Faire Leadership and Supervision Satisfaction HLM Fixed Effects Estimation

\begin{tabular}{|c|c|c|c|c|c|c|c|c|c|c|c|c|}
\hline \multirow[b]{2}{*}{ Fixed Eff. } & \multicolumn{3}{|c|}{ Model 1} & \multicolumn{3}{|c|}{ Model 2} & \multicolumn{3}{|c|}{ Model 3} & \multicolumn{3}{|c|}{ Model 4} \\
\hline & Coeff & $S E$ & Sig & Coeff & $S E$ & Sig & Coeff & $S E$ & Sig & Coeff & $S E$ & Sig \\
\hline $\begin{array}{c}\text { For Int1, } \\
\boldsymbol{\beta}_{\boldsymbol{0}} \\
\text { Int } 2, \gamma_{00}\end{array}$ & 17.71 & 2.06 & .00 & 21.11 & 3.24 & .00 & 17.37 & 2.14 & .00 & 17.44 & 2.11 & .00 \\
\hline
\end{tabular}




\begin{tabular}{|c|c|c|c|c|c|c|c|c|c|c|c|c|}
\hline $\begin{array}{c}\text { LFLead, } \\
\gamma_{01} \\
\text { Auton., } \\
\gamma_{02} \\
\text { I\&F, } \gamma_{02}\end{array}$ & -0.24 & 0.43 & .60 & $\begin{array}{l}-0.15 \\
-1.29\end{array}$ & $\begin{array}{l}0.44 \\
0.95\end{array}$ & $\begin{array}{l}.76 \\
.25\end{array}$ & -0.42 & 0.51 & .46 & -0.44 & 0.50 & .43 \\
\hline Effort, $\gamma_{02}$ & & & & & & & & & & 0.47 & 0.59 & .47 \\
\hline $\begin{array}{c}\text { For YOS } \\
\text { slope, } \boldsymbol{\beta}_{\boldsymbol{1}} \\
\text { Int } 2, \gamma_{10}\end{array}$ & 0.00 & 0.05 & .99 & 0.01 & 0.05 & .91 & 0.00 & 0.05 & .98 & 0.00 & 0.05 & .99 \\
\hline
\end{tabular}

Note. $\mathrm{N}=93$ (Level 1); $\mathrm{N}=7$ (Level 2)

\section{Table M3}

Laissez-Faire Leadership and Contingent Reward Satisfaction HLM Fixed Effects Estimation

\begin{tabular}{|c|c|c|c|c|c|c|c|c|c|c|c|c|}
\hline \multirow[b]{2}{*}{ Fixed Eff. } & \multicolumn{3}{|c|}{ Model 1} & \multicolumn{3}{|c|}{ Model 2} & \multicolumn{3}{|c|}{ Model 3} & \multicolumn{3}{|c|}{ Model 4} \\
\hline & Coeff & $S E$ & Sig & Coeff & $S E$ & Sig & Coeff & $S E$ & Sig & Coeff & $S E$ & Sig \\
\hline $\begin{array}{c}\text { For Int1, } \\
\boldsymbol{\beta}_{\boldsymbol{0}} \\
\text { Int } 2, \gamma_{00}\end{array}$ & 16.32 & 2.75 & .00 & 17.90 & 4.96 & .02 & 17.68 & 2.78 & .00 & 16.72 & 3.06 & .01 \\
\hline LFLead, & -0.76 & 0.57 & .24 & -0.65 & 0.66 & .38 & -0.17 & 0.67 & .81 & -0.35 & 0.72 & .66 \\
\hline $\begin{array}{c}\text { Auton., } \\
\gamma_{02} \\
\mathrm{I} \& \mathrm{~F}, \gamma_{02}\end{array}$ & & & & -0.69 & 1.41 & .65 & -1.15 & 0.65 & .15 & & & \\
\hline Effort, $\gamma_{02}$ & & & & & & & & & & -0.87 & 0.83 & .36 \\
\hline $\begin{array}{c}\text { For YOS } \\
\text { slope, } \boldsymbol{\beta}_{1} \\
\text { Int } 2, \gamma_{10}\end{array}$ & -0.07 & 0.09 & .49 & -0.06 & 0.09 & .55 & -0.08 & 9.98 & .36 & -0.07 & 0.09 & .48 \\
\hline
\end{tabular}

Note. $\mathrm{N}=93$ (Level 1); $\mathrm{N}=7$ (Level 2) 
Table M4

Laissez-Faire Leadership and Nature of Work Satisfaction HLM Fixed Effects Estimation

\begin{tabular}{|c|c|c|c|c|c|c|c|c|c|c|c|c|}
\hline \multirow[b]{2}{*}{ Fixed Eff. } & \multicolumn{3}{|c|}{ Model 1} & \multicolumn{3}{|c|}{ Model 2} & \multicolumn{3}{|c|}{ Model 3} & \multicolumn{3}{|c|}{ Model 4} \\
\hline & Coeff & $S E$ & Sig & Coeff & $S E$ & Sig & Coeff & $S E$ & Sig & Coeff & $S E$ & Sig \\
\hline $\begin{array}{c}\text { For Int1, } \\
\boldsymbol{\beta}_{\mathbf{0}} \\
\text { Int } 2, \gamma_{00}\end{array}$ & 16.80 & 2.30 & .00 & 22.26 & 2.67 & .00 & 16.50 & 2.65 & .00 & 16.48 & 2.35 & 00 \\
\hline LFLead, & -0.07 & 0.49 & .89 & -0.04 & 0.35 & .92 & -0.10 & 0.60 & .87 & -0.25 & 0.55 & .68 \\
\hline $\begin{array}{c}\text { Auton., } \\
\gamma_{02} \\
\mathrm{I} \& \mathrm{~F}, \gamma_{02}\end{array}$ & & & & -1.89 & 0.77 & .07 & 0.14 & 0.61 & .83 & & & \\
\hline Effort, $\gamma_{02}$ & & & & & & & & & & 0.46 & 0.63 & .51 \\
\hline $\begin{array}{c}\text { For YOS } \\
\text { slope, } \boldsymbol{\beta}_{1} \\
\text { Int } 2, \gamma_{10}\end{array}$ & 0.01 & 0.07 & .87 & 0.01 & 0.08 & .89 & 0.01 & 0.08 & .87 & 0.01 & 0.08 & .90 \\
\hline
\end{tabular}

Note. $\mathrm{N}=93$ (Level 1); $\mathrm{N}=7$ (Level 2)

\section{Table M5}

Laissez-Faire Leadership and Communication Satisfaction HLM Fixed Effects Estimation

\begin{tabular}{|c|c|c|c|c|c|c|c|c|c|c|c|c|}
\hline \multirow[b]{2}{*}{ Fixed Eff. } & \multicolumn{3}{|c|}{$\underline{\text { Model } 1}$} & \multicolumn{3}{|c|}{ Model 2} & \multicolumn{3}{|c|}{$\underline{\text { Model } 3}$} & \multicolumn{3}{|c|}{ Model 4} \\
\hline & Coeff & $S E$ & Sig & Coeff & $S E$ & Sig & Coeff & $S E$ & Sig & Coeff & $S E$ & Sig \\
\hline $\begin{array}{c}\text { For Int1, } \\
\boldsymbol{\beta}_{\mathbf{0}} \\
\text { Int } 2, \gamma_{00}\end{array}$ & 13.58 & 2.80 & .01 & 17.44 & 4.42 & .02 & 12.70 & 2.68 & .01 & 13.33 & 2.93 & .01 \\
\hline LFLead, & -0.08 & 0.59 & .90 & 0.02 & 0.60 & .98 & -0.52 & 0.64 & .47 & -0.25 & 0.70 & .74 \\
\hline $\begin{array}{c}\text { Auton., } \\
\gamma_{02} \\
\mathrm{I} \& \mathrm{~F}, \gamma_{02}\end{array}$ & & & & -1.47 & 1.28 & .32 & 0.81 & 0.63 & .27 & & & \\
\hline
\end{tabular}




\begin{tabular}{|c|c|c|c|c|c|c|c|c|c|c|c|c|}
\hline Effort, $\gamma_{02}$ & & & & & & & & & & 0.40 & 0.81 & .65 \\
\hline $\begin{array}{c}\text { For YOS } \\
\text { slope, } \boldsymbol{\beta}_{1} \\
\text { Int } 2, \gamma_{10}\end{array}$ & -0.01 & 0.07 & .86 & 0.00 & 0.08 & .96 & 0.00 & 0.08 & .99 & -0.01 & 0.08 & .88 \\
\hline
\end{tabular}

Note. $\mathrm{N}=93$ (Level 1); $\mathrm{N}=7$ (Level 2) 


\section{APPENDIX N}

Transformational Leadership and Dimensions of Satisfaction HLM Variance Components Estimation 
Table N1

Transformational Leadership and Overall Satisfaction HLM Variance Components Estimation

\begin{tabular}{|c|c|c|c|c|c|c|c|c|c|c|c|c|}
\hline \multirow[b]{2}{*}{$\begin{array}{c}\text { Random } \\
\text { Effect }\end{array}$} & \multicolumn{3}{|c|}{ No Climate Vars. } & \multicolumn{3}{|c|}{ Auton. Included } & \multicolumn{3}{|c|}{$\underline{\text { I\&F Included }}$} & \multicolumn{3}{|c|}{ Effort Included } \\
\hline & $S D$ & $V C$ & Sig & $S D$ & $V C$ & Sig & $S D$ & $V C$ & Sig & $S D$ & $V C$ & Sig \\
\hline $\begin{array}{l}\text { Idealized } \\
\text { Influence } \\
\text { Int }\end{array}$ & 5.80 & 33.59 & 02 & 5.78 & 33.42 & 02 & 6.08 & 36.97 & 01 & 6.10 & 37.22 & 01 \\
\hline $\begin{array}{c}\text { YOS } \\
\text { slope, } u_{l} \\
\text { Level-1, } r\end{array}$ & $\begin{array}{c}0.44 \\
13.68\end{array}$ & $\begin{array}{c}0.19 \\
187.10\end{array}$ & .02 & $\begin{array}{c}0.56 \\
13.48\end{array}$ & $\begin{array}{c}0.31 \\
181.80\end{array}$ & .02 & $\begin{array}{c}0.42 \\
13.71\end{array}$ & $\begin{array}{c}0.18 \\
188.06\end{array}$ & .02 & $\begin{array}{c}0.42 \\
13.72\end{array}$ & $\begin{array}{c}0.18 \\
188.23\end{array}$ & .02 \\
\hline $\begin{array}{c}\text { Inspi. } \\
\text { Motivat. } \\
\text { Int1, } u_{0}\end{array}$ & 5.60 & 31.34 & .03 & 6.25 & 39.04 & .02 & 6.08 & 36.98 & .01 & 6.12 & 37.48 & .01 \\
\hline $\begin{array}{c}\text { YOS } \\
\text { slope, } u_{l} \\
\text { Level-1, } r\end{array}$ & $\begin{array}{c}0.45 \\
13.67\end{array}$ & $\begin{array}{c}0.20 \\
186.99\end{array}$ & .02 & $\begin{array}{c}0.59 \\
13.40\end{array}$ & $\begin{array}{c}0.35 \\
179.64\end{array}$ & .02 & $\begin{array}{c}0.46 \\
13.66\end{array}$ & $\begin{array}{c}0.21 \\
186.53\end{array}$ & .02 & $\begin{array}{c}0.47 \\
13.64\end{array}$ & $\begin{array}{c}0.22 \\
186.13\end{array}$ & .02 \\
\hline $\begin{array}{l}\text { Intellect. } \\
\text { Stim. } \\
\text { Int } 1, u_{0}\end{array}$ & 5.28 & 27.89 & .04 & 6.52 & 42.55 & .02 & 5.45 & 29.70 & .02 & 5.11 & 26.13 & .03 \\
\hline $\begin{array}{c}\text { YOS } \\
\text { slope, } u_{l} \\
\text { Level-1, } r\end{array}$ & $\begin{array}{c}0.44 \\
13.65\end{array}$ & $\begin{array}{c}0.19 \\
186.29\end{array}$ & .02 & $\begin{array}{c}0.57 \\
13.48\end{array}$ & $\begin{array}{c}0.32 \\
181.65\end{array}$ & .02 & $\begin{array}{c}0.41 \\
13.71\end{array}$ & $\begin{array}{c}0.17 \\
188.00\end{array}$ & .02 & $\begin{array}{r}0.40 \\
13.71\end{array}$ & $\begin{array}{c}0.16 \\
187.91\end{array}$ & .02 \\
\hline $\begin{array}{l}\text { Individ. } \\
\text { Consider. }\end{array}$ & & & & & & & & & & & & \\
\hline
\end{tabular}




\begin{tabular}{c|ccc|ccc|ccc|ccc} 
Int1, $u_{0}$ & 5.61 & 31.49 & .03 & 6.27 & 39.34 & .02 & 6.10 & 37.20 & .01 & 6.11 & 37.34 & .01 \\
$\begin{array}{c}\text { YOS } \\
\text { slope, } u_{1}\end{array}$ & 0.45 & 0.20 & .02 & 0.58 & 0.34 & .02 & 0.44 & 0.20 & .02 & 0.46 & 0.21 & .02 \\
Level-1, $r$ & 13.68 & 187.15 & & 13.37 & 178.72 & & 13.68 & 187.01 & & 13.66 & 186.70 & \\
& & & & & & & & & & & & \\
\hline
\end{tabular}

Note. $\mathrm{N}=93$ (Level 1); $\mathrm{N}=7$ (Level 2); VC is abbreviation for Variance Component

Table N2

Transformational Leadership and Supervision Satisfaction HLM Variance Components Estimation

\begin{tabular}{|c|c|c|c|c|c|c|c|c|c|c|c|c|}
\hline \multirow[b]{2}{*}{$\begin{array}{c}\text { Random } \\
\text { Effect }\end{array}$} & \multicolumn{3}{|c|}{ No Climate Vars. } & \multicolumn{3}{|c|}{ Auton. Included } & \multicolumn{3}{|c|}{ I\&F Included } & \multicolumn{3}{|c|}{ Effort Included } \\
\hline & $S D$ & $V C$ & Sig & $S D$ & $V C$ & Sig & $S D$ & $V C$ & Sig & $S D$ & $V C$ & Sig \\
\hline $\begin{array}{l}\text { Idealized } \\
\text { Influence }\end{array}$ & & & & & & & & & & & & \\
\hline Int1, $u_{0}$ & 0.45 & 0.21 & .18 & 0.61 & 0.37 & .16 & 0.70 & 0.49 & .11 & 0.75 & 0.56 & .11 \\
\hline $\begin{array}{c}\text { YOS slope, } \\
u_{1}\end{array}$ & 0.03 & 0.00 & .30 & 0.05 & 0.00 & .30 & 0.04 & 0.00 & .30 & 0.04 & 0.00 & .30 \\
\hline Level-1, $r$ & 3.95 & 15.60 & & 3.92 & 15.39 & & 3.96 & 15.68 & & 3.96 & 15.66 & \\
\hline $\begin{array}{c}\text { Inspi. } \\
\text { Motivat. } \\
\text { Int } 1, u_{0}\end{array}$ & 0.44 & 0.19 & .19 & 0.66 & 0.43 & .16 & 0.69 & 0.48 & .12 & 0.72 & 0.51 & .11 \\
\hline
\end{tabular}




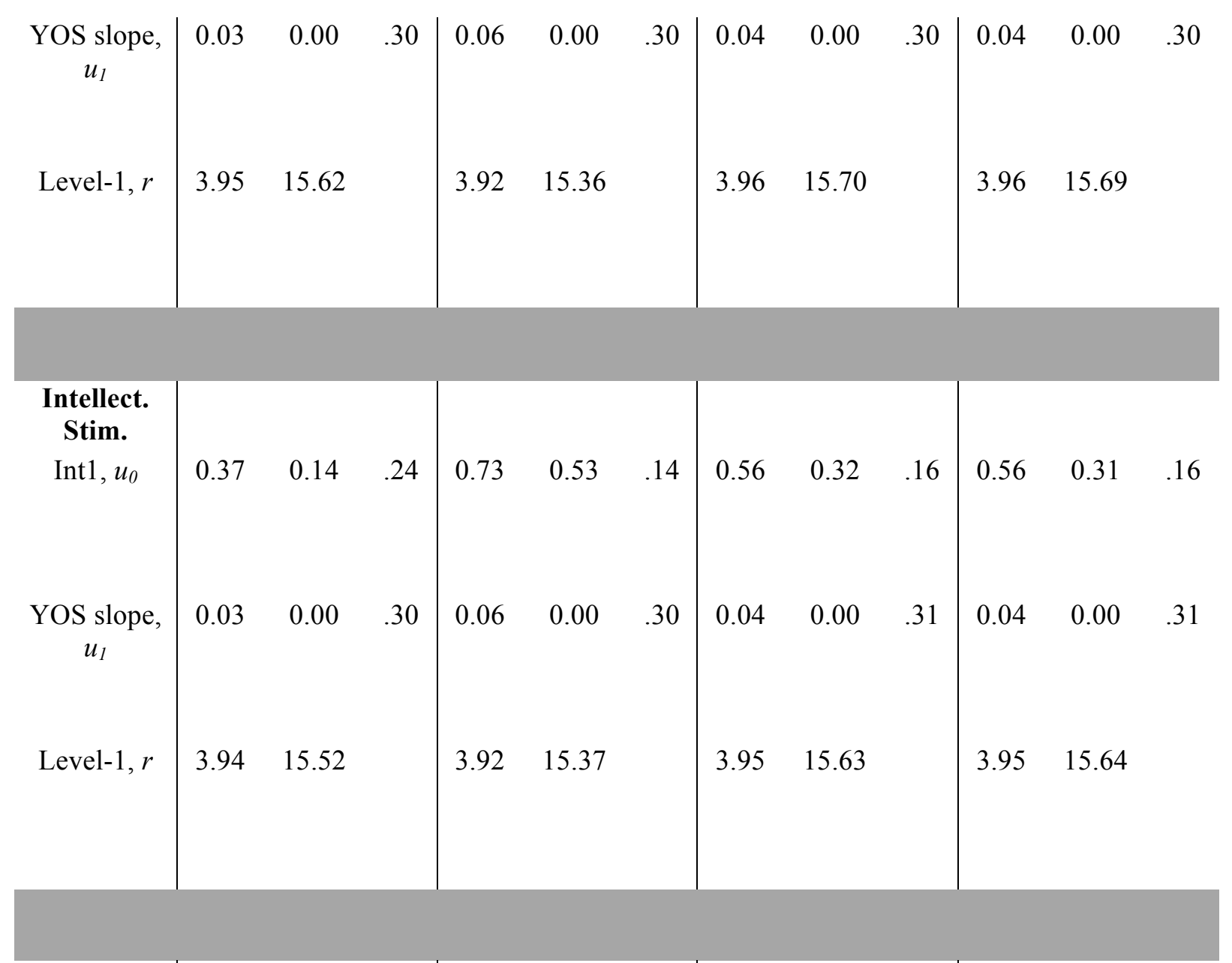

\begin{tabular}{|c|c|c|c|c|c|c|c|c|c|c|c|c|}
\hline $\begin{array}{c}\text { Individ. } \\
\text { Consider. }\end{array}$ & & & & & & & & & & & & \\
\hline Int $1, u_{0}$ & 0.48 & 0.23 & .19 & 0.67 & 0.46 & .16 & 0.72 & 0.52 & .11 & 0.72 & 0.52 & .11 \\
\hline $\begin{array}{c}\text { YOS slope, } \\
u_{1}\end{array}$ & 0.03 & 0.00 & .30 & 0.05 & 0.00 & .30 & 0.04 & 0.00 & .30 & 0.04 & 0.00 & .30 \\
\hline Level-1, $r$ & 3.95 & 15.59 & & 3.92 & 15.36 & & 3.96 & 15.68 & & 3.96 & 15.68 & \\
\hline
\end{tabular}

Note. $\mathrm{N}=93$ (Level 1); $\mathrm{N}=7$ (Level 2); VC is abbreviation for Variance Component 
Table N3

Transformational Leadership and Contingent Rewards Satisfaction HLM Variance Components Estimation

\begin{tabular}{|c|c|c|c|c|c|c|c|c|c|c|c|c|}
\hline \multirow[b]{2}{*}{$\begin{array}{l}\text { Random } \\
\text { Effect }\end{array}$} & \multicolumn{3}{|c|}{ No Climate Vars. } & \multicolumn{3}{|c|}{ Auton. Included } & \multicolumn{3}{|c|}{ I\&F Included } & \multicolumn{3}{|c|}{ Effort Included } \\
\hline & $S D$ & $V C$ & Sig & $S D$ & $V C$ & Sig & $S D$ & $V C$ & Sig & $S D$ & $V C$ & Sig \\
\hline $\begin{array}{l}\text { Idealized } \\
\text { Influence }\end{array}$ & & & & & & & & & & & & \\
\hline Int1, $u_{0}$ & 1.85 & 3.41 & .06 & 1.84 & 3.40 & .05 & 1.79 & 3.19 & .03 & 1.89 & 3.58 & .03 \\
\hline $\begin{array}{c}\text { YOS } \\
\text { slope, } u_{1}\end{array}$ & 0.16 & 0.03 & .05 & 0.16 & 0.03 & .05 & 0.13 & 0.02 & .04 & 0.14 & 0.02 & .05 \\
\hline Level-1, $r$ & 4.78 & 22.80 & & 4.77 & 22.76 & & 4.80 & 22.99 & & 4.80 & 23.03 & \\
\hline $\begin{array}{c}\text { Inspi. } \\
\text { Motivat. } \\
\text { Int1, } u_{0}\end{array}$ & 1.89 & 3.57 & .05 & 1.98 & 3.92 & .04 & 1.80 & 3.22 & .03 & 1.87 & 3.48 & .04 \\
\hline $\begin{array}{c}\text { YOS } \\
\text { slope, } u_{1}\end{array}$ & 0.16 & 0.03 & .05 & 0.17 & 0.03 & .05 & 0.13 & 0.02 & .04 & 0.14 & 0.02 & .05 \\
\hline Level-1, $r$ & 4.77 & 22.78 & & 4.76 & 22.70 & & 4.79 & 22.98 & & 4.80 & 23.01 & \\
\hline $\begin{array}{l}\text { Intellect. } \\
\text { Stim. } \\
\text { Int1, } u_{0}\end{array}$ & 1.64 & 2.69 & .11 & 1.95 & 3.81 & .05 & 1.58 & 2.48 & .05 & 1.25 & 1.56 & .11 \\
\hline $\begin{array}{c}\text { YOS } \\
\text { slope, } u_{1}\end{array}$ & 0.15 & 0.02 & .05 & 0.16 & 0.03 & .05 & 0.12 & 0.02 & .05 & 0.13 & 0.02 & .05 \\
\hline Level-1, $r$ & 4.79 & 22.96 & & 4.79 & 22.90 & & 4.79 & 22.96 & & 4.77 & 22.74 & \\
\hline $\begin{array}{c}\text { Individ. } \\
\text { Consider. } \\
\text { Int1, } u_{0}\end{array}$ & 1.87 & 3.51 & .05 & 1.93 & 3.73 & .05 & 1.79 & 3.20 & .03 & 1.93 & 3.74 & .03 \\
\hline $\begin{array}{c}\text { YOS } \\
\text { slope, } u_{1}\end{array}$ & 0.16 & 0.02 & .05 & 0.19 & 0.04 & .05 & 0.13 & 0.02 & .04 & 0.15 & 0.02 & .05 \\
\hline Level-1, $r$ & 4.77 & 22.73 & & 4.74 & 22.43 & & 4.80 & 22.99 & & 4.79 & 22.92 & \\
\hline
\end{tabular}


Note. $\mathrm{N}=93$ (Level 1); $\mathrm{N}=7$ (Level 2); $\mathrm{VC}$ is abbreviation for Variance Component

\section{Table N4}

Transformational Leadership and Nature of Work Satisfaction HLM Variance Components Estimation

\begin{tabular}{|c|c|c|c|c|c|c|c|c|c|c|c|c|}
\hline \multirow[b]{2}{*}{$\begin{array}{l}\text { Random } \\
\text { Effect }\end{array}$} & \multicolumn{3}{|c|}{ No Climate Vars. } & \multicolumn{3}{|c|}{ Auton. Included } & \multicolumn{3}{|c|}{ I\&F Included } & \multicolumn{3}{|c|}{ Effort Included } \\
\hline & $S D$ & $V C$ & Sig & $S D$ & $V C$ & Sig & $S D$ & $V C$ & Sig & $S D$ & $V C$ & Sig \\
\hline $\begin{array}{l}\text { Idealized } \\
\text { Influence }\end{array}$ & & & & & & & & & & & & \\
\hline Int1, $u_{0}$ & 1.19 & 1.41 & .05 & 1.39 & 1.93 & .03 & 1.32 & 1.75 & .03 & 1.32 & 1.75 & .03 \\
\hline $\begin{array}{c}\text { YOS slope, } \\
u_{1}\end{array}$ & 0.14 & 0.02 & .01 & 0.16 & 0.03 & .01 & 0.14 & 0.02 & .01 & 0.14 & 0.02 & .01 \\
\hline Level-1, $r$ & 3.24 & 10.52 & & 3.19 & 10.20 & & 3.23 & 10.45 & & 3.23 & 10.46 & \\
\hline $\begin{array}{l}\text { Inspi. } \\
\text { Motivat. } \\
\text { Int1, } u_{0}\end{array}$ & 1.27 & 1.61 & .05 & 1.40 & 1.95 & .03 & 1.43 & 2.04 & .02 & 1.46 & 2.12 & .02 \\
\hline $\begin{array}{c}\text { YOS slope, } \\
u_{1}\end{array}$ & 0.15 & 0.02 & .01 & 0.16 & 0.03 & .01 & 0.15 & 0.02 & .01 & 0.15 & 0.02 & .01 \\
\hline Level-1, $r$ & 3.23 & 10.44 & & 3.20 & 10.23 & & 3.23 & 10.41 & & 3.22 & 10.39 & \\
\hline
\end{tabular}




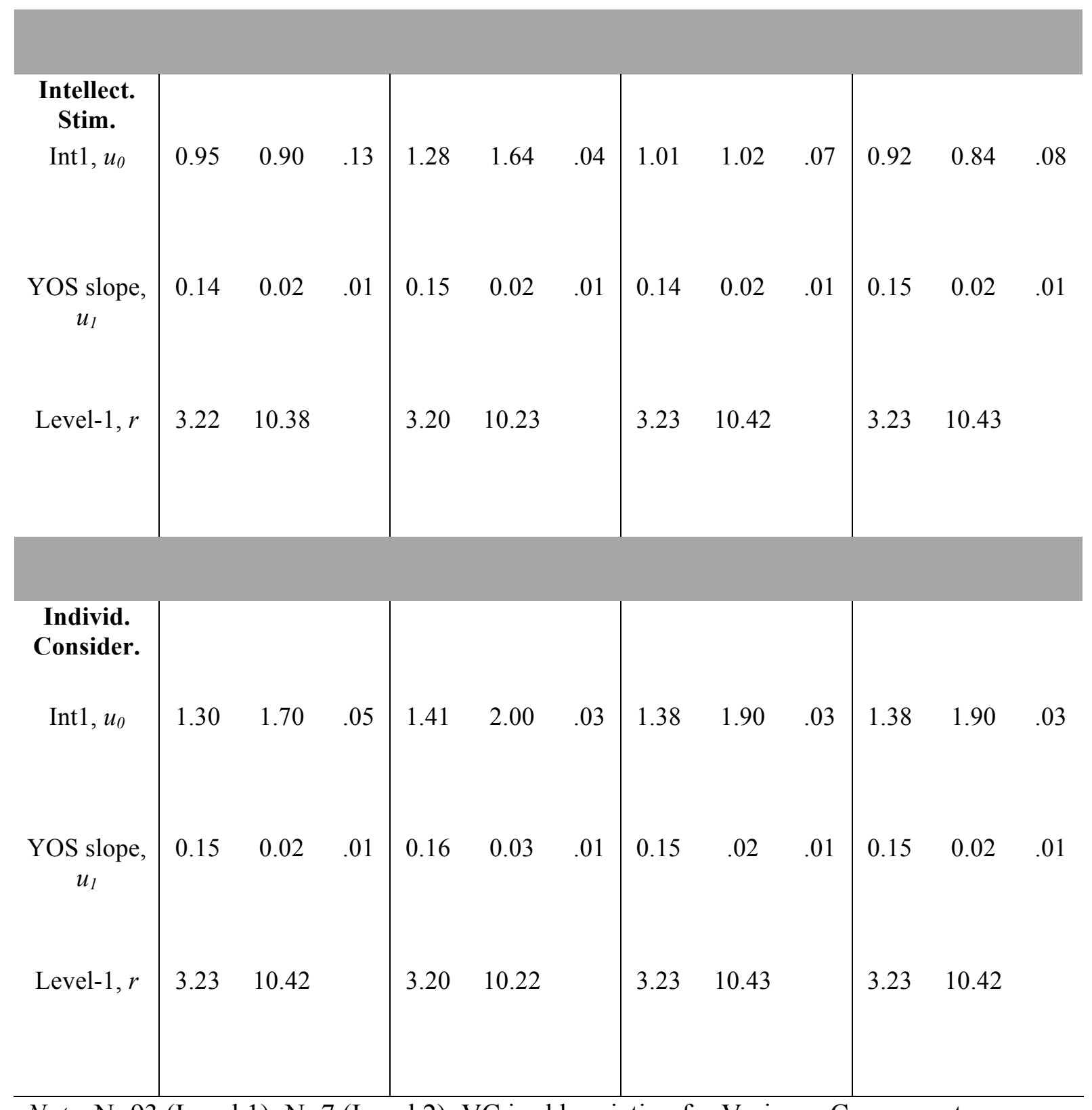

Note. $\mathrm{N}=93$ (Level 1); $\mathrm{N}=7$ (Level 2); $\mathrm{VC}$ is abbreviation for Variance Component 
Table N5

Transformational Leadership and Communication Satisfaction HLM Variance Components Estimation

\begin{tabular}{|c|c|c|c|c|c|c|c|c|c|c|c|c|}
\hline \multirow[b]{2}{*}{$\begin{array}{c}\text { Random } \\
\text { Effect }\end{array}$} & \multicolumn{3}{|c|}{ No Climate Vars. } & \multicolumn{3}{|c|}{ Auton. Included } & \multicolumn{3}{|c|}{ I\&F Included } & \multicolumn{3}{|c|}{ Effort Included } \\
\hline & $S D$ & $V C$ & Sig & $S D$ & $V C$ & Sig & $S D$ & $V C$ & Sig & $S D$ & $V C$ & Sig \\
\hline $\begin{array}{l}\text { Idealized } \\
\text { Influence }\end{array}$ & & & & & & & & & & & & \\
\hline Int1, $u_{0}$ & 1.57 & 2.48 & .04 & 1.55 & 2.40 & .05 & 1.36 & 1.84 & .07 & 1.42 & 2.02 & .07 \\
\hline $\begin{array}{c}\text { YOS slope, } \\
u_{1}\end{array}$ & 0.11 & 0.01 & .05 & 0.16 & 0.03 & .04 & 0.15 & 0.02 & .05 & 0.15 & 0.02 & .05 \\
\hline Level-1, $r$ & 4.76 & 22.64 & & 4.70 & 22.07 & & 4.73 & 22.37 & & 4.73 & 22.39 & \\
\hline $\begin{array}{c}\text { Inspi. } \\
\text { Motivat. } \\
\text { Int } 1, u_{0}\end{array}$ & 1.57 & 2.47 & .04 & 2.03 & 4.12 & .02 & 1.48 & 2.19 & .04 & 1.56 & 2.42 & .04 \\
\hline $\begin{array}{c}\text { YOS slope, } \\
u_{1}\end{array}$ & 0.11 & 0.01 & .05 & 0.17 & 0.03 & .04 & 0.14 & 0.02 & .05 & 0.14 & 0.02 & .05 \\
\hline Level-1, $r$ & 4.75 & 22.57 & & 4.66 & 21.72 & & 4.73 & 22.39 & & 4.74 & 22.42 & \\
\hline
\end{tabular}




\begin{tabular}{|c|c|c|c|c|c|c|c|c|c|c|c|c|}
\hline $\begin{array}{l}\text { Intellect. } \\
\text { Stim. } \\
\text { Int } 1, u_{0}\end{array}$ & 1.78 & 3.18 & .03 & 2.13 & 4.55 & .01 & 1.79 & 3.21 & .03 & 1.95 & 3.78 & .02 \\
\hline $\begin{array}{c}\text { YOS slope, } \\
u_{1}\end{array}$ & 0.11 & 0.01 & .05 & 0.16 & 0.02 & .04 & 0.13 & 0.02 & .05 & 0.11 & 0.01 & .05 \\
\hline Level-1, $r$ & 4.75 & 22.52 & & 4.69 & 22.03 & & 4.75 & 22.54 & & 4.76 & 22.64 & \\
\hline $\begin{array}{l}\text { Individ. } \\
\text { Consider. }\end{array}$ & & & & & & & & & & & & \\
\hline Int1, $u_{0}$ & 1.76 & 3.11 & .03 & 1.99 & 3.97 & .01 & 1.43 & 2.05 & .05 & 1.63 & 2.66 & .04 \\
\hline $\begin{array}{c}\text { YOS slope, } \\
u_{1}\end{array}$ & 0.11 & 0.01 & .05 & 0.14 & 0.02 & .04 & 0.14 & 0.02 & .05 & 0.13 & 0.02 & .05 \\
\hline Level-1, $r$ & 4.75 & 22.54 & & 4.71 & 22.16 & & 4.73 & 22.38 & & 4.74 & 22.50 & \\
\hline
\end{tabular}

Note. $\mathrm{N}=93$ (Level 1); $\mathrm{N}=7$ (Level 2); VC is abbreviation for Variance Component 


\title{
APPENDIX O
}

Transactional Leadership and Dimensions of Satisfaction HLM Variance Components

\author{
Estimation
}


Table O1

Transactional Leadership and Overall Satisfaction HLM Variance Components Estimation

\begin{tabular}{|c|c|c|c|c|c|c|c|c|c|c|c|c|}
\hline \multirow[b]{2}{*}{$\begin{array}{c}\text { Random } \\
\text { Effect }\end{array}$} & \multicolumn{3}{|c|}{ No Climate Vars. } & \multicolumn{3}{|c|}{ Auton. Included } & \multicolumn{3}{|c|}{ I\&F Included } & \multicolumn{3}{|c|}{ Effort Included } \\
\hline & $S D$ & $V C$ & Sig & $S D$ & $V C$ & Sig & $S D$ & $V C$ & Sig & $S D$ & $V C$ & Sig \\
\hline $\begin{array}{c}\text { Cont. } \\
\text { Rewards }\end{array}$ & & & & & & & & & & & & \\
\hline Int $1, u_{0}$ & 3.35 & 11.19 & .25 & 4.17 & 17.42 & .12 & 2.71 & 7.35 & .30 & 3.12 & 9.74 & .20 \\
\hline $\begin{array}{c}\text { YOS } \\
\text { slope, } u_{l}\end{array}$ & 0.51 & 0.26 & .02 & 0.52 & 0.27 & .02 & 0.54 & 0.30 & .02 & 0.52 & 0.27 & .02 \\
\hline $\begin{array}{c}\text { Level-1, } \\
r\end{array}$ & 13.44 & 180.68 & & 13.40 & 179.65 & & 13.42 & 180.21 & & 13.49 & 181.88 & \\
\hline $\begin{array}{c}\text { Mgt. By } \\
\text { Exc. } \\
\text { Int } 1, u_{0}\end{array}$ & 6.04 & 36.44 & .02 & 5.97 & 35.69 & .02 & 6.33 & 40.12 & .01 & 6.35 & 40.34 & .01 \\
\hline $\begin{array}{c}\text { YOS } \\
\text { slope, } u_{l}\end{array}$ & 0.44 & 0.20 & .02 & 0.54 & 0.29 & .02 & 0.44 & 0.19 & .02 & 0.43 & 0.19 & .02 \\
\hline $\begin{array}{c}\text { Level-1, } \\
r\end{array}$ & 13.60 & 185.05 & & 13.51 & 182.59 & & 13.66 & 186.68 & & 13.66 & 186.67 & \\
\hline
\end{tabular}

Note. $\mathrm{N}=93$ (Level 1); $\mathrm{N}=7$ (Level 2); $\mathrm{VC}$ is abbreviation for Variance Component 
Table O2

Transactional Leadership and Supervision Satisfaction HLM Variance Components Estimation

\begin{tabular}{|c|c|c|c|c|c|c|c|c|c|c|c|c|}
\hline \multirow[b]{2}{*}{$\begin{array}{c}\text { Random } \\
\text { Effect }\end{array}$} & \multicolumn{3}{|c|}{ No Climate Vars. } & \multicolumn{3}{|c|}{ Auton. Included } & \multicolumn{3}{|c|}{ I\&F Included } & \multicolumn{3}{|c|}{ Effort Included } \\
\hline & $S D$ & $V C$ & Sig & $S D$ & $V C$ & Sig & $S D$ & $V C$ & Sig & $S D$ & $V C$ & Sig \\
\hline $\begin{array}{c}\text { Cont. } \\
\text { Rewards }\end{array}$ & & & & & & & & & & & & \\
\hline Int $1, u_{0}$ & 0.13 & 0.02 & .50 & 0.44 & 0.19 & 0.27 & 0.27 & 0.07 & .40 & 0.24 & 0.06 & .35 \\
\hline $\begin{array}{c}\text { YOS } \\
\text { slope, } u_{1}\end{array}$ & 0.01 & 0.00 & .31 & 0.04 & 0.00 & .30 & 0.04 & 0.00 & .31 & 0.02 & 0.00 & .31 \\
\hline Level-1, $r$ & 3.94 & 15.52 & & 3.92 & 15.37 & & 3.94 & 15.55 & & 3.95 & 15.59 & \\
\hline $\begin{array}{l}\text { Mgt. By } \\
\text { Exc. }\end{array}$ & & & & & & & & & & & & \\
\hline Int $1, u_{0}$ & 0.58 & 0.33 & .17 & 0.60 & 0.36 & .16 & 0.80 & 0.63 & .10 & 0.84 & 0.71 & .10 \\
\hline $\begin{array}{c}\text { YOS } \\
\text { slope, } u_{1}\end{array}$ & 0.04 & 0.00 & .30 & 0.05 & 0.00 & .30 & 0.05 & 0.00 & .30 & 0.05 & 0.00 & .30 \\
\hline Level-1, $r$ & 3.94 & 15.52 & & 3.93 & 15.41 & & 3.94 & 15.56 & & 3.95 & 15.56 & \\
\hline
\end{tabular}

Note. $\mathrm{N}=93$ (Level 1); $\mathrm{N}=7$ (Level 2); VC is abbreviation for Variance Component 


\section{Table O3}

Transactional Leadership and Contingent Rewards Satisfaction HLM Variance Components Estimation

\begin{tabular}{|c|c|c|c|c|c|c|c|c|c|c|c|c|}
\hline \multirow[b]{2}{*}{$\begin{array}{l}\text { Random } \\
\text { Effect }\end{array}$} & \multicolumn{3}{|c|}{ No Climate Vars. } & \multicolumn{3}{|c|}{ Auton. Included } & \multicolumn{3}{|c|}{$\underline{\text { I\&F Included }}$} & \multicolumn{3}{|c|}{ Effort Included } \\
\hline & $S D$ & $V C$ & Sig & $S D$ & $V C$ & Sig & $S D$ & $V C$ & Sig & $S D$ & $V C$ & Sig \\
\hline \multicolumn{13}{|l|}{$\begin{array}{c}\text { Cont. } \\
\text { Rewards }\end{array}$} \\
\hline Int $1, u_{0}$ & 0.70 & 0.49 & .50 & 0.62 & 0.39 & .50 & 0.90 & 0.81 & .38 & 0.79 & 0.62 & .50 \\
\hline $\begin{array}{c}\text { YOS } \\
\text { slope, } u_{1}\end{array}$ & 0.18 & 0.03 & .04 & 0.18 & 0.03 & .04 & 0.16 & 0.03 & .04 & 0.17 & 0.03 & .04 \\
\hline Level-1, $r$ & 4.67 & 21.80 & & 4.69 & 21.99 & & 4.70 & 22.07 & & 4.69 & 22.02 & \\
\hline \multicolumn{13}{|l|}{$\begin{array}{c}\text { Mgt. By } \\
\text { Exc. }\end{array}$} \\
\hline Int $1, u_{0}$ & 1.90 & 3.61 & .08 & 1.98 & 3.94 & .05 & 1.81 & 3.28 & .03 & 1.99 & 3.95 & .03 \\
\hline $\begin{array}{c}\text { YOS } \\
\text { slope, } u_{1}\end{array}$ & 0.16 & 0.03 & .05 & 0.16 & 0.03 & .05 & 0.13 & 0.02 & .05 & 0.15 & .02 & .05 \\
\hline Level-1, $r$ & 4.79 & 22.98 & & 4.78 & 22.87 & & 4.79 & 22.91 & & 4.78 & 22.86 & \\
\hline
\end{tabular}

Note. $\mathrm{N}=93$ (Level 1); $\mathrm{N}=7$ (Level 2); VC is abbreviation for Variance Component 


\section{Table O4}

Transactional Leadership and Nature of Work Satisfaction HLM Variance Components Estimation

\begin{tabular}{|c|c|c|c|c|c|c|c|c|c|c|c|c|}
\hline \multirow[b]{2}{*}{$\begin{array}{c}\text { Random } \\
\text { Effect }\end{array}$} & \multicolumn{3}{|c|}{ No Climate Vars. } & \multicolumn{3}{|c|}{ Auton. Included } & \multicolumn{3}{|c|}{ I\&F Included } & \multicolumn{3}{|c|}{ Effort Included } \\
\hline & $S D$ & $V C$ & Sig & $S D$ & $V C$ & Sig & $S D$ & $V C$ & Sig & $S D$ & $V C$ & Sig \\
\hline $\begin{array}{c}\text { Cont. } \\
\text { Rewards }\end{array}$ & & & & & & & & & & & & \\
\hline Int $1, u_{0}$ & 0.56 & 0.31 & .24 & 1.08 & 1.17 & .08 & 0.47 & 0.22 & .23 & 0.49 & 0.24 & .22 \\
\hline $\begin{array}{c}\text { YOS } \\
\text { slope, } u_{1}\end{array}$ & 0.15 & 0.02 & .01 & 0.16 & 0.02 & .01 & 0.15 & 0.02 & .01 & 0.15 & 0.02 & .01 \\
\hline Level-1, $r$ & 3.22 & 10.34 & & 3.19 & 10.16 & & 3.22 & 10.33 & & 3.21 & 10.32 & \\
\hline $\begin{array}{c}\text { Mgt. By } \\
\text { Exc. }\end{array}$ & & & & & & & & & & & & \\
\hline Int $1, u_{0}$ & 1.28 & 1.64 & .04 & 1.41 & 1.98 & .03 & 1.41 & 1.98 & .02 & 1.40 & 1.95 & .02 \\
\hline $\begin{array}{c}\text { YOS } \\
\text { slope, } u_{1}\end{array}$ & 0.14 & 0.02 & .01 & 0.16 & 0.03 & .01 & 0.15 & 0.02 & .01 & 0.14 & 0.02 & .01 \\
\hline Level-1, $r$ & 3.24 & 10.48 & & 3.20 & 10.21 & & 3.24 & 10.49 & & 3.24 & 10.51 & \\
\hline
\end{tabular}

Note. $\mathrm{N}=93$ (Level 1); $\mathrm{N}=7$ (Level 2); VC is abbreviation for Variance Component 


\section{Table O5}

Transactional Leadership and Communication Satisfaction HLM Variance Components Estimation

\begin{tabular}{|c|c|c|c|c|c|c|c|c|c|c|c|c|}
\hline \multirow[b]{2}{*}{$\begin{array}{c}\text { Random } \\
\text { Effect }\end{array}$} & \multicolumn{3}{|c|}{ No Climate Vars. } & \multicolumn{3}{|c|}{ Auton. Included } & \multicolumn{3}{|c|}{$\underline{\text { I\&F Included }}$} & \multicolumn{3}{|c|}{ Effort Included } \\
\hline & $S D$ & $V C$ & Sig & $S D$ & $V C$ & Sig & $S D$ & $V C$ & Sig & $S D$ & $V C$ & Sig \\
\hline $\begin{array}{c}\text { Cont. } \\
\text { Rewards }\end{array}$ & & & & & & & & & & & & \\
\hline Int1, $u_{0}$ & 1.52 & 2.31 & .07 & 1.84 & 3.39 & .02 & 1.30 & 1.70 & .14 & 1.64 & 2.69 & .05 \\
\hline $\begin{array}{c}\text { YOS } \\
\text { slope, } u_{1}\end{array}$ & 0.12 & 0.01 & .05 & 0.13 & 0.02 & .05 & 0.15 & 0.02 & .04 & 0.13 & 0.02 & .05 \\
\hline Level-1, $r$ & 4.73 & 22.38 & & 4.72 & 22.25 & & 4.68 & 21.94 & & 4.74 & 22.43 & \\
\hline $\begin{array}{c}\text { Mgt. By } \\
\text { Exc. }\end{array}$ & & & & & & & & & & & & \\
\hline Int1, $u_{0}$ & 1.63 & 2.64 & .04 & 1.40 & 1.95 & .08 & 1.79 & 3.21 & .03 & 1.87 & 3.50 & .02 \\
\hline $\begin{array}{c}\text { YOS } \\
\text { slope, } u_{1}\end{array}$ & 0.11 & 0.01 & .05 & 0.16 & 0.02 & .05 & 0.13 & 0.02 & .05 & 0.12 & 0.01 & .05 \\
\hline Level-1, $r$ & 4.76 & 22.61 & & 4.69 & 22.00 & & 4.75 & 22.52 & & 4.75 & 22.57 & \\
\hline
\end{tabular}

Note. $\mathrm{N}=93$ (Level 1); $\mathrm{N}=7$ (Level 2); $\mathrm{VC}$ is abbreviation for Variance Component 


\section{APPENDIX P}

Laissez-Faire Leadership and Dimensions of Satisfaction HLM Variance Components

\section{Estimation}




\section{Table P1}

Laissez-Faire Leadership and Overall Satisfaction HLM Variance Components Estimation

\begin{tabular}{|c|c|c|c|c|c|c|c|c|c|c|c|c|}
\hline \multirow[b]{2}{*}{$\begin{array}{c}\text { Random } \\
\text { Effect }\end{array}$} & \multicolumn{3}{|c|}{ No Climate Vars. } & \multicolumn{3}{|c|}{ Auton. Included } & \multicolumn{3}{|c|}{ I\&F Included } & \multicolumn{3}{|c|}{ Effort Included } \\
\hline & $S D$ & $V C$ & Sig & $S D$ & $V C$ & Sig & $S D$ & $V C$ & Sig & $S D$ & $V C$ & Sig \\
\hline $\begin{array}{c}\text { LF } \\
\text { Lead }\end{array}$ & & & & & & & & & & & & \\
\hline $\operatorname{Int} 1, u_{0}$ & 5.10 & 26.04 & .04 & 5.97 & 35.67 & .02 & 5.52 & 30.45 & .02 & 5.48 & 30.05 & .02 \\
\hline $\begin{array}{c}\text { YOS } \\
\text { slope, } u_{l}\end{array}$ & 0.44 & 0.19 & .02 & 0.54 & 0.29 & .02 & 0.47 & 0.22 & .02 & 0.46 & 0.21 & .02 \\
\hline $\begin{array}{c}\text { Level-1, } \\
r\end{array}$ & 13.68 & 187.23 & & 13.49 & 182.01 & & 13.69 & 187.45 & & 13.72 & 188.18 & \\
\hline
\end{tabular}

Note. $\mathrm{N}=93$ (Level 1); $\mathrm{N}=7$ (Level 2); $\mathrm{VC}$ is abbreviation for Variance Component 


\section{Table P2}

Laissez-Faire Leadership and Supervision Satisfaction HLM Variance Components Estimation

\begin{tabular}{|c|c|c|c|c|c|c|c|c|c|c|c|c|}
\hline \multirow[b]{2}{*}{$\begin{array}{c}\text { Random } \\
\text { Effect }\end{array}$} & \multicolumn{3}{|c|}{ No Climate Vars. } & \multicolumn{3}{|c|}{ Auton. Included } & \multicolumn{3}{|c|}{ I\&F Included } & \multicolumn{3}{|c|}{ Effort Included } \\
\hline & $S D$ & $V C$ & Sig & $S D$ & $V C$ & Sig & $S D$ & $V C$ & Sig & $S D$ & $V C$ & Sig \\
\hline \multicolumn{13}{|l|}{ LF Lead } \\
\hline Int1, $u_{0}$ & 0.33 & 0.11 & .23 & 0.65 & 0.42 & .16 & 0.43 & 0.18 & .18 & 0.54 & 0.29 & .16 \\
\hline $\begin{array}{c}\text { YOS } \\
\text { slope, } u_{l}\end{array}$ & 0.02 & 0.00 & .31 & 0.05 & 0.00 & .30 & 0.03 & 0.00 & .31 & 0.04 & 0.00 & .31 \\
\hline Level-1, $r$ & 3.95 & 15.62 & & 3.92 & 15.38 & & 3.96 & 15.69 & & 3.95 & 15.62 & \\
\hline
\end{tabular}

Note. $\mathrm{N}=93$ (Level 1); $\mathrm{N}=7$ (Level 2); VC is abbreviation for Variance Component 


\section{Table P3}

Laissez-Faire Leadership and Contingent Rewards Satisfaction HLM Variance Components Estimation

\begin{tabular}{|c|c|c|c|c|c|c|c|c|c|c|c|c|}
\hline \multirow[b]{2}{*}{$\begin{array}{c}\text { Random } \\
\text { Effect }\end{array}$} & \multicolumn{3}{|c|}{ No Climate Vars. } & \multicolumn{3}{|c|}{ Auton. Included } & \multicolumn{3}{|c|}{$\underline{\text { I\&F Included }}$} & \multicolumn{3}{|c|}{ Effort Included } \\
\hline & $S D$ & $V C$ & Sig & $S D$ & $V C$ & Sig & $S D$ & $V C$ & Sig & $S D$ & $V C$ & Sig \\
\hline \multicolumn{13}{|l|}{ LF Lead } \\
\hline Int $1, u_{0}$ & 1.58 & 2.48 & .14 & 1.70 & 2.90 & .08 & 1.72 & 2.96 & .03 & 1.84 & 3.40 & .05 \\
\hline $\begin{array}{c}\text { YOS } \\
\text { slope, } u_{1}\end{array}$ & 0.16 & 0.03 & .05 & 0.17 & 0.03 & .05 & 0.13 & 0.02 & .05 & 0.15 & 0.02 & .05 \\
\hline Level-1, $r$ & 4.81 & 23.12 & & 4.80 & 23.01 & & 4.80 & 22.99 & & 4.79 & 22.96 & \\
\hline
\end{tabular}

Note. $\mathrm{N}=93$ (Level 1); $\mathrm{N}=7$ (Level 2); VC is abbreviation for Variance Component 


\section{Table P4}

Laissez-Faire Leadership and Nature of Work Satisfaction HLM Variance Components Estimation

\begin{tabular}{|c|c|c|c|c|c|c|c|c|c|c|c|c|}
\hline \multirow[b]{2}{*}{$\begin{array}{c}\text { Random } \\
\text { Effect }\end{array}$} & \multicolumn{3}{|c|}{ No Climate Vars. } & \multicolumn{3}{|c|}{ Auton. Included } & \multicolumn{3}{|c|}{ I\&F Included } & \multicolumn{3}{|c|}{ Effort Included } \\
\hline & $S D$ & $V C$ & Sig & $S D$ & $V C$ & Sig & $S D$ & $V C$ & Sig & $S D$ & $V C$ & Sig \\
\hline LF Lead & & & & & & & & & & & & \\
\hline $\operatorname{Int} 1, u_{0}$ & 1.31 & 1.73 & .04 & 1.37 & 1.87 & .03 & 1.44 & 2.08 & .02 & 1.36 & 1.85 & .03 \\
\hline $\begin{array}{c}\text { YOS } \\
\text { slope, } u_{1}\end{array}$ & 0.15 & 0.02 & .01 & 0.16 & 0.03 & .01 & 0.15 & .02 & .01 & 0.15 & 0.02 & .01 \\
\hline Level-1, $r$ & 3.22 & 10.38 & & 3.20 & 10.23 & & 3.22 & 10.38 & & 3.23 & 10.41 & \\
\hline
\end{tabular}

Note. $\mathrm{N}=93$ (Level 1); $\mathrm{N}=7$ (Level 2); $\mathrm{VC}$ is abbreviation for Variance Component 


\section{Table P5}

Laissez-Faire Leadership and Communication Satisfaction HLM Variance Components Estimation

\begin{tabular}{|c|c|c|c|c|c|c|c|c|c|c|c|c|}
\hline \multirow[b]{2}{*}{$\begin{array}{c}\text { Random } \\
\text { Effect }\end{array}$} & \multicolumn{3}{|c|}{ No Climate Vars. } & \multicolumn{3}{|c|}{ Auton. Included } & \multicolumn{3}{|c|}{ I\&F Included } & \multicolumn{3}{|c|}{ Effort Included } \\
\hline & $S D$ & $V C$ & Sig & $S D$ & $V C$ & Sig & $S D$ & $V C$ & Sig & $S D$ & $V C$ & Sig \\
\hline LF Lead & & & & & & & & & & & & \\
\hline Int $1, u_{0}$ & 1.72 & 2.95 & .03 & 2.04 & 4.17 & .01 & 1.73 & 2.98 & .03 & 1.91 & 3.65 & .02 \\
\hline $\begin{array}{c}\text { YOS } \\
\text { slope, } u_{1}\end{array}$ & 0.11 & 0.01 & .05 & 0.13 & 0.02 & .05 & 0.15 & 0.02 & .05 & 0.12 & 0.01 & .05 \\
\hline Level-1, $r$ & 4.75 & 22.57 & & 4.72 & 22.30 & & 4.73 & 22.37 & & 4.76 & 22.63 & \\
\hline
\end{tabular}

Note. $\mathrm{N}=93$ (Level 1); $\mathrm{N}=7$ (Level 2); VC is abbreviation for Variance Component 
IRB \#: IRB-2018-433

Title: Examining Inter-Relationships between Supervisor Full-Range Leadership, Organizational Climate, and Employee Job Satisfaction Using Multi-level Modeling

Creation Date: 5-2-2018

End Date: 5-3-2019

Status: Approved

Principal Investigator: Bharat Mohan

Review Board: USD IRB

Sponsor:

Study History

Submission Type Initial Review Type Expedited Decision Approved

\section{Key Study Contacts}

\begin{tabular}{lll}
\hline Member Bharat Mohan & Role Principal Investigator & Contact bmohan@sandiego.edu \\
\hline Member Fred Galloway & Role Primary Contact & $\begin{array}{l}\text { Contact } \\
\text { galloway@SanDiego.edu }\end{array}$ \\
\hline
\end{tabular}

